
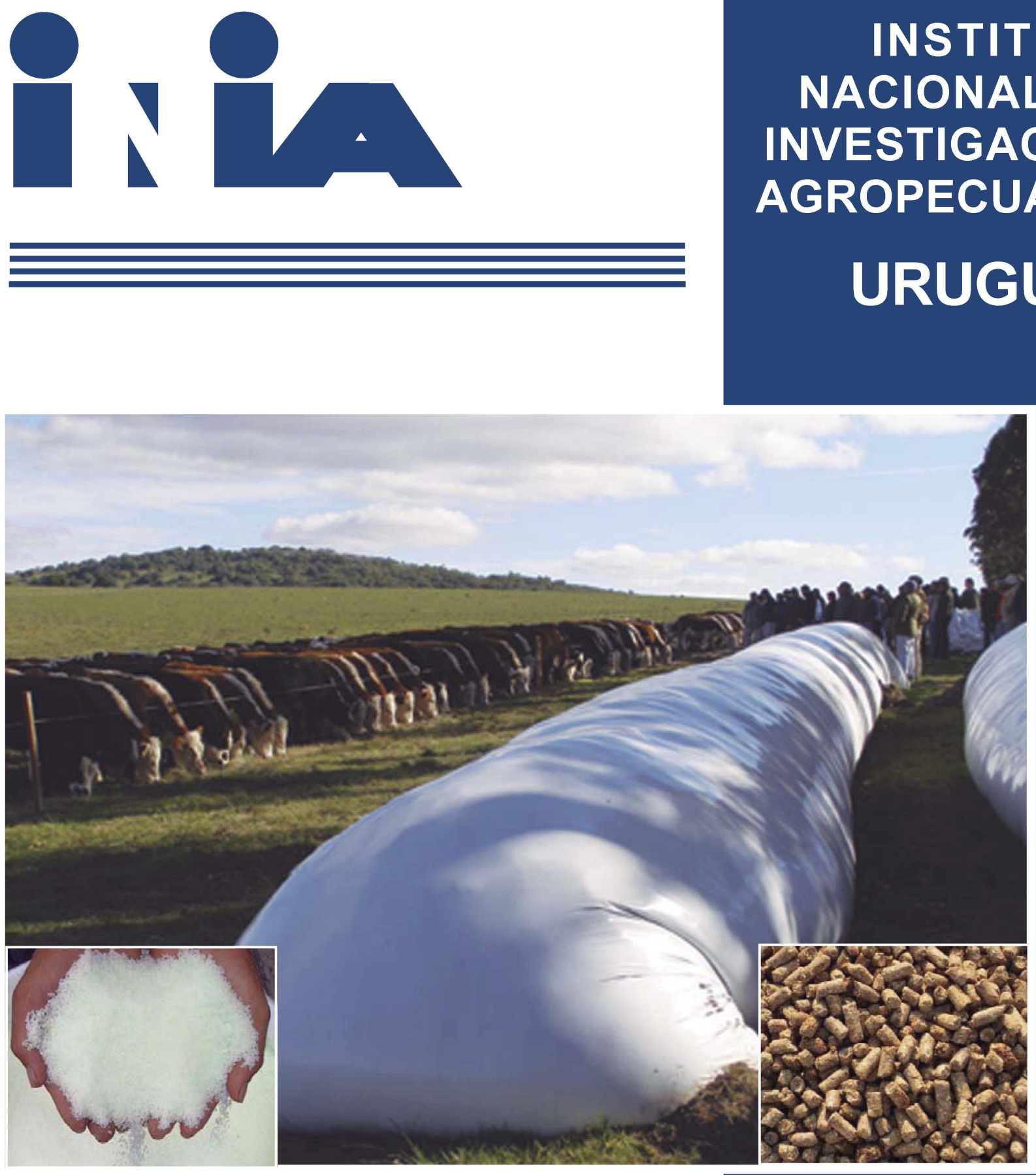

SUPLEMENTACIÓN

DE BOVINOS CON

GRANO HÚMEDO DE

SORGO Y FUENTES

PROTEICAS SOBRE

CAMPO NATURAL
INSTITUTO NACIONAL DE INVESTIGACIÓN AGROPECUARIA

URUGUAY

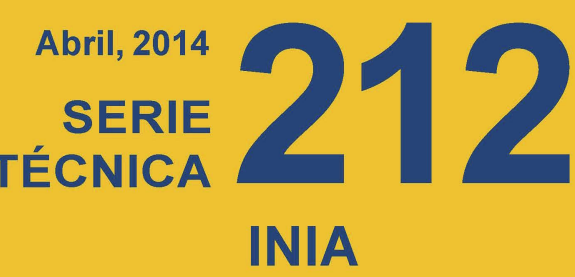




\title{
SUPLEMENTACIÓN DE BOVINOS CON GRANO HÚMEDO DE SORGO Y FUENTES PROTEICAS SOBRE CAMPO NATURAL
}

\author{
Editor: Pablo Rovira*
}


Título: SUPLEMENTACIÓN DE BOVINOS CON GRANO HÚMEDO DE SORGO Y FUENTES PROTEICAS SOBRE CAMPO NATURAL

Editor: Pablo Rovira

Serie Técnica $N^{\circ} 212$

(C) 2014, INIA

Editado por la Unidad de Comunicación y Transferencia de Tecnología del INIA Andes 1365, Piso 12. Montevideo - Uruguay

http://www.inia.uy

Quedan reservados todos los derechos de la presente edición. Esta publicación no se podrá reproducir total o parcialmente sin expreso consentimiento del INIA. 


\section{I nstituto Nacional de I nvestigación Agropecuaria}

\section{Integración de la Junta Directiva}

Ing. Agr., MSc., PhD. Álvaro Roel - Presidente

D.M.T.V., PhD. J osé Luis Repetto - Vicepresidente

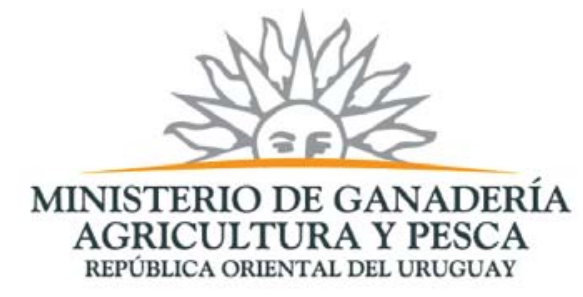

D.M.V. Álvaro Bentancur

D.M.V., MSc. Pablo Zerbino
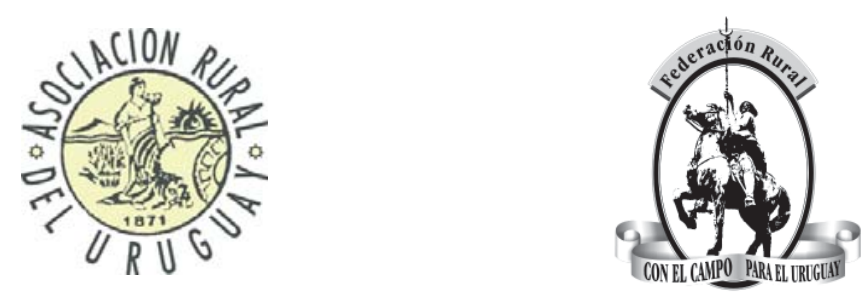

Ing. Agr. J oaquín Mangado

Ing. Agr. Pablo Gorriti
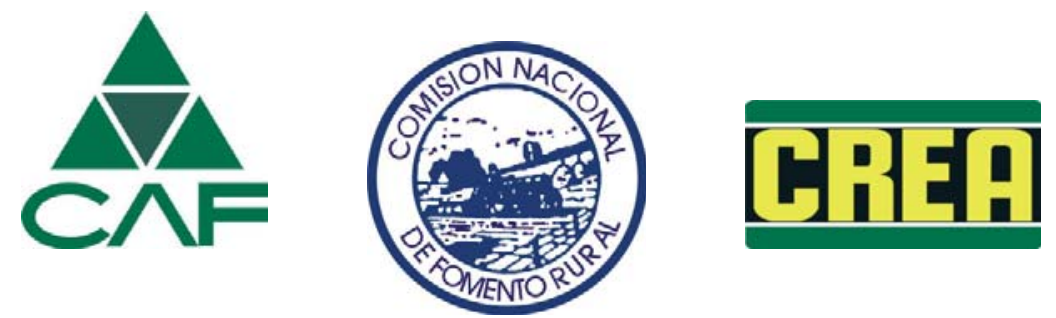


\section{CONTENIDO}

Página

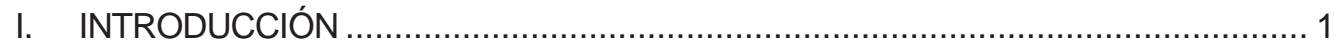

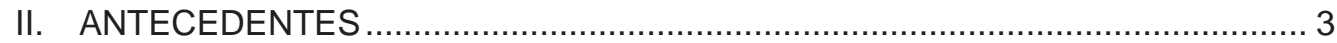

III. VALOR NUTRITIVO DEL GRANO HÚMEDO DE SORGO ........................... 11

Relevamiento del valor nutritivo de ensilajes de sorgo grano húmedo en

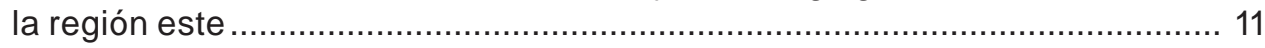

IV. INCLUSIÓN DE FUENTES PROTEICAS AL GRANO HÚMEDO DE SORGO EN ESQUEMAS DE SUPLEMENTACIÓN DE BOVINOS SOBRE CAMPO NATURAL

Efecto del agregado de fuentes proteicas al grano húmedo de sorgo en el crecimiento de terneros suplementados sobre campo natural

Efecto de la sustitución de proteína verdadera por nitrógeno no proteico en el desempeño productivo de terneros suplementados con grano húmedo de sorgo sobre campo natural

Desempeño productivo de terneros sobre campo natural suplementados con grano húmedo de sorgo y distintos niveles de nitrógeno de liberación lenta (Rumenfeed ${ }^{\mathrm{TM}}$ )

Efecto de la adición de urea al grano húmedo de sorgo en el desempeño productivo de novillos suplementados sobre campo natural

Efecto del nivel de suplementación de una mezcla de grano húmedo de sorgo y núcleo proteico en el desempeño productivo de terneros sobre campo natural 69

V. ANÁLISIS INTEGRADO DE LOS TRABAJOS EXPERIMENTALES 81

VI. CONSIDERACIONES FINALES. 91 


\section{ÍNDICE DE CUADROS}

Página

Relevamiento del valor nutritivo de ensilajes de sorgo grano húmedo en la región este

Cuadro 1. Valor nutricional de ensilajes de grano húmedo de sorgo en la región este y valores de referencia a nivel nacional

Efecto del agregado de fuentes proteicas al grano húmedo de sorgo en el crecimiento de terneros suplementados sobre campo natural

Cuadro 1. Disponibilidad (kg MS/ha) y altura (cm) del campo natural en 3 fechas

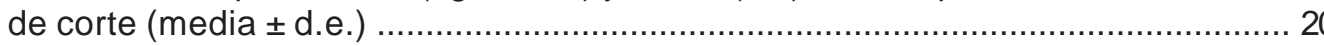

Cuadro 2. Composición química de los suplementos utilizados ............................ 22

Cuadro 3. Consumo de materia seca y aporte de energía metabolizable y proteína cruda proveniente del suplemento (base seca)

Cuadro 4. Ganancia de peso (media \pm d.e.) individual por periodo y total de los animales en los distintos tratamientos

Cuadro 5. Análisis económico de la suplementación (Precios de referencia invierno 2009)

Cuadro 6. Evolución de peso de los animales en la etapa post-suplementación (08/10/09-30/12/09)

Efecto de la sustitución de proteína verdadera por nitrógeno no proteico en el desempeño productivo de terneros suplementados con grano húmedo de sorgo sobre campo natural

Cuadro 1. Composición porcentual del suplemento de los distintos tratamientos (base seca)

Cuadro 2. Disponibilidad forrajera (kg MS/ha) por fecha de muestreo para cada tratamiento (media \pm desvío estándar)

Cuadro 3. Composición química del forraje del campo natural (media \pm desvío estándar) 35

Cuadro 4. Calidad de las fracciones verde y seca por fecha de muestreo ............ 36

Cuadro 5. Suplemento ofrecido a diario por animal (promedio en todo el período) ..... 36

Cuadro 6. Consumo y concentración de proteína cruda (PC) y energía metabolizable (EM) del suplemento ofrecido a los animales (promedio en todo el período)

Cuadro 7. Ganancia diaria (kg/a/d) por tratamiento y por período (media \pm desvío estándar)

Cuadro 8. Evolución del área de ojo de bife $\left(\mathrm{cm}^{2}\right)$ por tratamiento (media \pm desvío estándar)

Cuadro 9. Evolución del espesor de grasa $(\mathrm{mm})$ subcutánea por tratamiento (media \pm desvío estándar) 
Cuadro 10. Análisis económico de la suplementación (precios de referencia invierno 2010)

Desempeño productivo de terneros sobre campo natural suplementados con grano húmedo de sorgo y distintos niveles de nitrógeno de liberación lenta (Rumenfeed ${ }^{\mathrm{TM}}$ )

Cuadro 1. Valor nutritivo de los ingredientes utilizados (base seca) 52

Cuadro 2. Concentración de proteína y energía del suplemento ofrecido en cada tratamiento

Cuadro 3. Consumo diario ( $\mathrm{kg}$ MS/a/día) de cada ingrediente y total del suplemento ofrecido. (Entre paréntesis figura el porcentaje de cada ingrediente en la mezcla 53

Cuadro 4. Ganancia de peso por periodo (kg/a/día) \pm error estándar de la media y eficiencia de conversión (EC) 54

Cuadro 5. Evolución del área de ojo de bife (AOB) y el espesor de grasa subcutánea (EGS) medidos por ultrasonido

Cuadro 6. Análisis económico de la suplementación (precios de referencia invierno 2011) 56

Efecto de la adición de urea al grano húmedo de sorgo en el desempeño productivo de novillos suplementados sobre campo natural

Cuadro 1. Efecto de la suplementación diaria al $1 \%$ del peso vivo con grano húmedo de sorgo (GHS) y distintos niveles de urea (U0, U1, U2) en el desempeño productivo de novillos en pastoreo sobre campo natural 63

Efecto del nivel de suplementación de una mezcla de grano húmedo de sorgo y núcleo proteico en el desempeño productivo de terneros sobre campo natural

Cuadro 1. Tratamientos experimentales 70

Cuadro 2. Análisis (media \pm desvío estándar) de los suplementos (Laboratorio Nutrición Animal-INIA La Estanzuela) 71

Cuadro 3. Clasificación visual de las bostas según forma y consistencia 71

Cuadro 4. Composición (kg MS/a/día) del suplemento ofrecido a los animales (aporte porcentual de cada suplemento).

Cuadro 5. Análisis económico de la suplementación (precios de referencia setiembre 2013)

Cuadro 6. Desempeño productivo de los terneros durante la primavera 77

Análisis integrado de los trabajos experimentales

Cuadro 1. Ejemplos de mezclas de grano húmedo de sorgo + fuentes de proteína para lograr una mezcla con una concentración de $16 \%$ de proteína cruda 


\section{ÍNDICE DE FIGURAS}

Página

\section{Antecedentes}

Figura 1. Metabolismo de las proteínas en los rumiantes 5

Relevamiento del valor nutritivo de ensilajes de sorgo grano húmedo en la región este

Figura 1 Bolsa con ensilaje grano húmedo de sorgo 12

Figura 2 Relación entre la acidez del silo y la humedad del grano 15

Efecto del agregado de fuentes proteicas al grano húmedo de sorgo en el crecimiento de terneros suplementados sobre campo natural

Figura 1. Campo natural del experimento con predominio de restos secos 20

Figura 2. Composición química de las fracciones del forraje del campo natural

Figura 3. Composición química del forraje del campo natural al inicio y final del experimento

Figura 4. Evolución de peso vivo promedio de terneros en los distintos tratamientos.

Efecto de la sustitución de proteína verdadera por nitrógeno no proteico en el desempeño productivo de terneros suplementados con grano húmedo de sorgo sobre campo natural

Figura 1. Evolución de la altura del tapiz por tratamiento y fecha de muestreo 34

Figura 2. Relación entre altura y disponibilidad del forraje durante el periodo experimental 35

Figura 3. Evolución de peso de los terneros durante el periodo experimental ........ 37

Desempeño productivo de terneros sobre campo natural suplementados con grano húmedo de sorgo y distintos niveles de nitrógeno de liberación lenta (Rumenfeed ${ }^{\mathrm{TM}}$ )

Figura 1. Forraje disponible y altura del tapiz en cada fecha de muestreo (promedio sobre tratamientos)

Figura 2. Evolución de la proteína cruda, fibra detergente ácida y fibra detergente neutra del campo natural. Promedio sobre tratamientos

Figura 3. Evolución del porcentaje de forraje verde y seco como aporte a la materia seca total (promedio sobre tratamientos)

Figura 4. Evolución de peso vivo durante el periodo experimental 53

Figura 5. Relación entre ganancia de peso de los terneros y nivel de proteína en el suplemento ofrecido diariamente a $1 \%$ del peso vivo 55 
Efecto de la adición de urea al grano húmedo de sorgo en el desempeño productivo de novillos suplementados sobre campo natural

Figura 1. Evolución del forraje disponible por tratamiento 61

Figura 2. Evolución de la fracción verde y seca del forraje disponible 62

Efecto del nivel de suplementación de una mezcla de grano húmedo de sorgo y núcleo proteico en el desempeño productivo de terneros sobre campo natural

Figura 1. Evolución del forraje disponible y la altura del tapiz 72

Figura 2. Evolución de la calidad del forraje del campo natural 73

Figura 3. Observación del rebrote del campo natural (verde) hacia finales del mes de agosto

Figura 4. Evolución de peso vivo de los animales 74

Figura 5 Ganancia de peso según periodo de suplementación 74

Figura 6 Clasificación del tipo de bosta según consistencia y contenido visual de grano.

\section{Análisis integrado de los trabajos experimentales}

Figura 1. Valor nutritivo del campo natural durante el invierno 81

Figura 2. Análisis integrado de la ganancia de peso de los terneros en 3 años .... 82

Figura 3. Análisis integrado del peso vivo inicial y final de los terneros en 3 años 83

Figura 4. Relación entre la proteína ofrecida en el suplemento y la ganancia de peso de terneros suplementados sobre campo natural 85

Figura 5. Respuesta animal al incremento de la oferta de proteína a través de un incremento de la concentración proteica en el suplemento .....

Figura 6. Relación entre el cociente de nutrientes digestibles totales/proteína cruda en el suplemento y ganancia de peso de terneros suplementados al $1 \%$ del peso vivo sobre campo natural 86

Figura 7. Margen bruto (media \pm error de la media) de la suplementación por ternero (promedio de 4 años) 88

Figura 8. Ganancia de peso de terneros durante la primavera (octubre-diciembre) según manejo de la suplementación invernal 


\section{PRÓLOGO}

En una ganadería moderna y de cara al siglo XXI, las pérdidas de peso de las diferentes categorías bovinas durante el período invernal tienen que ser parte del pasado. Ello repercute negativamente en la productividad e ingreso del productor, afectando la competitividad de toda la Cadena Cárnica Bovina del Uruguay. Esta es una restricción productiva asociada a la baja producción invernal de las pasturas naturales y a la alta carga animal que normalmente manejan los productores en este periodo crítico. Esta situación empeora aún más cuando estas comunidades vegetales están dominadas por especies perennes estivales, donde el valor nutricional del forraje consumido por los animales es relativamente bajo frente a su demanda de nutrientes, afectando así negativamente la producción y bienestar animal. En la región Este, esta es una situación que se presenta normalmente durante el periodo otoño-invernal.

Dentro de las acciones de investigación y transferencia de tecnología orientadas a las regiones ganaderas extensivas del Uruguay, el Programa Nacional de Carne y Lana del INIA tiene como objetivo prioritario la búsqueda de diferentes alternativas tecnológicas que permitan mejorar la productividad y bienestar animal durante el periodo invernal. Dentro de las diferentes opciones que se manejan en nuestra cartera de proyectos, se incluye y destaca la suplementación con granos y sus subproductos. En este escenario, de las alternativas disponibles, el cultivo de sorgo es una de ellas, donde se destaca su amplia adaptación a las condiciones agroclimáticas predominantes del País y su histórico bajo costo de producción relativo frente a otros granos. Estos aspectos no son menores para los productores, frente a los costos incrementales que se observan en los fletes de los granos, situación que no se observa que cambie sustancialmente en el futuro. Por ello, la producción y utilización del grano para la alimentación animal en el propio predio es parte de una estrategia atractiva del punto de vista productivo y económico, de ahí la importancia del sorgo en la mejora de la productividad e ingreso en los sistemas ganaderos. A esto se le debe agregar su uso incremental que se observa en las rotaciones agrícolas o agrícola-ganaderas como parte del cumplimento de la nueva reglamentación de uso y manejo del suelos que se está aplicado a nivel nacional, con sus particularidades regionales.

El método de conservación de este cultivo de sorgo es clave para la mejor utilización de esta fuente extra de nutrientes para nuestra ganadería. La tecnología de ensilaje de grano húmedo es una excelente oportunidad para el uso eficiente del sorgo, mejorando sus cualidades nutricionales para una ganadería más eficiente. EI INIA junto a gremiales de productores, el IPA, empresas privadas y El Diario Rural de AM 610 promovió esta tecnología en todo el Uruguay a través del Concurso Nacional de Silos, pero en particular en las regiones ganaderas más extensivas, donde más se necesitaba. Dentro de las áreas de mejora de esta tecnología, del punto de vista nutricional, se resalta que el sorgo es una muy buena fuente de energía de bajo costo, pero que tiene limitantes en su degradabilidad de la energía a nivel ruminal además del bajo nivel de proteína cruda. Estas limitantes adquieren aún mayor relevancia cuando esta fuente nutricional es utilizada en categorías jóvenes que tienen alta demandas de nutrientes fácilmente disponibles, donde la proteína dietaría es clave para lograr una producción animal eficiente.

Los trabajos de investigación que se presentan y resumen en esta publicación para un uso eficiente del ensilaje de grano húmedo en la producción ganadera son el producto del aporte y esfuerzo de investigadores del Programa Nacional de Carne y Lana del INIA que tienen base en INIA Treinta y Tres. Esta publicación contempla e informa sobre aspectos relevantes en el uso de esta tecnología, donde se destacan: la caracterización y relevamiento del valor nutricional del ensilaje de grano de húmedo de sorgo en la región Este, la evaluación de diferentes fuentes proteicas para mejorar la eficiencia de utilización del sorgo sobre 
campo natural en distintas categorías de bovinos y la medición del impacto productivo y económico de estas tecnologías.

Es nuestro deseo que esta contribución tecnológica del INIA sea de utilidad a los técnicos y productores en el proceso de toma de decisiones para mejorar la productividad e ingreso a nivel predial así como en el caso de la formación de estudiantes en ciencias agrarias.

Finalmente, una de las importantes preocupaciones que tenía el destacado Profesor Jaime Rovira era la baja productividad invernal de nuestras pasturas y bovinos, lo cual se transformaba en un obstáculo para el desarrollo de la ganadería del Uruguay. Las nuevas generaciones siguen la rica tradición de aportar soluciones tecnológicas para los desafíos que tiene y tendrá la ganadería nacional. Celebramos ser parte de ello.

Ing. Agr. PhD. Fabio Montossi

Director Programa Nacional de Carne y Lana de INIA 
El ensilaje de grano húmedo de sorgo es una tecnología que ha dinamizado los sistemas ganaderos de la región este del país. Se define como la cosecha de grano de sorgo con $25-35 \%$ de humedad, procesado físicamente (quebrado y/o molido) y embolsado en condiciones de ausencia de aire hasta su suministro a los animales. Como toda tecnología tiene ventajas y desventajas. La principal ventaja es económica, obteniendo un suplemento por lo general con un menor costo absoluto (dólares/tonelada) comparado con otras alternativas energéticas (maíz, raciones balanceadas). Como principal desventaja, se destaca los requerimientos de escala y logística para que el grano en la chacra de sorgo pueda ser efectivamente cosechado y embolsado acorde a las especificaciones de la tecnología. Lo que resulta innegable es la rápida expansión y adopción que ha tenido entre los productores ganaderos de la región, fundamentalmente en aquellos que disponen mano de obra ya sea familiar o contratada para realizar el suministro diario a los animales.

En muchos de dichos sistemas ganaderos la recría de vacunos se realiza sobre campo natural en invierno en una situación de déficit forrajero en cantidad y calidad. En esa situación, la utilización de grano húmedo de sorgo puede ser una alternativa para intentar al menos disminuir las pérdidas de peso vivo que ocurren en los animales aunque el sorgo presenta valores de proteína limitantes para categorías jóvenes en crecimiento. Por tal motivo, la hipótesis de los trabajos que se presentan a continuación es que el agregado de fuentes de proteína al grano húmedo de sorgo permite mejorar el crecimiento de terneros y novillitos suplementados sobre campo natural en el invierno. Dentro de las fuentes de proteína disponible existen las de origen vegetal (ej. expeller de soja o girasol), las de origen sintético (ej. urea de uso agrícola, urea de liberación lenta) y las que son una mezcla de ambas fuentes (núcleos proteicos comerciales).

En un escenario de buenas expectativas para el negocio ganadero en el mediano-largo plazo como sector productor de alimentos, más allá de vaivenes de mercados y precios en el corto plazo, la intensificación de la recría vacuna juega un rol fundamental en el contexto del sistema de producción global. Permite acelerar el proceso de engorde de los novillos y/o disminuir la edad al primer entore de las hembras, mejorando la eficiencia de producción del predio precisamente en la etapa que el animal es más eficiente biológicamente (recría). La suplementación invernal es una alternativa para cumplir dicho objetivo, pero sin descuidar su inserción en el contexto del predio en donde aspectos básicos deben ser cumplidos para maximizar las ganancias (ej.: sanidad, ajuste de carga animal, área mejorada, disponibilidad de agua y sombra, etc.).

La presente Serie Técnica se basa en trabajos experimentales realizados en el periodo 2008-2013. En todos ellos la metodología fue similar, incluyendo la caracterización de la base forrajera (campo natural), la respuesta productiva de los animales a la suplementación con o sin fuentes de proteína en el grano húmedo de sorgo (invierno), el resultado económico de la suplementación y el desempeño productivo de los animales durante la etapa post-suplementación (primavera). La variabilidad registrada entre años desde el punto de vista climático, forrajero y de precios (suplementos y terneros) permite sacar conclusiones con mayor robustez y precisión que lo que puede ser un experimento puntual en un año en particular. El objetivo final es que la información brindada pueda ser utilizada como un insumo más por técnicos y productores al momento de tomar decisiones. 
CARACTERÍSTICAS DE LAS PASTURAS NATURALES EN LA REGIÓN DE LOMADAS DEL ESTE

Las pasturas naturales de la zona de lomadas del este, en donde se realizaron los experimentos que se describen en la presente publicación, presentan una marcada estacionalidad con máximas tasas de crecimiento en primavera y verano, dependiendo de las lluvias, y mínimas en invierno. Estas pasturas muestran una predominancia de gramíneas estivales perennes (80-85\%) de baja calidad que limita el potencial de producción de dichas pasturas.

La estimación de producción promedio estacional realizada en la Unidad Experimental Palo a Pique (INIA Treinta y Tres), en el transcurso de 13 años fue de $3425 \pm 1055 \mathrm{~kg}$ MS/ha/año, correspondiendo un 35\% a la producción de verano, $26 \%$ a la de otoño, $11 \%$ a la de invierno y un $28 \%$ a la de primavera (Ayala y Bermúdez, 2005). Del forraje total producido el $77 \%$ es aportado solamente por 10 especies, entre las que se pueden destacar dos especies con un aporte del $30 \%$ a dicha producción: Paspalum notatum $(16,7 \%)$ y Axonopus affinis (13,5\%) (Ayala y Bermúdez, 2005). También la gramilla (Cynodon dactylon) hace un importante aporte de forraje debido a que un área significativa de la zona de lomadas del este se destinó al cultivo de soja con prácticas de laboreo convencional en las décadas del 80 y 90 que luego derivó en tapices regenerados naturalmente sin el establecimiento de una rotación cultivo-pasturas adecuada.
En el invierno en los campos de lomadas del este es común que la oferta de forraje sea de muy baja calidad, compuesta principalmente por restos secos que se acumulan desde el verano y otoño, y que presentan una digestibilidad muy baja. SI bien la calidad de la fracción verde es mayor, su disponibilidad es totalmente limitante. Esto repercute directa y negativamente en el comportamiento animal, manifestándose importantes pérdidas de peso vivo en los animales durante los meses de invierno (Quintans et al., 1994). La concentración de proteína cruda (PC) encontrada por Carrera et al. (1996) en la Unidad Experimental Palo a Pique (INIA Treinta y Tres) en invierno fue $10,5 \%$ en forraje verde y en forraje seco $5,5 \%$. Valores similares de PC fueron encontrados por Gaggero et al. (1996) para el mismo sitio experimental. Esto estaría indicando que en caso de un predominio de la fracción seca en el campo natural se limitaría la producción animal dado el bajo valor proteico de la misma, y que en terneros el efecto negativo sería mayor, ya que aún se encuentran en crecimiento y requieren niveles proteicos adecuados para la síntesis de tejido muscular (Di Marco, 1994)

En caso de pasturas de baja calidad, los animales no consumen lo necesario como para lograr una ganancia de peso adecuada, aún teniendo acceso a disponibilidades de forraje mayores de $2000 \mathrm{~kg} \mathrm{MS} / \mathrm{ha}$. En estas condiciones de baja calidad de las pasturas es factible incrementar la ganancia de peso de los animales por medio de la suplementación (Santini y Rearte, 1997). 


\section{CARACTERÍSTICAS DEL GRANO HÚMEDO DE SORGO}

El grano de sorgo es un alimento energético, los cuales se definen como aquellos alimentos que contienen menos de $18 \%$ de fibra cruda y menos de $20 \%$ de PC en base seca (NRC, 2000). Se trata de un alimento que posee alto contenido de almidón y bajo en calcio y fibra cruda. En comparación con el maíz, el contenido de energía metabolizable de la mayoría de las variedades tiende a ser menor y el contenido de proteínas tiende a ser mayor (Cecava, 1995).

El almidón de los granos de sorgo es generalmente considerado como menos accesible a la degradación enzimática del animal que el de otros granos como el trigo o el maíz. La ruptura de la barrera física que recibe el grano a través del procesamiento, no solo reduce el tamaño de la partícula, sino que también incrementa la superficie de contacto disponible para la acción de los microorganismos y el ataque enzimático. Para el grano de sorgo, donde la ruptura por masticación es muy escasa (5 a 25\% del grano entero, dependiendo del peso del animal), es indispensable su procesamiento para alimentar bovinos de cualquier categoría y así obtener una elevada digestibilidad (Montiel y Elizalde, 2004).

La degradación del almidón del grano de sorgo a su vez dependerá básicamente del genotipo en cuestión (Repetto y Cajarville, 2009). Las principales diferencias entre genotipos están dadas por las características del endosperma y la presencia de taninos, compuestos que disminuyen el aprovechamiento digestivo del grano de sorgo fundamentalmente al formar complejos indigestibles con proteínas y almidón. El efecto de los taninos puede verse reducido mediante la fermentación anaeróbica (ensilado) del grano o la adición de sustancias como álcalis o ácidos, tratamientos que además alterarían el endosperma aumentando la digestibilidad del almidón (Curbelo, 2010).

El sorgo para grano se puede almacenar bajo condiciones de alto contenido de humedad en un medio ácido, obtenido mediante una fermentación anaeróbica (NRC,
2000). La eficiencia alimenticia del ganado suplementado con grano húmedo de sorgo, es de 10 a 18\% mayor en comparación con el ganado alimentado con grano de sorgo seco (Cecava, 1995), siempre y cuando se logre un ensilaje de buena calidad.

Los factores más importantes que afectan la calidad del proceso de ensilado son: el contenido de humedad del grano, el contenido de azúcares simples (solubles), el tipo de bacterias presentes y predominantes, la exclusión de aire y la velocidad de fermentación. La humedad de campo más buscada en el material a guardar ronda el entorno de 26 al 30\%; este factor guarda estrecha relación con el nivel de acidez o pH de la reserva. El nivel de acidez es el principal responsable por la calidad y la longevidad del material guardado, teniendo un valor óptimo de 4,75 o inferior. El contenido de materia seca afecta la calidad de la fermentación, mostrando «desvíos» o procesos indeseables, los que se «leen» como nivel de $\mathrm{N}$ amoniacal $\left(\mathrm{N}-\mathrm{NH}_{3}\right)$ desarrollado por la reserva. Los valores óptimos de $\mathrm{N}-\mathrm{NH}_{3}$ son inferiores a 5$8 \%$; este parámetro nos indica la posible vida útil del material y la eventualidad de problemas de aceptación por parte de los animales. También el contenido de azúcares simples (solubles) es otro factor importante, ya que éstos son la fuente de energía con que las bacterias que fermentan el grano cuentan para multiplicarse y crecer, colonizar toda la masa de material guardado, fermentarlo y de esta forma alcanzar el producto final (Acosta, 2010).

El valor de fibra detergente neutro (FDN) es otro aspecto importante a considerar, ya que niveles altos de ésta reflejan un aumento del contenido de material fibroso dentro del silo, generalmente proveniente de la panoja de la planta. Al incrementar la fibra en el silo de grano húmedo se incrementa el volumen total de MS del silo aunque la digestibilidad y valor energético de dicha fibra es sensiblemente menor a la energía aportada por el grano (Rovira y Velazco, 2010a).

El bajo contenido de proteína del grano húmedo de sorgo hace que no sea recomendable su utilización como único suplemento en esquemas de suplementación sobre cam- 
po natural, fundamentalmente en categorías jóvenes en activo crecimiento (terneros), que presentan elevados requerimientos de proteína (Rovira y Velazco, 2010a). Esto se acentúa cuando los animales en crecimiento son manejados con una dieta base que tiene un contenido bajo de proteína como puede ser el campo natural (Santini y Rearte, 1997). En esta situación, la inclusión de fuentes proteicas de origen vegetal (soja, girasol) o de origen sintético como la urea podría ser una alternativa válida para incrementar el contenido de proteína cruda (PC) de los ensilajes de grano húmedo, sobre todo cuando se lo va a utilizar como suplemento para terneros manejados en campo natural (Rovira y Velazco, 2010b). La suplementación con pro- teínas en este caso sería fundamental para el uso óptimo de forrajes de baja calidad (DelCurto et al., 1999).

\section{SUPLEMENTOS PROTEICOS}

Independientemente de la fuente de proteína utilizada, una parte de la proteína de la dieta es degradada en el rumen liberando péptidos, aminoácidos y $\mathrm{NH}_{3}$ (amoníaco) (Figura 1). Gran parte del $\mathrm{NH}_{3}$ es utilizado por las bacterias del rumen para sintetizar proteína microbiana. La fracción de proteína del alimento que escapa a la degradación ruminal se denomina sobrepasante o bypass y es digerida en el intestino delgado junto a la proteína microbiana.

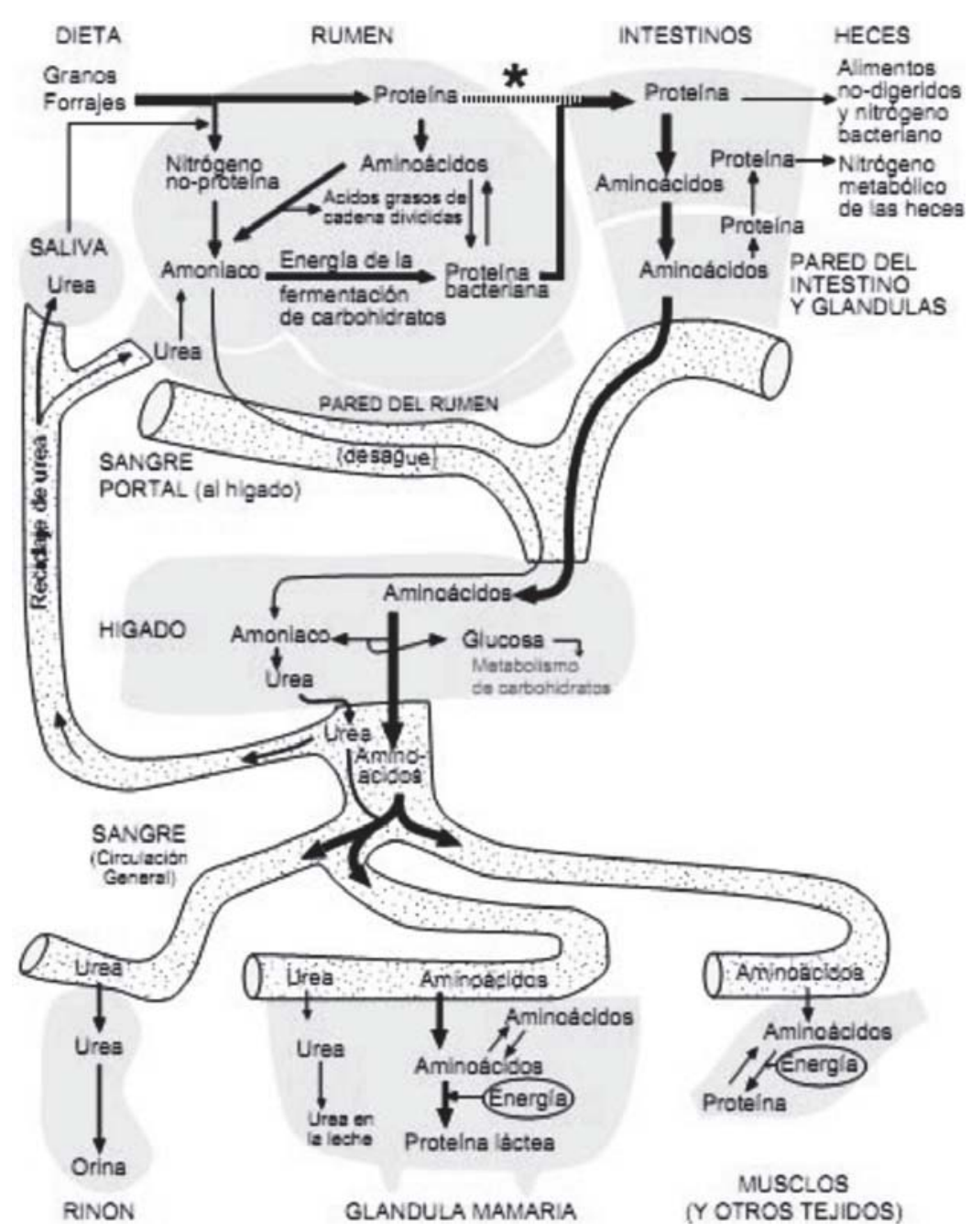

Figura 1. Metabolismo de las proteínas en los rumiantes (Wattiauz, 1994; Adaptado de Pick, 2010). 
Las fuentes comerciales de suplementos proteicos de origen vegetal más usadas en el país proceden de las harinas y tortas de soja, girasol y subproductos de la industria del maíz. Dentro de las primeras, la harina de girasol es una de las más utilizadas en la alimentación animal. El contenido de proteína de este suplemento se encuentra en el entorno del $35 \%$, y un porcentaje elevado del nitrógeno $(\mathrm{N})$, más de $95 \%$, aparece como proteína verdadera, muy digestible, que le confiere un valor biológico elevado a su proteína. Sin embargo, su alto contenido de fibra de baja digestibilidad hace que la composición química de esta harina varíe en cuanto a sus aportes de proteína y energía cuando es utilizada en combinación con otros alimentos (Cozzolino, 2000). Con respecto a la harina o expeller de soja, obtenidos de la extracción de aceite, presentan un elevado aporte energético (similar al de los cereales) y un importante contenido de PC (46 a 48\%) de alto valor biológico (Repetto et al., 2003). Al comparar la degradabilidad ruminal del expeller de girasol, la harina de soja aporta un mayor porcentaje de proteína sobrepasante o bypass debido a que la degradabilidad de la proteína en rumen se considera en torno al 66\% (NRC, 2000).

Por otra parte, la fuente más importante de nitrógeno no proteico (NNP) empleada en la nutrición de rumiantes es la urea. El equivalente proteico de la urea se estima en $287 \%$, y éste surge de multiplicar el porcentaje de $N$ en la urea (46\%) por el factor 6,25 , asumiendo que las proteínas poseen $16 \%$ de $\mathrm{N}$ (Cozzolino, 2000). El 100\% del nitrógeno de la urea se libera en forma amoniacal en el rumen, es decir no hay proteína sobrepasante o bypass como en las fuentes de origen vegetal. Un exceso de $\mathrm{NH}_{3}$ ruminal, cuando se ve saturada su capacidad de utilización por las bacterias del rumen, es dirigido al hígado donde se transforma en urea para ser eliminado por la orina. Para evitar el riesgo de intoxicaciones por $\mathrm{NH}_{3}$, la urea no debería administrarse en cantidades mayores al 3\% del concentrado (Escalona et al., 2007), o no superar al $1,5 \%$ de la dieta (Repetto et al., 2003), o limitar el consumo a un tercio de la PC (Emerick, 1993). Adicionalmente, siempre que sea factible, debe consumirse en comidas reducidas y frecuentes (McDonald et al., 2006).

La utilización de amonio $\left(\mathrm{NH}_{3}\right)$ por los microbios del rumen permite la utilización de los compuestos a base NNP de la dieta, tales como la urea, así como la captura de reciclado de $\mathrm{N}$-urea, que de otro modo se excretaría por la orina (Broderick, 2010). Para que resulte óptima la utilización del NNP la dieta deberá contener cantidades suficientes de carbohidratos fáciles de fermentar. Si el rumen no dispone de energía suficiente para proporcionar los esqueletos de carbono necesarios para elaborar nuevos aminoácidos a partir del NNP, en el caso de tener un gran exceso de $\mathrm{NH}_{3}$ este será absorbido hacia la corriente sanguínea, parte penetrará en la sangre periférica y puede causar intoxicación por $\mathrm{NH}_{3}$ (Schingoethe, 1993).

Según McCollum y Horn (1990), los efectos positivos al suplementar con $\mathrm{N}$ a una dieta carente de él, pueden deberse, independientemente de la fuente, a una corrección de una deficiencia de $\mathrm{N}$ no ruminal, lo que permitiría incrementos en el flujo de $\mathrm{N}$ no amoniacal al duodeno, ya sea proteína microbiana o proteína vegetal no degradable en el rumen. Las proteínas microbianas son de excelente calidad con una buena composición de aminoácidos para los rumiantes y pueden ser responsables de más del $50 \%$ de los aminoácidos absorbidos en el intestino delgado (NRC, 2000). Las fuentes de proteína verdadera, a diferencia de la urea, permitirían además corregir la deficiencia de algún aminoácido o desbalance a nivel de tejido, lo que promovería la deposición de tejido. Dichas fuentes constituyen además una fuente energética, aportan minerales y vitaminas al intestino, por lo que se debe de tener en cuenta a la hora de formular dietas balanceadas utilizando urea como fuente de NNP (Mieres, 1997). También se ha demostrado que el crecimiento de las bacterias es más rápido cuando las fuentes de $\mathrm{N}$ provienen de proteínas y no de NNP (Relling y Mattioli, 2002). 


\section{RELACIÓN PROTEÍNA-ENERGÍA}

La ganancia de peso de los animales depende del suministro de aminoácidos (AA) y energía a los tejidos, hasta llegar a un umbral de síntesis proteica determinado por la genética, el cual generalmente no es alcanzado por los animales en sistemas pastoriles. A su vez, el suministro de AA a los tejidos depende del contenido de proteína de la dieta, la transferencia de proteína del rumen hacia el intestino ya sea como proteína no degradable a nivel ruminal o como proteína microbiana, y de la absorción de proteína a nivel del intestino delgado (Poppi y McLennan, 1995).

En pasturas templadas de alta digestibilidad, las pérdidas de proteína o ineficiencias en el metabolismo comienzan a producirse cuando la relación proteínaenergía supera el umbral de $210 \mathrm{~g}$ de proteína/kg energía digestible de materia orgánica. Dicho valor representa una relación proteína cruda degradable/energía disponible para los microbios del rumen de 50 o $39 \mathrm{~g}$ de proteína cruda/Mcal de energía metabolizable para proteínas con degradabilidad de 90 o 70\%, respectivamente (Poppi y McLennan, 1995). Las pasturas «secas» con digestibilidades en el entorno de 50\% y aún menores generalmente no superan dicho umbral y presentan una concentración proteica inferior a 7-8\%, valor por debajo del cual se limita el consumo voluntario. La suplementación energética en pasturas de baja calidad produce una disminución en el consumo y digestibilidad del forraje (Chase y Hibberd, 1987). Sin embargo, la suplementación proteica en dicha situación estimularía el consumo de forraje (McCollum y Galyean, 1985).

Para lograr una tasa de ganancia de $0,300 \mathrm{~kg} / \mathrm{a} / \mathrm{d}$ en terneros de aproximadamente $200 \mathrm{~kg}$ se requiere el suministro extra de $150 \mathrm{~g}$ de proteína a nivel intestinal (Mbongo et al., 1994). El suministro extra no sólo de proteína, sino también de energía en el rumen, es una estrategia eficaz para satisfacer las necesidades proteicas del animal estimulando la captura de nitrógeno a nivel ruminal y la síntesis de proteína microbiana que luego será absorbida a nivel intestinal. De acuerdo a ecuaciones de la AFRC (1992) se requieren en torno de $1,2 \mathrm{~kg}$ de grano (ej. sorgo) para proveer los $150 \mathrm{~g}$ de proteína adicional mencionados anteriormente. Dicha estrategia tiene la ventaja que suministra energía y proteína a la vez, aunque luego es difícil determinar si el incremento en la ganancia de peso se debe a la mejora de la oferta energética y/o proteica en el suplemento (Thomas et al. 1988).

Para ser efectivo debe haber una sincronía entre la energía y proteína. Las fuentes energéticas más utilizadas son los granos de cereales, en donde la velocidad de descomposición del almidón en el rumen puede afectar la cantidad de amonio que es capturado para la síntesis de proteína que luego será absorbida a nivel intestinal. Por ejemplo, los granos de invierno (trigo, cebada) tienen una mayor y más rápida degradación a nivel ruminal que los granos de verano (maíz, sorgo).

\section{SUPLEMENTACIÓN PROTEICA EN CATEGORÍAS EN CRECIMIENTO}

Dentro de los trabajos nacionales que analizaron la suplementación proteica de categorías en crecimiento sobre pasturas de baja calidad se encuentran los realizados por Ochoa y Vidal (2004) quienes utilizaron como suplemento un núcleo proteico de origen comercial con 38\% de PC. Dichos autores registraron ganancias de peso vivo (PV) moderadas en terneras de destete del orden de $0,193 \mathrm{~kg} / \mathrm{animal} / \mathrm{día}$ durante el período invernal, logradas con consumos de suplemento de $0,15 \%$ del $\mathrm{PV}$, presentando diferencias significativas $(P<0,05)$ respecto a los grupos testigos que no fueron suplementados (-0,032 kg/animal/día). Gómez et al. (1995) evaluaron el efecto de la suplementación energética, proteica y energético-proteico en terneras de destete pastoreando campo natural en su primer invierno de vida. El experimento evaluó 4 tratamientos: un lote testigo que no contó con suplementación, y 3 lotes que contaron con una fuente energética (sorgo molido), fuente proteica (expeller de girasol) o fuente energética- 
proteica (afrechillo de arroz). Los suplementos fueron iso-energéticos, variando el nivel de PC $(8,1 \%$ para sorgo, $14,6 \%$ para afrechillo, 32,5\% para girasol). Existieron diferencias significativas $(P<0,05)$ para el consumo de PC y la ganancia diaria promedio entre los tratamientos suplementados respecto al testigo $(p<0,05)$. Se concluyó que la suplementación invernal de terneras de destete se tradujo en performances animales superiores a las terneras sin suplementar, logrando ganancias del orden de los $0,200 \mathrm{~kg} / \mathrm{a} / \mathrm{d}$. Utilizando niveles de suplementación del 0,7 al $1 \%$ del PV, fue posible obtener $0,200 \mathrm{~kg} / \mathrm{animal} / \mathrm{día}$ sin diferencias significativas a favor de un determinado suplemento.

Sampaio (2007) y Figueiras et al. (2010) evaluaron el consumo, digestibilidad y dinámica ruminal en bovinos alimentados con heno o pastura de baja calidad suplementados con nitrógeno, y reportaron que el flujo de compuestos nitrogenados microbianos al intestino delgado, así como los coeficientes de digestibilidad total de la materia seca, materia orgánica, proteína cruda y fibra detergente neutro se relacionaron lineal y positivamente con los niveles de PC en la dieta. Los autores concluyeron que los beneficios sobre la utilización del forraje basal de baja calidad son obtenidos con suplementos que permitan elevar el tenor de PC de la dieta a niveles de por lo menos 9 a 10\%.

Hennessy y Williamson (1990) evaluaron el efecto del nivel de urea en el consumo y desempeño de bovinos alimentados con heno de baja calidad. Obtuvieron ganancias de peso en todos los grupos suplementados con urea, mientras que los animales que consumieron la dieta basal (heno de baja calidad) perdieron peso. No obstante, observaron una tendencia en el ganado a tener mayores ganancias en los niveles más bajos de consumo de urea (15 y $23 \mathrm{~g} / \mathrm{animal} /$ día) que los más altos (42 y 53 g/animal/día). Dixon (1999) reveló que cuando la urea se incluyó en la dieta base (paja, paja tratada con álcali y heno de leguminosas) para novillos, la concentración de $\mathrm{NH}_{3}$ aumentó rápidamente después de comer, pero luego disminuyó rápidamente, de manera que la concentración fue inferior a $50 \mathrm{mg} \mathrm{N} / \mathrm{L}$ du- rante aproximadamente 12 horas cada día, lo que según el mismo autor podría afectar la digestión microbiana de los componentes fibrosos de la dieta, particularmente si los forrajes tienen bajo contenido de $\mathrm{N}$, alto contenido en fibra y baja digestibilidad.

Resultados similares fueron encontrados por Kozloski et al. (2000), quienes evaluaron la influencia de la adición de urea en dietas aproximadamente iso-energéticas e isonitrogenadas sobre el lugar y la extensión de la digestión de los componentes no nitrogenados en novillos, y determinaron que la concentración de amonio ruminal aumentó por la adición de urea en la dieta, pero solamente en las tres primeras horas después de la ingestión del alimento, no siendo influenciada significativamente en los demás horarios. En el mismo estudio, dichos autores registraron que el $\mathrm{pH}$ aumentó linealmente con la adición de urea en la dieta en las dos primeras horas después de la ingestión del alimento, lo que podría haber favorecido la actividad inicial de bacterias celulolíticas.

Kropp et al. (1977) evaluaron diferentes niveles de urea y la compararon con la harina de soja en novillos consumiendo heno de baja calidad (sustituciones de 25, 50 y $75 \%$ del $\mathrm{N}$ suplementado por urea), determinaron que la producción de proteína ruminal parece ser igual, independientemente de la fuente de $\mathrm{N}$, sin embargo cuando se sustituyó harina de soja por urea la digestibilidad aparente de la materia seca y orgánica, al igual que el flujo de nutrientes al abomaso, se redujeron.

\section{BIBLIOGRFÍA}

AcosTA, Y. 2010 Detalles de confección y su efecto sobre el valor nutricional. En: Ensilaje de grano húmedo de sorgo. INIA. Serie de Actividades de Difusión No 604. p 1-8.

AFRC. 1992. Technical committee on responses to nutrients. No 9. Nutritive requirements of ruminant animals: Protein. Nutr. Abstr. Ser. B Livest. Feeds Feeding 62:787.

AYALA, W.; BERMÚDEZ, R. 2005 Producción de forraje de un campo natural de la zona de lomadas del este. En: Gómez, R., Albicette, M. (eds). Seminario de 
Actualización Técnica en Manejo de Campo Natural. INIA. Serie Técnica $N^{\circ}$ 151, p 33-39.

BRODERICK, G. 2010. Nuevas perspectivas en la eficiencia del uso de nitrógeno en vacas lecheras. Simposio, Claves para el Manejo Nutricional de la Vaca de Alto Potencial en el Marco de una Lechería en Expansión. Montevideo, Departamento de Educación Continua. Facultad de Veterinaria. p. 1-18.

CARRERA, M.; GONZÁLEZ, R.; GONZÁLEZ, D.; ROVIRA, P. 1996. Efecto de la dotación y manejo del pastoreo en la productividad del campo natural y mejorado. Tesis Facultad Agronomía, Universidad de la República, Montevideo, Uruguay, $121 \mathrm{p}$.

CECAVA, M. 1995. Concentrates for beef cattle. En: Petty, T., Cecava, M. eds. Beef Cattle Feeding and Nutrition, $2^{\mathrm{a}}$ ed. Indiana, Academic Press. p 138-166.

CHASE, C. C.; HIBBERD 1987, C.A. Utilization of low-quality native grass hay by beef cows fed increasing quantities of corn grain. J. Anim. Sci.65, 557

COZZOLINO, D. 2000. Características de los suplementos utilizados en el Uruguay para su empleo en alimentación animal. INIA. Serie Técnica No 110, 16 p.

CURBELO, A. 2010. Ensilaje de grano de sorgo con diferente contenido en taninos: efecto sobre la composición química, degradabilidad ruminal, digestibilidad intestinal y fermentescibilidad. Tesis Magister en Ciencias Agrarias opción Ciencia Animal, Facultad Agronomía, Universidad de la República, Montevideo, Uruguay. $89 \mathrm{p}$.

DELCURTO, T.; HESS, B.; HUSTON, J.; OLSON, K. 1999. Optimum supplementation strategies for beef cattle consuming lowquality roughages in the western United States. Proceedings of the American Society of Animal Science, $16 \mathrm{p}$.

DI MARCO, O. 1994. Crecimiento y respuesta animal. Buenos Aires, INTA EEA Balcarce, $126 \mathrm{p}$.

DIXON, R. 1999. Effects of addition of urea to a low nitrogen diet on the rumen digestion of a range of roughages. Australian Journal of Agricultural Research 50:1091-1098.
EMERICK, R. 1993. Intoxicaciones por nitrato y urea. En: Church, C. (ed). El rumiante, fisiología digestiva y nutrición. Zaragoza, Acribia, p. 553-558.

ESCALONA, R.; RAMÍREZ, P.; BARZAGA, G; DE LA CRUZ B.; MAURENIS, C. 2007. Intoxicación por urea en rumiantes. Facultad de Medicina Veterinaria, Universidad de Granma. 4p.

FIGUEIRAS, J.; DETMANN, E.; PAULINO, M.; PEREIRA, T.; VALADARES, S.; LAZZARINI, I. 2010. Intake and digestibility in cattle under grazing supplemented with nitrogenous compounds during dry season. Revista Brasileira de Zootecnia 39(6):1303-1312

GAGGERO, R.; GAMBETTA, A.; LACA, L.; MATEO, A. 1996. Efecto de la dotación y manejo del pastoreo en la productividad del campo natural y mejorado. Tesis Facultad Agronomía, Universidad de la República, Montevideo, Uruguay, 79 p.

GÓMEZ, F.; MASTROPIERRO, J.; ROVIRA SANZ, A. 1995. Efecto de la suplementación energética, proteica y energético proteica en el crecimiento de terneras de destete pastoreando campo natural. Tesis Facultad Agronomía, Universidad de la República, Montevideo, Uruguay. 95 p.

HENNESSY, D.; WILLIAMSON, P. 1990. Feed intake and liveweight of cattle on subtropical native pasture hays. I. The effect of urea. Australian Journal of Agricultural Research 41:1169-1177.

KOZLOSKI, G.; RIBEIRO, H.; ROCHA, J. 2000. Ureia na dieta de novilhos. Efeito sobre a digestao dos compostos nao nitrogenados. Canadian Journal of Animal Science 713-719.

KROPP, J.; JOHNSON, R.; MALES, J.; OWENS, F. 1977. Microbial protein synthesis with low quality roughage rations: isonitrogenous substitution of urea for soybean meal. Journal of Animal Science 46(4):837-843.

MBONGO, T.; POPPI, D.P.; WINTER, W.H. 1994. The live weight gain response of cattle grazing Setaria spacelata pastures when supplemented with formaldehyde treated casein. Proc. Aust. Soc. Anim. Prod. 20, 342.

MCCOLLUM, E T.; GALYEAN, M.L. 1985. Influence of cottonseed meal 
supplementation on voluntary intake, rumen fermentation and rate of passage of prairie hay in beef steers. J. Anim. Sci. 60:570.

McCOLLUM, F.; HORN, G. 1990. Protein supplementation of grazing livestock. A review. The Professional Animal Scientist 6:1-16.

MCDONALD, P.; EDWARDS, R.; GREENHALGH, J.; MORGAN, C. 2006. Concentrados proteicos. En: McDonald, P., Edwards, R., Greenhalgh, J., Morgan, C. Nutrición Animal. 6a ed. Zaragoza, Acribia. p. 495-521.

MIERES, J. 1997. Tipo de suplemento y su efecto sobre el forraje. En: Martins, D.V., (ed). Suplementación estratégica para el engorde de ganado. INIA. Serie Técnica $\mathrm{N}^{\circ}$ 83, p. 11-15.

MONTIEL, M.; ELIZALDE, J. 2004. Factores que afectan la utilización ruminal del grano de sorgo en vacunos. Revisión bibliográfica. Revista Argentina de Producción Animal 24:20.

NRC. 2000. Nutrient Requirements of Beef Cattle. Chapter: Protein. $7^{\mathrm{a}}$ ed, Update 2000. p. 17-21.

OCHOA, S.; VIDAL, P. 2004. Evaluación de la respuesta a la suplementación proteica de terneras de destete pastoreando campo natural diferido. Tesis Facultad Agronomía, Universidad de la República, Montevideo, Uruguay, 95p.

PICK, G. 2010. Utilización de nitrogeno no proteico en recría de bovinos. Trabajo Final de Ingeniería en Producción Agropecuaria. Facultad de Ciencias Agrarias, Universidad Católica Argentina.

POPPI, D.P.; MCLENNAN, S.R. 1995. Protein and energy utilization by ruminants at pasture. Journal of Animal Science 73, 278-290.

QUINTANS, G.; VAZ MARTINS, D.; CARRIQUIRY, E. 1994. Alternativas de suplementación de vaquillonas. En: Bovinos para Carne, Avances en la Suplementación de la Recría e Invernada Intensiva. INIA. Actividades de Difusión No 34. p. 22 - 27.

RELLING, A.; MATTIOLI, G. 2002. Fisiología digestiva y metabólica de los rumiantes. Facultad de Ciencias Veterinarias. Cátedra de Fisiología. Universidad Nacional de La Plata, Argentina. Disponible en:http://www.fcv.unlp.edu.ar/ sitios-atedras/41/material/fisio.pdf. Fecha de consulta: 14/9/2010.

REPETTO, J.; CAJARVILLE, C. 2009. ¿ES posible lograr la sincronización de nutrientes en sistemas pastoriles intensivos? XXXVII Jornadas Uruguayas de Buiatría, Paysandú, Uruguay, p. 60-67.

REPETTO, J.; CAJARVILLE, C.; CURBELO, A.; SAPRIZA, D. 2003. Suplementos. Curso a distancia sobre nutrición de rumiantes. Montevideo, Facultad de Veterinaria. Módulo 4, 155 p.

ROVIRA, P.; VELAZCO, J. 2010a Valor nutritivo de ensilajes de sorgo de planta entera y grano húmedo en la región Este. En: Jornada de Divulgación, Ensilaje de Grano Húmedo de Sorgo. INIA. Actividades de Difusión: N 604. p. 9-13.

ROVIRA, P.; VELAZCO, J. 2010b. Efecto del agregado de fuentes proteicas al grano húmedo de sorgo en el crecimiento de terneros suplementados sobre campo natural. En: Jornada de Divulgación, Ensilaje de Grano Húmedo de Sorgo. INIA. Actividades de Difusión: No 604. p.14-21.

THOMAS, C.; GIBBS, B.G.; BEEVER, D.E.; THURNHAM, B.R.. 1988. The effect of date of cut and barley substitutiono $n$ gain and on the efficiency of utilization of grass silage by growing cattle. Br.J. Nutr. 60:297.

SANTINI, F.; REARTE, D. 1997. Estrategia de alimentación en invernada. En: Vaz Martins, D., (ed.). Suplementación estratégica para el engorde de ganado. INIA. Serie Técnica No 83. p. 37-46.

SAMPAIO, C. 2007. Digestibilidade, consumo e dinamica ruminal em bovinos alimentados com forragem tropical de baixa qualidade suplementados com compostos nitrogenados. Univesidade Federal de Viçosa, Minas, Gerais, Brasil. 53 p.

SCHINGOETHE, D. 1993. Necesidades nutritivas de rumiantes en comparación con especies monogastricas. En: Church, C. (ed.). El rumiante, fisiología digestiva y nutrición. Zaragoza, Acribia. p. 515-523.

WATTIAUX, M.A. 1994. Esenciales lecheras. Metabolismo de las proteínas en las vacas lecheras. Instituto Babcock para la Investigación y Desarrollo Internacional de la Industria Lechera. Universidad de Wisconsin-Madison. 


\title{
III. VALOR NUTRITIVO DEL GRANO HÚMEDO DE SORGO
}

\author{
P. Rovira ${ }^{1}$ \\ J. Velazco ${ }^{2}$
}

\section{RELEVAMIENTO DEL VALOR NUTRITIVO DE ENSILAJES DE SORGO GRANO HÚMEDO EN LA REGIÓN ESTE}

\section{RESUMEN}

Entre marzo y agosto de 2008 se relevó el valor nutricional de 12 silos de grano húmedo de sorgo en la región este del país. El valor promedio de humedad del grano estuvo acorde a lo recomendado para la tecnología $(27,2 \pm 7,9 \%)$, aunque en un tercio de los silos la humedad estuvo por debajo de $20 \%$ lo que compromete la estabilidad y vida útil del silo. En dichas situaciones la baja humedad del silo fue atribuida a la demora en el arribo de la máquina embolsadora debido a la escasez de oferta de servicios de contratación de maquinaria en regiones tradicionalmente ganaderas. Los valores de calidad nutricional correspondientes a proteína cruda $(8,8 \pm 1,4 \%)$, fibra detergente ácida $(11,8 \pm 1,3 \%)$, fibra detergente neutro $(28,4 \pm 11,8 \%)$, digestibilidad in vitro $(75,9 \pm 7,4 \%)$, energía metabolizable $(3,1 \pm 0,03 \mathrm{Mcal} / \mathrm{kg} \mathrm{MS})$ y cenizas $(2,2 \pm 0,4 \%)$ estuvieron dentro del rango esperado. Desde el punto de vista de la calidad de la confección del silo, el pH ácido obtenido $(4,7 \pm 0,8)$ y la baja proporción de nitrógeno amoniacal $(2,2 \pm 0,7 \%)$ aseguran la estabilidad y conservación de silo en el mediano plazo. La calidad nutricional y de confección de los silos en la región este del país fue similar a la registrada en silos de otras regiones del país con mayor experiencia y tradición en el uso de la tecnología de grano húmedo de sorgo.

Palabras clave: ensilaje, sorgo, grano húmedo, valor nutritivo

The chemical composition and nutritional value of twelve high moisture sorghum grain silages in the eastern region of Uruguay were analyzed between March and August 2008. Even though grain moisture (media \pm s.d.) was according to the guidelines for wet silages (27.2 $\pm 7.9 \%$ ), one third of the silages registered a moisture content below $20 \%$ which compromises silage stability and conservation. Those situations were attributed to the delay in the arrival of the equipment required for harvesting, carrying, processing and ensiling the grain. Mean values of crude protein (8.8 $\pm 1.4 \%)$, acid detergent fiber $(11.8 \pm 1.3 \%)$, neutral detergent fiber $(28.4 \pm 11.8 \%)$, in vitro digestibility $(75.9 \pm 7.4 \%)$, metabolizable energy (3.1 $\pm 0.03 \mathrm{Mcal} / \mathrm{kg} \mathrm{DM})$ and ashes $(2.2 \pm 0.4 \%)$ were within the expected range. The acid $\mathrm{pH}$ registered $(4.7 \pm 0.8)$ and the low proportion of ammonia nitrogen $(2.2 \pm 0.7 \%)$ ensure the silage stability and nutritional value in the medium-term. Even though livestock-based enterprises in the eastern region of Uruguay have less experience in more intensive technologies and less availability of resources (i.e. logistic, machinery services), overall chemical composition and nutritional value of high moisture sorghum grain silages were in accordance with data from silages in more intensive systems of production (i.e. dairy farms, feedlots).

Key words: silage, sorghum, high moisture grain, nutritional value 


\section{INTRODUCCIÓN}

El cultivo de sorgo dentro de los establecimientos agropecuarios en la región este ha tenido una gran expansión en los últimos años, asociado a su rusticidad en ambientes limitantes y a la intensificación de los sistemas de produccion animal. Concretamente, cada vez es más común observar la tecnología de ensilaje de grano húmedo de sorgo en predios ganaderos de la región. La misma consiste en la cosecha del grano con 25-35\% de humedad en el estado de madurez fisiológica, y posterior quebrado y embolsado en condiciones anaerobias (ausencia de aire) en bolsas de silo (Figura 1).

A nivel nacional existe información sobre el valor nutritivo de dicha reserva de alimento (ej.: Concurso Nacional de Silos), pero fundamentalmente se origina en las regiones más intensivas, localizadas en el litoral y sur del país, en donde establecimientos lecheros o de engorde intensivo de vacunos hace años vienen adoptando la tecnología con éxito. Aspectos característicos de cada región, como el clima, sistema de producción, tipo de suelo, materiales adaptados y/o la calidad y disponibilidad de servicios de maquinaria así como la experiencia del productor, pueden afectar la confección y el valor nutritivo del silo.
El objetivo del presente trabajo fue caracterizar el valor nutritivo de ensilajes de grano húmedo de sorgo en la región este del país y contrastarlo con valores de referencia obtenidos a nivel nacional.

\section{MATERIALES Y MÉTODOS}

Entre marzo y agosto de 2008 se muestrearon 12 silos de grano húmedo de sorgo, correspondiendo a 11 establecimientos agropecuarios distribuidos en los departamentos de Maldonado, Rocha, Treinta y Tres y Cerro Largo. En la mayoría de los casos cada silo se muestreó tomando entre 5-10 puñados del frente abierto del silo y formando 2 muestras compuestas de $1 \mathrm{~kg}$ cada una. En aquellos casos en que el silo aún no estaba abierto para consumo animal, se tomaron las muestras a través de un corte lateral en la bolsa.

Una vez tomadas las muestras eran inmediatamente refrigeradas y enviadas al Laboratorio de Nutrición Animal de INIA La Estanzuela para análisis de Digestibilidad de la Materia Orgánica (DMO), Proteína Cruda (PC), Fibra Detergente Neutra (FDN), Fibra Detergente Acida (FDA), Cenizas (C), acidez $(\mathrm{pH})$, nitrógeno amoniacal $\left(\mathrm{N}-\mathrm{NH}_{3}\right)$ y cálculo de la Energía Metabolizable (EM).

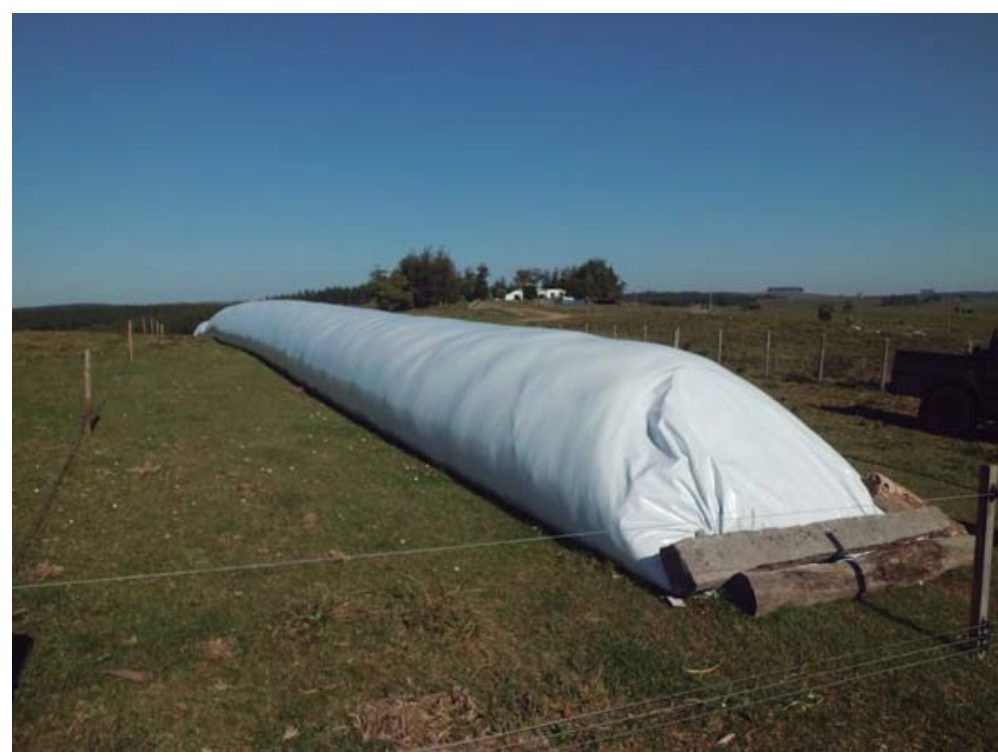

Figura 1. Bolsa con ensilaje grano húmedo de sorgo. 


\section{RESULTADOS Y DISCUSIÓN}

El Cuadro 1 muestra el valor nutritivo de 12 silos de grano húmedo localizados en la región este del país y su comparación con valores de referencia a nivel nacional.

\section{Porcentaje de humedad}

El valor promedio de humedad del grano estuvo dentro del rango recomendado para grano húmedo (25-35\%), aunque se registraron valores mínimos y máximos de 17,3\% y $40,1 \%$, respectivamente. Una humedad excesivamente baja en el grano $(<20 \%)$ dificulta el proceso de quebrado y partido al momento del embolsado, disminuye la velocidad del embolsado y dificulta la compactación del material dentro de la bolsa afectando el proceso de fermentación y por lo tanto el valor nutritivo del ensilaje. En el otro extremo, un grano excesivamente húmedo (>40\%) puede producir pérdidas importantes por efluentes así como el desarrollo de fermentaciones indeseables.

Cuatro de los 12 silos muestreados $(33,3 \%)$ registraron un valor de humedad por debajo del 20\% (promedio de 18,5\%). Ensilajes con baja humedad son característicos en regiones ganaderas con escasa disponibilidad de servicios de maquinaria. Concretamente en la región este, la falta de máquinas embolsadoras determina que exista una muy alta demanda por el servicio de embolsado en un periodo muy concentrado lo que retrasa la operativa, más aún en otoños lluviosos.

\section{Proteína cruda}

Como característica principal del grano húmedo se destaca su bajo contenido proteico. El valor promedio de proteína del grano en los ensilajes relevados fue $8,8 \%$. Las proteínas dominantes en el grano de sorgo son las prolaminas, y se encuentran principalmente en el endosperma. Las mismas son deficientes en aminoácidos esenciales como metionina, lisina y triptófano, lo que determina la baja calidad nutricional de la proteína del grano de sorgo (Montiel y Elizalde, 2004). El bajo contenido de proteína del grano húmedo de sorgo hace que no sea recomendable su utilización como único suplemento en esquemas de suplementación sobre campo natural, fundamentalmente en categorías jóvenes en activo crecimiento (terneros/as).

Es común que la fracción proteica sufra distintos procesos de degradación durante la etapa de ensilaje. En ensilajes bien fermentados, el nitrógeno está constituido principalmente por aminoácidos libres. Sin embargo, en ensilajes mal conservados, los aminoácidos son degradados por microorganismos del género de Clostridium y Entero-

Cuadro 1. Valor nutricional de ensilajes de grano húmedo de sorgo en la región este y valores de referencia a nivel nacional

\begin{tabular}{llc}
\hline & \multicolumn{2}{c}{ Valor (media \pm desvío estándar) } \\
\cline { 2 - 3 } Parámetro & Región este & Referencia $^{1}$ \\
\hline Humedad, \% & $27,2 \pm 7,9$ & $26,7 \pm 8,7$ \\
Proteína Cruda, \% & $8,8 \pm 1,4$ & $7,7 \pm 1,7$ \\
Digestibilidad Materia Orgánica, \% & $75,9 \pm 7,4$ & $85,2 \pm 4,0$ \\
Fibra Detergente Ácida, \% & $11,8 \pm 1,3$ & $11,6 \pm 4,7$ \\
Fibra Detergente Neutro, \% & $28,4 \pm 11,8$ & - \\
Cenizas, \% & $2,2 \pm 0,4$ & $2,6 \pm 1,4$ \\
Energía Metabolizable, Mcal/kg MS & $3,1 \pm 0,03$ & $3,1 \pm 0,08$ \\
pH & $4,7 \pm 0,8$ & $4,7 \pm 0,8$ \\
$\mathrm{~N}^{-N_{3}}{ }_{3}, \%$ & $2,2 \pm 0,7$ & $2,4 \pm 2,3$ \\
\hline
\end{tabular}

${ }^{1}$ Concurso Nacional de Ensilajes - INIA (Acosta, 2010) 
bacterias, produciéndose elevadas concentraciones de amidas, aminas y amoníaco. Una alta temperatura del silo y/o elevado $\mathrm{pH}$ favorecen la rápida solubilización de proteínas, fundamentalmente en los primeros días de confección del silo (Fernández Meyer, 1998).

\section{Fibra detergente ácida}

La fibra detergente ácida (FDA) considera el contenido de celulosa y lignina del alimento. Debido a que son compuestos altamente indigestibles por parte del animal, el valor de FDA está negativamente relacionado a la digestibilidad. Cuanto mayor el valor de FDA, menor la digestibilidad del ensilaje y por lo tanto, también es menor el contenido de energía. En el presente relevamiento el bajo contenido de FDA $(11,8 \%)$ se correspondió con un alto valor de digestibilidad $(75,9 \%)$.

\section{Digestibilidad de la materia orgánica}

El valor de digestibilidad de los ensilajes muestreados varió entre 65 y 85\%. La tendencia es a una pérdida de digestibilidad a medida que se incrementa la materia seca del silo debido a limitantes en la fermentación que favorecen otros procesos no deseados (oxidación, respiración, calentamiento) (Acosta, 2010). En un trabajo realizado por Neuhaus y Totusek (1971), si bien la máxima digestibilidad de ensilajes de grano hú- medo de sorgo se obtuvo con valores en el rango de 30 a $35 \%$ de humedad, el incremento más significativo de la digestibilidad se produjo al pasar de 22 a $26 \%$ de humedad.

\section{Energía metabolizable}

La energía metabolizable del silo fue el parámetro con menor coeficiente de variación $(<1 \%)$, probablemente debido al protocolo de análisis de las muestras. Una vez llegadas al laboratorio, las muestras son secadas a peso constante y luego sufren un proceso de molido fino, enmascarando diferencias en el procesamiento del grano entre distintos ensilajes (presencia de granos enteros). En el campo, dentro de la bolsa, los ensilajes de grano húmedo pueden presentar un contenido variable de grano entero de sorgo. Ensilajes de grano húmedo de sorgo con altas proporciones de grano entero tienden a tener pobres desempeños como suplementos debido a que la energía retenida en el grano no puede ser utilizada por los microorganismos del rumen debido a las estructuras físicas del grano (Nording y Campling, 1976). Cuando el proceso de quebrado es deficiente, el grano entero tiende a aparecer en la bosta sin digerir (Acosta, 2007). Stritzler et al. (1982) utilizando novillos de $250 \mathrm{~kg}$ alimentados con grano de sorgo entero, hallaron que aproximadamente la mitad de los granos consumidos se excretaron enteros por las heces.

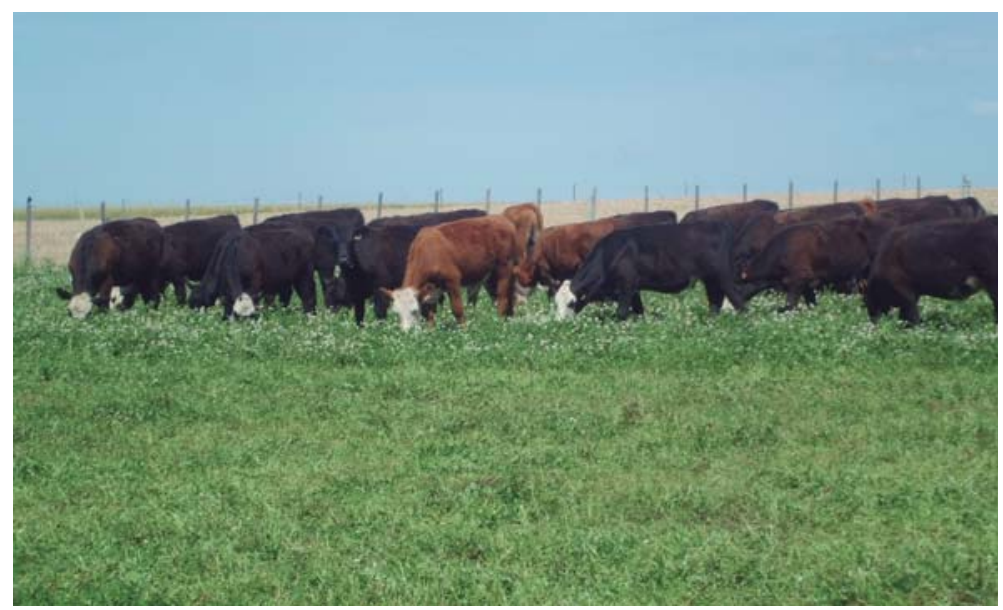

Mejoramientos de campo, praderas sembradas y verdeos de invierno son las pasturas que mejor se complementan con el valor nutricional del grano húmedo de sorgo (alto en energía y bajo en proteína). 


\section{Fibra detergente neutro}

El parámetro que presentó el mayor coeficiente de variación (41\%) fue la fibra detergente neutro (FDN). El mínimo y máximo de FDN fue $16 \%$ y $49 \%$, respectivamente. Valores altos de FDN reflejan un aumento del contenido de material fibroso dentro del silo, generalmente proveniente de la panoja de la planta (envoltorios del grano, raquis, etc.), no siendo tan exigente en la limpieza del material en la zaranda de la cosechadora. Al incrementar la fibra en el silo de grano húmedo se incrementa el volumen total de materia seca del silo (más toneladas) aunque la digestibilidad y valor energético de dicha fibra es sensiblemente menor a la energía aportada por el grano. En muchos casos, la realización de ensilajes de grano húmedo con alto contenido de fibra se debe a que luego dichos ensilajes se utilizarán sobre verdeos y/o praderas con escaso contenido de fibra y materia seca («aguachentos»). De esta manera, la fibra corta aportada por el ensilaje mejora las actividades de rumia, salivación y masticación, resultando en un mejor aprovechamiento del forraje disponible y evitando posibles disturbios ruminales.

La fracción FDN brinda una estimación de la fibra presente en el alimento, fundamentalmente celulosa, hemicelulosa y lignina, y está íntimamente relacionado al consumo de materia seca. A medida que el valor de FDN se incrementa, el consumo animal disminuye. Generalmente se estima que los rumiantes pueden llegar a consumir un máximo de FDN cercano al 1,2\% del peso vivo (García, 2003).

\section{Cenizas}

El contenido de cenizas de las muestras analizadas varió entre 1,7 y 3,3\%, estando dentro del rango normal. Generalmente se utiliza como indicador del contenido de minerales. En algunas ocasiones, cuando su contenido es excesivamente alto, puede ser indicador de contaminación con tierra. Esto sucede más a menudo en ensilajes de planta entera de sorgo en donde el corte con la ensiladora ocurre más cercano a la superficie del suelo.

\section{Acidez}

El pH promedio de los ensilajes muestreados $(\mathrm{pH}=4,7)$ está dentro del rango adecuado para mantener el valor nutritivo del material embolsado. Analizando los datos se encontró una relación alta y negativa $(r=$ 0,80 ) entre la humedad del grano y el $\mathrm{pH}$ del silo, en dónde a medida que se incrementó la humedad del grano el $\mathrm{pH}$ del silo disminuyó, al menos en el rango de 17-40\% de humedad del grano (Figura 2). Esto es debido a que un grano más húmedo es más fácil de

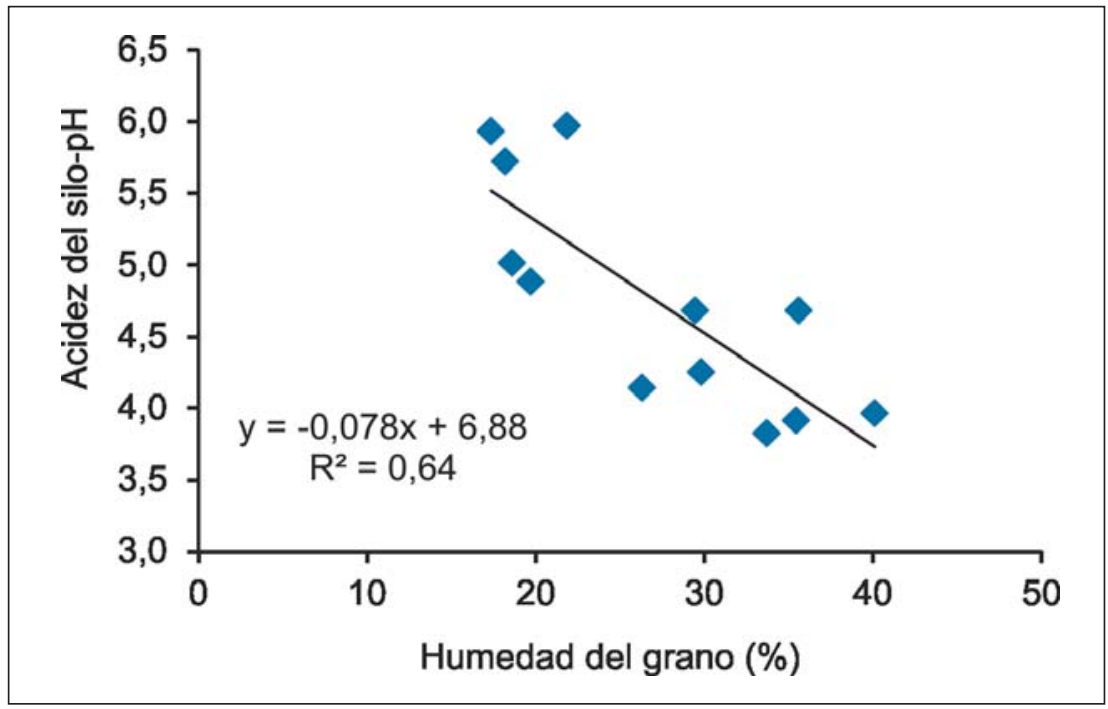

Figura 2. Relación entre la acidez del silo y la humedad del grano. 
procesar al momento del embolsado resultando en una mejor compactación dentro de la bolsa, asegurando la ausencia de aire y la proliferación de bacterias lácticas responsables del descenso del pH del silo. A menor humedad (más materia seca) el descenso del $\mathrm{pH}$ se realiza más dificultosamente, resultando en silos más inestables. La longevidad y conservación de la calidad del material embolsado en un silo con $\mathrm{pH}$ elevado $(\mathrm{pH}>5)$ probablemente se vea comprometida, lo que en términos prácticos implica la utilización del silo por parte de los animales en el corto plazo a los efectos de evitar pérdidas significativas del valor nutritivo asociadas a fermentaciones indeseables.

\section{Nitrógeno amoniacal}

El contenido de nitrógeno amoniacal junto a la acidez del silo son indicativos de la calidad del proceso fermentativo. De manera general el ensilaje de sorgo se considera de buena calidad cuando el nitrógeno amoniacal está por debajo del 10\% (Ribeiro et al. 2007). Cantidades mayores de amoníaco son indicadores de fermentaciones indeseadas que producen activa degradación de las proteínas. En el presente relevamiento, los valores de nitrógeno amoniacal en relación al nitrógeno no superó el 3,5\% en ninguno de los silos muestreados en forma individual. El riesgo de alcanzar valores elevados de amonio crece en los ensilajes con bajo contenido de materia seca por el riesgo de fermentaciones producidas por bacterias del género Clostridium (Acosta, 2010). Un exceso de nitrógeno amoniacal puede reducir la aceptabilidad del alimento por parte de los animales debido a condiciones organolépticas no deseadas.

\section{CONCLUSIONES}

Los resultados de los análisis se encontraron dentro del rango esperado para ensilajes de grano húmedo de sorgo. Esto confirma el éxito en la adopción de la tecnología en la región este del país, a pesar de las limitantes operativas y logísticas existentes.

\section{AGRADECIMIENTOS}

A todos los productores y técnicos que colaboraron con el presente trabajo, ya sea permitiendo y/o realizando el muestreo así como suministrando información.

\section{BIBLIOGRAFÍA}

ACOSTA, Y. 2007. Suplementación del ganado con ensilaje de grano húmedo de sorgo: potencial y limitantes. En: INIA Treinta y Tres (ed.). Producción Animal. Unidad Experimental Palo a Pique. INIA Treinta y Tres. p. 41-48. (Actividades de Difusión, 511).

FERNÁNDEZ MEYER, A. 1998. Forrajes conservados y su impacto sobre comportamiento animal. En: Jornadas de Nutrición Animal para Profesionales.

GARCíA, A. 2003. Interpreting corn silage analysis. Extension Extra 4027. South Dakota State University.

MONTIEL, M.D.; ELIZALDE, J.C. 2004. Factores que afectan la utilización ruminal del grano de sorgo en vacunos. Revista Argentina de Producción Animal 24: 1-20.

NEUHAUS, V.; TOTUSEK, R. 1971. Factors affecting the in vitro digestibility of high moisture sorghum grain. Journal of Animal Science 33: 1321-1326.

NORDING M.; CAMPLING R.C. 1976. Digestibility studies with cows given whole and rolled cereal grains. Animal Production 23: 305-315.

RIBEIRO, L.G.; RODRÍGUEZ, N.M.; GONCALVEZ, L.C.; ANANIAS, D. 2007. Consideraciones sobre ensilajes de sorgo. En: Jornada sobre producción y utilización de ensilajes. Universidad Nacional del Sur, Bahía Blanca, Argentina. p. 51-68. Disponible en: http://www.cpatsa.embrapa.br/ public_eletronica/downloads/ OPB1703.pdf

STRITZLER, N.; GINGIS, M.; SANTUCHO, G. 1982. Efecto del molido sobre la digestibilidad del grano de sorgo en bovinos. Producción Animal 9: 3-7.

VAZ MARTINS, D.; OLIVERA, L.; COZZOLINO, D. 2006. Ensilajes de maíz como componente en la dieta en la fase de terminación de novillos. Revista INIA N ${ }^{0} 7$. p. 5-8. 


\title{
IV. INCLUSIÓN DE FUENTES PROTEICAS AL GRANO HÚMEDO DE SORGO EN ESQUEMAS DE SUPLEMENTACIÓN DE BOVINOS SOBRE CAMPO NATURAL
}

P. Rovira ${ }^{1}$

J. Velazco ${ }^{2}$

\author{
EFECTO DEL AGREGADO DE FUENTES PROTEICAS AL \\ GRANO HÚMEDO DE SORGO EN EL CRECIMIENTO DE \\ TERNEROS SUPLEMENTADOS SOBRE CAMPO NATURAL
}

\section{RESUMEN}

El objetivo fue evaluar el efecto de la adición de fuentes proteicas al grano húmedo de sorgo en el desempeño de terneros pastoreando campo natural durante el invierno. Se utilizaron 56 terneros $(188 \pm 14 \mathrm{~kg})$ asignados en los siguientes tratamientos: 1) testigo sin suplementación $(\mathrm{T}), 2$ ) suplementación con sorgo grano húmedo $(\mathrm{SGH}), 3$ ) suplementación con SGH + expeller de girasol ( $S G H+E G)$, y 4) suplementación con $\mathrm{SGH}+$ suplemento proteico (SGH + SP 30\% proteína cruda ). El nivel de suplementación fue $1 \%$ del peso vivo (base seca) y aquellas mezclas que incluyeron fuentes de proteína fueron iso-proteicas (12\% PC) con un mayor nivel de proteína que el tratamiento SGH (7\% PC). El contenido de proteína del forraje varió de 6,6\% (inicio) a 9,1\% (final). La inclusión de una fuente proteica al SGH incrementó el peso final de los terneros comparado con el tratamiento SGH $(229 \pm 16 \mathrm{~kg}$ y $206 \pm 21 \mathrm{~kg}$, respectivamente). La misma tendencia se registró para la variable ganancia de peso (0,391 y 0,248 kg/a/día, respectivamente). No existieron diferencias significativas en el desempeño productivo de los terneros debido a la fuente de proteína utilizada. La eficiencia de conversión, expresada en base seca, fue de 6,0 (SGH), 4,5 (SGH + EG) y 4,1 (SGH + SP) kg de suplemento para depositar $1 \mathrm{~kg}$ de peso vivo adicional comparado con el desempeño productivo del grupo testigo $(-0,082 \mathrm{~kg} / \mathrm{a} / \mathrm{d})$. La adición de fuentes proteicas al grano húmedo de sorgo es una alternativa válida para evitar la pérdida de peso vivo invernal de terneros sobre campo natural.

Palabras claves: suplementación, terneros, proteína, sorgo

\section{ABSTRACT}

The aim of this study was to evaluate the effect of the addition of protein sources in the performance of calves supplemented with high moisture sorghum grain grazing natural pastures during winter. Fifty six calves $(188 \pm 14 \mathrm{~kg})$ were assigned to 4 treatments: 1 ) control without supplementation $(T), 2)$ supplementation with high moisture sorghum grain (HMSG), 3) supplementation with HMSG + sunflower expeller (HMSG+SE), 4) supplementation with HMSG + protein ration (PR 30\% crude protein). The level of supplementation was $1 \%$ of the body weight (DM basis) and both treatments with protein

${ }^{1}$ INIA Treinta y Tres.

${ }^{2}$ INIA Treinta y Tres. 
sources had 12\% CP (iso-protein) compared with treatment HMSG (7\% CP). Protein concentration of pastures ranged from 6.6\% CP (beginning) and 9.1\% CP (end). Final weight of calves supplemented with protein sources was significantly greater than the final weight of calves in the HMSG treatment $(229 \pm 16 \mathrm{~kg}$ y $206 \pm 21 \mathrm{~kg}$, respectively). The same tendency was registered for the variable average daily gain $(0.391$ y $0.248 \mathrm{~kg} / \mathrm{a} / \mathrm{d}$, respectively). Comparing iso-protein treatments animal performance was not affected by the protein source. Feed efficiency (DM basis) was 6.0 (HMSG), 4.5 (HMSG+SE) and 4.1 (HMSG+PR) kg of supplement to gain 1 additional $\mathrm{kg}$ compared with the performance of the control group $(-0.082 \mathrm{~kg} / \mathrm{a} / \mathrm{d})$. The addition of protein sources to high moisture sorghum grain improved performance of supplemented calves grazing natural pastures during winter.

Key words: supplementation, calves, protein, sorghum

\section{INTRODUCCIÓN}

El uso del ensilaje de grano húmedo de sorgo en la alimentación de bovinos se ha incrementado significativamente en los últimos años en los establecimientos ganaderos del Uruguay. El éxito de la adopción de la tecnología se basa en que permite obtener en forma rentable un volumen importante de energía, el nutriente de mayor demanda y de mejor respuesta en sistemas de producción animal. Consiste en la cosecha del grano de sorgo con 25 a 35\% de humedad y posterior quebrado y embolsado del grano en condiciones anaeróbicas hasta su utilización por parte del ganado. La conservación del valor nutritivo del material se basa en el pH ácido dentro de la bolsa como consecuencia de la proliferación de bacterias productoras de ácido láctico en ausencia de aire (Nishino, 2008).

En los sistemas más intensivos de producción, el grano húmedo de sorgo se utiliza en la etapa final del engorde de los animales, ya sea sobre pasturas de alta calidad (praderas, verdeos) o formando parte de dietas balanceadas en corrales de feedlot. En sistemas más extensivos de producción, en establecimientos criadores o de ciclo completo, es común observar la suplementación de categorías de recría (terneros/as, vaquillonas) con grano húmedo de sorgo sobre campo natural. En estas condiciones, se debe considerar que si bien los ensilajes de grano húmedo de sorgo aportan energía, son alimentos carentes en proteína, por lo que para su mejor uso se debe tener en cuenta el balance entre dichos nutrientes en la dieta (Acosta, 2007).
La inclusión de fuentes proteicas de origen vegetal (soja, girasol) o de origen sintético (urea) es una alternativa válida para incrementar el contenido de proteína cruda de los ensilajes de grano húmedo (Pordomingo et al., 2002; Jobim et al., 2008). Es de esperar que el incremento del nivel de proteína en el silaje se refleje en una mejora del desempeño productivo de los animales suplementados. En Argentina, Montiel et al. (2005) incrementaron la ganancia diaria de peso $(+14 \%)$ de terneros suplementados con grano húmedo de sorgo al agregar urea en la dieta.

El objetivo general del presente experimento fue evaluar el efecto de la adición de distintas fuentes proteicas al grano húmedo de sorgo en la respuesta animal de terneros pastoreando pasturas de baja calidad durante el invierno. La hipótesis de trabajo fue que la adición de fuentes proteicas al ensilaje de grano húmedo de sorgo mejora la ganancia de peso y la eficiencia de conversión del suplemento de terneros pastoreando campo natural en el invierno.

\section{MATERIALES Y MÉTODOS}

La etapa de suplementación se realizó entre el $1^{\circ}$ de julio y el 8 de octubre de 2009 (100 días) en la Unidad Experimental Palo a Pique de INIA Treinta y Tres (Uruguay). Se utilizaron 17,5 ha de campo natural con predominancia de especies estivales, fundamentalmente Cynodon dactylon (gramilla), sin pastoreo desde abril hasta el inicio del ensayo. Se utilizaron 56 terneros cruza Hereford $x$ Aberdeen Angus provenientes del 
rodeo de cría de la Unidad Experimental con 9 meses de edad y $188 \pm 14 \mathrm{~kg}$ de peso vivo (PV). Al inicio del experimento fueron dosificados contra parásitos externos e internos y luego re-dosificados en función del conteo de huevos por gramo (hpg) en las heces.

Los animales fueron asignados al azar en los siguientes tratamientos: 1) Testigo sin suplementación $(\mathbf{T}), 2)$ Suplementación con sorgo grano húmedo (SGH), 3) Suplementación con SGH + Expeller de Girasol (SGH + EG), y 4) Suplementación con SGH + Suplemento proteico (SGH + SP). En todos los casos la dotación fue de 3,2 terneros/ha en régimen de pastoreo continuo. En los tratamientos con suplementación se utilizaron 16 terneros en 5 ha, mientras que en el tratamiento testigo se utilizaron 8 terneros en 2,5 ha.

El sorgo grano húmedo fue cosechado, quebrado y embolsado el 7 de abril de 2009. Se mantuvo herméticamente cerrado hasta el 9 de junio de 2009, fecha en la cual comenzó el periodo de acostumbramiento de los animales a la suplementación (21 días). El suplemento se ofreció todos los días temprano en la mañana. El nivel de suplementación durante el periodo experimental fue de $1 \%$ del peso vivo (base seca). En los tratamientos con adición de fuentes proteicas, tanto expeller de girasol como suplemento proteico, las mismas se incorporaron diariamente en mezcla con el grano húmedo de manera de ofrecer dietas iso-energéticas (2,9-3,0 Mcal EM/kg MS) variando la fuente y el nivel de proteína. El expeller de girasol y el suplemento proteico ( $40 \%$ de proteína según etiqueta) fueron adquiridos a nivel comercial y el objetivo fue realizar una mezcla con el grano húmedo de sorgo que permitiera llegar a una concentración de 12\% de proteína cruda.

Al inicio del experimento y cada 21 días se registró el peso vivo (PV) sin ayuno de los animales. Luego de cada pesada se ajustó la cantidad de suplemento por animal en función de la evolución del peso vivo. Se estimó la eficiencia de conversión del suplemento a carne mediante la relación entre el consumo de suplemento y la ganancia dia- ria individual de peso vivo, comparado con la ganancia de peso vivo del tratamiento testigo sin suplementación.

La disponibilidad de materia seca ( $\mathrm{kg} \mathrm{MS/ha)} \mathrm{en} \mathrm{el} \mathrm{campo} \mathrm{natural} \mathrm{se} \mathrm{deter-}$ minó en 3 momentos del ensayo (16/06, $28 / 07,23 / 09)$, mediante el corte con tijera eléctrica de 5 muestras por tratamiento, utilizando cuadros de 50 por $20 \mathrm{~cm}$. Los cortes se realizaron al ras del suelo. En cada tratamiento el muestreo fue realizado en forma dirigida, intentando seleccionar áreas representativas del potrero. Previo al corte se registró la altura promedio del tapiz $(\mathrm{cm})$ a ser muestreado dentro de cada cuadro de muestreo. En cada fecha de muestreo se tomó una muestra representativa y se determinó la relación verde/seco. Al inicio y fin del experimento se enviaron al Laboratorio de Nutrición Animal de INIA La Estanzuela muestras de materia seca (general) y de las fracciones verde y seca del campo natural para el análisis (base seca) de digestibilidad materia orgánica (DMO), proteína cruda (PC), fibra detergente neutro (FDN), fibra detergente ácida (FDA) y cenizas (C). Adicionalmente, al inicio y mediados del experimento se tomaron muestras del silo de grano húmedo para estimar, además de los parámetros arriba mencionados, la acidez $(\mathrm{pH})$ y el nitrógeno amoniacal $\left(\mathrm{N}-\mathrm{NH}_{3}\right)$ del silo.

Luego de finalizada la etapa de suplementación y hasta el 30 de diciembre de 2009 (83 días) los animales provenientes de todos los tratamientos fueron manejados en forma conjunta sobre campo natural y praderas para observar el efecto de los distintos tratamientos invernales en el desempeño productivo de los terneros en el mediano plazo (primavera).

El análisis estadístico se realizó utilizando el comando GLM de SAS con el efecto principal del tratamiento en las variables disponibilidad, altura de forraje, peso vivo y ganancia de peso. Cuando el análisis de varianza obtuvo resultados de $\mathrm{P}<0,05$ se procedió a la comparación de medias entre tratamientos mediante el test de Tukey. 


\section{RESULTADOS Y DISCUSIÓN}

\section{Características de la pastura}

En el Cuadro 1 se presenta la disponibilidad y altura del tapiz en las tres fechas de corte. Ambas variables no resultaron afectadas por el tratamiento tanto dentro de cada fecha de corte como promediando sobre las fechas de corte $(P>0,05)$. La disponibilidad y altura promedio (media \pm d.e.) fueron 2649 $\pm 1124 \mathrm{~kg} \mathrm{MS} / \mathrm{ha}$ y $10,8 \pm 4,9 \mathrm{~cm}$, respectivamente. La alta disponibilidad de forraje del campo natural al inicio del periodo experimental (3248 kg MS/ha) fue debido a la subutilización del forraje durante el periodo estival previo que permitió la acumulación y transferencia de forraje hacia el invierno.

Existió un efecto significativo de la fecha de corte en las características del campo natural promediando sobre los tratamientos
$(P<0,05)$. El campo natural presentó una menor disponibilidad de forraje en la última fecha de corte (1657 kg MS/ha el 23/09) comparado con el promedio de las dos primeras fechas de corte (3145 kg MS/ha). En el mismo sentido, la altura del tapiz disminuyó de $12,8 \mathrm{~cm}$ (promedio 16/06 y 28/07) a $6,7 \mathrm{~cm}$ (23/09). El efecto significativo de la fecha de corte en la disponibilidad y altura del tapiz fue debido al consumo de forraje por parte de los animales asociado a la baja tasa de crecimiento del campo natural en el invierno.

El porcentaje de restos secos en proporción a la disponibilidad de forraje (base seca) en las 3 fechas de corte fueron $57 \%(16 / 06)$, $84 \%(28 / 07)$ y $45 \%(23 / 09)$, promediando sobre los tratamientos. La elevada proporción de restos secos en todos los tratamientos fue debido a la transferencia y pérdida de calidad del forraje al pasar del verano hacia el invierno. La Figura 1 ilustra la situa-

Cuadro 1. Disponibilidad (kg MS/ha) y altura $(\mathrm{cm})$ del campo natural en 3 fechas de corte (media \pm d.e.)

\begin{tabular}{lllllll}
\hline \multicolumn{5}{c}{} & \multicolumn{5}{c}{ Fecha de corte } \\
16/06 & \multicolumn{3}{c}{$\mathbf{2 8 / 0 7}$} & $\mathbf{2 3 / 0 9}$ \\
\cline { 2 - 7 } Tratamiento $^{1}$ & Disponible & Altura & Disponible & Altura & Disponible & Altura \\
\hline Testigo & $3216 \pm 964^{\mathrm{a}}$ & $12,4 \pm 5,6^{\mathrm{a}}$ & $3363 \pm 908^{\mathrm{a}}$ & $13,0 \pm 6,7^{\mathrm{a}}$ & $1659 \pm 298^{\mathrm{a}}$ & $10,8 \pm 3,3^{\mathrm{a}}$ \\
SGH & $2853 \pm 967^{\mathrm{a}}$ & $13,0 \pm 6,4^{\mathrm{a}}$ & $3243 \pm 648^{\mathrm{a}}$ & $13,2 \pm 6,7^{\mathrm{a}}$ & $1886 \pm 1198^{\mathrm{a}}$ & $10,9 \pm 2,9^{\mathrm{a}}$ \\
SGH+EG & $3375 \pm 1279^{\mathrm{a}}$ & $12,2 \pm 6,2^{\mathrm{a}}$ & $2235 \pm 801^{\mathrm{a}}$ & $10,2 \pm 3,7^{\mathrm{a}}$ & $1498 \pm 824^{\mathrm{a}}$ & $9,7 \pm 3,4^{\mathrm{a}}$ \\
SGH+SP & $3547 \pm 972^{\mathrm{a}}$ & $15,4 \pm 9,4^{\mathrm{a}}$ & $3328 \pm 855^{\mathrm{a}}$ & $13,8 \pm 5,2^{\mathrm{a}}$ & $1586 \pm 611^{\mathrm{a}}$ & $11,9 \pm 1,6^{\mathrm{a}}$ \\
\hline
\end{tabular}

${ }^{1} \mathrm{SGH}$ : Sorgo Grano Húmedo, EG: Expeller Girasol, SP: Suplemento Proteico.

${ }^{a}$ Letras diferentes dentro de una misma columna difieren significativamente $(P<0,05)$.

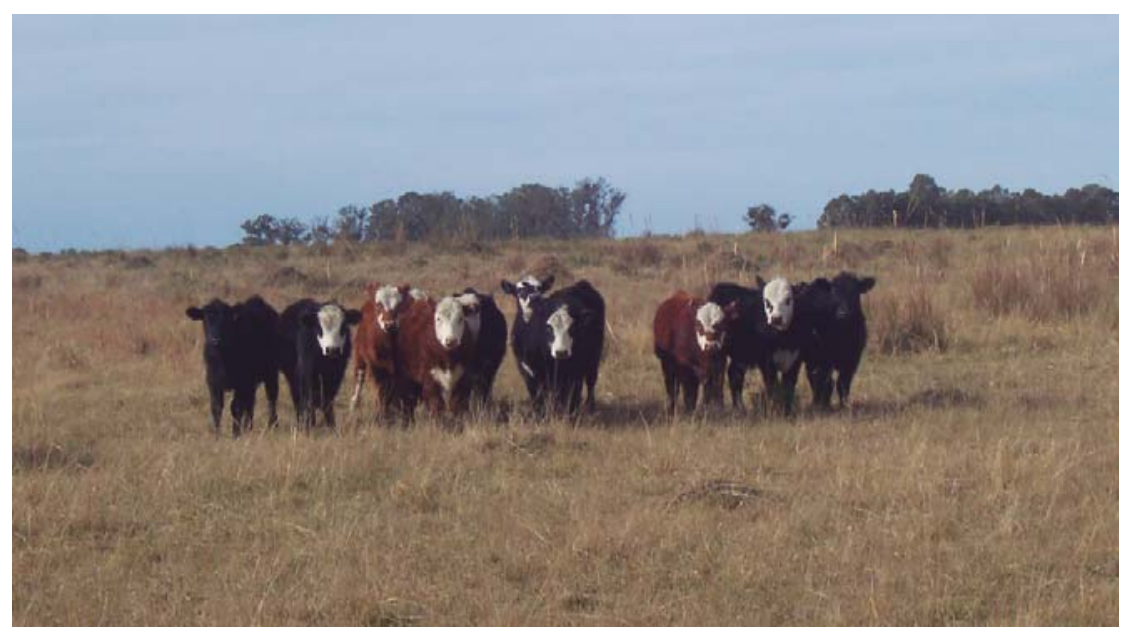

Figura 1. Campo natural del experimento con predominio de restos secos. 


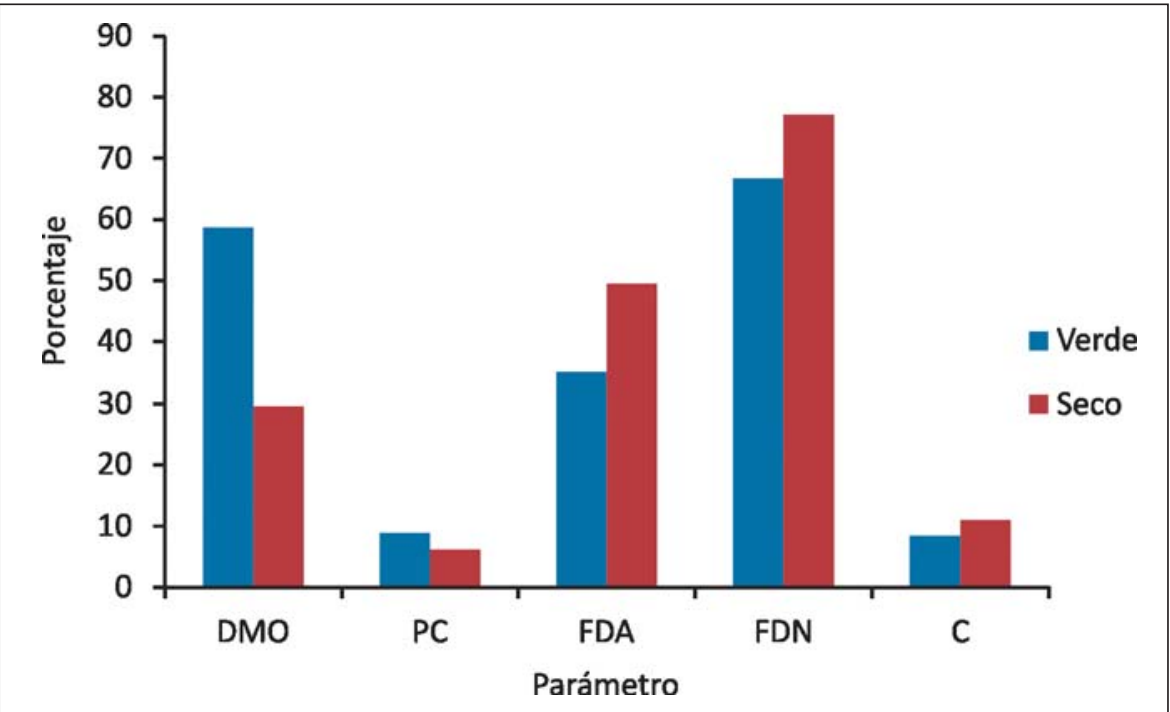

Figura 2. Composición química de las fracciones del forraje del campo natural. (DMO: Digestibilidad Materia Orgánica, PC: Proteína Cruda, FDA: Fibra Detergente Ácida, FDN: Fibra Detergente Neutro, C: Cenizas). Fuente: Laboratorio Nutrición Animal-INIA La Estanzuela.

ción del campo natural hacia mediados del periodo experimental. La composición química de las distintas fracciones del campo natural, verde y seco, fue significativamente diferente (Figura 2). La mayor variación se observó en la digestibilidad de la materia orgánica, correspondiendo a valores de 59 y
$30 \%$, en el forraje verde y seco, respectivamente. Los valores de proteína cruda, parámetro de especial importancia en categorías jóvenes en crecimiento, fueron de 8,9\% (fracción verde) y 6,1\% (fracción seca).

La Figura 3 presenta la composición química del forraje al inicio y final del periodo

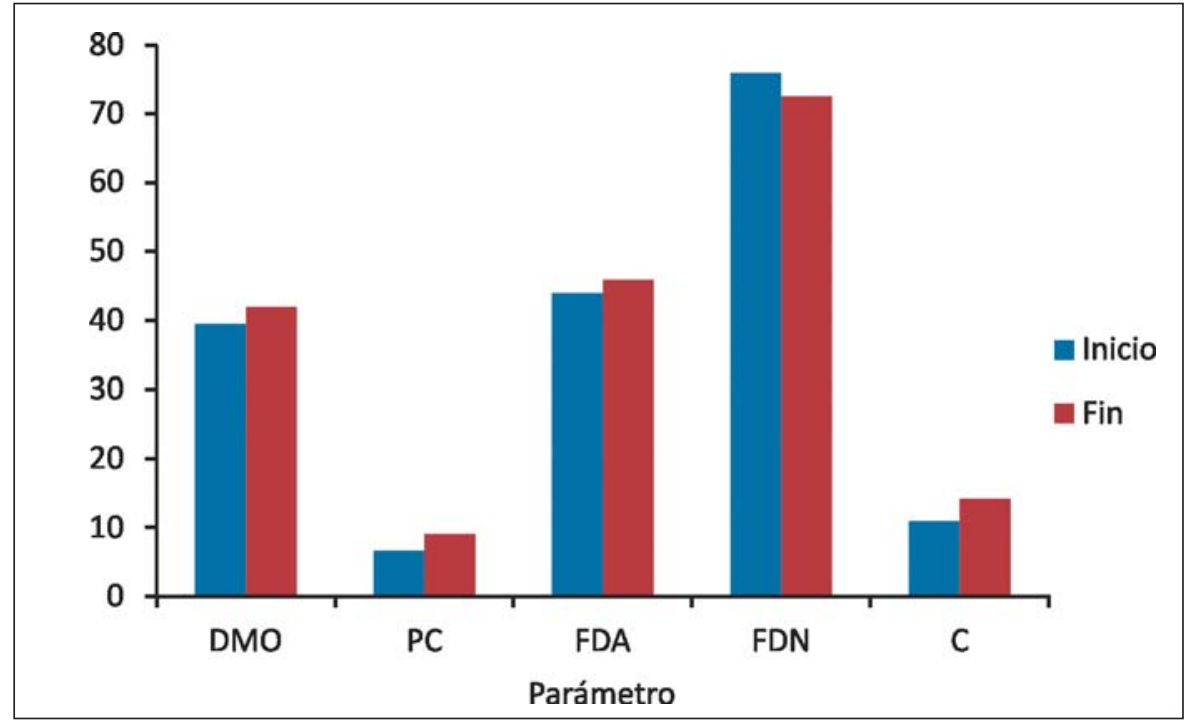

Figura 3. Composición química del forraje del campo natural al inicio y final del experimento.

(DMO: Digestibilidad Materia Orgánica, PC: Proteína Cruda, FDA: Fibra Detergente Ácida, FDN: Fibra Detergente Neutro, C: Cenizas). Valores expresados en base seca. Las líneas verticales en cada columna indican desviación estándar. Fuente: Laboratorio Nutrición Animal-INIA La Estanzuela. 
experimental promediando sobre los tratamientos. El cambio más importante correspondió al valor de proteína cruda, el cual se incrementó de 6,6 a 9,1\% desde el inicio hacia el fin del ensayo, respectivamente. Dicho incremento estuvo asociado a la mayor proporción de la fracción verde en la última fecha de muestreo. El único parámetro que disminuyó fue la fibra detergente neutro, correspondiendo a valores de 75,9 y $72,6 \%$, al inicio y fin del experimento, respectivamente.

\section{Valor nutritivo y consumo de los suplementos}

La composición química del silo de grano húmedo y de las fuentes de proteína utilizadas se presenta en el Cuadro 2. El valor nutricional del grano húmedo de sorgo estuvo dentro del rango esperado destacándose el bajo valor proteico y el alto aporte de energía. El nitrógeno amoniacal $\left(\mathrm{N}^{-\mathrm{NH}_{3}}\right)$ y la acidez del silo $(\mathrm{pH})$, ambos parámetros relacionados a la conservación del silo, también estuvieron dentro del rango esperado asegurando una alta calidad del material ensilado.

El expeller de girasol utilizado en el presente trabajo se destacó por su contenido medio de proteína y alto en energía. La variabilidad en el valor nutricional es una característica de los sub-productos de origen industrial, en el caso del expeller de girasol está asociada a la eficiencia de extracción del aceite de la semilla. En el suplemento proteico de origen comercial, la proteína fue principalmente de origen vegetal aunque incluyó un máximo de $6,5 \%$ de urea según etiqueta de la planta elaboradora. La concentración proteica del suplemento fue de 31,1\% determinada por análisis de laboratorio si bien la información de la etiqueta aseguraba un mínimo de $40 \%$.

En los tratamientos con adición de fuentes proteicas, el expeller de girasol y el suplemento proteico representaron un 22 y $23 \%$ de la mezcla con el grano húmedo, respectivamente (Cuadro 3), para llegar a una concentración de proteína en la mezcla en torno del $12 \%$. Las dietas fueron iso-energéticas, variando el nivel y fuente de proteína. Como resultado, el aporte diario de proteína se incrementó un 71 y $83 \%$ al adicionar expeller de girasol o un suplemento proteico al grano húmedo de sorgo, respectivamente.

Al aporte de proteína del suplemento se le debe sumar la proteína proveniente de la pastura. De acuerdo al elevado valor de FDN del campo natural (>70\%) se puede estimar un consumo diario de forraje no mayor al $2 \%$ del peso vivo de los animales. En términos absolutos, para terneros de $200 \mathrm{~kg}$ de peso vivo y con una concentración de proteína en la pastura entre 7 y $8 \%$, el aporte de proteína proveniente del campo natural sería aproximadamente $0,300 \mathrm{~kg} / \mathrm{a} / \mathrm{d}$. En el caso del tratamiento testigo, sin aporte de suplementos, dicho consumo de proteína equivaldría a un nivel de mantenimiento del peso vivo (NRC, 2000).

Cuadro 2. Composición química de los suplementos utilizados

\begin{tabular}{lccc}
\hline & $\begin{array}{c}\text { Sorgo grano } \\
\text { húmedo }\end{array}$ & $\begin{array}{c}\text { Expeller de } \\
\text { girasol }\end{array}$ & $\begin{array}{c}\text { Suplemento } \\
\text { proteico }\end{array}$ \\
\hline Materia seca, \% & 73,6 & 90,4 & 90,4 \\
Proteína cruda, \% & 7,1 & 29,6 & 31,1 \\
Fibra detergente ácido, \% & 12,8 & 22,8 & 32,8 \\
Fibra detergente neutro, \% & 29,0 & 38,0 & 46,9 \\
Cenizas, \% & 1,9 & 9,6 & 8,4 \\
Energía metabolizable, Mcal/kg MS & 3,0 & 2,7 & 2,4 \\
$\mathrm{~N}-\mathrm{NH}_{3,} \%$ & 1,8 & - & - \\
$\mathrm{pH}$ & 4,8 & - & - \\
\hline
\end{tabular}

Fuente: Laboratorio de Nutrición Animal (INIA La Estanzuela) y Laboratorio Bioagro (Paysandú). 
Cuadro 3. Consumo de materia seca y aporte de energía metabolizable y proteína cruda proveniente del suplemento (base seca)

\begin{tabular}{lrrrr}
\hline & \multicolumn{3}{c}{ Tratamiento } \\
\cline { 2 - 5 } & Testigo & SGH & SGH + EG & SGH + SP \\
\hline Consumo, kg MS/a/día & & & & 1,58 \\
Sorgo grano húmedo & - & 1,99 & 1,56 & - \\
Expeller girasol & - & - & 0,44 & 0,47 \\
Suplemento proteico & - & - & - & \\
Total & & & & 2,88 \\
\hline Energía Metabolizable & & & & 5,9 \\
Mcal/kg MS & 3,01 & 2,95 & \\
Mcal/a/d & 6,0 & 5,9 & 0,126 \\
\hline Proteína Cruda & & & 0,258 \\
kg/kg MS & & 0,071 & 0,120 & \\
kg/a/día & & 0,141 & 0,241 & \\
\hline
\end{tabular}

\section{RESPUESTA ANIMAL}

\section{Etapa de suplementación}

En la Figura 4 se presenta la evolución del peso vivo promedio del grupo de animales de cada tratamiento. El peso vivo inicial \pm d.e. fue $188 \pm 14 \mathrm{~kg}(P>0,05)$. Al término del periodo de suplementación se detectaron diferencias significativas en el peso vivo final (PVF) de los animales. En primer lugar,
Ios animales suplementados registraron mayor PVF que los animales sin suplementación $(221 \pm 20 \mathrm{~kg}$ y $182 \pm 13 \mathrm{~kg}$, respectivamente) $(P<0,05)$. En segundo lugar, considerando los tratamientos con suplementación, la inclusión de una fuente proteica al sorgo grano húmedo (SGH) incrementó el PVF de los terneros comparado con el tratamiento de sólo SGH $(229 \pm 16 \mathrm{~kg}$ y $206 \pm 21 \mathrm{~kg}$, respectivamente) $(\mathrm{P}<0,05)$. Por último, dentro de los tratamientos con agregado de fuentes pro-

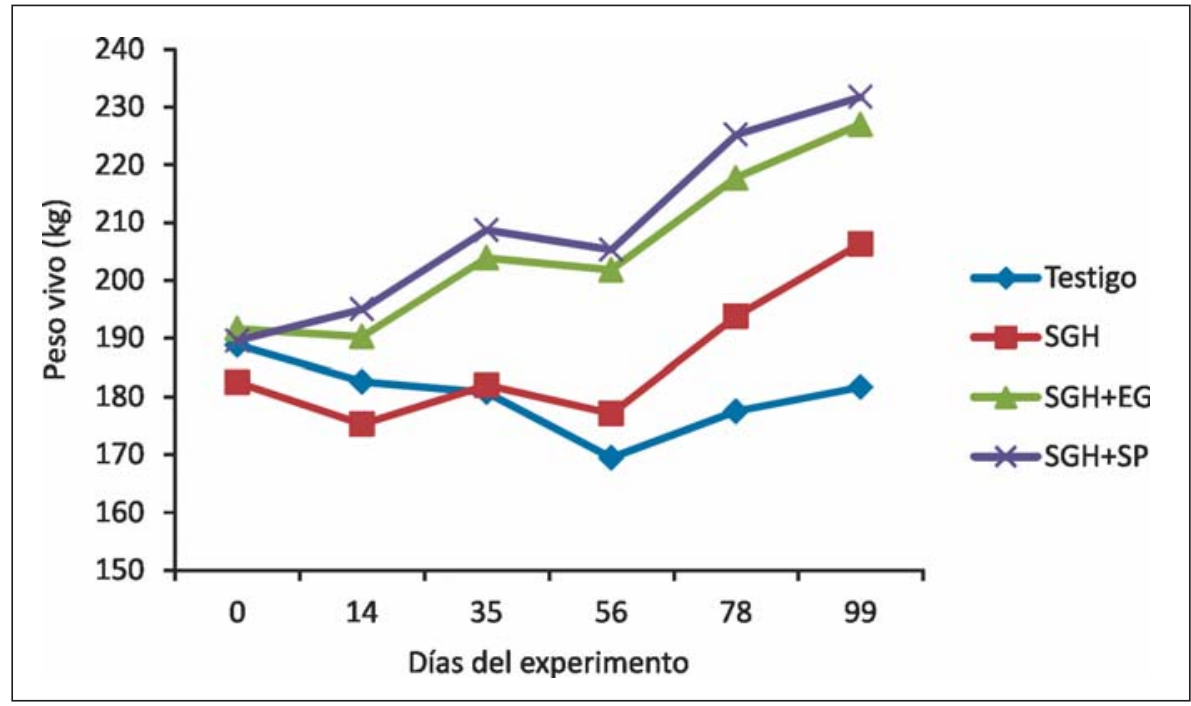

Figura 4. Evolución de peso vivo promedio de terneros en los distintos tratamientos (SGH: Sorgo Grano Húmedo, EG: Expeller de Girasol, SP: Suplemento Proteico). 
teicas, no hubo diferencias significativas en el PVF de terneros suplementados con expeller de girasol (EG) o suplemento proteico (SP) $(227 \pm 15 \mathrm{~kg}$ y $232 \pm 16 \mathrm{~kg}$, respectivamente) $(P>0,05)$.

La ganancia diaria de peso individual (media \pm d.e.) en los 99 días de suplementación fue $-0,082 \pm 0,090 \mathrm{~kg} / \mathrm{a} / \mathrm{d}$ (testigo sin suplemento), 0,248 $\pm 0,077 \mathrm{~kg} / \mathrm{a} / \mathrm{d}(\mathrm{SGH})$, $0,363 \pm 0,117 \mathrm{~kg} / \mathrm{a} / \mathrm{d}(\mathrm{SGH}+\mathrm{EG}) \mathrm{y}$ 0,419 $\pm 0,142 \mathrm{~kg} / \mathrm{a} / \mathrm{d}$ (SGH + SP) (Cuadro 4). La pérdida de peso vivo de los terneros sin suplementación estuvo asociada a un consumo insuficiente de energía digestible y a una ineficiente utilización de dicha energía debido a la falta de proteína (Lippke and Ellis, 1989). Existió un efecto significativo $(P<0,05)$ de la adición de fuentes proteicas en la ganancia de peso individual comparado con la suplementación con SGH sin fuente adicional de proteína $(0,391$ y 0,248 kg/a/día, respectivamente). Dicho incremento en la ganancia de peso vivo (+58\%), demostró que la deficiencia de proteína fue limitante para el crecimiento animal. Si bien la tecnología de grano húmedo de sorgo incrementa el valor nutritivo y la digestibilidad del grano comparado con el grano seco, debido a una mayor disponibilidad ruminal de carbohidratos y proteína (Stock et al., 1987; Streeter et al., 1989), no fue suficiente por sí sola, al menos en el nivel de suplementación utilizado, para satisfacer los altos requerimientos nutricionales de animales jóvenes en crecimiento. La suplementación proteica aportó nitrógeno en el rumen que captó parcialmente la energía aportada por el grano húmedo de sorgo con el consecuente incremento en la síntesis de proteína microbiana y pasaje de proteína metabolizable al intestino.

No hubo efecto significativo $(P=0,15)$ del tipo de fuente proteica (expeller de girasol o suplemento proteico) en la ganancia de peso individual, aunque numéricamente los animales del tratamiento SGH + SP lograron un 15\% más de ganancia diaria individual que los animales del tratamiento SGH + EG. La eficiencia de conversión de la proteína adicional a peso vivo fue de 0,115 y 0,146 kg/a/ día de ganancia de peso por cada $0,100 \mathrm{~kg}$ de proteína adicionada de expeller de girasol y suplemento proteico, respectivamente, comparado con el tratamiento de suplementación con SGH.

Cuando se analizó la ganancia de peso vivo por periodo de suplementación la respuesta al agregado de fuentes proteicas fue más significativa durante el primer periodo (0-56 d) comparado con el segundo periodo (56-99 d). En el primer periodo la calidad del campo natural fue más limitante para el crecimiento de los terneros determinando una mayor respuesta al agregado de las fuentes proteicas. En el segundo periodo, comprendido entre fines de agosto y principios de octubre, la disminución de la severidad y frecuencia de temperaturas extremas (heladas) y el rebrote del campo natural incrementaron el aporte proteico proveniente de la pastura. Terneros suplementados únicamente con grano húmedo de sorgo prácticamente mantuvieron peso hasta el día 56 del periodo de suplementación, periodo en el cual aquellos animales suplementados con fuentes de proteína registraron leves ganancias de peso.

Cuadro 4. Ganancia de peso (media \pm d.e.) individual por periodo y total de los animales en los distintos tratamientos

\begin{tabular}{lcccc}
\hline & \multicolumn{4}{c}{ Tratamientos $^{1}$} \\
\cline { 2 - 5 } & Testigo & SGH & SGH + EG & SGH + SP \\
\hline Ganancia, kg/a/d & & & & \\
0-56 d & $-0,346 \pm 0,114$ a & $-0,096 \pm 0,128$ b & $0,181 \pm 0,182$ c & $0,246 \pm 0,240$ c \\
$56-99$ d & $0,284 \pm 0,145$ a & $0,679 \pm 0,132$ b & $0,586 \pm 0,125$ b & $0,594 \pm 0,156$ b \\
0-99 d & $-0,082 \pm 0,090$ a & $0,248 \pm 0,077$ b & $0,363 \pm 0,117$ c & $0,419 \pm 0,142$ c \\
\hline
\end{tabular}

${ }^{1}$ SGH: Sorgo Grano Húmedo, EG: Expeler de Girasol, SP: Suplemento Proteico.

${ }^{a b c}$ Diferentes letras en una misma fila diferencias significativas entre tratamientos $(P<0,05)$. 
La respuesta positiva a la suplementación proteica también se reflejó en una mejor eficiencia de conversión del suplemento a peso vivo medida como los kg de ración necesarios para depositar $1 \mathrm{~kg}$ de peso vivo adicional comparado con el tratamiento testigo sin suplementación. La eficiencia de conversión, expresada en base seca, fue de $6,0(\mathrm{SGH}), 4,5(\mathrm{SGH}+\mathrm{EG})$ y $4,1(\mathrm{SGH}+$ $\mathrm{SP})$. Los animales con suplementación proteica fueron más eficientes en la conversión del suplemento a peso vivo debido a una mejor disponibilidad y sincronía de los nutrientes energía y proteína en el rumen.

Si se analiza el resultado económico de la suplementación, la misma produjo márgenes brutos por animal positivos comparado con el tratamiento testigo que fue negativo (Cuadro 5). El agregado de fuentes proteicas incrementó el margen bruto en aproximadamente un $40 \%$ comparado con el suministro únicamente de sorgo, debido a la respuesta productiva significativa que existió a la suplementación proteica.

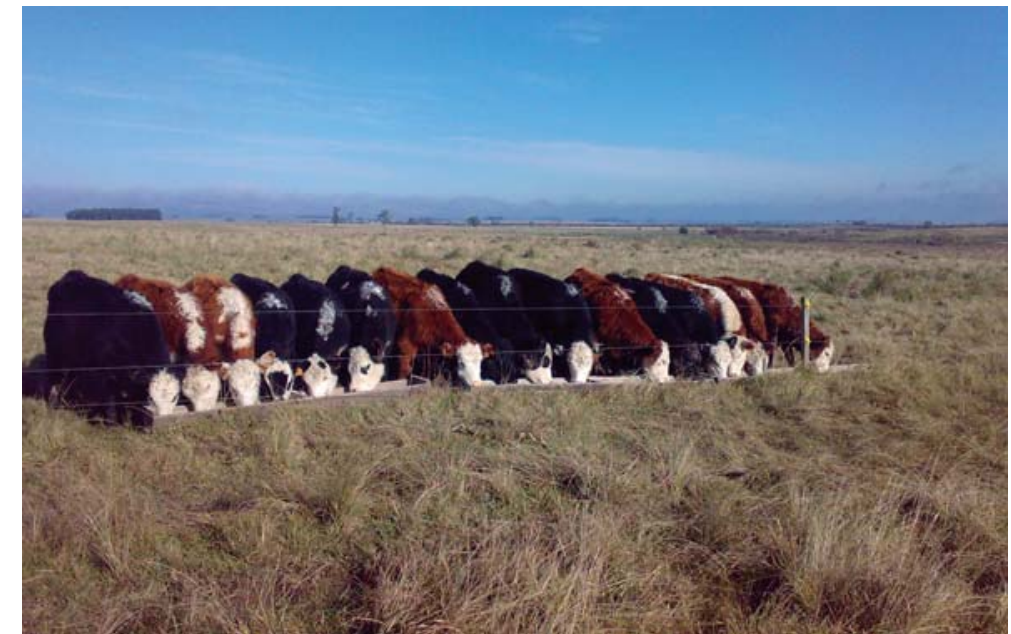

El agregado de una fuente proteica (30\% PC) al grano húmedo de sorgo en una relación $23 \%$ fuente proteica $-77 \%$ sorgo (base seca) mejoró el desempeño productivo y eficiencia de conversión de terneros suplementados sobre campo natural en invierno

Cuadro 5. Análisis económico de la suplementación (Precios de referencia invierno 2009)

\begin{tabular}{|c|c|c|c|c|}
\hline & \multicolumn{4}{|c|}{ Tratamiento $^{1}$} \\
\hline & Testigo & SGH & SGH+EG & SGH+SP \\
\hline Precio del suplemento ${ }^{2}$ (USS/ton) & - & 92 & 127 & 148 \\
\hline Costo diario suplementación ${ }^{3}$ (U\$S/a) & - & 0,18 & 0,25 & 0,30 \\
\hline Costo suplementación en 100 días (U\$S/a) & - & 18 & 25 & 30 \\
\hline Peso vivo agregado en 100 días $^{4}(\mathrm{~kg} / \mathrm{a})$ & -8 & 32 & 44 & 50 \\
\hline Valorización kg producidos (U\$S/a) ${ }^{5}$ & -10 & 41 & 56 & 64 \\
\hline Margen Bruto $(\mathrm{U} \$ S / a)^{6}$ & -10 & 23 & 31 & 34 \\
\hline
\end{tabular}

${ }^{1} \mathrm{SGH}$ : Sorgo Grano Húmedo, EG: Expeller de Girasol, SP: Suplemento Proteico.

2Sorgo: 92 U\$S/ton; expeller de girasol 250 U\$S/ton, suplemento proteico 335 U\$S/ton. Mezclas según Cuadro 3. ${ }^{3}$ Según cantidades realmente suministradas (Cuadro 3).

${ }^{4}$ Según desempeño productivo real (Cuadro 4)

${ }^{5}$ Valor de referencia Asociación Consignatarios de Ganado setiembre 2009: 1,28 U\$S/kg.

${ }^{6}$ Valorización $\mathrm{kg}$ producidos-costo de la suplementación en 100 días. 


\section{Etapa post-suplementación}

Entre el 8 de octubre y el 30 de diciembre de 2009 (83 días) todos los animales se manejaron en forma conjunta sobre un área de campo natural y praderas. La ganancia media de peso de todos los animales fue $0,628 \pm 0,127 \mathrm{~kg} / \mathrm{a} / \mathrm{día}$, siendo menor a la esperada debido a las condiciones climáticas adversas (seca) registradas durante dicho periodo. Los animales del tratamiento SGH fueron los que presentaron el mayor ritmo de ganancia de peso, siendo $11 \%$ superior que el promedio de ganancia de los animales que habían tenido suplementación proteica durante el invierno $(0,670$ y 0,602 $\mathrm{kg} / \mathrm{a} / \mathrm{día}$, respectivamente) (Cuadro 6). Esto determinó que se acortara la brecha en peso vivo de los animales en los distintos tratamientos de suplementación, si bien los animales suplementados con fuentes proteicas siguieron siendo más pesados que los animales del tratamiento SGH al 30 de diciembre (278 y $262 \mathrm{~kg}$, respectivamente) $(P<0,05)$. Al final del periodo, el peso vivo final de los terneros en los tratamientos SGH y SGH + EG fue significativamente igual $(P>0,05)$ aunque con una diferencia numérica de $12 \mathrm{~kg}$ (262 y $274 \mathrm{~kg}$, respectivamente). Por otro lado, los animales del tratamiento SGH + SP siguieron siendo significativamente más pesados $(\mathrm{P}<0,05)$ que los animales del tratamiento SGH (282 y $262 \mathrm{~kg}$, respectivamente).

En el periodo post-suplementación, los animales del tratamiento testigo (sin suplementación invernal) presentaron una ganancia de peso intermedia. Dichos animales siguieron siendo más livianos al 30 de diciembre comparados con el peso vivo promedio de los animales suplementados (236 y $278 \mathrm{~kg}$, respectivamente) $(P<0,05)$. No hubo un crecimiento compensatorio significativo en la primavera que permitiera la recuperación de los animales sin suplementación en el invierno, probablemente debido al ritmo de ganancia moderado registrado durante la primavera asociado a las condiciones climáticas.

\section{CONCLUSIONES}

El agregado de fuentes proteicas al ensilaje de grano húmedo de sorgo incrementó la ganancia diaria y el peso vivo final de terneros sobre pasturas naturales de baja calidad en los meses de invierno.

No existieron diferencias significativas en la respuesta animal al agregado de expeller de girasol o un suplemento proteico como fuente de proteína al grano húmedo de sorgo. Numéricamente, los animales suplementados con el suplemento comercial registraron una ganancia de peso $15 \%$ superior que aquellos con acceso a expeller de girasol.

La práctica de agregado de fuentes de proteína al grano húmedo de sorgo incrementó el margen bruto por animal comparado con el suministro únicamente de sorgo.

Luego de 83 días de finalizado el experimento aquellos animales suplementados con fuentes proteicas continuaron siendo significativamente más pesados que aquellos que no tuvieron acceso a fuentes de proteína.

Cuadro 6. Evolución de peso de los animales en la etapa post-suplementación (08/10/09 -30/12/09)

\begin{tabular}{lllll}
\hline & \multicolumn{4}{c}{ Tratamientos $^{1}$} \\
\cline { 2 - 5 } & \multicolumn{1}{c}{ Testigo } & \multicolumn{1}{c}{ SGH } & SGH + EG & \multicolumn{1}{c}{ SGH + SP } \\
\hline Peso inicial, kg & $182 \pm 13$ & $206 \pm 21$ & $227 \pm 15$ & $232 \pm 16$ \\
Peso final, kg & $236 \pm 25$ a & $262 \pm 30$ b & $274 \pm 21 \mathrm{~b} \mathrm{c}$ & $282 \pm 22 \mathrm{c}$ \\
Ganancia, kg/a/día & $0,648 \pm 0,158$ ab & $0,670 \pm 0,139$ a & $0,567 \pm 0,121$ b & $0,638 \pm 0,091$ ab
\end{tabular}

${ }^{1}$ SGH: Sorgo Grano Húmedo, EG: Expeller Girasol, SP: Suplemento Proteico.

${ }^{a b c}$ Letras diferentes dentro de una misma columna difieren significativamente $(P<0,05)$. 


\section{BIBLIOGRAFÍA}

ACOSTA, Y. 2007. Suplementación del ganado con ensilaje de grano húmedo de sorgo: potencial y limitantes. In Producción Animal ed. INIA Treinta y Tres (Uruguay). Actividades de Difusión 511. pp.41-48.

JOBIM, C.C.; MACEDO, F.A.F; BRANCO, A.F.; ALCALDE, C.R. 2008. Quality of high moisture corn silage added of whole soybean, whole sunflower or urea. In Multifunctional Grasslands in a Changing World ed. International Committee of XXI IGC/IRC Congress (Guangzhou, China). 79p.

LIPPKE, H.; ELLIS, W.C. 1989. Protein supplements fed to yearlings steers grazing common Bermudagrass pastures. In Forage Research ed. Texas A\&M University. pp.5-7.

MONTIEL, M.D.; DEPETRIS, G.I; SANTINI, F.J.; CHICATUN, A.; VILLAREAL, F.L. 2005. Evaluación de agregado de urea a un silaje de grano húmedo de sorgo alto tanino y su comparación con el maíz en el engorde a corral. INTA EEA Balcarce (Buenos Aires, Argentina). Consultado on-line el 28/12/09.Sitio: http:// www.inta.gov.ar/balcarce/info/ documentos/ganaderia/bovinos/ nutricion/urea.html
NISHINO, N. 2008. Progress in silage research in relation to animal production and food safety. In Multifunctional Grasslands in a Changing World ed. International Committee of XXI IGC/IRC Congress (Guangzhou, China). pp.639-644.

NRC. 2000. Nutrient Requirements of Beef Cattle. National Academy Press, Washington D.C.

PORDOMINGO, A.J.; JUAN, N.A.; AZCARATE, M.P. 2002. Grano de maíz húmedo conservado con urea en dietas de engorde a corral. Rev. Arg. Prod. Anim. 22: 101-113.

SCOLLAN, N.D.; SARGEANT, A.; MCALLAN, A.B.; DHANOA, M.S. 2001. Protein supplementation of grass silages of differing digestibility for growing steers. J. Agric. Sci. 136: 89-98.

STOCK, R.A.; BRINK, D.R.; KREIKEMEIER, K.K.; SMITH, K.K. 1987. Evaluation of earlyharvested and reconstituted grain sorghum in finishing steers. J. Anim. Sci. 65: 548-556.

STREETER, M.N.; WAGNER, D.G.; OWENS, F.N.; HIBBERD, C.A. 1989. Combinations of high-moisture harvested sorghum grain and dry-rolled corn: effects on site and extent of digestion in beef heifers. J. Anim. Sci. 67:1623-1633. 


\title{
EFECTO DE LA SUSTITUCIÓN DE PROTEÍNA VERDADERA POR NITRÓGENO NO PROTEICO EN EL DESEMPEÑO PRODUCTIVO DE TERNEROS SUPLEMENTADOS CON GRANO HÚMEDO DE SORGO SOBRE CAMPO NATURAL*
}

\author{
S. Benítez ${ }^{1}$, F. Cunha ${ }^{2}$ \\ G. Fernández ${ }^{3}$, J. Velazco $^{4}$ \\ P. Rovira ${ }^{5}$
}

\begin{abstract}
RESUMEN
El objetivo del trabajo fue evaluar el efecto de la adición de fuentes nitrogenadas y la sustitución de proteína verdadera por nitrógeno no proteico (urea) en el desempeño productivo de terneros suplementados con silo de grano húmedo de sorgo sobre campo natural $(\mathrm{CN})$. Se utilizaron 64 terneros de destete asignados en los siguientes tratamientos: T1) Silo de sorgo de grano húmedo (SGH), T2) SGH + expeller de girasol (EG), T3) $S G H+E G+$ urea (U), T4) SGH + U. Los tratamientos consistieron en la suplementación diaria al 1\% del PV (base seca) de los animales. Los suplementos de los T 2, 3, 4 fueron iso-proteicos (16\% PC) a diferencia del T1 (9\% PC). Cada tratamiento contó con 5 ha de $\mathrm{CN}$ y 16 terneros (dotación 3,2 terneros/ha) en pastoreo continuo. Se determinó la disponibilidad de porcentaje de forraje en el CN cada 28 días $(2827 \pm 1247$ $\mathrm{kg} \mathrm{MS} / \mathrm{ha}$ ) con $63 \%$ de restos secos y $6,4 \pm 0,3$ proteína cruda (PC). Se observaron diferencias $(P<0,05)$ en el $P V$ vacío de los terneros del tratamiento $T 1$ respecto a los restantes tratamientos $(T 2, T 3, T 4)$ a partir del día 55 del experimento $(151 \pm 17,163 \pm 13,161 \pm 15$, $163 \pm 16 \mathrm{~kg}$, respectivamente). Dicha diferencia se mantuvo hasta el final del período experimental, siendo el PV vacío final $176 \pm 18,195 \pm 17,196 \pm 18,193 \pm 21$ para los T 1, 2, 3 y 4 respectivamente. Los terneros de los tratamientos T2, T3 y T4 presentaron ganancias de PV diarias similares siendo estas mayores $(P<0,05)$ a T1 $(0,199 \pm 0,079$, $0,217 \pm 0,013,0,182 \pm 0,155$ y $0,03 \pm 0,07$ respectivamente). Bajo estas condiciones la adición de fuentes nitrogenadas al SGH mejoró el desempeño productivo de terneros suplementados sobre $\mathrm{CN}$, pero en el rango evaluado, la sustitución de EG por U como fuente nitrogenada no tuvo un efecto significativo en el desempeño productivo de los animales.
\end{abstract}

Palabras claves: terneros, sorgo, proteína, urea

\section{ABSTRACT}

The aim of this study was to evaluate the effect of the addition of nitrogen sources and the substitution of true protein by non-protein nitrogen (urea) in the performance of calves supplemented with high moisture sorghum grain silo grazing natural pastures. Sixty four Hereford $\times \mathrm{A}$. Angus calves were randomly assigned to 4 treatments consisting in daily supplementation (1\% of BW dry basis) of animals with: T1) High moisture sorghum grain silo (HMSG), T2) HMSG + sunflower expeller (SE), T3) HMSG + SE + urea (U), T4) HMSG + U. Each treatment had 5 ha and 16 animals (stocking rate 3.2 calves/ha) in continuous grazing. Supplements on treatments 2, 3 and 4 were iso-protein (16\% crude protein, CP) differing from CP in T1 (9\% CP). Forage availability was determined every 28 days averaging $2827 \pm 1247 \mathrm{~kg} \mathrm{DM} / \mathrm{ha}$ with a green to dead material ratio of $37: 63$ and $6.4 \pm 0.3 \% \mathrm{CP}$. Differences were observed $(P<0.05)$ at day 55 of the experiment in the empty BW of calves in T1 compared to those in T2, T3 and T4 (151 \pm 19 , $163 \pm 13,161 \pm 15,163 \pm 16 \mathrm{~kg}$, respectively). This difference was maintained until the end of the experimental period. Final empty body weight was $176 \pm 18,195 \pm 17,196 \pm 18$, and 
$193 \pm 21 \mathrm{~kg}$ for animals in treatments $1,2,3$, and 4, respectively. Calves in treatments T2, T3 and T4 had similar ADG, being higher $(P<0.05)$ than in T1 $(0.199 \pm 0.079,0.217 \pm 0.013$, $0.182 \pm 0.155$ and $0.03 \pm 0.07 \mathrm{~kg} / \mathrm{a} / \mathrm{d}$, respectively). Under these conditions the addition of nitrogen sources to HMSG improved performance of supplemented calves grazing natural pastures. The substitution of a true protein source by urea had no significant effect on the performance of animals.

Key words: calves, sorghum, protein, urea

\section{INTRODUCCIÓN}

La ganadería en Uruguay se realiza básicamente sobre pasturas naturales, las cuales presentan una marcada distribución estacional, teniendo como común denominador en todo el país un importante déficit invernal. Esto trae aparejado un fuerte desbalance entre la disponibilidad forrajera y los requerimientos del animal. Este comportamiento se ve reflejado en los bajos índices productivos como es el caso de edad avanzada (4-5 años) de faena de una proporción de los novillos ya que durante el invierno, los animales pierden cantidades importantes de peso que tienden a recuperar entre la primavera y el verano, para volver a perder en el siguiente invierno.

Sumado a esto, en los últimos años en el Uruguay se ha generado una reducción en el área dedicada a la ganadería debido principalmente al crecimiento del área agrícola y forestal, desplazando de esta forma la ganadería a zonas menos fértiles y de menor uso agrícola. Sin embargo, este defasaje entre la oferta y la demanda de forraje es cuantificable y potencialmente corregible mediante estrategias adecuadas de alimentación. Dentro de este marco, la suplementación aparece como una medida de manejo estratégica. Esta práctica se ha visto favorecida por el crecimiento del área agrícola, que trajo aparejado la disponibilidad de maquinaria en la zona este del país, donde hasta hace un tiempo resultaban escasas, permitiendo hoy que el uso de tecnologías como el ensilado de grano húmedo de sorgo esté al alcance de los establecimientos criadores y de ciclo completo.

La tecnología de grano húmedo de sorgo se basa en que permite tener en forma rentable un volumen importante de energía, nutriente de mayor demanda, aunque defi- ciente en proteína, sobre todo para categorías de animales en crecimiento. Por ello, la inclusión de fuentes proteicas de origen vegetal o de origen sintético (urea) se presenta como una alternativa para incrementar el contenido de proteína de grano húmedo de sorgo, pudiendo mejorar así el desempeño productivo de los animales. En este contexto, el presente trabajo pretende brindar información nacional sobre el efecto de la suplementación en terneros de recría, con silo de grano húmedo de sorgo adicionando fuentes proteicas de origen vegetal y sintético.

\section{MATERIALES Y MÉTODOS}

El experimento se realizó en la Unidad Experimental Palo a Pique (UEPP) perteneciente a INIA Treinta y Tres (S 330 15'38.77", W 54 $\left.24^{\circ} 45.34^{\prime \prime}\right)$. El trabajo de campo se extendió desde el 26 de mayo hasta el 14 de setiembre de 2010 (113 días). El total de precipitaciones durante el período del ensayo fue $397 \mathrm{~mm}$, un 13\% por debajo para la serie histórica 1973-2009 (458mm, Estación Meteorológica Unidad Experimental Paso de la Laguna). Durante el periodo experimental se registraron 36 heladas agrometeorológicas (césped) y 12 heladas meteorológicas (casilla), correspondiendo a valores 6 y $33 \%$ mayor, respectivamente, que el promedio de la serie histórica 1973-2009.

El experimento se llevó a cabo sobre 20 ha de $\mathrm{CN}$, reservadas desde fines del verano hacia el otoño. El área se subdividió en 4 potreros de 5 ha cada uno. En el tapiz predominaban especies estivales en estado de madurez, tales como Paspalum dilatatum y Cynodon dactylon, especies indicadoras de campo bruto regenerado. El potrero contaba con un tajamar central al cual los animales de los diferentes tratamientos accedían libremente sin mezclarse. Se utilizaron 64 bo- 
vinos cruza Hereford x Aberdeen Angus, categoría terneros de destete (fecha promedio de nacimiento 22/09/2009 \pm 19 días), provenientes del Módulo de Cría de la UEPP (peso inicial promedio $184 \pm 14 \mathrm{~kg}$ ). Los animales fueron estratificados por PV en 2 bloques (livianos y pesados) y asignados al azar en los tratamientos. Cada tratamiento contó con 5 ha de $\mathrm{CN}$ y 16 terneros (dotación 3,2 terneros/ha) manejados en pastoreo continuo. Los tratamientos consistieron en la suplementación diaria de los animales con:

T1) Sorgo Grano Húmedo (SGH)

T2) SGH + Expeller de Girasol (EG)

T3) $S G H+E G+$ Urea (SGH+EG+U)

T4) SGH + Urea (SGH+U)

Los animales asignados a los 4 tratamientos fueron suplementados al 1\% del PV en base seca de acuerdo a las dietas que se observan en el Cuadro 1. El objetivo fue que las dietas de los tratamientos 2, 3 y 4 fueran iso-proteicas (igual nivel de proteína por $\mathrm{kg}$ de MS) con un porcentaje de PC de $16 \%$ con una mínima variación en la concentración energética de las dietas. El ajuste final de la proporción de los distintos componentes en cada dieta se estableció en función de los resultados del análisis del valor nutritivo de los suplementos utilizados.

El silo de grano húmedo provino de 6 ha de sorgo granífero (variedad MS 109) cosechadas en el área de rotaciones de la UEPP. El cultivo fue sembrado en siembra directa el 9 de diciembre de 2009, cosechado el 14 de abril del 2010 con 23,4 \% humedad. Una vez cosechado, el grano fue quebrado previo al embolsado en condiciones anaeróbicas (silobag) utilizando una embolsadora marca Richiger de 6 pies de diámetro. El tiempo de espera entre el embolsado y la apertura del silo para suministro a los animales fue de 30 días. Una mayor descripción y caracterización del silo de grano húmedo se realiza en la sección de Resultados. Los suplementos proteicos utilizados, tanto el EG como la urea (uso agrícola), fueron de origen comercial.

La suplementación se realizó de lunes a domingo durante la mañana. El sorgo se extrajo del silo el mismo día del suministro a los animales, excepto los fines de semana en donde se dejaron las cantidades ya pesadas en bolsas identificadas el día viernes. El agregado de urea se realizó en el momento de la extracción del sorgo de la bolsa de silo, en tanto el expeller se mezcló con el sorgo en el comedero. En ambos casos se realizó un mezclado homogéneo, con las manos. El acostumbramiento al sorgo se realizó durante los 12 días previos al inicio del ensayo sobre $\mathrm{CN}$ empezando con $0,5 \mathrm{~kg} / \mathrm{a} / \mathrm{d}$ hasta llegar a $2 \mathrm{~kg} / \mathrm{a} / \mathrm{d}$ ía (base fresca). El período de acostumbramiento a la urea para los tratamientos 3 y 4 se inició en el día 0 del experimento ( $5 \mathrm{~g} / \mathrm{a} / \mathrm{d}$ ) llegando a 22 y 42 g/a/d a los 14 días en T3 y T4, respectivamente.

Para evitar problemas de parásitos gastrointestinales los animales fueron dosificados previo al comienzo del período experimental. Las drogas suministradas fueron $\mathrm{Ni}$ tromic ${ }^{\circledR}$ (Nitroxinil) vía subcutánea el día 7 de mayo de 2010, y cuatro días más tarde se dosificó con Ricoverm ${ }^{\circledR}$ (Ricobendazol) vía subcutánea. Las dosis utilizadas fueron las indicadas según el laboratorio fabricante. Adicionalmente, los terneros se vacunaron contra fiebre aftosa, siendo ésta de carácter obligatorio en el país. En la mitad del experimento se tomaron muestras de heces del recto de un $25 \%$ de los animales (4 animales/tratamiento) y se enviaron a laboratorio para análisis copro-parasitario. Posteriormente se dosificó la totalidad de los anima-

Cuadro 1. Composición porcentual del suplemento de los distintos tratamientos (base seca)

\begin{tabular}{lcccc}
\hline & \multicolumn{4}{c}{ Tratamientos } \\
\cline { 2 - 5 } Ingredientes (\%) & T1 $^{1}$ & T2 $^{2}$ & T3 $^{3}$ & T4 $^{4}$ \\
\hline Sorgo grano húmedo (SGH) & 100 & 75,0 & 86,6 & 97,7 \\
Urea (U) & - & - & 1,2 & 2,3 \\
Expeller Girasol (EG) & - & 25,0 & 12,2 & - \\
\hline
\end{tabular}

${ }^{1} \mathrm{SGH},{ }^{2} \mathrm{SGH}+\mathrm{EG},{ }^{3} \mathrm{SGH}+\mathrm{EG}+\mathrm{U},{ }^{4} \mathrm{SGH}+\mathrm{U}$. 
les del experimento debido a que el número de huevos por gramo de materia fecal (HPG) superó los 300 en el $50 \%+1$ de los animales en al menos un tratamiento. Los fármacos utilizados fueron Bifetacel 10\%® (Fenbendazol) por vía oral y Cydectin $\mathrm{NF} \otimes($ Moxidectin) utilizando las dosis indicadas por el laboratorio fabricante. Con el objetivo de chequear la eficiencia de la dosificación antihelmíntica, 12 días más tarde de la misma se realizaron muestreos para análisis coprológico, obteniéndose resultados por debajo de 300 HPG en todas las muestras extraídas (4 animales por tratamiento).

La disponibilidad de forraje en el CN se determinó cada 28 días totalizando 5 fechas de muestreo $(0,28,56,84,112 \mathrm{~d})$. Se realizó a través de corte al ras del suelo con tijera manual, de diez cuadros de $50 \times 20 \mathrm{~cm}$ por tratamiento. El muestreo fue realizado en forma dirigida, intentando seleccionar áreas representativas del potrero. Previo al corte de cada cuadro se registró la altura promedio del tapiz a ser muestreado. Se determinó a través de 5 mediciones sobre cada área dentro del rectángulo de corte (en los 4 ángulos y 1 en el medio) utilizando una regla graduada. En el laboratorio, cada corte se pesó fresco individualmente y luego se procedió a mezclar todos los cortes por tratamiento formando una muestra compuesta por tratamiento. De cada muestra se extrajeron 3 sub-muestras de aproximadamente $200 \mathrm{~g}$ cada una. Dos sub-muestras fueron colocadas en estufa hasta peso constante (48 horas) a una temperatura de $60^{\circ} \mathrm{C}$. Luego por diferencia entre peso fresco y peso seco se determinó el porcentaje de MS de la pastura, el cual fue utilizado para el cálculo de la disponibilidad de forraje. En la restante submuestra se separó manualmente la fracción verde y seca, las cuales fueron secadas individualmente siguiendo el procedimiento antes mencionado. Las muestras de MS (general) y de las fracciones verde y seca de las fechas de muestreo 0, 56 y 112 días se enviaron al Laboratorio de Nutrición Animal de INIA La Estanzuela. Se realizaron los análisis de MS por secado de la muestra a $104^{\circ} \mathrm{C}$ (AOAC, 1984), digestibilidad de la MO (DMO) «in vitro» según método de Tilley y Terry (1963), PC por método Kjeldahl (AOAC,
1984), fibra detergente neutro (FDN) y fibra detergente ácida (FDA) según método de Van Soest et al. (1991), y cenizas por incineración de la muestra a $550^{\circ} \mathrm{C}$ (AOAC, 1984).

A inicio, mitad y fin del experimento se tomó una muestra del EG y otra del SGH y se enviaron al Laboratorio Analítico Agroindustrial (Paysandú) para análisis de MS, PC y FDA. Adicionalmente, en 6 ocasiones se tomó una muestra compuesta de $500 \mathrm{~g}$ del silo de grano húmedo y se separaron manualmente las fracciones físicas correspondientes a grano entero, partido y molido. Cada fracción se pesó en base fresca y se expresó porcentualmente. La acidez del silo $(\mathrm{pH})$ se registró en 5 ocasiones utilizando un $\mathrm{pH}$-metro manual colocado en 3 posiciones (arriba, centro y abajo) en la boca del silo.

Los animales se pesaron llenos (sin desbaste) cada 14 días $(0,14,28,42,56,70$, 84,98 y 112 día) a primera hora de la mañana. Con dicha pesada se ajustó la cantidad de suplemento por animal en función de la evolución del PV. Adicionalmente, se pesaron vacíos (12 h de ayuno) en las pesadas correspondientes a 0,28, 56, 84 y 112 días. Los animales fueron retirados de las parcelas todos al mismo tiempo, para luego ser pesados. Una vez por mes (junio, julio, agosto y setiembre) se registró el área de ojo de bife (AOB) y el espesor de grasa subcutánea de todos los animales a través de ultrasonografía en el músculo Longissimus dorsi.

Las variables disponibilidad de forraje y altura del tapiz se analizaron según un diseño completamente al azar, usando un modelo que evaluó el efecto del tratamiento en cada fecha de muestreo y promediando sobre todo el período experimental. En cada fecha de muestreo cada sub-muestra (rectángulo) fue considerada como una repetición dentro de cada tratamiento. El modelo utilizado fue el siguiente:

$$
Y_{i j}=\mu+\alpha_{i}+\varepsilon_{i j}
$$

Siendo:

$Y_{\mathrm{ij}}=$ disponibilidad de forraje $\mathrm{o}$ altura de tapiz ( $\mathrm{i}=1,2,3,4$ tratamientos; $\mathrm{j}=1,2, \ldots .$. , 10 repeticiones) 
$\mu=$ media general

$\alpha_{i}=$ efecto del i-ésimo tratamiento ( $\mathrm{i}=1$,

$2,3,4)$

$\varepsilon_{\mathrm{ij}}=$ error experimental

Adicionalmente, se evaluó el efecto de la fecha de muestreo en la altura y disponibilidad de forraje (promediando sobre los tratamientos) con el objetivo de describir la evolución de las características de la pastura en el tiempo. En todos los casos se utilizó el procedimiento GLM de SAS, realizando comparación de medias mediante test de Tukey cuando el análisis de varianza fue significativo $(P<0,05)$. Se estudió la asociación entre la altura del tapiz y la disponibilidad de forraje utilizando un modelo de regresión lineal del tipo: $y=a+b x$; siendo $y=$ forraje disponible, $y \mathrm{x}=$ altura del tapiz. Los resultados de verde/seco y el valor nutritivo de la pastura (calidad) se describieron y analizaron numéricamente.

En las variables registradas en el animal el análisis estadístico se realizó en base a un diseño con bloques completos al azar. Los animales fueron distribuidos en bloques según su PV inicial (bloque 1: 159-183 kg; bloque 2: $184-228 \mathrm{~kg}$ ) y luego asignados al azar en los distintos tratamientos. EI PV, $A O B, y$ espesor de grasa subcutánea fueron analizadas como medidas repetidas con el procedimiento MIXED de SAS siendo el modelo utilizado:

$\underset{i \mathrm{ijk}}{+\varepsilon_{i \mathrm{j}}}=\mu+\alpha_{\mathrm{i}}+\beta_{\mathrm{j}}+\gamma_{\mathrm{k}}+(\alpha \beta)_{\mathrm{ij}}+(\alpha \gamma)_{\mathrm{ik}}+(\beta \gamma)_{\mathrm{jk}}+\sigma_{\mathrm{il}}$ $+\varepsilon_{\mathrm{ijk}}$

\section{Donde:}

$Y_{i \mathrm{j} k}$ : evolución de peso, ganancia media diaria, AOB, espesor de grasa subcutánea y altura de anca del j-ésimo bloque perteneciente al i-ésimo tratamiento en el k-ésimo período.

$\mu$ : media general

$\alpha_{i}$ : efecto fijo del $\mathrm{i}$-ésimo tratamiento $(\mathrm{j}=$ $1,2,3,4)$

$\beta_{\mathrm{j}}$ : efecto fijo del $\mathrm{j}$-ésimo bloque $(i=1,2)$

$\gamma_{k}$ : efecto fijo del k-ésimo período $(k=$ $1,2,3,4,5)$

$(\alpha \beta)_{i j}$ : efecto de la interacción entre el iésimo tratamiento y j-ésimo bloque $(\alpha \gamma)_{i \mathrm{k}}$ : efecto de la interacción entre el iésimo tratamiento y k-ésimo período

$(\beta \gamma)_{j \mathrm{k}}$ : efecto de la interacción entre el jésimo bloque y k-ésimo período

$\sigma_{\mathrm{il}}$ : efecto aleatorio del l-ésimo animal en el i-ésimo tratamiento

$\varepsilon_{\mathrm{ijk}}$ : error experimental

Las medidas de ultrasonografía (AOB y espesor de grasa subcutánea) fueron corregidas por sus respectivos valores iniciales (covariable inicial). El análisis de la ganancia diaria promedio de peso ( $\mathrm{kg} / \mathrm{animal} / \mathrm{día}$ ) se realizó de dos maneras. En primer lugar se corrigió utilizando un modelo de regresión lineal tipo: $y=a+b(x)$; siendo $y=P V ; a=$ $P V$ inicial, $b=$ ganancia de peso; $y x=$ días entre pesadas (regresión de PV en el tiempo). En segundo lugar, también se calculó considerando la diferencia entre el PV final e inicial de los animales sobre el total del período (sin considerar las pesadas intermedias). Tanto la ganancia diaria promedio de peso (113 d) como la ganancia registrada en cada período ( $28 \mathrm{~d}$ ) comprendido entre pesadas de los animales vacíos se analizó utilizando el comando PROC GLM con los efectos fijos del tratamiento y bloque, y la interacción entre ambos, de acuerdo al modelo:

$$
Y_{i j k}=\mu+\alpha_{i}+\beta_{j}+(\alpha \beta)_{i j}+\varepsilon_{i j k}
$$

Donde:

$Y_{i j}$ : ganancia media diaria de peso

$\mu$ : media general

$\alpha_{\mathrm{i}}$ : efecto fijo del i-ésimo tratamiento ( $\mathrm{j}=$ $1,2,3,4)$

$\beta_{\mathrm{j}}$ : efecto fijo del $\mathrm{j}$-ésimo bloque $(\mathrm{i}=1,2)$

$(\alpha \beta)_{\mathrm{ij}}$ : efecto de la interacción entre el iésimo tratamiento y j-ésimo bloque

$$
\varepsilon_{\mathrm{ijk}} \text { : error experimental }
$$

En todos los casos, cuando un efecto fue significativo $(P<0,05)$ fue utilizado el Test de Tukey o el comando LSMEANS/PDIFF para comparación de medias. Cuando existieron interacciones significativas entre efectos fijos, el análisis de las mismas se priorizó sobre el análisis de los efectos fijos individuales. 


\section{RESULTADOS}

\section{Pasturas}

El Cuadro 2 presenta la información detallada de la disponibilidad de forraje en cada tratamiento por fecha de muestreo. La disponibilidad forrajera inicial mostró diferencias significativas $(P<0,05)$ entre T4 (4177 kg MS/ha) y T2 (2342 kg MS/ha), no existiendo otras diferencias $(P>0,05)$ entre los tratamientos. En las siguientes fechas de muestreo no se encontraron diferencias en el forraje disponible entre tratamientos. La diferencia establecida en el disponible inicial repercutió en el promedio por tratamiento en todo el período, determinando diferencias $(P<0,05)$ entre T4 (3447 kg MS/ha) con respecto a T2 (2497 kg MS/ha) y T3 (2517 kg MS/ha). El T1
(2847 kg MS/ha) no presentó diferencias $(P>0,05)$ de disponibilidad promedio de forraje con el resto de los tratamientos.

En función de la disponibilidad de forraje promedio, la dotación y la duración del experimento se estimó la asignación de forraje por animal y por día, correspondiendo a valores de 7,9 (T1), 6,9 (T2), 6,95 (T3) y 9,5 (T4) kg MS/animal/día (no se consideró el crecimiento diario de la pastura). Dichos valores están en el rango de asignación diaria de forraje de 4,0-5,5\% del PV en función de la evolución de peso de los animales.

La evolución de la altura del tapiz acompañó la misma tendencia que la evolución del forraje disponible, disminuyendo a medida que avanzó el período experimental (Figura 1). No se presentaron diferencias significativas $(P>0,05)$ de altura entre tratamien-

Cuadro 2. Disponibilidad forrajera (kg MS/ha) por fecha de muestreo para cada tratamiento (media \pm desvío estándar)

\begin{tabular}{lllll}
\hline & \multicolumn{4}{c}{ Tratamientos } \\
\cline { 2 - 5 } Fecha de muestreo & \multicolumn{1}{c}{ T1 $^{1}$} & \multicolumn{1}{c}{ T2 $^{2}$} & \multicolumn{1}{c}{ T3 $^{3}$} & \multicolumn{1}{c}{ T4 $^{4}$} \\
\hline $27 / 5 / 2010$ & $3324 \pm 1458$ ab & $2342 \pm 909$ a & $2830 \pm 1156$ ab & $4177 \pm 1276 \mathrm{~b}$ \\
$24 / 6 / 2010$ & $3022 \pm 2131$ & $2540 \pm 1017$ & $2553 \pm 865$ & $3722 \pm 1573$ \\
$26 / 7 / 2010$ & $3222 \pm 1378$ & $2727 \pm 999$ & $2757 \pm 1563$ & $4202 \pm 1971$ \\
$19 / 8 / 2010$ & $3123 \pm 2220$ & $2767 \pm 1041$ & $2382 \pm 629$ & $2838 \pm 925$ \\
$15 / 9 / 2010$ & $1543 \pm 1108$ & $2110 \pm 843$ & $2065 \pm 953$ & $2296 \pm 915$ \\
\hline
\end{tabular}

${ }^{1} \mathrm{SGH},{ }^{2} \mathrm{SGH}+\mathrm{EG},{ }^{3} \mathrm{SGH}+\mathrm{EG}+\mathrm{U},{ }^{4} \mathrm{SGH}+\mathrm{U}$.

Letras distintas en una misma fila indican diferencias significativas entre tratamientos.

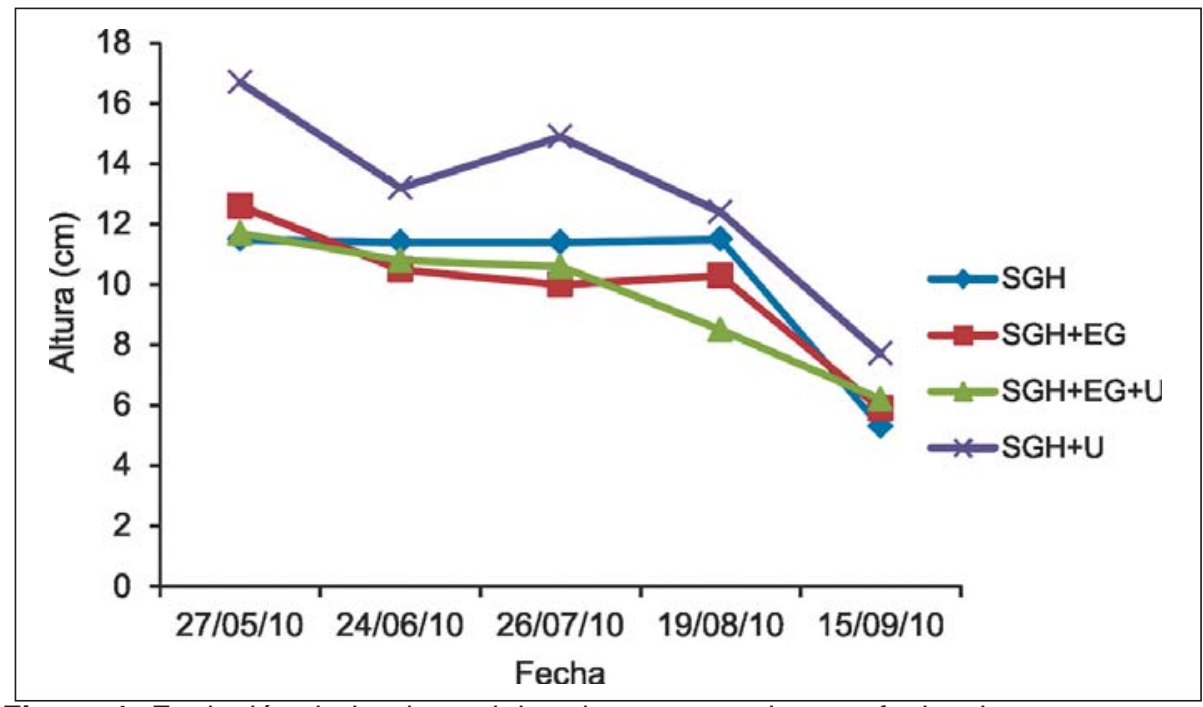

Figura 1. Evolución de la altura del tapiz por tratamiento y fecha de muestreo. 


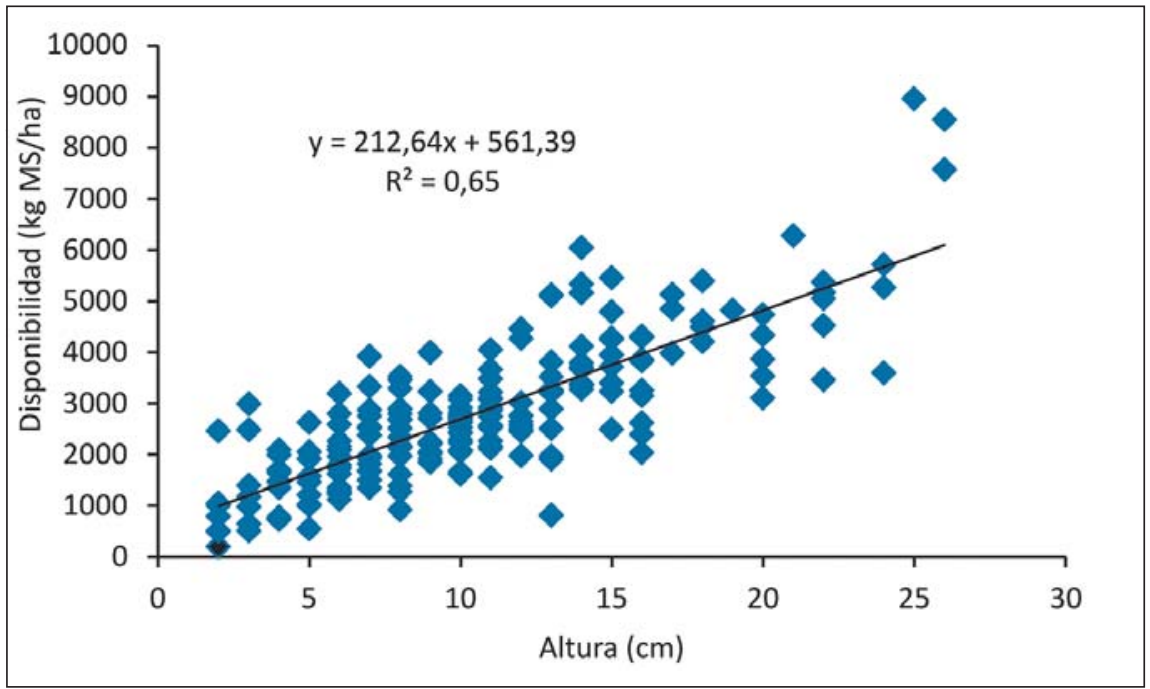

Figura 2. Relación entre altura y disponibilidad del forraje durante el periodo experimental.

tos por fecha de muestreo, únicamente al inicio del ensayo el T4 mostró una tendencia $(P=0,09)$ a ser mayor que los restantes. Al promediar la altura en todo el período el valor registrado en T4 $(12,98 \mathrm{~cm})$ mostró diferencias significativas $(P<0,05)$ con el promedio de altura de los restantes tratamientos $(9,88 \mathrm{~cm})$. Se encontró una correlación positiva y alta $(r=0,80)$ entre la disponibilidad forrajera y la altura del forraje, lo que indica que valores de altura mayores se traducen en más $\mathrm{kg} \mathrm{MS/ha.} \mathrm{Cada} \mathrm{cm} \mathrm{de} \mathrm{incre-}$ mento de altura representó $213 \mathrm{~kg} \mathrm{MS} / \mathrm{ha}$ en el rango de 2 a $26 \mathrm{~cm}$ (Figura 2).

El porcentaje promedio de fracción verde entre tratamientos en el forraje ofrecido al inicio y fin del experimento fue de 55 y $38 \%$, respectivamente, sin diferencias entre tratamientos. Si se calcula la asignación de fo- rraje verde por animal y por día promedio para todo el período, los valores serían de 2,95, 2,97, 2,22, 3,59 kg MS/animal/día, para T1, T2, T3 y T4 respectivamente. Los kg MS de la fracción verde/ha no presentaron diferencias significativas $(P>0,05)$ por fecha de muestreo entre tratamientos.

Como no se encontraron diferencias en la calidad del CN entre los tratamientos, los datos presentados en el Cuadro 3 son valores promedios de los 4 tratamientos por fecha de muestreo. La evolución de los valores de calidad del $\mathrm{CN}$ no mostró variaciones importantes en las diferentes fechas de muestreo. Los valores de proteína cruda (PC) al inicio del experimento se encuentran dentro de lo esperado para este tipo de pastura, al igual que su evolución, donde se puede observar una disminución de este valor ha-

Cuadro 3. Composición química del forraje del campo natural (media \pm desvío estándar)

\begin{tabular}{cccc}
\hline & \multicolumn{3}{c}{ Fecha de muestreo } \\
\cline { 2 - 4 } Parámetro (\%) & $\mathbf{2 7 / 5 / 2 0 1 0}$ & $\mathbf{2 6 / 7 / 2 0 1 0}$ & $\mathbf{1 5 / 9 / 2 0 1 0}$ \\
\hline DMO $^{1}$ & $31,3 \pm 3,7$ & $31,4 \pm 2,3$ & $34,8 \pm 2,6$ \\
FDA $^{2}$ & $52,0 \pm 2,7$ & $51,1 \pm 1,5$ & $48,9 \pm 1,7$ \\
FDN $^{3}$ & $72,9 \pm 1,1$ & $73,3 \pm 1,0$ & $69,8 \pm 1,9$ \\
CEN $^{4}$ & $11,8 \pm 1,0$ & $11,8 \pm 1,0$ & $15,3 \pm 2,0$ \\
PC $^{5}$ & $6,6 \pm 0,5$ & $5,7 \pm 0,2$ & $6,9 \pm 0,3$
\end{tabular}

${ }^{1}$ Digestibilidad de la Materia Orgánica, ${ }^{2}$ Fibra Detergente Ácido, ${ }^{3}$ Fibra Detergente Neutro, ${ }^{4}$ Cenizas, ${ }^{5}$ Proteína Cruda. 
Cuadro 4. Calidad de las fracciones verde y seca por fecha de muestreo

\begin{tabular}{lcccccc}
\hline & \multicolumn{5}{c}{ Fecha de muestreo } \\
\cline { 2 - 7 } & \multicolumn{2}{c}{$\mathbf{2 7 / 5 / 2 0 1 0}$} & \multicolumn{2}{c}{$\mathbf{2 6 / 7 / 2 0 1 0}$} & \multicolumn{1}{c}{$\mathbf{1 5 / 9 / 2 0 1 0}$} \\
\hline Parámetro (\%) & Verde & Seco & Verde & Seco & Verde & Seco \\
\hline DMO $^{1}$ & 42,5 & 22,4 & 47,4 & 28,8 & 52,3 & 28,6 \\
FDA $^{2}$ & 44,4 & 55,5 & 40,7 & 52,9 & 37,6 & 53,0 \\
FDN $^{3}$ & 70,5 & 74,9 & 67,6 & 75,3 & 68,7 & 68,3 \\
CEN $^{4}$ & 11,4 & 13,9 & 10,1 & 12,2 & 11,1 & 16,7 \\
PC $^{5}$ & 9,1 & 5,2 & 8,8 & 6,3 & 12,0 & 5,4 \\
\hline
\end{tabular}

${ }^{1}$ Digestibilidad Materia Orgánica, ${ }^{2}$ Fibra Detergente Acido, ${ }^{3}$ Fibra Detergente Neutro, ${ }^{4}$ Cenizas, ${ }^{5}$ Proteína Cruda.

cia la mitad del invierno debido a una reducción de la fracción verde y hacia el final un aumento de ésta con un correspondiente aumento de PC.

La composición química de las fracciones del CN verde y seca presentaron variaciones importantes entre ellas. Se encontró una mayor digestibilidad y \% de PC de la fracción verde respecto al seco, parámetro de especial importancia en la categoría de terneros (Cuadro 4).

\section{Suplementos}

Los valores del análisis físico del ensilaje de grano húmedo de sorgo no mostraron variaciones importantes a lo largo del período experimental, predominando el porcentaje de grano molido $(58,6 \%)$ y quebrado $(39,4 \%)$, mientras que el valor promedio de $\mathrm{pH}$ fue 4,9. Promediando sobre tres fechas de muestreo la energía metabolizable del sorgo y expeller de girasol fue $3,26 \pm 0,05$ y $2,34 \pm 0,12 \mathrm{Mcal} / \mathrm{kg}$ MS, respectivamente. En lo que refiere a proteína cruda los valores fueron $9,1 \pm 0,8 \%$ (sorgo) y $34,7 \pm 3,5 \%$ (expeller girasol). Los valores ofrecidos a diario de suplemento por tratamiento por animal se presentan en el Cuadro 5.

La concentración y el consumo de proteína y energía de la mezcla de suplementos ofrecidos diariamente a los animales se observa en el Cuadro 6. Los tratamientos que incluyeron una fuente proteica fueron considerados iso-proteicos con un rango de variación mínimo de 15,2-15,5\% PC y se diferenciaron del tratamiento testigo de sólo grano húmedo $(9,1 \% \mathrm{PC})$. Los suplementos presentaron una variación menor desde el punto de vista energético (3,03-3,26 Mcal EM/kg MS) que no fue corregida. Los \% del nitrógeno (N) total que se suministraron en forma de urea en los suplementos de los T3 y T4 equivalen al $21 \%$ y $41 \%$ respectivamente.

Cuadro 5. Suplemento ofrecido a diario por animal (promedio en todo el período)

\begin{tabular}{|c|c|c|c|c|c|c|c|c|}
\hline \multirow[b]{2}{*}{ Tratamientos $^{3}$} & \multicolumn{2}{|c|}{ Sorgo } & \multicolumn{2}{|c|}{ Expeller Girasol } & \multicolumn{2}{|c|}{ Urea } & \multicolumn{2}{|c|}{ Total } \\
\hline & $\mathrm{Kg} \mathrm{MS}^{1}$ & $\% \mathrm{MS}^{2}$ & Kg MS & $\% \mathrm{MS}$ & Kg MS & \%MS & $\mathrm{Kg}$ & MS \\
\hline $\mathrm{T} 1$ & 1,65 & $(100)$ & - & - & - & - & 1,65 & (100) \\
\hline T2 & 1,32 & $(75,0)$ & 0,44 & $(25,0)$ & - & - & 1,76 & (100) \\
\hline T3 & 1,52 & $(86,7)$ & 0,21 & $(12,2)$ & 0,02 & $(1,2)$ & 1,75 & (100) \\
\hline T4 & 1,71 & $(97,7)$ & - & - & 0,04 & $(2,3)$ & 1,75 & (100) \\
\hline
\end{tabular}

${ }^{1} \mathrm{Kg}$ MS aportado diariamente a la mezcla, ${ }^{2} \%$ de MS aportado diariamente a la mezcla, ${ }^{3}$ total de $\mathrm{Kg}$ MS de suplemento ofrecidos a diario por animal, $\mathrm{T} 1=\mathrm{SGH}, \mathrm{T} 2=\mathrm{SGH}+\mathrm{EG}, \mathrm{T} 3=\mathrm{SGH}+\mathrm{EG}+\mathrm{U}, \mathrm{T} 4=\mathrm{SGH}+\mathrm{U}$. 
Cuadro 6. Consumo y concentración de proteína cruda (PC) y energía metabolizable (EM) del suplemento ofrecido a los animales (promedio en todo el período)

\begin{tabular}{lrrrr}
\hline & \multicolumn{4}{c}{ Tratamiento } \\
\cline { 2 - 5 } Parámetro & T1 $^{1}$ & T2 $^{2}$ & T3 $^{3}$ & T4 $^{4}$ \\
\hline $\mathrm{PC}$, g/a/d & 151 & 273 & 270 & 266 \\
$\mathrm{PC}$, g/Kg MS & 91 & 155 & 154 & 152 \\
$\mathrm{EM}, \mathrm{Mcal} / \mathrm{a} / \mathrm{d}$ & 5,37 & 5,32 & 5,43 & 5,57 \\
$\mathrm{EM}, \mathrm{Mcal} / \mathrm{Kg} \mathrm{MS}$ & 3,26 & 3,03 & 3,11 & 3,18 \\
\hline${ }^{1} \mathrm{SGH},{ }^{2} \mathrm{SGH}+\mathrm{EG},{ }^{3} \mathrm{SGH}+\mathrm{EG}+\mathrm{U},{ }^{4} \mathrm{SGH}+\mathrm{U} \cdot$ & & &
\end{tabular}

\section{Producción Animal}

En la Figura 3 se presenta la evolución de peso vivo (PV) de cada tratamiento, siendo el PV inicial promedio entre tratamientos de $172 \pm 14 \mathrm{~kg}$. La evolución de PV presentó dos períodos claramente diferenciados para todos los tratamientos, con una disminución del PV hacia la mitad del período (20/07), teniendo un punto de inflexión en dicha fecha para luego aumentar hacia el final del ensayo. En las dos primeras fechas de pesada (26/05 y 22/06) no se observaron diferencias significativas $(P>0,05)$ entre los tratamientos, pero en las siguientes pesadas (20/7, 18/8 y 16/9) se apreciaron diferencias estadísticas $(P<0,05)$. Los animales del T1 registraron un $\mathrm{PV}$ final significativamente $(P<0,05)$ menor que el promedio de los ani- males en el resto de los tratamientos $(176 \pm 18$ y $195 \pm 19 \mathrm{~kg}$ respectivamente).

La ganancia diaria de peso por período fue reflejo de la evolución de PV de los animales (Cuadro 7). Existieron 2 períodos claramente diferenciados: uno de pérdida de peso (27 de mayo al 26 de julio, 55 días) y otro de ganancia de peso ( 26 de julio al 15 de setiembre, 58 días). En el primer período existieron diferencias estadísticas $(P<0,05)$ del T1 con los restantes tratamientos, ocurriendo lo mismo en el segundo período. Con respecto a los que contaron con suplementación nitrogenada (T2, T3 y T4) se revelaron diferencias significativas $(P<0,05)$ solamente en el segundo período entre T3 y T4. En promedio la ganancia de peso de los animales suplementados sin fuentes proteicas fue significativamente menor que el promedio de

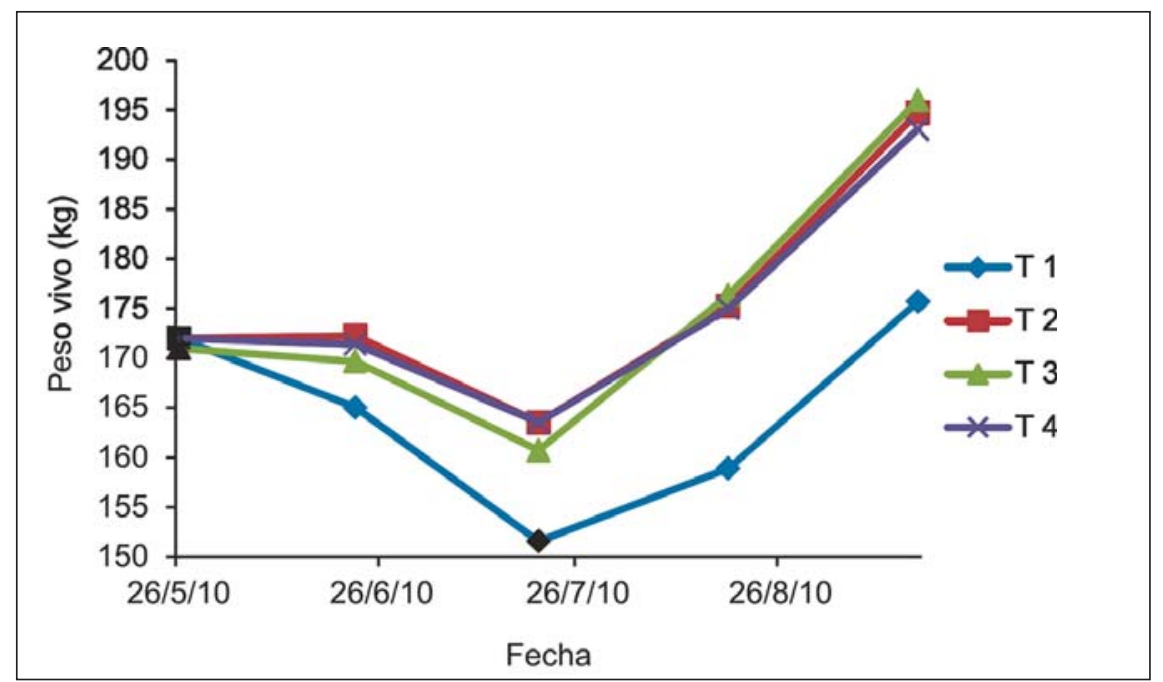

Figura 3. Evolución de peso de los terneros durante el periodo experimental. $\mathrm{T} 1=\mathrm{SGH}, \mathrm{T} 2=\mathrm{SGH}+\mathrm{EG}, \mathrm{T} 3=\mathrm{SGH}+\mathrm{EG}+\mathrm{U}, \mathrm{T} 4=\mathrm{SGH}+\mathrm{U}$. 
Cuadro 7. Ganancia diaria (kg/a/d) por tratamiento y por período (media \pm desvío estándar)

\begin{tabular}{lclcc}
\hline & \multicolumn{4}{c}{ Tratamientos } \\
\cline { 2 - 5 } Periodos & \multicolumn{1}{c}{ T1 $^{1}$} & \multicolumn{1}{c}{ T2 $^{2}$} & T3 $^{3}$ & T4 $^{4}$ \\
\hline 0 - 55 días & $-0,378 \pm 0,133 \mathrm{a}$ & $-0,160 \pm 0,091 \mathrm{~b}$ & $-0,195 \pm 0,158 \mathrm{~b}$ & $-0,163 \pm 0,238 \mathrm{~b}$ \\
55 - 113 días & $0,416 \pm 0,092 \mathrm{a}$ & $0,538 \pm 0,143 \mathrm{bc}$ & $0,607 \pm 0,102 \mathrm{~b}$ & $0,509 \pm 0,124 \mathrm{C}$ \\
0 -113 días & $0,03 \pm 0.088 \mathrm{a}$ & $0,190 \pm 0,089 \mathrm{~b}$ & $0,217 \pm 0,103 \mathrm{~b}$ & $0,182 \pm 0,165 \mathrm{~b}$ \\
\hline
\end{tabular}

${ }^{1} \mathrm{SGH},{ }^{2} \mathrm{SGH}+\mathrm{EG},{ }^{3} \mathrm{SGH}+\mathrm{EG}+\mathrm{U},{ }^{4} \mathrm{SGH}+\mathrm{U}$.

los animales suplementados con EG y/o urea ( 0,030 y $0,199 \mathrm{~kg} /$ animal/día, respectivamente), no existiendo un efecto significativo de la fuente de proteína $(P>0,05)$. Cabe mencionar que no hubo un efecto del bloque ni interacción tratamiento por bloque en las ganancias diarias de peso.

Para el cálculo de la eficiencia de conversión del suplemento se consideró un tratamiento testigo «teórico» sin suplementación, aunque dicho tratamiento no existió en el diseño del experimento. El desempeño de los animales en ese tratamiento se estimó en función de la calidad del CN, categoría y peso de un animal supuesto en el programa NRC 1996. Como resultado se estimó una pérdida de 0,200 kg/a/día en condiciones de pastoreo sobre CN sin suplementación. Pérdidas de peso similares a $\mathrm{CN}$ en la unidad experimental en años anteriores fueron encontrados por Rovira y Velazco (2010b), Straumann et al. (2003), Quintans et al. (1994). La eficiencia de conversión de los animales suplementados con SGH y fuentes proteicas correspondió a 4,5 (SGH+EG); $4,3(\mathrm{SGH}+\mathrm{EG}+\mathrm{U})$ y $4,6(\mathrm{SGH}+\mathrm{U}) \mathrm{kg}$ de suplemento por kg de peso vivo adicional comparado con el tratamiento testigo «teórico», siendo mejor que aquella registrada por los animales suplementados sólo con SGH $(7,3)$.
No hubo diferencias significativas en área de ojo de bife (AOB) y espesor de grasa subcutánea entre tratamientos $(P>0,05)$ (Cuadros 8 y 9). EI AOB tendió a incrementarse en forma numérica a lo largo del período experimental desde $24 \mathrm{~cm}^{2}$ al inicio hasta 28 $\mathrm{cm}^{2}$ al final del experimento, promediando sobre tratamientos. En el caso de la evolución de la cobertura de grasa se observó una recuperación de los valores hacia el final del experimento luego de sufrir una disminución en las fechas intermedias.

El Cuadro 10 es un ejercicio del resultado económico de la suplementación medido a través del margen bruto por animal considerando únicamente los costos asociados al suplemento. A tales efectos se incluyó un tratamiento teórico sin suplementación (T0) sobre campo natural en donde acorde a los resultados de la investigación se puede esperar una pérdida de $0,200 \mathrm{~kg} / \mathrm{a} / \mathrm{d}$ (20 kg en 100 días del invierno). La sustitución parcial o total de expeller de girasol por urea mejoró el resultado económico de la suplementación debido al alto aporte de equivalente proteico de la urea que permitió disminuir la proporción de la fuente de proteína en la mezcla (que siempre va a ser más cara que el sorgo). El incremento absoluto (dólares/tonelada) del costo del suplemento por la adición

Cuadro 8. Evolución del área de ojo de bife $\left(\mathrm{cm}^{2}\right)$ por tratamiento (media \pm desvío estándar)

\begin{tabular}{lcccc}
\hline & \multicolumn{4}{c}{ Área de Ojo de Bife $\left(\mathbf{c m}^{2}\right)$} \\
\cline { 2 - 5 } Fechas & T1 $^{1}$ & T2 $^{2}$ & T3 $^{3}$ & T4 $^{4}$ \\
\hline $1 / 6 / 2010$ & $23,89 \pm 3,58$ & $23,86 \pm 3,94$ & $23,66 \pm 3,58$ & $24,21 \pm 2,55$ \\
$9 / 7 / 2010$ & $26,11 \pm 4,74$ & $26,00 \pm 3,51$ & $26,32 \pm 3,96$ & $25,78 \pm 3,65$ \\
$12 / 8 / 2010$ & $24,53 \pm 4,70$ & $26,36 \pm 4,15$ & $26,62 \pm 3,58$ & $26,54 \pm 3,21$ \\
$16 / 9 / 2010$ & $26,11 \pm 3,75$ & $28,09 \pm 4,19$ & $28,00 \pm 3,87$ & $28,71 \pm 3,74$ \\
\hline
\end{tabular}

${ }^{1} \mathrm{SGH},{ }^{2} \mathrm{SGH}+\mathrm{EG},{ }^{3} \mathrm{SGH}+\mathrm{EG}+\mathrm{U},{ }^{4} \mathrm{SGH}+\mathrm{U}$. No se registraron diferencias significativas entre tratamientos. 
Cuadro 9. Evolución del espesor de grasa $(\mathrm{mm})$ subcutánea por tratamiento (media \pm desvío estándar)

\begin{tabular}{lcccc}
\hline \multirow{4}{*}{ Fechas } & T1 $^{1}$ & T2 $^{2}$ & T3 $^{3}$ & T4 $^{4}$ \\
\cline { 2 - 5 } $1 / 6 / 2010$ & $2,34 \pm 0,24$ & $2,37 \pm 0,35$ & $2,44 \pm 0,28$ & $2,59 \pm 0,36$ \\
$9 / 7 / 2010$ & $2,42 \pm 0,32$ & $2,56 \pm 0,27$ & $2,64 \pm 0,23$ & $2,61 \pm 0,25$ \\
$12 / 8 / 2010$ & $2,31 \pm 0,15$ & $2,42 \pm 0,36$ & $2,55 \pm 0,28$ & $2,49 \pm 0,23$ \\
$16 / 9 / 2010$ & $2,59 \pm 0,26$ & $2,79 \pm 0,47$ & $2,64 \pm 0,23$ & $2,49 \pm 0,29$
\end{tabular}

${ }^{1} \mathrm{SGH},{ }^{2} \mathrm{SGH}+\mathrm{EG},{ }^{3} \mathrm{SGH}+\mathrm{EG}+\mathrm{U},{ }^{4} \mathrm{SGH}+\mathrm{U}$. No se presentó diferencias significativas entre tratamientos.

Cuadro 10. Análisis económico de la suplementación (Precios de referencia invierno 2010)

\begin{tabular}{|c|c|c|c|c|c|}
\hline & \multicolumn{5}{|c|}{ Tratamiento $^{1}$} \\
\hline & TO & T1 & T2 & T3 & T4 \\
\hline Precio del suplemento ${ }^{2}$ (U\$S/ton) & - & 100 & 140 & 124 & 108 \\
\hline Costo diario suplementación ${ }^{3}$ (U\$S/a) & - & 0,17 & 0,25 & 0,22 & 0,19 \\
\hline Costo suplementación en 100 días (U\$S/a) & - & 17 & 25 & 22 & 19 \\
\hline Peso vivo agregado en 100 días $^{4}$ (kg/a) & -20 & 23 & 39 & 42 & 38 \\
\hline Valorización kg producidos (U\$S/a $)^{5}$ & -36 & 41 & 70 & 76 & 68 \\
\hline Margen Bruto (U\$S/a $)^{6}$ & -36 & 24 & 45 & 54 & 49 \\
\hline
\end{tabular}

${ }^{1}$ T0: tratamiento teórico sin suplemento; T1: SGH; T2: SGH+EG, T3: $\mathrm{SGH}+\mathrm{EG}+\mathrm{U}, \mathrm{T} 4: \mathrm{SGH}+\mathrm{U}$.

2Sorgo: 100 U\$S/ton; expeller de girasol 260 U\$S/ton, urea 460 U\$S/ton. Mezclas según Cuadro 1.

${ }^{3}$ Según cantidades realmente suministradas (Cuadro 5)

${ }^{4}$ Según desempeño productivo real (Cuadro 7). En TO se estima pérdida de 0,200 kg/a/d

${ }^{5}$ Valor de referencia Asociación Consignatarios de Ganado: 1,80 U\$S/kg

${ }^{6}$ Valorización $\mathrm{kg}$ producidos - costo de la suplementación en 100 días

de una fuente proteica fue compensado por la mejora en el desempeño productivo de los animales que determinó una mayor valorización de los kg producidos durante el periodo de suplementación.

\section{DISCUSIÓN}

La alta disponibilidad promedio al inicio del período experimental entre tratamientos (3168 kg MS/ha) se puede atribuir a la subutilización del forraje durante los meses previos, que permitió transferencia de éste hacia el invierno. Los valores de forraje diario total asignado por animal (entre 6,9 y $9,5 \mathrm{~kg}$ $\mathrm{MS} / \mathrm{a} / \mathrm{d}$ ) no fueron limitantes para el consumo en ninguno de los tratamientos, tomando en cuenta lo mencionado por Rovira (1996) y Santini y Rearte (1997). Es importante señalar que la altura del forraje disponible tampoco habría sido restrictiva para el consumo animal, habiéndose registrado en todas las mediciones alturas promedio superiores a los $6 \mathrm{~cm}$ (Berretta, 2005).

Si bien la disponibilidad y/o altura de forraje no habría sido limitante para el consumo animal, éste podría haber sido afectado por la calidad de la pastura, debido a su alto contenido de fibra detergente neutro (FDN). Esto estaría relacionado con que la proporción de la fracción verde fue muy baja, lo que concuerda con lo obtenido por Quintans et al. (1994). Estos autores comentan que esta situación se repite cada invierno, donde la oferta de forraje es de muy baja calidad, compuesta principalmente por restos secos que se acumulan desde el verano y otoño, y que presentan una digestibilidad muy baja, asociada a la predominancia de gramíneas estivales perennes en la pastura (Ayala y Bermúdez, 2005). En esta situación sería esperable que la limitante al con- 
sumo sea de orden físico (por llenado del rumen) (Santini y Rearte, 1997).

La composición química del CN no presentó grandes variaciones a lo largo del período experimental y se encuentra dentro del rango presentado por Mieres et al. (2004) sobre calidad de CN. Los valores de proteína cruda (PC) total en la pastura son inferiores al 7\%, y de acuerdo a Caton et al. (1988) y Delcurto et al. (1990) serían limitantes para el consumo animal, ya que se afectaría la actividad de los microorganismos del rumen, la degradación de la fibra y reduciría la tasa de pasaje (Santini y Rearte, 1997). Tanto la composición química del SGH como del EG estuvieron dentro del rango esperado (Cecava, 1995). Con respecto a la variación en el contenido de PC del EG, esto puede ser atribuible a que es un subproducto industrial y a que las partidas del proveedor pudieron ser de diferentes orígenes. Además, Kingsley (1977) resalta que la calidad del EG puede variar como resultado del proceso de elaboración, debido a la cantidad de calor utilizado en la extracción del aceite. Los valores de urea aportados a la dieta, siempre estuvieron por debajo de los niveles máximos tolerados (Escalona et al. 2007; Repetto et al. 2003; Emerick, 1993), no presentándose a lo largo del experimento ningún episodio de intoxicación en los animales.

Las pérdidas de ganancias diarias registradas en el primer período (0-55 días) podrían ser explicadas por el acostumbramiento a la suplementación y/o factores climáticos. Si bien las precipitaciones estuvieron 13\% por debajo de la serie histórica en todo el experimento, concretamente en julio llovió un $23 \%$ por encima de lo normal, mientras que las temperaturas medias y mínimas registradas en junio, julio y agosto estuvieron por debajo del promedio de la serie histórica y se registró un mayor número de heladas. Todos estos factores según Arias (2008) pueden afectar la producción animal y podrían explicar las menores ganancias diarias en el primer período. Para los tratamientos con urea, Owens y Zinn (1993) mencionan que el acostumbramiento suele descender ligeramente el consumo y rendimiento durante un mes aproximadamente cuando los animales inician el consumo de una dieta que contie- ne urea, debido posiblemente a un menor aporte de aminoácidos esenciales procedentes de la proteína de la dieta que escapa de la digestión ruminal. Posteriormente suele mejorar el rendimiento cuando los animales se adaptan a la urea. Otro factor a tener en cuenta sería la calidad de la pastura en el primer período, que fue algo menor, debido a que una mala calidad forrajera se relaciona con una digestión más lenta y un lento pasaje de la digesta a través del aparato digestivo (Fick et al. 1973). En el segundo período se registraron valores positivos de ganancias diarias que se pueden atribuir a la disminución de la severidad y frecuencia de temperaturas extremas y a una mejor calidad de la pastura.

Las diferencias de peso de los tratamientos que contaron con adición de fuentes proteicas con respecto al tratamiento testigo, sólo con sorgo, demostraron que la deficiencia de proteína pudo ser una limitante para el crecimiento animal. Estos resultados son similares a los encontrados por Rovira y Velazco (2010), los cuales registraron un efecto significativo de la adición de fuentes proteicas al SGH en la ganancia de peso individual comparado con la suplementación sólo con SGH sin fuente adicional de proteína (391 y 248 g/animal/día respectivamente) en terneros pastoreando $\mathrm{CN}$ durante invierno. Ochoa y Vidal (2004) trabajando con suplementación proteica en terneras de destete sobre $\mathrm{CN}$, también concluyeron que la suplementación invernal con alimentos ricos en proteína se traduce en diferencias significativas, tanto en ganancia diaria como en peso final, con respecto a aquellos animales que no reciben suplemento. Los efectos al suplementar con nitrógeno (N) a una dieta carente de él, se pueden deber, independientemente de la fuente usada (nitrógeno no proteico o proteína verdadera), a una corrección de una deficiencia de $\mathrm{N}$ ruminal. Esto permitiría un incremento en el flujo de $\mathrm{N}$ no amoniacal al duodeno, ya sea proteína microbiana o proteína no digestible en el rumen (McCollum y Horn, 1990). Según Hannah et al. (1991), Oliveira et al. (2010) y Figueiras et al. (2010) la suplementación proteica permitiría mejorar los procesos de digestión, aumentando la degradabilidad 
efectiva de la MS, la PC y la FDN, lo que aceleraría la tasa de pasaje y reduciría el tiempo medio de retención en rumen, permitiendo que el animal aumente su ingesta de nutrientes. Esta optimización del uso de forrajes de baja calidad se lograría cuando los suplementos consiguen elevar el nivel de proteína de la dieta a valores de por lo menos 9 a 10\% según Sampaio (2007) y Figueiras et al. (2010).

Las diferencias de ganancias encontradas al suplementar con SGH más fuentes nitrogenadas podrían deberse a la sincronización lograda al proporcionar al sistema ruminal las fuentes de proteína y energía en forma simultánea y en las cantidades requeridas a fin de optimizar su utilización por la microbiota asociada; teóricamente de esta forma se lograría el máximo crecimiento microbiano y el mayor aporte de nutrientes para el animal (Repetto y Cajarville, 2009). Sin embargo, algunos trabajos indican que la sincronía de nutrientes ruminal no es importante debido a que el reciclaje del $\mathrm{N}$ al rumen y otros mecanismos fisiológicos mitigan a corto plazo variaciones en el suministro de $\mathrm{N}$ ruminal (Cole y Todd, 2007). Si la tasa de degradación de proteínas es superior a la de fermentación de los hidratos de carbono, grandes cantidades de $\mathrm{N}$ se convierten en amoníaco, que será absorbido hacia la corriente sanguínea y podría causar intoxicación por $\mathrm{NH}_{3}$ (Schingoethe, 1993; Sewell, 1993).

Para mitigar los efectos de la rápida degradación de la urea, se podría plantear la utilización de compuestos de liberación lenta (biuret, materiales recubiertos, urea con formaldehido o melazas) 0 la distribución frecuente del alimento, el cual mejoraría la eficiencia de multiplicación de los microbios del rumen. Hay que tener en cuenta que algu- nos autores como Owens y Zinn (1993) mencionan que, aunque el frenado de la tasa de liberación de amoníaco para conseguir que se mantenga más paralela a la tasa con que se dispone de energía para la multiplicación bacteriana, no logra mejorar la utilización del $\mathrm{N}$ ni el rendimiento del vacuno en pruebas de campo o de laboratorio. La liberación lenta del amoníaco no mejora el consumo de alimento en los animales, ni la digestibilidad, retención de $\mathrm{N}$ o rendimiento. Aparentemente, el sistema para el reciclado de $\mathrm{N}$ hacia el rumen compensa fácilmente la rapidez en la liberación de amoníaco. Resultados obtenidos por Beraza et al. (2010) en novillos y terneros alimentados a corral, no encontraron diferencias significativas en ganancias diarias al comparar distintas fuentes de nitrógeno no proteico (NNP): urea con Optigen, la combinación de ambos y éstas con proteína vegetal.

En general, es de esperar un efecto de adición con estímulo al incorporar suplementos proteicos a la dieta que tiene como base pasturas de baja calidad (Pigurina, 1994), debido a que la suplementación nitrogenada mejora la digestibilidad, aumenta la tasa de pasaje y aumenta el consumo voluntario al

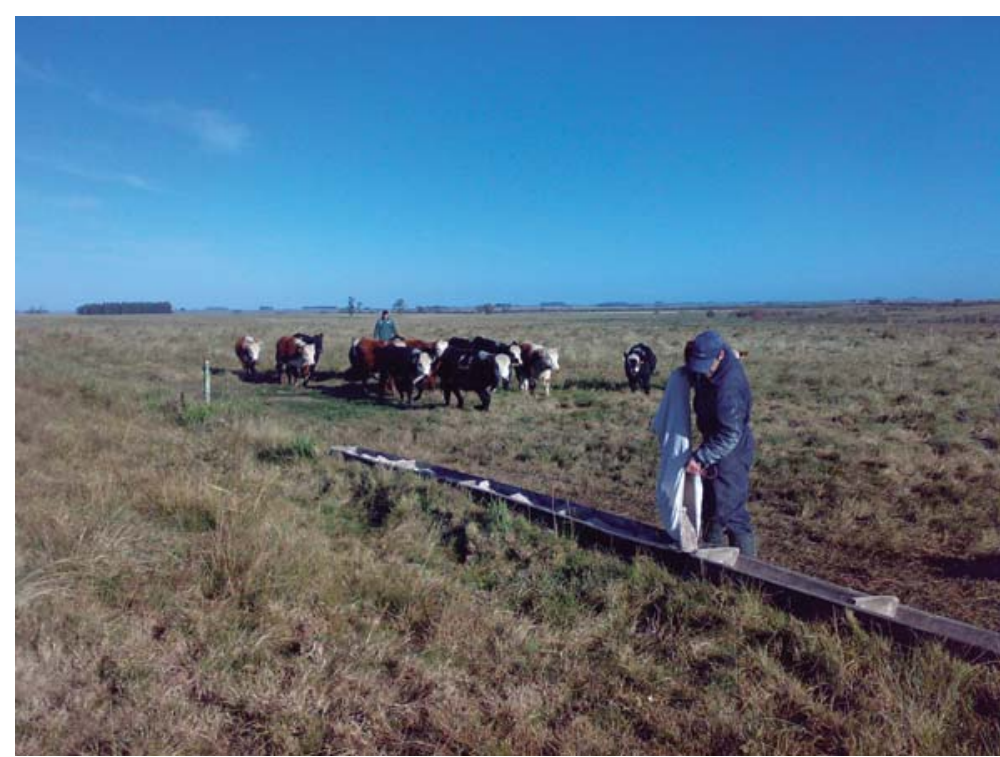

La sustitución parcial de proteína de origen vegetal (expeller de girasol) por nitrógeno no proteico (urea) no afectó el desempeño productivo de terneros suplementados con grano húmedo de sorgo sobre campo natural en invierno. 
incrementar el nivel de PC de la dieta (Fick et al. 1973; Bohnert et al. 2007). Si bien en nuestro caso no podemos aseverar dicha respuesta, debido a que no se determinó el consumo de pastura, la misma podría haberse dado en los tratamientos suplementados con $\mathrm{N}$, permitiendo obtener mejores ganancias diarias en estos terneros, confirmando así la primera hipótesis del trabajo en la cual la adición de fuentes nitrogenadas al SGH mejora el desempeño productivo de terneros suplementados sobre CN.

Los tratamientos con suplementación proteica no revelaron diferencias significativas de ganancia de peso entre sí, dejando de manifiesto que la fuente de proteína no influiría en el desempeño productivo de los animales en los niveles evaluados. Esto puede ser debido a que los microorganismos del rumen son capaces de utilizar como fuente de $\mathrm{N}$ para la síntesis de sus propias proteínas, tanto proteína de la dieta, como NNP (Yokoyama y Johnson, 1993; Broderick, 2010). Esta particularidad hace que los rumiantes puedan obtener ganancias de peso cuando son suplementados con urea como único suplemento nitrogenado (Hennessy y Williamson, 1990). Tieri et al. (2010) trabajando con terneros a corral concluyeron que a mayor nivel de proteína, mayor la ganancia y eficiencia, y que la inclusión de urea en un $1 \%$ de la dieta, se mostró inferior en la ganancia diaria y en la eficiencia de conversión que su tratamiento iso-nitrogenado a base de proteína vegetal (misma PC 15\%); sin embargo cuando se suministró urea en un $0,5 \%$ de la dieta no presentó diferencias significativas. Hennessy y Williamson, (1990) evaluaron el efecto de la urea en el consumo y desempeño de bovinos pastoreando forraje de baja calidad y observaron mayores ganancias en las tasas más bajas de consumo de urea (15 y $23 \mathrm{~g} / \mathrm{animal} / \mathrm{día}$ ) que los de las tasas más altas (42 y 53 g/animal/día). Esto indicaría que la utilización de la urea sería posible dentro de determinados porcentajes de la proteína total para optimizar la producción animal. En nuestro caso, el aporte de proteína proveniente de la urea, expresado como porcentaje de la proteína total fue de $21 \%$ en el T3 y de $41 \%$ en el T4, en estos niveles de sustitución de EG por urea como fuente nitrogenada no se observó un efecto significativo en el desempeño productivo de terneros sobre $\mathrm{CN}$ suplementados con $\mathrm{SGH}$, tal como fue planteado en la segunda hipótesis. En definitiva, lo que determina la producción animal es la masa o actividad microbiana en el rumen, por lo tanto la urea sería útil como fuente de $\mathrm{N}$ rápidamente disponible ajustando las cantidades a suministrar y su sincronía con una fuente energética.

Según Sewell (1993), el uso de urea para aumentar el nivel de proteína de las raciones de alta energía por encima de 12 a 13\% PC en base a MS, rara vez da un aumento en el rendimiento del ganado joven, mientras que el uso de proteínas vegetales para aumentar la proteína de este nivel a menudo aumentó la ganancia de los terneros livianos. Esto se debe a que la urea no tiene valor si las bacterias del rumen ya tienen suficiente $\mathrm{NH}_{3}$, por lo tanto, no sería lógico esperar que un suplemento no proteico elevara el nivel de proteína efectiva de la ración una vez que las bacterias en el rumen no pueden convertir el $\mathrm{NH}_{3}$ adicional. Pordomingo (1993) y Gómez et al. (1995) mencionan que las fuentes de NNP como la urea se utilizan con menor eficiencia que la proteína verdadera por los rumiantes. Ello es debido a que la degradabilidad de esta última en rumen es más lenta adecuándose mejor a la fermentación de los otros componentes de la dieta. Además, estos suplementos presentan cierto porcentaje de la proteína total bajo la forma de proteína sobrepasante, necesaria sobre todo en animales de alto potencial de producción, y también aportan energía a diferencia de la urea. Broderick y Reynal (2009) en vacas lecheras encontraron que cuanto mayor es la sustitución de proteína verdadera degradable en rumen (harina de soja) con la de NNP (urea) se reduce el aumento de peso, se deprime el consumo de MS y disminuye el rendimiento de los componentes de la leche. Estos resultados se lo asignaron a que probablemente el $\mathrm{N}$ amoniacal no satisface por sí solo los requisitos microbianos de aminoácidos y péptidos, reduciendo así la formación de proteína en el rumen. Sin embargo, se debe tener en cuenta que en los tratamientos 2 y 3 del presente experimento se utilizó como fuente de pro- 
teína verdadera expeller de girasol, cuya proteína en gran parte se degrada en rumen y de forma rápida (Repetto et al. 2003), lo que podría resultar en una gran producción de $\mathrm{NH}_{3}$. Sumado a que el aporte de proteína sobrepasante y la concentración de energía de este alimento es baja, y que no se buscaban elevados niveles de ganancias en estos animales, esto explicaría por qué no se encontraron diferencias entre suplementar con proteína verdadera o con NNP. La consecuencia práctica es que en el rango evaluado, la sustitución de EG por urea como fuente nitrogenada no tuvo un efecto significativo en el desempeño productivo de terneros sobre CN suplementados con SGH, coincidiendo con la segunda hipótesis.

Suponiendo que el suplemento proteico utilizado hubiese sido una harina o expeller de soja, sería de esperar una diferencia en los resultados con respecto a los animales que contaron con urea como fuente nitrogenada (Broderick y Reynal, 2009), ya que la harina de soja aportaría un mayor porcentaje de proteína sobrepasante o bypass debido a que la degradabilidad de la proteína en rumen se considera en torno al 66\% (NRC, 2000).

La falta de efecto de los tratamientos en los valores de área ojo de bife (AOB) y grasa subcutánea, podría ser atribuido al corto período de tiempo del experimento, a la categoría evaluada, al nivel de suplementación, a la tendencia de la suplementación a ser iso-energética entre los 4 tratamientos, e isoproteicas entre tratamientos $2,3,4$, y a la calidad de la pastura que limitó las ganancias de peso. Cuando la ganancia de peso está limitada, la retención de grasa está más afectada que la de proteínas. Este efecto tiene mayor incidencia en los animales jóvenes o livianos que acumulan relativamente poca grasa (Di Marco, 1994; Arrieta et al. 2008). Arrieta et al. (2008) obtuvieron resultados en las que el consumo de suplemento en novillos sobreaño marcó diferencias significativas en las ganancias de PV, AOB y espesor de grasa medido en la $12-13^{\text {er }}$ costiIla a favor de los que consumieron afrechillo de arroz a razón del 1\% del PV durante otoño e invierno con respecto a los que consumieron EG y solo $\mathrm{CN}$. Otros estudios en- contraron a la alimentación como un factor que marcó diferencias significativas en el AOB (Camfield et al. 1999; Gil y Huertas 2001); donde se resalta que animales alimentados con granos resultan con una superficie significativamente mayor que animales alimentados sobre pasturas (Gil y Huertas, 2001, Realini et al. 2004). Boleman et al. (1996) encontraron que el nivel de proteína en la dieta puede modificar el área del músculo Longissimus dorsi, para la cual una dieta de alto valor proteico da lugar a áreas más grandes del músculo. Estos datos no concuerdan con los obtenidos en este experimento, por lo mencionado anteriormente y porque en el presente trabajo no se comparó con animales manejados solo a $\mathrm{CN}$, con los que sí se podrían haber encontrado diferencias con los suplementados.

\section{CONCLUSIONES}

El agregado de fuentes proteicas al grano húmedo de sorgo incrementó la ganancia diaria, el peso vivo final y la eficiencia de conversión de terneros en su primer invierno de vida sobre campo natural de baja calidad, comparado con animales suplementados únicamente con grano húmedo de sorgo.

La sustitución de proteína verdadera (expeller de girasol) por nitrógeno no proteico (urea), en los niveles evaluados, no mostró diferencias significativas en el desempeño productivo de terneros suplementados con grano húmedo de sorgo sobre campo natural. Numéricamente, la mezcla de expeller de girasol más urea fue la que obtuvo el mejor desempeño productivo y económico (margen bruto por animal).

\section{BIBLIOGRAFÍA}

AOAC (Association of Official Agricultural Chemists). 1984. Official methods of analysis. $14^{\mathrm{a}}$ ed. Arlington, AOAC. $1102 \mathrm{p}$.

ARIAS, R.; MADER, T.; ESCOBAR, P. 2008. Factores climáticos que afectan el desempeño productivo del ganado bovino de carne y leche. Revisión bibliográfica. Archivos de Medicina Veterinaria 40:7-22. 
ARRIETA, G.; LAGOMARSINO, X.; OLIVERA, J.; TRINDADE, G. 2008. Incidencia de diferentes dietas sobre el crecimiento animal, el rendimiento carnicero y la calidad de la carne. Tesis Facultad Agronomía, Universidad de la República, Montevideo, Uruguay. 231 p.

AYALA, W.; BERMÚDEZ, R. 2005. Producción de forraje de un campo natural de la zona de lomadas del este. En: Gómez, R., Albicette, M. (eds). Seminario de Actualización Técnica en Manejo de Campo Natural. INIA. Serie Técnica N ${ }^{\circ}$ 151, p 33-39.

BERAZA, D.; EICHIN, M.; GALLO, J.; SCHNEEBERGE, R. R. 2010. Evaluación de la fuente proteica en dietas concentradas para novillos y terneros alimentados a corral. Tesis Facultad Agronomía, Universidad de la República, Montevideo, Uruguay, $94 \mathrm{p}$.

BERRETTA, E. 2005. Algunas consideraciones sobre el pastoreo racional Voisin. Seminario de actualización técnica en manejo de campo natural. En: Gómez, R., Albicette, M. (eds). Seminario de Actualización Técnica en Manejo de Campo Natural. INIA. Serie Técnica N ${ }^{\circ}$ 151, p 115-123.

BOHNERT, D.; DELCURTO, T.; CLARK, A.; MERRILL, M.; FALCK, S.; HARMON, D. 2007. Protein supplementation of ruminants consuming low-quality coolor warm-season forage: differences in intake and digestibility. Proceedings, Western Section, American Society of Animal Science 58:217-220.

BOLEMAN, S.; MILLAR, R.; BUYCK, M.; CROSS, H.; SAVELL, J. 1996. Influence of realimentation of mature cows on maturity, color, collagen solubility, and sensory characteristics. Journal of Animal Science 74:2187-2194.

BRODERICK, G. 2010. Nuevas perspectivas en la eficiencia del uso de nitrógeno en vacas lecheras. Simposio, Claves para el Manejo Nutricional de la Vaca de Alto Potencial en el Marco de una Lechería en Expansión. Montevideo, Departamento de Educación Continua. Facultad de Veterinaria. p. 1-18.

BRODERICK, G., REYNAL, S. 2009. Effect of source of rumen-degraded protein on production and ruminal metabolism in lactating dairy cows. Journal of Dairy Science 92(6):2822-2834.

CAMFIELD, P.; PROWN, A.; JOHNSON, Z.; BROWN, C.; LEWIS, P.; RAKES, L. 1999. Effects of growth type on carcass traits of pastureor feedlot-development steers. Journal of Animal Science 77:2437-2443.

CATON, J.; FREEMAN, A.; GALYEAN, M. 1988. Influence of protein supplementation on forage intake, in situ forage disappearance, ruminal fermentation and digesta passage rates in steers grazing dormant blue grama rangeland. Journal of Animal Science 66:2262-2271.

CECAVA, M. 1995. Concentrates for beef cattle. En: Petty, T., Cecava, M. eds. Beef Cattle Feeding and Nutrition, $2^{\mathrm{a}}$ ed. Indiana, Academic Press. p 138-166.

COLE, N., TODD, R. 2007. Opportunities to enhance performance and efficiency trough nutrient synchrony in concentratefed ruminants. Journal of Animal Science 86:E318-E333.

DELCURTO, T.; COCHRAN, R.; NAGARAJA, T.; CORAH, L.; BEHARKA, A.; VANZANT, E. 1990. Comparison of soybean meal/ sorghum grain, alfalfa hay and dehydrated alfalfa pellets as supplemental protein sources for beef cattle consuming dormant tallgrassprairie forage. Journal of Animal Science 68:2901-2915.

DI MARCO, O. 1994. Crecimiento y respuesta animal. Buenos Aires, INTA EEA Balcarce, $126 \mathrm{p}$.

EMERICK, R. 1993. Intoxicaciones por nitrato y urea. En: Church, C. (ed). El rumiante, fisiología digestiva y nutrición. Zaragoza, Acribia, p. 553-558.

ESCALONA, R.; RAMÍREZ, P.; BARZAGA, G.; DE LA CRUZ B.; MAURENIS, C. 2007. Intoxicación por urea en rumiantes. Facultad de Medicina Veterinaria, Universidad de Granma. 4p. Disponible en: http://www.produccionbovina.com/ i n formacion te c n i c al suplementacion_proteica_y_con_nitrogeno_ no_proteico/31-intoxicacion_por_urea. pdf. Fecha de consulta: 2/8/2011.

FICK, K.; AMMERMAN, C.; MCGOWAN, C.; LOGGINS, P.; CORNEL, J. 1973. Influence of supplemental energy and biuret nitrogen on the utilization of low quality 
roughage by sheep. Journal of Animal Science 36(1):137-143.

FIGUEIRAS, J.; DETMANN, E.; PAULINO, M.; PEREIRA, T.; VALADARES, S.; LAZZARINI, I. 2010. Intake and digestibility in cattle under grazing supplemented with nitrogenous compounds during dry season. Revista Brasileira de Zootecnia 39(6):1303-1312.

GIL, A.; HUERTAS, S. 2001. Efectos de los diferentes sistemas de producción de bovinos sobre la composición y calidad de las carnes. Montevideo, INIA. Serie FPTA (Fondo de Promoción de Tecnología Agropecuaria), $\mathrm{N}^{\circ} 04, \quad$ p. 15-46.

GÓMEZ, F.; MASTROPIERRO, J.; ROVIRA SANZ, A. 1995. Efecto de la suplementación energética, proteica y energético proteica en el crecimiento de terneras de destete pastoreando campo natural. Tesis Facultad Agronomía, Universidad de la República, Montevideo, Uruguay. $95 \mathrm{p}$.

HANNAH, S.; COCHRAN, R.; VANZANT, R.; HARMON, D. 1991. Influence of protein supplementation on site and extent of digestion, forage intake, and nutrient flow characteristics in steers consuming dormant bluestem-range forage. Journal of Animal Science 69:2624-2633.

HENNESSY, D.; WILLIAMSON, P. 1990. Feed intake and liveweight of cattle on subtropical native pasture hays. I. The effect of urea. Australian Journal of Agricultural Research 41:1169-1177.

KINGSLEY, R. 1977 . Nutritional value of sunflower meal for ruminants. Thesis in animal nutrition master of science. Faculty of Texas Tech University, $42 \mathrm{p}$.

MCCOLLUM, F.; HORN, G. 1990. Protein supplementation of grazing livestock. A review. The Professional Animal Scientist 6:1-16

MIERES, J. (ED.); ASSANDRI, L.; CÚNEO, M. 2004. Tabla de valor nutritivo de alimentos. En: Guía para la alimentación de rumiantes. INIA. Serie Técnica No142, p 13-68.

NRC (National Research Council).1996. Nutrient requirements of beef cattle. Subcomittee on Beef Cattle Nutrition. Board Agriculture. 6 ${ }^{\mathrm{a}}$ ed. Washington, D. C. National Academy Press.
NRC (National Research Council) 2000. Nutrient Requirements of Beef Cattle. Chapter: Protein. $7^{\mathrm{a}}$ ed, Update 2000. p. 17-21.

OCHOA, S.; VIDAL, P. 2004. Evaluación de la respuesta a la suplementación proteica de terneras de destete pastoreando campo natural diferido. Tesis Facultad Agronomía, Universidad de la República, Montevideo, Uruguay, 95p.

OLIVEIRA, L.; OLIVEIRA, E.; GONÇALVES, L.; BORGES, I.; BARBOSA, P.; FIALHO, M. 2010. Digestibilidade in situ e cinética ruminal de bovinos de corte a pasto sob suplementação com proteinados. Revista Brasileira de Zootecnia 39(6):1328-1335.

OWENS, F.; ZINN, R. 1993. Metabolismo de la proteína en los rumiantes. En: Church, C. (ed.) El rumiante, fisiología digestiva y nutrición. Zaragoza, Acribia. p. 255-281.

PIGURINA, G. 1994. Suplementación dentro de una estrategia de manejo en áreas de ganadería extensiva. En: Carambula, M., Vaz Martins, D., Indarte, E. (eds.). Pasturas y Producción Animal en Areas de Ganadería Extensiva. INIA. Serie Técnica N¹3, p. 195-197.

PORDOMINGO, A. 1993. Alimentación práctica de bovinos en pastoreo. Instituto Nacional de Tecnología Agropecuaria, Buenos Aires, Argentina. Serie de Divulgación Técnica. Proyecto Integrado Pampas. Año $1 \mathrm{~N}^{0} 2.27$ p.

QUINTANS, G.; VAZ MARTINS, D.; CARRIQUIRY, E. 1994. Alternativas de suplementación de vaquillonas. En: Bovinos para Carne, Avances en la Suplementación de la Recría e Invernada Intensiva. INIA. Actividades de Difusión No 34. p. 2-2 2-7.

REALINI, C.; DUCKETT, S.; BRITO, G.; DALLA RIZZA, M.; DE MATTOS, D. 2004. Effect of pasture vs concentrate feeding with or without antioxidants on carcass characteristics, fatty acid composition, and quality of Uruguayan beef. Meat Science 66:657-577.

REPETTO, J.; CAJARVILLE, C. 2009. ¿ES posible lograr la sincronización de nutrientes en sistemas pastoriles intensivos? XXXVII Jornadas Uruguayas de Buiatría, Paysandú, Uruguay, p. 60-67. 
REPETTO, J.; CAJARVILLE, C.; CURBELO, A.; SAPRIZA, D. 2003. Suplementos. Curso a distancia sobre nutrición de rumiantes. Montevideo, Facultad de Veterinaria. Módulo 4, 155 p.

ROVIRA, P.; VELAZCO, J. 2010b. Efecto del agregado de fuentes proteicas al grano húmedo de sorgo en el crecimiento de terneros suplementados sobre campo natural. En: Jornada de Divulgación, Ensilaje de Grano Húmedo de Sorgo. INIA. Actividades de Difusión: No 604. p.14-21.

ROVIRA, J. 1996. Manejo nutritivo de los rodeos de cría. Montevideo. Hemisferio Sur. 288 p.

SAMPAIO, C. 2007. Digestibilidade, consumo e dinamica ruminal em bovinos alimentados com forragem tropical de baixa qualidade suplementados com compostos nitrogenados. Univesidade Federal de Viçosa, Minas, Gerais, Brasil. $53 \mathrm{p}$.

SANTINI, F.; REARTE, D. 1997. Estrategia de alimentación en invernada. En: Martins, D.V., (ed.). Suplementación estratégica para el engorde de ganado. INIA. Serie Técnica No 83. p. 37-46.

SCHINGOETHE, D. 1993. Necesidades nutritivas de rumiantes en comparación con especies monogastricas. En: Church, C. (ed.). El rumiante, fisiología digestiva y nutrición. Zaragoza, Acribia. p. 515-523.
SEWELL, H. 1993. Urea supplements for beef cattle. University of Missouri. Department of Animal Sciences. Disponible en: http:/ /extension.missouri.edu/p/G 2071. Fecha de consulta: 12/7/2011.

STRAUMANN, J.; VÁZQUEZ, A.; AYALA, W.; QUINTANS, G. 2003. Efecto del manejo nutricional pos-destete sobre el inicio de la pubertad en ternera cruza bajo pastoreo. En: Jornada Anual de Producción Animal. INIA. Actividades de Difusión No 332. p. 19-27.

TIERI, M.; LA MANNA, A.; FERNÁNDEZ, E.; MIERES, J.; SCHRÖEDER, F.; PÉREZ, E.; BALDI, F.; BANCHERO, G. 2010. Efecto de diferentes niveles de proteína y sustitución de proteína verdadera por NNP (UREA) en la performance $y$ desarrollo de terneros cruza Hereford $X$ Angus y su impacto posterior en la recría. En: Producción de Carne Desde una Invernada de Precisión. INIA. Serie de Actividades de Difusión Nº 609, p 23-26.

TILLEY, J.; TERRY, R. 1963. A two-step technique for the in vitro digestion of forage crops. Journal of the British Grassland Society 18:104-111.

VAN SOEST, P.; ROBERTSON, J.; LEWIS, B. 1991. Methods for dietary fiber, neutral detergent fiber, and nonstarch polysaccharides in relation to animal nutrition. Journal of Dairy Science 74:3583-3597.

YOKOYAMA, J. 1993. Microbiología del rumen e intestino. En: Church, C. (8ed.). El rumiante, fisiología digestiva y nutrición. Zaragoza, Acribia., p 137-157. 
RESUMEN

El objetivo del trabajo fue evaluar una fuente de nitrógeno no proteico $(140 \% \mathrm{PC})$ de liberación lenta a nivel ruminal (Rumenfeed ${ }^{\mathrm{TM}}$ ) en mezcla con grano húmedo de sorgo (GHS) para mejorar el crecimiento de terneros $(143 \pm 13 \mathrm{~kg})$ sobre campo natural en invierno. Existió un grupo control de animales sin suplementación (T1) y luego 4 tratamientos con suplementación al $1 \%$ del peso vivo (base seca): T2) $100 \%$ GHS; T3) 97,3\% GHS + 2,7\% Rumenfeed ${ }^{\mathrm{TM}}$; T4) 94,5\% GHS + 5,5\% Rumenfeed ${ }^{\mathrm{TM}}$; T5) 76,5\% GHS $+18 \%$ expeller girasol $+5,5 \%$ Rumenfeed $^{\mathrm{TM}}$. La disponibilidad promedio de forraje fue $2235 \pm 926 \mathrm{~kg} \mathrm{MS} / \mathrm{ha}$ siendo un $72 \%$ aportado por restos secos. La proteína cruda del forraje fue $7,9 \%$ mientras que las distintas mezclas de suplemento aportaron $8,9 \%$ (T2); $12,5 \%$ (T3); $16,1 \%$ (T4) y 20,8\% PC (T5). Durante los 102 días del ensayo, los animales suplementados con los niveles más altos de proteína (T4 y T5) registraron una ganancia de peso promedio de $0,459 \mathrm{~kg} / \mathrm{a} / \mathrm{d}$, significativamente mayor que la registrada por aquellos animales en los tratamientos T2 y T3 $(0,305 \mathrm{~kg} / \mathrm{a} / \mathrm{d})$. La eficiencia de conversión ( $\mathrm{kg}$ de suplemento/kg peso vivo adicional), calculada en función del desempeño del grupo control T1 $(0,046 \mathrm{~kg} / \mathrm{a} / \mathrm{d})$ fue mejor en aquellos animales suplementados con niveles altos de proteína en el suplemento ( 3,6 y 4,2 para T4 y T5, respectivamente) comparado con los tratamientos T2 y T3 (5,2 y 6,4; respectivamente). El uso de una fuente de nitrógeno no proteico de liberación lenta en mezcla con grano húmedo de sorgo elevando el nivel de proteína del sorgo al menos a 16\% permitió mejorar el desempeño productivo y eficiencia de conversión de terneros suplementados al $1 \%$ del peso vivo sobre campo natural.

Palabras claves: nitrógeno no proteico, urea liberación lenta, sorgo, terneros, campo natural

The objective of the study was to evaluate the addition of a slow-release ruminal non protein source (Rumenfeed ${ }^{\top M}$ ) to high moisture sorghum grain (HMSG) on performance of weaning calves grazing low-quality native pastures during winter. There was one control group of animals without supplement (T1) and then 4 groups of animals daily supplemented at $1 \%$ of body weight (dry matter basis) with the following supplements: T2) $100 \%$ HMSG; T3) $97.3 \%$ HMSG + 2.7\% (Rumenfeed ${ }^{\mathrm{TM}}$ ); T4) $94.5 \%$ HMSG + 5.5\% (Rumenfeed ${ }^{\mathrm{TM}}$ ); T5) $76.5 \%$ HMSG $+18.0 \%$ sunflower expeller $+5.5 \%$ (Rumenfeed $^{\mathrm{TM}}$ ). Average pasture allowance was $2235 \pm 926 \mathrm{~kg} \mathrm{DM} / \mathrm{ha}$ being $72 \%$ of that value supplied by dead and dry forage. Average crude protein (CP) of forage was $7.9 \%$ while the different combinations of supplements had a CP concentration of $8.9 \%$ (T2); $12.5 \%$ (T3); $16.1 \%$ (T4) y $20.8 \%$ PC (T5). During the $102 \mathrm{~d}$ of the experiment calves supplemented with higher levels of CP (T4 and T5) had an average daily gain (ADG) of $0.459 \mathrm{~kg} / \mathrm{a} / \mathrm{d}$ which was significantly higher than the ADG expressed by animals in T2 and T3 $(0.305 \mathrm{~kg} / \mathrm{a} /$ d).Feed efficiency, expressed as the $\mathrm{kg}$ of supplement required to gain $1 \mathrm{~kg}$ additional compared with the performance of the control group ( $\mathrm{T} 1=0.046 \mathrm{~kg} / \mathrm{a} / \mathrm{d}$ ), improved in 
animals supplemented with higher levels of protein (3.6 and 4.6 for T4 and T5, respectively) compared with animals in T2 and T3 (5.2 and 6.4, respectively). The use of (Rumenfeed $^{\mathrm{TM}}$ ) in combination with high moisture sorghum grain in order to achieve a $16 \%$ CP concentration increase performance and feed efficiency of calves supplemented at $1 \%$ of the body weigh grazing low-quality native pastures.

Key words: non protein nitrogen, urea, sorghum, calves, native pastures

\section{INTRODUCCIÓN}

La fuente más común de nitrógeno no proteico (NNP) usada en la alimentación de rumiantes es la urea, debido a su bajo costo y a su equivalente proteico elevado de $281 \%$ (Catañeda-Serrano et al., 2013). El problema mayor con la urea es su degradación ruminal rápida la cual es difícil de sincronizar con la degradación de carbohidratos y el crecimiento microbiano, procesos que ocurren más lentamente, y la rápida liberación de amoniaco en el rumen ocasiona un uso ineficiente del nitrógeno por los microorganismos, limitando la inclusión de urea en las dietas de rumiantes (Satter y Roffler, 1975). Una fuente de NNP de liberación lenta podría reducir el riesgo de intoxicación causada por la urea y aumentar el espacio para la inclusión de ingredientes en la dieta sustituyendo fuentes de proteína vegetal, las cuales son de costo alto y disponibilidad limitada, mejorando la sincronía de nutrientes en el rumen sin comprometer el rendimiento animal (Souza et al., 2010).

En el presente experimento se evaluó concretamente una fuente de proteína compuesta por nitrógeno de liberación lenta, energía (almidones) y minerales, obtenida a través de un proceso de extrusión de urea con almidones de maíz y mandioca. El modo de acción consiste en la liberación lenta a nivel ruminal del nitrógeno proveniente de la urea extrusada a la vez que el almidón gelatinizado aumenta la disponibilidad para la producción de proteína microbiana y la digestibilidad de todos los nutrientes. El objetivo general del experimento fue mejorar la recría invernal de terneros suplementados con grano húmedo de sorgo sobre campo natural a través de la inclusión de dicha fuente de nitrógeno de liberación lenta.

\section{MATERIALES Y MÉTODOS}

El experimento se realizó sobre 22,5 ha de campo natural de la Unidad Alférez pertenecientes al Módulo de Invernada de Bovinos para Carne en la «Unidad Experimental Palo a Pique» (UEPP) de INIA Treinta y Tres entre el 23 de junio y el 4 de octubre de 2011 (103 días). El diseño experimental fue de bloques completamente al azar con cinco tratamientos sin repeticiones. Se utilizaron 54 terneros de destete cruza Hereford $x$ Aberdeen Angus provenientes del Módulo de Cría de la UEPP (peso vacío \pm desvío estándar: $143 \pm 13 \mathrm{~kg}$ ). Los animales fueron estratificados por peso vivo en 2 bloques, «livianos» $(131 \pm 5 \mathrm{~kg})$ y «pesados» $(154 \pm 8 \mathrm{~kg})$, y asignados al azar dentro de cada bloque a los distintos tratamientos.

Los tratamientos fueron:

1. Testigo sin suplementación.

2. Suplementación con grano húmedo de sorgo (GHS).

3. Suplementación con GHS $(97,3 \%)+$ Rumenfeed $^{\mathrm{TM}}(2,7 \%)$.

4. Suplementación con GHS (94,5\%) + Rumenfeed $^{\mathrm{TM}}(5,5 \%)$.

5. Suplementación con GHS $(76,5 \%)+$ Rumenfeed $^{\mathrm{TM}}(5,5 \%)+$ Expeller Girasol (18\%).

En todos los tratamientos la dotación fue de 1,2 UG/ha en sistema de pastoreo continuo. Los tratamientos con suplementación contaron con 12 terneros en 5 ha cada uno. El tratamiento testigo tenía menos animales y superficie ( 6 terneros en 2,5 ha) debido al pobre desempeño productivo que se espera de dichos animales tratando de que no se comprometa el resultado global de la invernada que se desarrolla en la UEPP. La inclusión de dicho tratamiento testigo se jus- 
tificó para el cálculo de la eficiencia de conversión del suplemento a peso vivo.

La suplementación se realizó al 1\% del peso vivo en base seca. La mezcla de suplementos ofrecidos en las dietas de los tratamientos 2,3 , 4 y 5 posee un nivel esperado mínimo de proteína de 8, 12, 16 y 20\%, respectivamente para obtener la curva de respuesta al incremento del nivel de proteína. La inclusión del expeller en el tratamiento 5 se justificó para llegar a $20 \%$ de proteína valor que no sería alcanzable sólo con Rumenfeed ${ }^{\mathrm{TM}}$ por riesgo de toxicidad. El silo de grano húmedo provino de 6 ha de sorgo granífero cosechadas en el área de Rotaciones de la UEPP. El cultivo fue sembrado en siembra directa en noviembre de 2010 y cosechado en marzo de 2011. El grano fue quebrado previo al embolsado en condiciones anaeróbicas (silobag) utilizando una embolsadora marca Richiger de 6 pies de diámetro. La urea de liberación lenta (Rumenfeed $^{\mathrm{TM}}$ ) fue proporcionada por la empresa Deribal S.A. y el expeller de girasol se adquirió a nivel comercial.

La suplementación se realizó de lunes a domingo durante la mañana. El sorgo se extrajo del silo el mismo día del suministro a los animales, excepto los fines de semana en donde se dejaron las cantidades ya pesadas en bolsas identificadas el viernes de tarde. El agregado de la fuente nitrogenada se realizó el día del suministro a los animales asegurando un mezclado homogéneo. El periodo de acostumbramiento al grano húmedo de sorgo se realizó durante 14 días previo al inicio del experimento. El periodo de acostumbramiento a la urea se inició el día 0 del experimento en los tratamientos que correspondía y se desarrolló durante 18 días.

Los animales fueron dosificados con 2 dosis de Ricoverm previo al inicio del ensayo, según recomendación de Médico Veterinario en función del análisis coprológico realizado. Se realizó un $2^{\circ}$ coprológico a los 18 días de iniciado el experimento y efectivamente los animales estaban «limpios». En el día 56 del periodo experimental se tomaron muestras de heces del recto de un $1 / 3$ de los animales en cada tratamiento y se enviaron nuevamente a Laboratorio para análisis coprológico. Como consecuencia del resultado (530 hpg) se recomendó la dosificación con Ivermectina y Levamisol, realizada el día 60 del experimento. No se observaron en el campo síntomas clínicos de enfermedades en los animales (intoxicación por urea, acidosis).

Los registros de precipitaciones se obtuvieron del pluviómetro ubicado en el campo experimental. La disponibilidad de forraje en el campo natural se determinó cada 28 días totalizando 5 fechas de muestreo. Se realizó a través de corte al ras del suelo con tijera eléctrica de diez cuadros de 50 por $20 \mathrm{~cm}$ por tratamiento. El muestreo se realizó en forma dirigida, intentando seleccionar áreas representativas del potrero. Previo al corte se registró la altura promedio del tapiz $(\mathrm{cm})$ a ser muestreado. Se determinó a través de 5 mediciones sobre cada área dentro del rectángulo de corte (en los 4 ángulos y 1 en el medio) utilizando una regla graduada.

En el laboratorio, cada corte se pesó verde individualmente y luego se procedió a mezclar todos los cortes por tratamiento formando una muestra compuesta (pool) por tratamiento. De cada pool se extrajeron 3 sub-muestras de aproximadamente $200 \mathrm{~g}$ cada una. Dos de las sub-muestras fueron colocadas en estufa durante al menos 48 horas a una temperatura de $60^{\circ} \mathrm{C}$. Luego por diferencia entre peso fresco y peso seco se determinó el porcentaje de materia seca de la pastura, el cual se utilizó para el cálculo de la disponibilidad de forraje. En la restante sub-muestra extraída del pool, se separó manualmente la fracción verde y seca, las cuales se secaron individualmente siguiendo el mismo procedimiento arriba mencionado. Las muestras de materia seca (general) $y$ de las fracciones verde y seca de las fechas de muestreo al inicio, mitad y fin del experimento se enviaron al Laboratorio de Nutrición Animal de INIA La Estanzuela. Se realizaron los análisis de materia seca (MS), proteína cruda (PC), fibra detergente neutra (FDN), y fibra detergente ácida (FDA). Dos veces durante el periodo experimental se tomaron muestras del grano húmedo de sorgo y del expeller de girasol para análisis del valor nutritivo. Se analizaron los parámetros de MS, PC, FDN, FDA, y acidez (silo). 
Los animales se pesaron llenos (sin desbaste) cada 14 días a primera hora de la mañana. Con dicha pesada se ajustaba la cantidad de suplemento por animal en función de la evolución del peso vivo. Adicionalmente, los animales se pesaron vacíos (12 h de ayuno) cada 28 días. Se estimó la eficiencia de conversión del suplemento a peso vivo mediante la relación entre el consumo de suplemento y la diferencia en ganancia diaria individual de peso vivo entre los tratamientos suplementados y el testigo sin suplementación. Al inicio y final del experimento se registraron variables de crecimiento y desarrollo del animal por ultrasonido (área de ojo de bife, engrasamiento).

El análisis estadístico se realizó utilizando el paquete estadístico del SAS. Las variables que se analizaron estadísticamente fueron disponibilidad de forraje (MS $\mathrm{kg} / \mathrm{ha}$ ) total, verde, y seco; altura del tapiz $(\mathrm{cm})$, peso vivo, ganancia de peso diaria, área de ojo de bife y espesor de grasa. Se evaluó el efecto principal del tratamiento y posibles interacciones con bloques (peso vivo) y periodo de evaluación. Cuando el valor de probabilidad fue $P<0,05$ existieron diferencias significativas y se realizó la separación de medias por Ismeans.

\section{RESULTADOS Y DISCUSIÓN}

\section{Campo natural}

La información se presenta promediando sobre tratamientos ya que el diseño del experimento no permitió detectar diferencias en la base forrajera debido a la aplicación de los tratamientos. Durante el periodo experimental se registraron $293 \mathrm{~mm}$ de lluvia distribuidos en 10 días. La disponibilidad de forraje promedio \pm d.e. fue $2235 \pm 926 \mathrm{~kg} \mathrm{MS} / \mathrm{ha}$, con un mínimo y máximo de $1574 \pm 690$ (06/09/11) y $3036 \pm 934$ (12/07/11) kg MS/ha, respectivamente (Figura 1). Dicha variación estuvo asociada básicamente al porcentaje de materia seca de la pastura ya que la altura del tapiz se mantuvo relativamente estable, promediando $6,0 \pm 2,3 \mathrm{~cm}$ con un mínimo y máximo al inicio y final del experimento $(5,3$ $\pm 1,6$ y $6,9 \pm 2,8 \mathrm{~cm}$, respectivamente). Ambas variables, disponibilidad y altura, tendieron a disminuir a medida que avanzó el periodo experimental hasta el mes de setiembre, con tendencia a incrementarse en el último mes de evaluación. Cabe recordar que tanto la disponibilidad como la altura fueron estimadas con cortes al ras del suelo por lo que un alto porcentaje del forraje disponible no era accesible por parte de los animales.

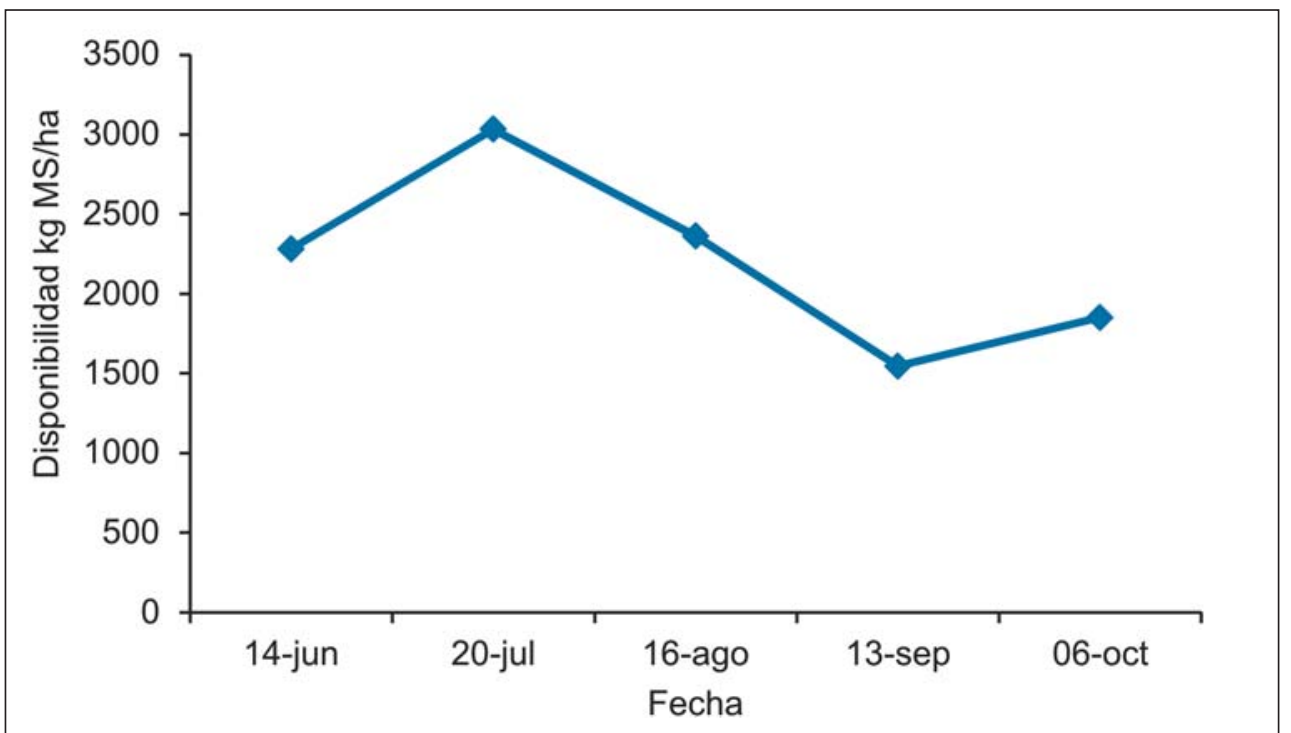

Figura 1. Forraje disponible en cada fecha de muestreo (promedio sobre tratamientos). 


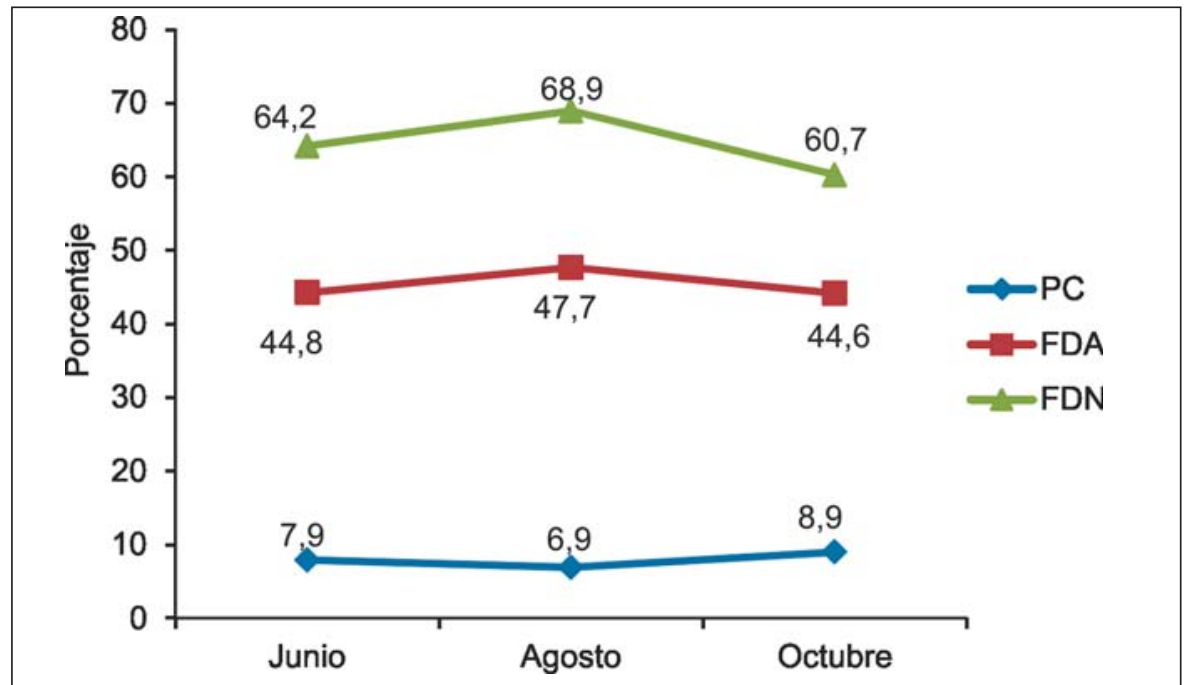

Figura 2. Evolución de la proteína cruda (PC), fibra detergente ácida (FDA) y fibra detergente neutra (FDN) del campo natural. Promedio sobre tratamientos.

La evolución de la calidad del campo natural se observa en la Figura 2. Los datos son promediando sobre tratamientos ya que no se encontraron diferencias significativas entre tratamientos en los parámetros proteína cruda (PC), fibra detergente neutro (FDN) y fibra detergente ácida (FDA) en las distintas fechas de muestreo. El valor de PC se mantuvo por debajo del $10 \%$, con un mínimo y máximo de 6,9 y 8,9\%, respectivamente. Los niveles de fibra se mantuvieron elevados a lo largo del periodo experimental promediando $45,4 \%$ (FDA) y $64,5 \%$ (FDN), con una tendencia a disminuir hacia el final del experimento. La baja calidad del campo natural determina que la restricción del consumo voluntario de los animales sea del orden físico (llenado del rumen por alto contenido de FDN) asociado a una actividad limitada de los microorganismos del rumen por la baja digestibilidad y niveles críticos de proteína en el forraje disponible lo que enlentece la tasa de pasaje del alimento.

La evolución de la calidad del campo natural acompañó la evolución de la relación verde/seco (Figura 3). La fracción restos se-

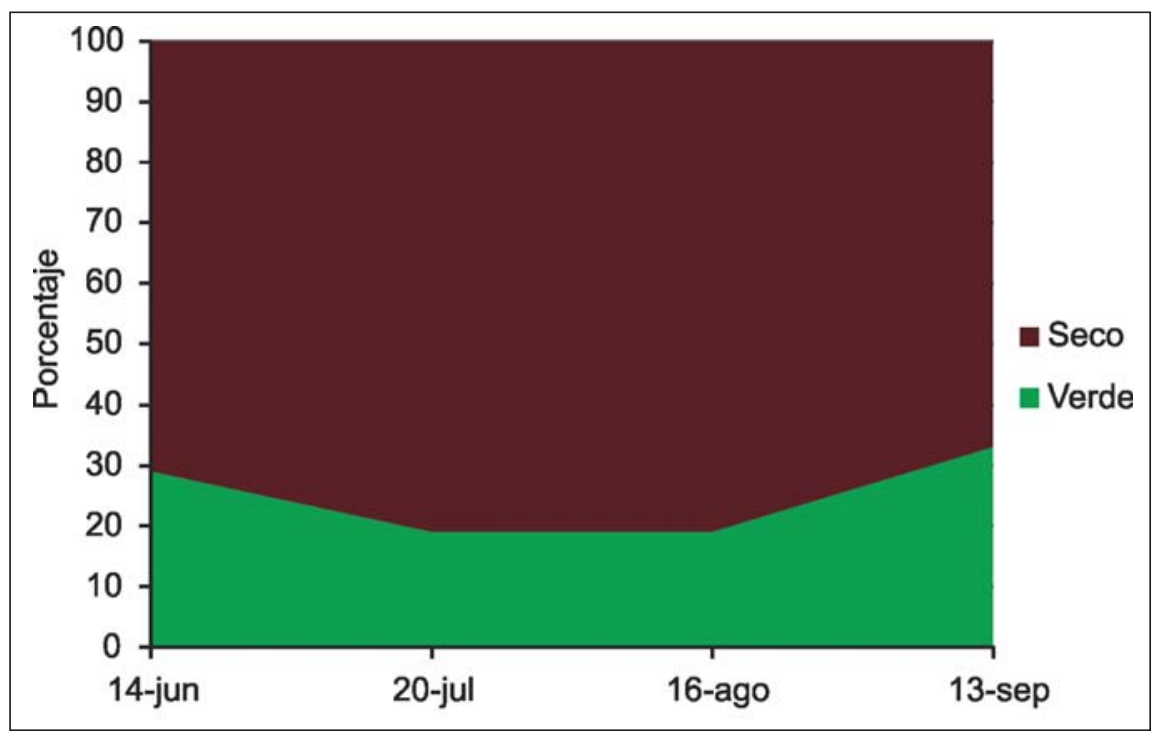

Figura 3. Evolución del porcentaje de forraje verde y seco como aporte a la materia seca total (promedio sobre tratamientos). 
cos del forraje predominó durante el ensayo. En promedio un $72 \%$ del forraje ofrecido, expresado como kg MS/ha, estuvo compuesto por restos secos, con un mínimo y máximo de $59 \%$ (octubre) y $81 \%$ (julio-agosto) respectivamente. Esta situación es común en el invierno sobre los suelos de lomadas del Este, donde la oferta de forraje es de muy baja calidad, compuesta principalmente por restos secos que se acumulan desde el verano y otoño asociado a la predominancia de gramíneas estivales perennes en la pastura. Los restos secos presentaron en promedio un contenido de PC significativamente inferior que el registrado en el forraje verde $(6,3 \%$ y $13,1 \%$, respectivamente). Con respecto a los parámetros de fibra, los valores de FDA y FDN fueron 9\% y $36 \%$ superiores, respectivamente, en los restos secos comparado con la fracción verde del campo natural. La presión de selección de los animales sobre el forraje de mayor calidad (selectividad) fue limitada debido a la baja proporción de forraje verde a lo largo del periodo experimental.

\section{Suplementos}

El valor nutritivo de los ingredientes se encontró dentro del rango esperado (Cuadro 1). En el caso del Rumenfeed ${ }^{\mathrm{TM}}$ el alto nivel de proteína se basa en el aporte de nitrógeno no proteico de la urea en tanto el aporte energético corresponde a almidón de maíz.

A través de la combinación de los distintos ingredientes se lograron establecer dietas con niveles bien diferenciados de proteína en el suplemento ofrecido variando de $8,9 \%$ a $20,8 \%$ PC (Cuadro 2). El aporte de proteína proveniente de Rumenfeed ${ }^{\mathrm{TM}}$ (nitrógeno no proteico) varió entre 30 y $48 \%$ de la proteína total del suplemento según el tratamiento. El contenido de energía metabolizable del suplemento ofrecido registró un coeficiente de variación de 2,3\% entre tratamientos debido a que no se ajustó por energía, aunque no se consideró que dicha variación fuera significativa al momento de explicar los resultados obtenidos. A medida que disminuyó el porcentaje de sorgo en la ra-

Cuadro 1. Valor nutritivo de los ingredientes utilizados (base seca)

\begin{tabular}{|c|c|c|c|}
\hline & \multicolumn{3}{|c|}{ Ingrediente } \\
\hline & $\begin{array}{c}\text { Sorgo grano } \\
\text { húmedo }^{1}\end{array}$ & Rumenfeed $^{\mathrm{TM} 2}$ & $\begin{array}{l}\text { Expeller } \\
\text { girasol }^{1}\end{array}$ \\
\hline Materia seca, \% & 73,1 & 90,7 & 89,6 \\
\hline Proteína cruda, \% & 8,9 & 140,0 & 35,0 \\
\hline Nutrientes digestibles totales, $\%$ & 78 & 36 & 68 \\
\hline Energía metabolizable, Mcal/kg & 2,86 & 1,32 & 2,48 \\
\hline
\end{tabular}

${ }^{1}$ Promedio de 2 muestreos realizados.

${ }^{2}$ Según etiqueta del producto.

Cuadro 2. Concentración de proteína y energía del suplemento ofrecido en cada tratamiento a razón de $1 \%$ del peso vivo por día (base seca)

\begin{tabular}{llllll}
\hline & \multicolumn{5}{c}{ Tratamiento $^{1}$} \\
\cline { 2 - 6 } & T1 & \multicolumn{1}{c}{ T2 } & T3 & \multicolumn{1}{c}{ T4 } & \multicolumn{1}{c}{ T5 } \\
\hline Proteína cruda (PC), kg/kg MS & - & 0,089 & 0,125 & 0,161 & 0,208 \\
Proteína proveniente de Rumenfeed, \% & - & - & 30 & 48 & 37 \\
Nutrientes digestibles totales (NDT), \% & - & 78 & 77 & 76 & 74 \\
Relación NDT/PC & - & 8,8 & 6,2 & 4,7 & 3,6 \\
Energía metabolizable, Mcal/kg MS & - & 2,86 & 2,82 & 2,77 & 2,71 \\
\hline
\end{tabular}

T1: Testigo; T2: 100\% grano húmedo de sorgo (GHS); T3: GHS (97,3\%) + Rumenfeed ${ }^{\mathrm{TM}}(2,7 \%) ;$ T4: GHS $(94,5 \%)+$ Rumenfeed $^{\mathrm{TM}}(5,5 \%) ; \mathrm{T} 5$ : GHS $(76,5 \%)+$ Rumenfeed $^{\mathrm{TM}}(5,5 \%)+$ Expeller Girasol $(18 \%)$. 
Cuadro 3. Consumo diario (kg MS/a/día) de cada ingrediente y total del suplemento ofrecido. (Entre paréntesis figura el porcentaje de cada ingrediente en la mezcla)

\begin{tabular}{ccccc}
\hline & \multicolumn{5}{c}{ Ingrediente } \\
\cline { 2 - 5 } Tratamiento & Sorgo grano húmedo & Rumenfeed $^{\mathrm{TM}}$ & Expeller girasol $^{\text {Total }}$ \\
\hline T1 & - & - & - & - \\
T2 & $1,45(100)$ & - & - & $1,45(100)$ \\
T3 & $1,50(97,3)$ & $0,042(2,7)$ & - & $1,54(100)$ \\
T4 & $1,56(94,5)$ & $0,090(5,5)$ & - & $1,65(100)$ \\
T5 & $1,19(76,5)$ & $0,085(5,5)$ & $0,279(18,0)$ & $1,55(100)$
\end{tabular}

T1: Testigo; T2: 100\% grano húmedo de sorgo (GHS); T3: GHS (97,3\%) + Rumenfeed ${ }^{\mathrm{TM}}(2,7 \%)$; T4: GHS $(94,5 \%)+$ Rumenfeed $^{\mathrm{TM}}(5,5 \%) ;$ T5: GHS $(76,5 \%)+$ Rumenfeed $^{\mathrm{TM}}(5,5 \%)+$ Expeller Girasol $(18 \%)$

ción, el contenido energético de la misma también disminuyó expresado a través de NDT o energía metabolizable. Como consecuencia, la relación NDT/PC tendió a disminuir a medida que se incrementó el porcentaje de proteína en la dieta.

El Cuadro 3 muestra la composición y consumo del suplemento ofrecido en cada tratamiento. La variación en el consumo total de suplemento entre tratamientos fue debido a la diferente evolución de peso de los tratamientos, ya que el nivel de suplementación se ajustó cada 14 días al 1\% del peso vivo lleno (base seca).

\section{Desempeño productivo de los animales}

La Figura 4 muestra la evolución del peso vivo vacío de los animales. A partir del día 45 del experimento (9 de agosto) se comenzaron a registrar diferencias significativas $(P<$ $0,05)$ en el peso vivo entre los tratamientos, las cuales tendieron a acentuarse hacia el final del experimento. Claramente se diferenciaron tres grupos: el tratamiento testigo T1; los tratamientos T2 y T3 (8,9-12,6\% PC en el suplemento); y los tratamientos T4 y T5 (16,1-20,8\% PC en el suplemento);. El peso vivo final $(\mathrm{kg})$ fue $148(\mathrm{~T} 1), 174(\mathrm{~T} 2)$,

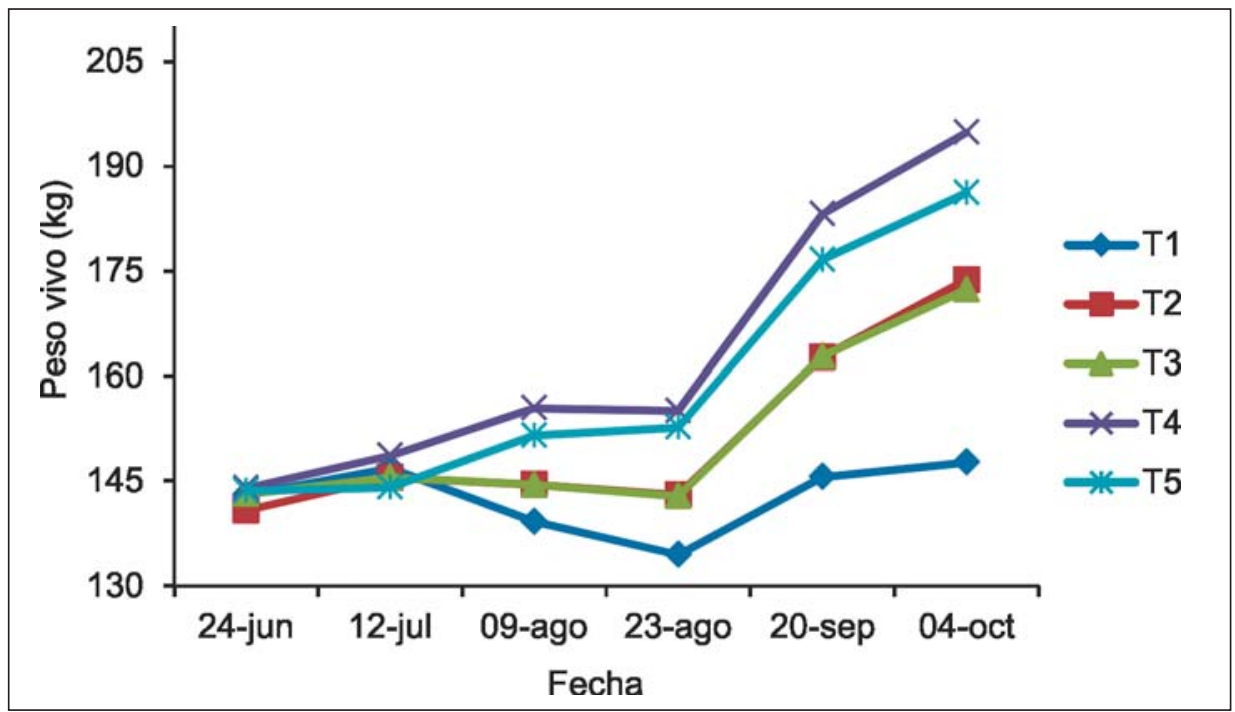

Figura 4. Evolución de peso vivo durante el periodo experimental.

T1: Testigo; T2: 100\% grano húmedo de sorgo (GHS); T3: GHS $(97,3 \%)+$ Rumenfeed $^{\mathrm{TM}}$ $(2,7 \%) ;$ T4: GHS $(94,5 \%)+$ Rumenfeed ${ }^{\mathrm{TM}}(5,5 \%) ;$ T5: GHS $(76,5 \%)+$ Rumenfeed $^{\mathrm{TM}}(5,5 \%)+$ Expeller Girasol (18\%). 
172 (T3), 195 (T4), y 185 (T5). Los animales en el tratamiento T5 fueron los únicos que no registraron pérdida de peso vivo a lo largo del periodo experimental.

Durante el periodo de acostumbramiento al Rumenfeed ${ }^{\mathrm{TM}}(0-18 \mathrm{~d})$ no se registraron diferencias significativas $(P<0,05)$ en la ganancia de peso de los animales (Cuadro 4). Los animales del tratamiento T5 tendieron a ganar menos que aquellos animales en T2 y $\mathrm{T} 4$, probablemente asociado a la presencia de los pellets de expeller de girasol en el suplemento ya que no hubo un incremento gradual de dicho componente en la mezcla. Observaciones prácticas realizadas en experimentos anteriores indican que puede haber cierto rechazo o demora inicial de los animales al consumo de pellets de girasol. En el periodo 18-60 d los animales sin suplementación perdieron peso en forma significativa, e incluso, aquellos animales en T2 y T3 no lograron evitar la pérdida de peso asociada a las rigurosas condiciones climáticas y a las características del forraje. El periodo 60-102 d (fines de agosto a principios de octubre) se destacó por ganancias positivas y altas en todos los tratamientos suplementados, promedio de 0,796 kg/a/d, significativamente superior a la ganancia de peso del grupo testigo $(0,315 \mathrm{~kg} / \mathrm{a} / \mathrm{d})$. La mejora de las condiciones climáticas y de las características de la pastura, sumado a un posible crecimiento compensatorio, fueron los determinantes de la mejora en el desempeño productivo de los animales durante la segunda mitad del periodo experimental. En ninguno de los periodos evaluados existió un efecto significativo del bloque (peso vivo) en la ganancia de peso ni una interacción bloque * tratamiento significativa.

En términos generales, durante los 102 días del ensayo, los animales suplementados con los niveles más altos de proteína (T4 y T5) registraron una ganancia de peso promedio de $0,459 \mathrm{~kg} / \mathrm{a} / \mathrm{d}$, la cual fue significativamente mayor que la registrada por aquellos animales en los tratamientos suplementados con niveles más bajos de proteína (T2 y T3), quiénes promediaron 0,305 kg/a/d. Estos resultados confirman que el agregado de fuentes proteicas al grano húmedo de sorgo mejora el crecimiento de categorías de recría suplementadas sobre campo natural (Rovira y Velazco, 2010; Benítez et al., 2011). El efecto positivo es a través de la corrección parcial de la deficiencia de nitrógeno amoniacal del rumen, acompañada por el suministro adecuado de energía para mantener una sincronización entre ambos nutrientes. Aunque algunos autores afirman que la posible contribución de la urea de liberación lenta a la sincronía ruminal de la energía y el nitrógeno carece de importancia práctica, siendo el mayor interés de estos

Cuadro 4. Ganancia de peso por periodo (kg/a/día) \pm error estándar de la media y eficiencia de conversión (EC)

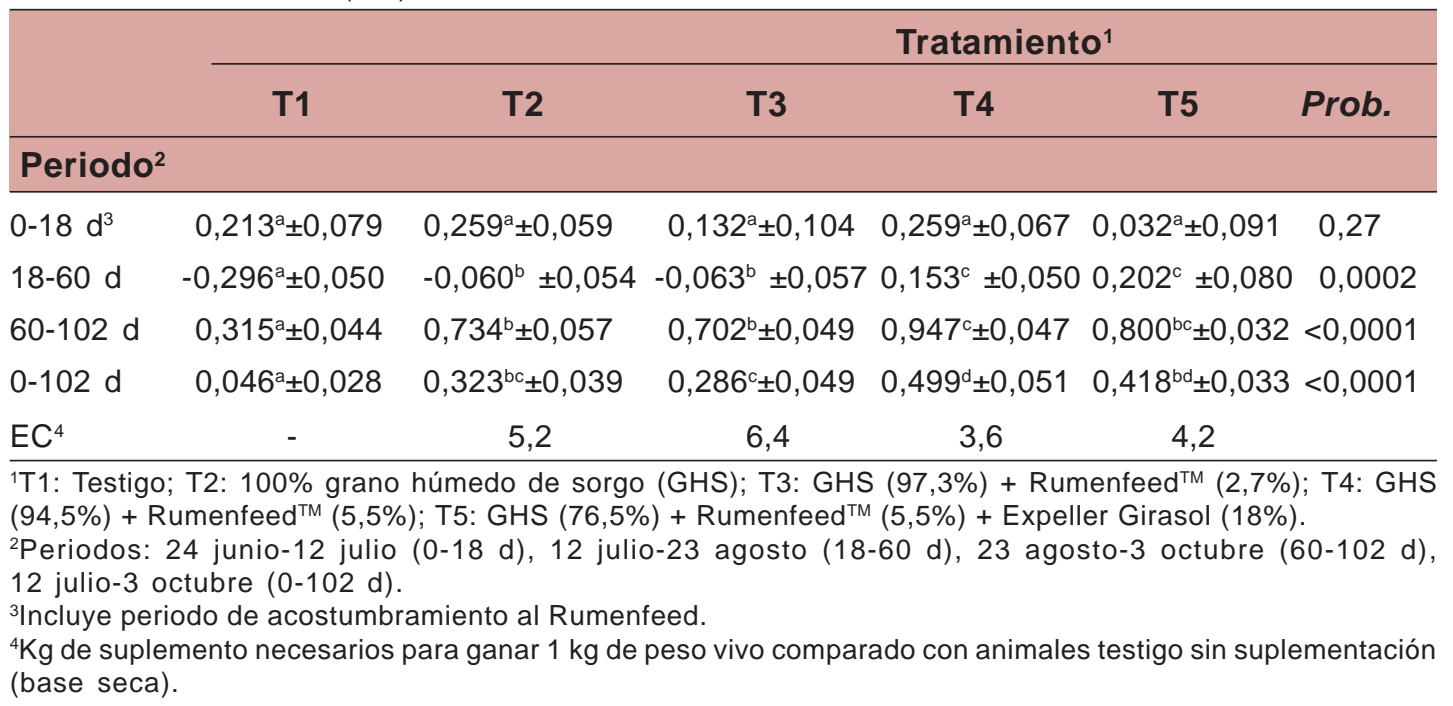


productos en que ofrecen una alternativa útil para reducir la inclusión de concentrados de proteína vegetal en las dietas de los rumiantes en un escenario de mayor demanda de productos vegetales para alimentación humana y biocombustibles (Martínez-Marín, 2009).

La eficiencia de conversión (kg de suplemento para ganar $1 \mathrm{~kg}$ de peso vivo adicional con respecto al grupo testigo) fue mejor en aquellos animales suplementados con niveles altos de proteína en el suplemento $(3,6$ y 4,2 para T4 y T5, respectivamente) comparado con los tratamientos T2 y T3 $(5,2$ y 6,4 ; respectivamente). Los valores de eficiencia de conversión se encuentran dentro del rango esperado para esta categoría animal. La utilización de fuentes de urea de liberación lenta no afectaría negativamente el crecimiento de vacunos, tal cual fue reportado por numerosos trabajos (Löest et al. 2001; Tedeschi et al. 2002; Wahrmund y Hersom 2007; Pinos-Rodríguez et al., 2010).

La Figura 5 muestra la curva de respuesta al agregado de proteína en el suplemento con niveles de suplementación de $1 \%$ del peso vivo para 3 periodos: $18-60 \mathrm{~d}, 60-102 \mathrm{~d}$ y 0-102 d. En primer lugar, la curva de respuesta que más ajustó para los 3 periodos fue de tipo polinomial con incrementos decrecientes en la ganancia de peso de los terneros a medida que el porcentaje de proteína se aproximó a los niveles más altos. El periodo de mayor respuesta fue el de $18-60 \mathrm{~d}$ con un coeficiente $\mathrm{R}^{2}$ muy alto de 0,99 ; presentando los otros 2 periodos coeficientes intermedios de 0,40 y 0,46 para 60-102 d y 0-102 d, respectivamente. La mayor respuesta al agregado de proteína en el suplemento en el periodo $18-60$ d se asoció al menor contenido de proteína del forraje y a la menor relación verde/seco del forraje en la primera mitad del experimento comparado con dichos valores en la segunda mitad del experimento.

La mayor ganancia de peso registrada en el tratamiento T4 (sorgo + Rumenfeed ${ }^{\mathrm{TM}} \mathrm{ni}-$ vel alto) confirma la habilidad de los microorganismos del rumen, incluso en categorías jóvenes como terneros, de utilizar eficientemente como fuente de proteína nitrógeno no proteico proveniente de urea. En las condiciones que se realizó el experimento, la principal limitante nutricional fue el contenido amoniacal en el rumen, por lo tanto existió una respuesta positiva al incremento del mismo más allá de la fuente proteica utilizada. En la medida que se mejora el aporte de proteína de la dieta probablemente se comience a registrar un efecto diferencial de la fuente o calidad de la proteína ofrecida.

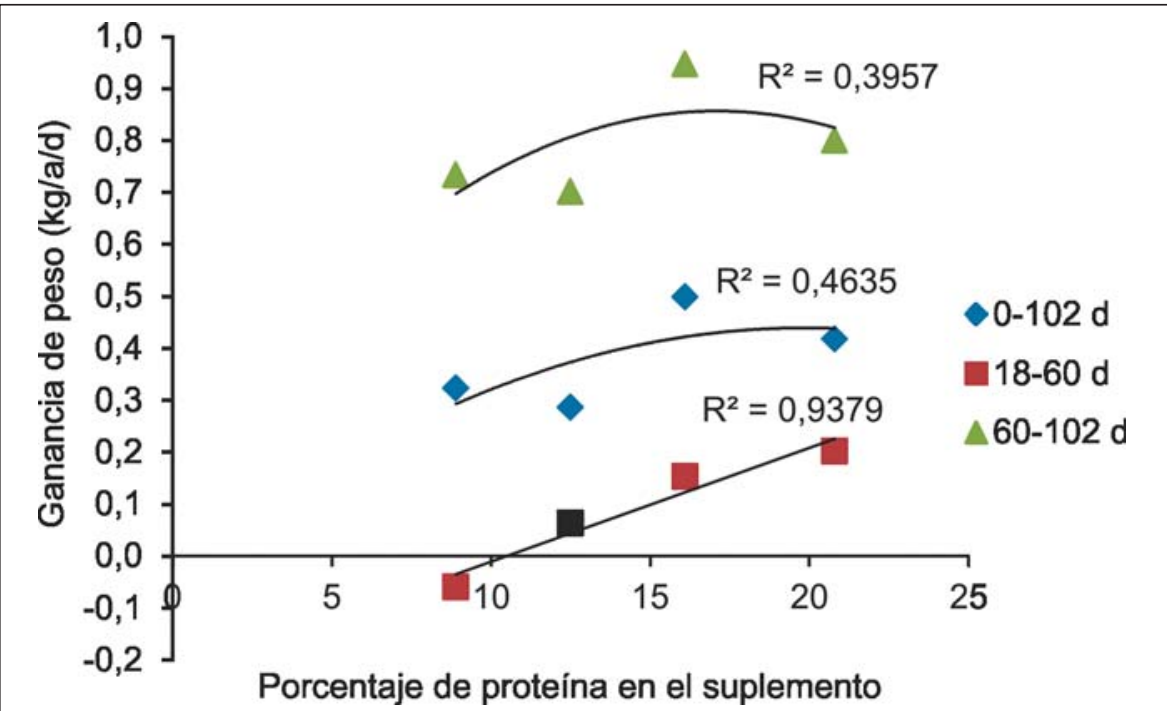

Figura 5. Relación entre ganancia de peso de los terneros y nivel de proteína en el suplemento ofrecido diariamente a $1 \%$ del peso vivo. 


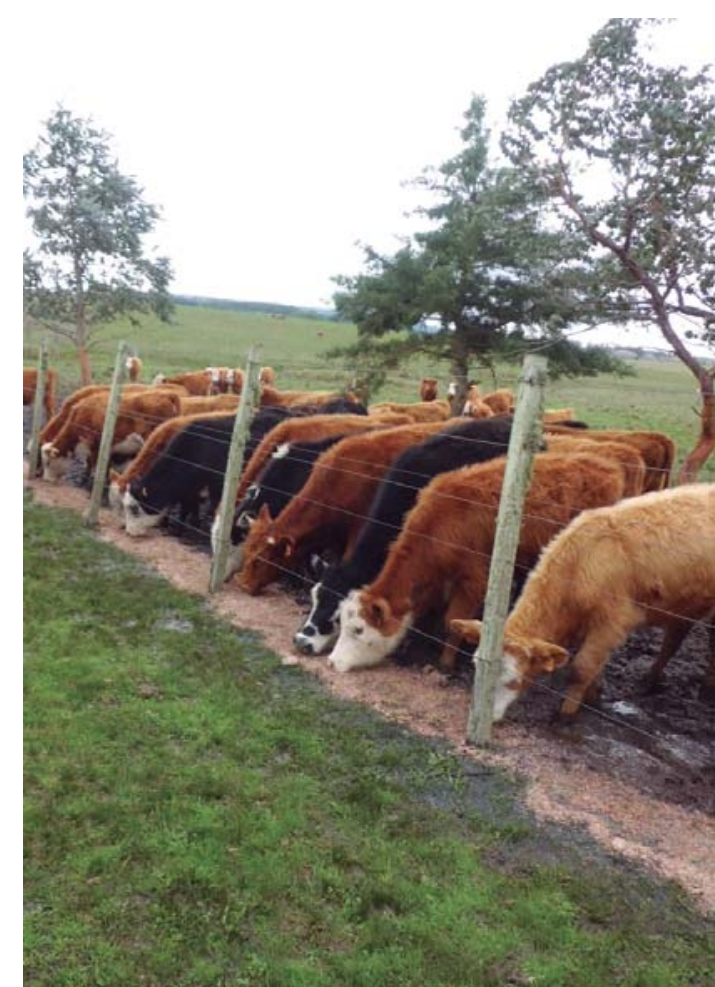

El uso de urea de liberación lenta es una alternativa válida para mezclar con grano húmedo de sorgo en esquemas de suplementación de terneros sobre campo natural.

\section{Registros de ultrasonido}

No existieron diferencias significativas $(P>0,05)$ en la evolución del área de ojo de bife (AOB) y del espesor de grasa subcutánea (EGS) a lo largo del periodo de evaluación (Cuadro 5). En el caso de AOB, el valor inicial y final promediando sobre tratamientos fue 24,4 y $28,0 \mathrm{~cm}^{2}$, respectivamente. Si bien al final del periodo hubo una diferencia numérica a favor de los tratamientos suplementados comparado con el testigo sin suplementación (28,4 y $26,6 \mathrm{~cm}^{2}$, respectivamente), la misma no resultó significativa $(P>0,05)$. La misma tendencia se observó en la variable EGS, la cual registró valores de $2,15 \mathrm{~mm}$ (inicio) y $2,24 \mathrm{~mm}$ (fin) promediando sobre tratamientos $(P>0,05)$. Al final del periodo los tratamientos suplementados tuvieron un engrasamiento numéricamente mayor comparado con el tratamiento testigo (2,28 y $2,07 \mathrm{~mm}$, respectivamente) $(P>0,05)$. La falta de efecto significativo de los tratamientos en los valores de AOB y EGS puede ser atribuido al corto periodo de tiempo del experimento, la categoría animal, el nivel de suplementación, el plano nutricional $y$ al nivel de ganancia de peso registrado, entre otros factores.

\section{Resultado económico}

La suplementación mejoró el margen bruto por animal comparado con el testigo sin suplementación (Cuadro 6). Concretamente, el tratamiento que combinó $94,5 \%$ grano húmedo de sorgo + 5,5 Rumenfeed ${ }^{\mathrm{TM}}$ fue el que obtuvo el mayor margen bruto, cercano a los 100 U\$S/animal en los 102 días de suplementación. A pesar del alto costo en términos absolutos (U\$S/tonelada) de la fuen-

Cuadro 5. Evolución del área de ojo de bife (AOB) y el espesor de grasa subcutánea (EGS) medidos por ultrasonido

\begin{tabular}{lcccccc}
\hline & \multicolumn{7}{c}{ Tratamiento $^{1}$} \\
\cline { 2 - 7 } & T1 & T2 & T3 & T4 & T5 & Prob. \\
\hline AOB $^{2}, \mathbf{c m}^{2}$ & \multicolumn{7}{c}{} \\
\hline Inicial & $24,7^{\mathrm{a}} \pm 3,7$ & $24,4^{\mathrm{a}} \pm 2,7$ & $23,9^{\mathrm{a}} \pm 3,9$ & $24,3^{\mathrm{a}} \pm 3,1$ & $24,6^{\mathrm{a}} \pm 3,1$ & 0,98 \\
Final & $26,6^{\mathrm{a}} \pm 2,0$ & $29,4^{\mathrm{a}} \pm 2,7$ & $27,1^{\mathrm{a}} \pm 5,4$ & $28,0^{\mathrm{a}} \pm 4,4$ & $29,1^{\mathrm{a}} \pm 3,6$ & 0,41 \\
EGS $^{2}, \mathrm{~mm}$ & & & & & & \\
Inicial & $2,02^{\mathrm{a}} \pm 0,38$ & $2,15^{\mathrm{a}} \pm 0,43$ & $2,25^{\mathrm{a}} \pm 0,38$ & $2,20^{\mathrm{a}} \pm 0,23$ & $2,12^{\mathrm{a}} \pm 0,41$ & 0,74 \\
Final & $2,07^{\mathrm{a}} \pm 0,45$ & $2,23^{\mathrm{a}} \pm 0,30$ & $2,31^{\mathrm{a}} \pm 0,13$ & $2,27^{\mathrm{a}} \pm 0,26$ & $2,32^{\mathrm{a}} \pm 0,18$ & 0,37 \\
\hline
\end{tabular}

${ }^{1}$ T1: Testigo; T2: 100\% grano húmedo de sorgo (GHS); T3: GHS (97,3\%) + Rumenfeed ${ }^{\mathrm{TM}}$ (2,7\%); T4: GHS $(94,5 \%)+$ Rumenfeed $^{\mathrm{TM}}(5,5 \%) ;$ T5: GHS $(76,5 \%)+$ Rumenfeed $^{\mathrm{TM}}(5,5 \%)+$ Expeller Girasol $^{(18 \%)}$. ${ }^{2}$ Valores ajustados por peso vivo (covariable). 
Cuadro 6. Análisis económico de la suplementación (Precios de referencia invierno 2011)

\begin{tabular}{|c|c|c|c|c|c|}
\hline & \multicolumn{5}{|c|}{ Tratamiento $^{1}$} \\
\hline & T1 & T2 & T3 & T4 & T5 \\
\hline Precio del suplemento ${ }^{2}$ (U\$S/ton) & - & 115 & 144 & 175 & 201 \\
\hline Costo diario suplementación ${ }^{3}$ (U\$S/a) & - & 0,17 & 0,22 & 0,29 & 0,31 \\
\hline Costo suplementación en 102 días (U\$S/a) & - & 17 & 22 & 30 & 32 \\
\hline Peso vivo agregado en 102 días $^{4}$ (kg/a) & 5 & 33 & 29 & 51 & 42 \\
\hline Valorización kg producidos (U\$S/a $)^{5}$ & 12 & 82 & 72 & 127 & 105 \\
\hline Margen Bruto (U\$S/a $)^{6}$ & 12 & 65 & 50 & 97 & 73 \\
\hline
\end{tabular}

${ }^{1}$ T1: Testigo; T2: 100\% grano húmedo de sorgo (GHS); T3: GHS (97,3\%) + Rumenfeed ${ }^{\mathrm{TM}}(2,7 \%)$; T4: GHS $(94,5 \%)+$ Rumenfeed $^{\mathrm{TM}}(5,5 \%) ;$ T5: GHS $(76,5 \%)+$ Rumenfeed $^{\mathrm{TM}}(5,5 \%)+$ Expeller Girasol $(18 \%)$

2Sorgo: 115 U\$S/ton; expeller de girasol 260 U\$S/ton, Rumenfeed ${ }^{\mathrm{TM}} 1200$ U\$S/ton. Mezclas según Cuadro 3. ${ }^{3}$ Según cantidades realmente suministradas (Cuadro 3).

${ }^{4}$ Según desempeño productivo real (Cuadro 4).

${ }^{5}$ Valor de referencia Asociación Consignatarios de Ganado setiembre 2009: 2,5 U\$S/kg.

${ }^{6}$ Valorización kg producidos-costo de la suplementación en 102 días.

te de nitrógeno de liberación lenta utilizada, tanto la pequeña proporción de la misma en la mezcla como la alta respuesta a la suplementación proteica permitieron obtener márgenes brutos positivos y altos.

\section{CONCLUSIONES}

Desde el punto de vista biológico la mejor eficiencia de conversión y mayor ganancia de peso se logró a través de la combinación de grano húmedo de sorgo $(94,5 \%)$ y Rumenfeed ${ }^{\mathrm{TM}}(5,5 \%)$ que resultó en una oferta de PC de $16 \%$ y una relación NDT/PC 4,7 en el suplemento ofrecido diariamente a razón de 1\% PV. Como estrategia de recomendación del producto Rumenfeed ${ }^{\mathrm{TM}}$ la dosis alta evaluada $(90 \mathrm{~g} / \mathrm{a} / \mathrm{d})$ superó en términos de respuesta animal a la dosis baja (42 g/a/ d). La mayor respuesta a la adición de proteína en el suplemento se registró en los primeros $60 \mathrm{~d}$ del ensayo, cuando las condiciones climáticas y las características de la pastura fueron más adversas. La incorporación de Rumenfeed ${ }^{\mathrm{TM}}$ como fuente de nitrógeno de liberación lenta al grano húmedo de sorgo es una alternativa válida para mejorar la ganancia de peso invernal de terneros suplementados sobre campo natural de lomadas del Este con predominancia de gramíneas estivales perennes.

\section{AGRADECIMIENTOS}

A la empresa Deribal S.A. por haber contribuido a la realización del presente experimento.

\section{BIBLIOGRAFÍA}

CASTAÑEDA-SERRANO, R.D.; FERRIANIBRANCO, A.; TEIXEIRA, S.; GARCÍA-DÍAZ T; DIEGO-SOFIATI, A. 2013. Urea de liberación lenta en dietas para bovinos productores de carne: digestibilidad, síntesis microbiana y cinética ruminal. Agrociencia 47, 13-24.

BENÍTEZ, S.; CUNHA, F.; FERNÁNDEZ, G. 2011. Efecto de la sustitución de proteína verdadera por nitrógeno no proteico en el desempeño productivo de terneros suplementados con grano húmedo de sorgo sobre campo natural. Tesis de Grado Facultad de Veterinaria, Universidad de la República.

LÖEST, C.A.; TITGEMEYER, E.C.; DROUILLARD, J.S.; LAMBERT, B.D.; TRATER, A.M.; 2001. Urea and biuret as nonprotein nitrogen sources in cooked molasses blocks for steers fed prairie hay. Animal Feed Science and Technology 94:115-126.

MARTÍNEZ MARÍN, A.L. 2009. Urea de lenta degradación ruminal como sustituto de proteína vegetal en dietas para rumiantes. Revista Electrónica de Veterinaria 10 (12): 120906. 
PINOS-RODRÍGUEZ, J.M.; PEÑA, L.Y.; GONZÁLEZ-MUÑOZ, S.S.; BÁRCENA, R.; SALEM, A. 2010. Effects of a slowrelease coated urea product on growth performance and ruminal fermentation in beef steers. Italian Journal of Animal Science.

ROVIRA, P.; VELAZCO, J. 2010 Efecto del agregado de fuentes proteicas al grano húmedo de sorgo en el crecimiento de terneros suplementados sobre campo natural. En: Jornada de Divulgación, Ensilaje de Grano Húmedo de Sorgo. INIA. Actividades de Difusión No 604. pp.14-21.

SATTER, L.D.; ROFFLER, R.E. 1975. Nitrogen requirement and utilization in dairy cattle. J. Dairy Sci. 58: 1219-37.
SOUZA, V. L.; ALMEIDA, R.; SILVA D. F. F.; PIEKARSKI, P.R.B.; JESUS, C.P.; PEREIRA, E.M.N. 2010. Substituição parcial de farelo de soja por ureia protegida na produção e composição do leite. Arq. Bras. Med. Vet. Zootec. 62: 1415-1422.

TEDESCHI, L.O.; BAKER, M.J.; KETCHEN, D. J.; FOX, D. G. 2002. Performance of growing and finishing cattle supplemented with a slow-release urea product and urea. Canadian Journal of Animal Science 82:567-573.

WAHRMUND, J.L.; HERSOM, M.J. 2007. Evaluation of dried distillers grains or soybean hulls with and without Optigen II ${ }^{\circledR}$ to background beef calves. Journal of Animal Science 85 (Suppl. 1), 410. 


\section{EFECTO DE LA ADICIÓN DE UREA AL GRANO HÚMEDO DE SORGO EN EL DESEMPEÑO PRODUCTIVO DE NOVILLOS SUPLEMENTADOS SOBRE CAMPO NATURAL}

P. Rovira ${ }^{1}$

\section{RESUMEN}

El objetivo del experimento fue evaluar el efecto de la suplementación diaria al $1 \%$ del peso vivo (PV) con grano húmedo de sorgo (GHS) más el agregado de urea en el desempeño de novillos sobre campo natural en otoño-invierno. Treinta y dos novillos $(290 \pm 39 \mathrm{~kg})$ fueron asignados al azar en 4 tratamientos con 2 repeticiones: testigo sin suplementación (T) y suplementación con 100\% GHS sin urea (U0); 98,6\% GHS+1,4\% urea (U1); y $97,2 \%$ GHS+2,8\% urea (U2). La concentración de proteína fue 9,9\% en la pastura y $11,1 \%(\mathrm{U} 0) ; 14,9 \%$ (U1) y $18,7 \%$ (U2) en los suplementos. El campo natural

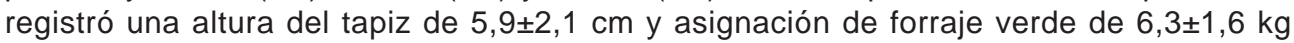
MS/100 kg PV/día. En todo el periodo (114 d) los animales suplementados registraron una ganancia de peso significativamente mayor que aquellos testigo (554 y $238 \mathrm{~g} / \mathrm{a} / \mathrm{d}$ ) no existiendo diferencias significativas entre los tratamientos suplementados (493, 550 y $618 \mathrm{~g} / \mathrm{a} / \mathrm{d}$; U0, U1 y U2, respectivamente). La respuesta animal al agregado de urea fue significativa en el periodo $58-114$ d $(283,422$ y $477 \mathrm{~g} / \mathrm{a} / \mathrm{d}$; U0, U1 y U2, respectivamente). En dicho periodo la eficiencia de conversión (kg MS suplemento/kg PV adicional) mejoró de 8,2 (U0) a 5,8 (U2). El área de ojo de bife y espesor de grasa de los animales no fueron afectados por la suplementación. La suplementación con grano húmedo de sorgo mejoró el desempeño de los animales. La adición de urea al grano húmedo de sorgo se justificó cuando la calidad del forraje disminuyó debido al incremento de restos secos.

Palabras clave: novillos, suplementación, sorgo, urea

ABSTRACT

The objective of the experiment was to evaluate the performance of yearling steers grazing natural pastures during autumn and winter supplemented with high moisture sorghum grain $(H M S G)$ plus different levels of urea. Thirty-two steers $(290 \pm 39 \mathrm{~kg})$ were randomly assigned to 4 treatments with 2 replicates: control without supplementation (C) and daily supplementation at 1\% of body weight (BW) with 100\% HMSG without urea (U0); 98.6\% HMSG+1.4\% urea (U1); and 97.2\% HMSG+2.8\% urea (U2). Pasture crude protein concentration was $9.9 \%$ and the supplements had $11.1 \%$ (U0); $14.9 \%$ (U1) and $18.7 \%$ (U2). Sward height and green forage allowance averaged $5.9 \pm 2.1 \mathrm{~cm}$ and $6.3 \pm 1.6$ $\mathrm{kg}$ dry matter/100 kg BW/day, respectively, over the 114 days of the study. Overall average daily gain of supplemented animals $(554 \mathrm{~g} / \mathrm{a} / \mathrm{d})$ was significantly higher than unsupplemented animals $(238 \mathrm{~g} / \mathrm{a} / \mathrm{d})$ without differences among supplemented treatments (493, 550 and $618 \mathrm{~g} / \mathrm{a} / \mathrm{d}$; U0, U1 y U2, respectively). Animal response to urea was significant between the 58 and $114 \mathrm{~d}$ of the study $(283,422$ and $477 \mathrm{~g} / \mathrm{a} / \mathrm{d}$; U0, U1 y U2, respectively) where the efficiency of conversion of the supplement $(\mathrm{kg}$ of supplement required to gain $1 \mathrm{~kg}$ additional of BW compared with the control group) improved from $8.2(\mathrm{U} 0)$ to $5.8(\mathrm{U} 2)$. Ultrasound measures of rib eye area and fat depth were not affected by treatments. Supplementation with HMSG improved animal performance during autumn-winter. The addition of urea had a significant impact on animal performance during the second half of the study where forage quality decreased due to an increase of dead and dry forage.

Key words: steers, supplementation, sorghum, urea 


\section{INTRODUCCIÓN}

La producción de carne bovina en Uruguay tradicionalmente ha estado basada en sistemas pastoriles sobre campo natural con disponibilidad y calidad de forraje variable según la época del año. Novillos en crecimiento sobre pasturas naturales durante el otoño e invierno pueden sufrir deficiencias de energía y/o proteína en el forraje ofrecido. La suplementación puede ser una herramienta válida para mejorar la ganancia de peso de dichos animales y prepararlos mejor para la siguiente etapa de engorde y terminación. La suplementación con concentrados energéticos, principalmente grano de sorgo, es la alternativa más difundida debido a la expansión del área del cultivo en zonas ganaderas. Sin embargo, el consumo y digestibilidad del forraje puede disminuir y por lo tanto afectar el desempeño esperado de los animales cuando se utilizan granos con alto contenido de almidón y bajo nivel de proteína sobre pasturas de baja calidad (Horn y McCollum, 1987; Bowman y Sanson, 1996; Caton y Dhuyvetter, 1997). En dichas condiciones, la adición de una fuente de proteína de rápida degradación ruminal en conjunto con el grano, puede mejorar la utilización del forraje y la respuesta animal (Olson y col 1999; Bodine y col, 2000, 2001; Bodine y Purvis, 2003).

El objetivo del presente experimento fue evaluar el efecto de la suplementación con grano húmedo de sorgo con el agregado de distintos niveles de urea en el desempeño productivo de novillos en pastoreo sobre campo natural de mediana a baja calidad.

\section{MATERIALES Y MÉTODOS}

El experimento se desarrolló entre el 10 de abril y 2 de agosto de 2012 (114 días) en el Instituto Nacional de Investigación Agropecuaria (INIA) en la localidad de Treinta y Tres, región este del Uruguay (latitud $33^{\circ} 14^{\prime}$ S, longitud: $54^{\circ} 15^{\prime} \mathrm{O}$ ). El manejo y procedimientos aplicados sobre los animales fueron aprobados por el Comité de Ética del Programa de Producción de Carne y Lana de INIA. El diseño experimental consistió en bloques completamente al azar con cuatro tratamientos y dos repeticiones. Treinta y dos novillos de $1 \frac{1}{2} 2$ años cruza Hereford $x$ Aberdeen Angus con peso vivo (PV) inicial \pm desvío estándar (DE) de 289 $\pm 34 \mathrm{~kg}$ fueron asignados al azar en cuatro tratamientos (4 novillos/repetición): 1) testigo sin suplementación $(T), 2$ ) suplementación con $100 \%$ grano húmedo de sorgo (GHS), 3) suplementación con $98,6 \%$ GHS $+1,4 \%$ urea (U1), 4) suplementación con $97,2 \%$ GHS + 2,8\% urea (U2). El sistema de pastoreo fue continuo a una dotación de 1,6 animales por hectárea sobre campo natural dominado por especies nativas de crecimiento estival. El suministro de suplemento fue diario al $1 \%$ del peso vivo (PV) en base seca (BS). El GHS fue cosechado con $29 \%$ de humedad, quebrado y almacenado en ausencia de aire en una bolsa de silo (60 m de largo) la cual se mantuvo herméticamente cerrada durante 30 días previo al inicio de la suplementación. La composición del GHS (BS) fue: 11,1\% proteína cruda (PC); 12,1\% fibra detergente ácido (FDA); 15,8\% fibra detergente neutro (FDN); $1,9 \%$ cenizas (C). La urea utilizada fue de uso agrícola con $46 \%$ de nitrógeno equivalente a un potencial de $281 \%$ PC sintética. De acuerdo a la composición de los suplementos el nivel de PC y energía metabolizable (EM) presente en la mezcla ofrecida diariamente al 1\% PV en los tratamientos correspondientes fue $11,1 \%$ PC y $3,10 \mathrm{Mcal}$ $\mathrm{EM} / \mathrm{kg}$ MS (GHS); 14,9\% PC y $3,06 \mathrm{Mcal}$ $\mathrm{EM} / \mathrm{kg} \mathrm{MS}$ (GHS+U1); $18,7 \%$ PC y $3,01 \mathrm{Mcal}$ $\mathrm{EM} / \mathrm{kg} \mathrm{MS}$ (GHS+U2). Las distintas mezclas de suplemento ofrecidas fueron consideradas iso-energéticas variando el nivel de PC. La urea fue mezclada manualmente con el GHS al momento de extracción de la bolsa de silo, correspondiendo una cantidad promedio de 45 y $90 \mathrm{~g} / \mathrm{a} / \mathrm{d}$ en los tratamientos $\mathrm{GHS}+\mathrm{U} 1$ y GHS+U2, respectivamente. Catorce días previo al inicio del experimento existió un periodo de acostumbramiento de los animales a la rutina de suplementación en donde las cantidades de GHS y urea ofrecidos por animal se fueron incrementando gradualmente hasta llegar al nivel objetivo de 1\% PV. 
La disponibilidad de forraje ( $\mathrm{kg} \mathrm{MS} / \mathrm{ha}$ ) y altura del tapiz $(\mathrm{cm})$ fueron registrados en cada repetición cada 28 días a través del corte al ras del suelo de 10 rectángulos $\left(0,1 \mathrm{~m}^{2}\right)$. Las muestras de forraje fueron colocadas en estufas a $60^{\circ} \mathrm{C}$ durante 48 horas para estimar $\%$ MS y disponibilidad de forraje. Al inicio y fin del periodo experimental se analizó el valor nutritivo del forraje ofrecido mediante la aplicación de técnicas estándar en el Laboratorio de Nutrición Animal de INIA La Estanzuela (Fassio et al. 2009). Los animales fueron pesados sin previo ayuno cada 14 días para ajustar la cantidad de suplemento ofrecido. El peso vivo vacío (12 horas de ayuno) fue registrado cada 14 días para estimar la ganancia de peso diaria (kg/a/día) mediante la regresión lineal del peso vivo en el tiempo. La eficiencia de conversión del suplemento (ECS) a peso vivo fue calculada como los $\mathrm{kg}$ de suplemento (BS) necesarios para depositar $1 \mathrm{~kg}$ de peso vivo adicional comparado con el desempeño productivo del grupo de animales testigo sin suplementación. Al inicio y fin del periodo experimental se registró el área de ojo de bife $\left(A O B, \mathrm{~cm}^{2}\right)$ y espesor de grasa dorsal (EG, $\mathrm{mm}$ ) a nivel del músculo Longissimus dorsi entre la $12^{\mathrm{a}}$ y $13^{\mathrm{a}}$ costilla mediante el uso de un aparato de ultrasonido.
Las variables de pasturas y producción animal fueron sometidas a análisis de varianza considerando el efecto principal del tratamiento utilizando el paquete estadístico SAS versión 9.12 (SAS Institute, Cary, NC, USA). La unidad experimental fue el grupo de cuatro animales en cada repetición. Las medias de los tratamientos fueron comparadas mediante el test de Tukey cuando el valor de $F$ fue significativo $(P<0,05)$.

\section{RESULTADOS}

Existió una diferencia significativa en la disponibilidad de forraje $(P<0,05)$, en donde los tratamientos T y GHS+U2 $(2477 \pm 500 \mathrm{~kg}$ $\mathrm{MS} / \mathrm{ha}$ ) registraron un mayor registro comparado con los tratamientos GHS GHS+U0 y GHS+U1 (1717 \pm 299 kg MS/ha). Dicha diferencia fue atribuida a distintos niveles de disponibilidad de forraje al inicio del experimento, diferencia que se mantuvo en las distintas fechas de muestreo (Figura 1). La evolución del forraje disponible registró la misma tendencia en todos los tratamientos con un incremento hacia el final del periodo experimental. Como consecuencia de los distintos valores de disponibilidad, la asignación de forraje ( $\mathrm{kg} \mathrm{MS}$ total/día/100 kg de peso

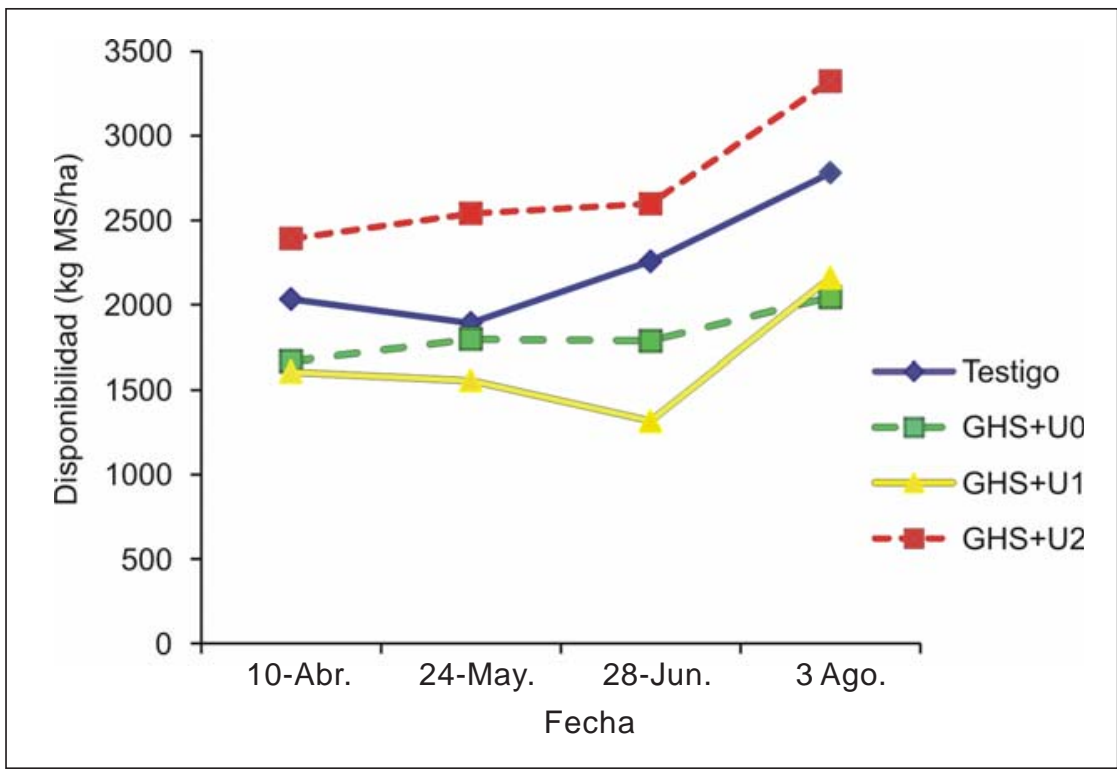

Figura 1. Evolución del forraje disponible por tratamiento. GHS: grano húmedo de sorgo; U0, U1, U2: urea 0; 1,4 y 2,8\% del suplemento ofrecido diariamente. 
vivo) fue mayor en los tratamientos $\mathrm{T} y$ GHS+U2 $(11,9 \pm 2,4)$ comparado con el promedio de los tratamientos GHS GHS+U0 y GHS+U1 $(8,3 \pm 1,0)(P<0,05)$. Sin embargo no existieron diferencias significativas $(P>0,05)$ entre tratamientos en la asignación de forraje verde promediando $6,3 \pm 1,6 \mathrm{~kg}$ MS de forraje verde/día/100 kg de peso vivo.

No se registraron diferencias significativas $(P>0,05)$ entre tratamientos en las variables altura del tapiz $(5,9 \pm 2,1 \mathrm{~cm})$, disponibilidad de forraje verde $(1104 \pm 481 \mathrm{~kg} \mathrm{MS} / \mathrm{ha})$ y disponibilidad de forraje seco $(993 \pm 671 \mathrm{~kg}$ $\mathrm{MS} / \mathrm{ha}$ ). En las primeras dos fechas de muestreo los restos secos representaron un $23 \%$ del forraje disponible mientras que en la segunda mitad del experimento los restos secos aportaron un $67 \%$ del forraje disponible (Figura 2). Dicho incremento se debió a un efecto combinado de presencia de especies forrajeras de crecimiento estival en estado de madurez llegando al fin de su ciclo (Paspalum notatum, Axonopus affinis, Cynodon dactylon) y a temperaturas por debajo de $0^{\circ} \mathrm{C}$ registradas a nivel de césped (heladas agrometeorológicas). Datos obtenidos en la estación meteorológica de la Unidad Experimental Paso de la Laguna (INIA Treinta y Tres) registraron 2, 2, 12 y 21 días con heladas agrometeorológicas en abril, mayo, junio y julio de 2012, respectivamen- te. El valor nutritivo de la fracción seca expresado a través de los valores de PC $(7,6 \pm 1,2 \%)$, FDA $(52,0 \pm 2,5 \%)$ y FDN $(69,8 \pm 0,9)$ fue menor comparado con la fracción verde del forraje disponible $(12,2 \pm 1,3 \%$ PC; $39,1 \pm 3,5 \%$ FDA; $61,7 \pm 8,5 \%$ FDN). El valor nutritivo del forraje ofrecido fue $52,3 \pm 2,6 \%$ digestibilidad MS (DMS), $55,1 \%$ nutrientes digestibles totales (NDT), $9,9 \pm 1,0 \%$ (PC), 47,0 $\pm 3,3 \%$ (FDA) y $65,0 \pm 2,9 \%$ (FDN) promediando sobre dos fechas de análisis.

No existieron diferencias significativas en peso vivo inicial y peso vivo final entre tratamientos $(P>0,05)$, aunque numéricamente los animales suplementados fueron $10 \%$ más pesados al final del experimento comparado con los animales sin suplementación (357 y $324 \mathrm{~kg}$, respectivamente) (Cuadro 1). De forma similar, no existieron diferencias significativas $(P=0,08)$ entre tratamientos en la ganancia de peso para el total del periodo (0-114 d) aunque existió diferencia significativa cuando se contrastó la ganancia de peso del grupo de animales testigo ( $238 \mathrm{~g} / \mathrm{a} / \mathrm{d})$ con el registro promedio de los tres grupos suplementados $(554 \mathrm{~g} / \mathrm{a} / \mathrm{d})(\mathrm{P}=0,04)$. Dicha diferencia en ganancia de peso se definió en el periodo 58-114 d del experimento, coincidente con las condiciones climáticas y forrajeras más limitantes, en donde los ani-

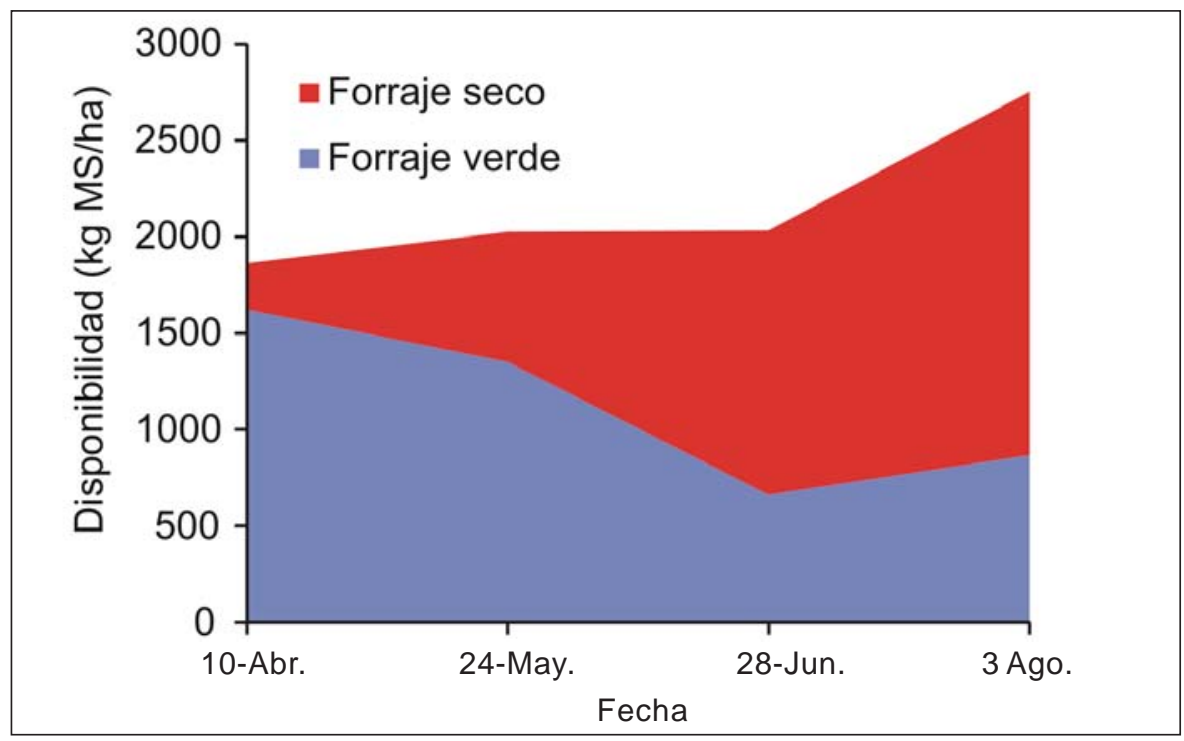

Figura 2. Evolución de la fracción verde y seca del forraje disponible (promedio sobre tratamientos). 
Cuadro 1. Efecto de la suplementación diaria al 1\% del peso vivo con grano húmedo de sorgo (GHS) y distintos niveles de urea (U0, U1, U2) en el desempeño productivo de novillos en pastoreo sobre campo natural

\begin{tabular}{lcccc}
\hline & \multicolumn{4}{c}{ Tratamientos $^{1}$} \\
\cline { 2 - 5 } & Testigo & GHS+U0 & GHS+U1 & GHS+U2 \\
\hline Peso inicial, kg & $291^{\mathrm{a}} \pm 39$ & $290^{\mathrm{a}} \pm 40$ & $290^{\mathrm{a}} \pm 37$ & $291^{\mathrm{a}} \pm 40$ \\
Peso final, kg & $324^{\mathrm{a}} \pm 40$ & $350^{\mathrm{a}} \pm 31$ & $359^{\mathrm{a}} \pm 25$ & $362^{\mathrm{a}} \pm 25$ \\
Consumo, kg MS/a/d & & & & \\
Grano húmedo sorgo & - & 3,40 & 3,39 & 3,37 \\
Urea & - & - & 0,045 & 0,090 \\
Ganancia de peso, g/a/d & & & & \\
0-58 d & $731^{\mathrm{a}} \pm 26$ & $771^{\mathrm{a}} \pm 124$ & $762^{\mathrm{a}} \pm 179$ & $863^{\mathrm{a}} \pm 54$ \\
58-114 d & $-148^{\mathrm{a}} \pm 32$ & $283^{\mathrm{a}} \pm 43$ & $422^{\mathrm{b}} \pm 25$ & $477^{\mathrm{c}} \pm 68$ \\
0-114 d & $238^{\mathrm{a}} \pm 36$ & $493^{\mathrm{a}} \pm 107$ & $550^{\mathrm{a}} \pm 137$ & $618^{\mathrm{a}} \pm 126$ \\
Eficiencia de conversión & & & & \\
0-58 d & - & 81,8 & 106,7 & 23,2 \\
58-114 d & - & 8,2 & 6,3 & 5,8 \\
0-114 d & - & 13,3 & 11,0 & 9,1 \\
Área de ojo de bife inicial $\left(\mathrm{cm}^{2}\right)$ & $43,6^{\mathrm{a}} \pm 2,3$ & $46,9^{\mathrm{a}} \pm 5,1$ & $41,9^{\mathrm{a}} \pm 4,7$ & $43,9^{\mathrm{a}} \pm 3,6$ \\
Área de ojo de bife final $\left(\mathrm{cm}^{2}\right)$ & $47,7^{\mathrm{a}} \pm 3,0$ & $53,1^{\mathrm{a}} \pm 4,7$ & $49,1^{\mathrm{a}} \pm 3,7$ & $49,9^{\mathrm{a}} \pm 2,8$ \\
Espesor de grasa inicial $\left(\mathrm{mm}^{2}\right)$ & $3,08^{\mathrm{a}} \pm 0,40$ & $2,32^{\mathrm{a}} \pm 0,40$ & $2,77^{\mathrm{a}} \pm 0,67$ & $2,38^{\mathrm{a}} \pm 0,13$ \\
Espesor de grasa final $\left(\mathrm{mm}^{2}\right.$ & $2,85^{\mathrm{a}} \pm 0,1$ & $3,31^{\mathrm{a}} \pm 0,59$ & $3,11^{\mathrm{a}} \pm 0,68$ & $2,80^{\mathrm{a}} \pm 0,29$ \\
\hline
\end{tabular}

a,b $\mathrm{b}$ etras diferentes en una misma fila diferencia significativa $(\mathrm{P}<0,05)$.

${ }^{1}$ GHS+U0: $100 \%+0 \%$; GHS+U1: $98,6 \%+1,4 \%$; GHS+U2: $97,2 \%+2,8 \%$.

${ }^{2} \mathrm{~kg}$ de suplemento necesarios para ganar $1 \mathrm{~kg}$ de peso vivo adicional comparado con el tratamiento testigo.

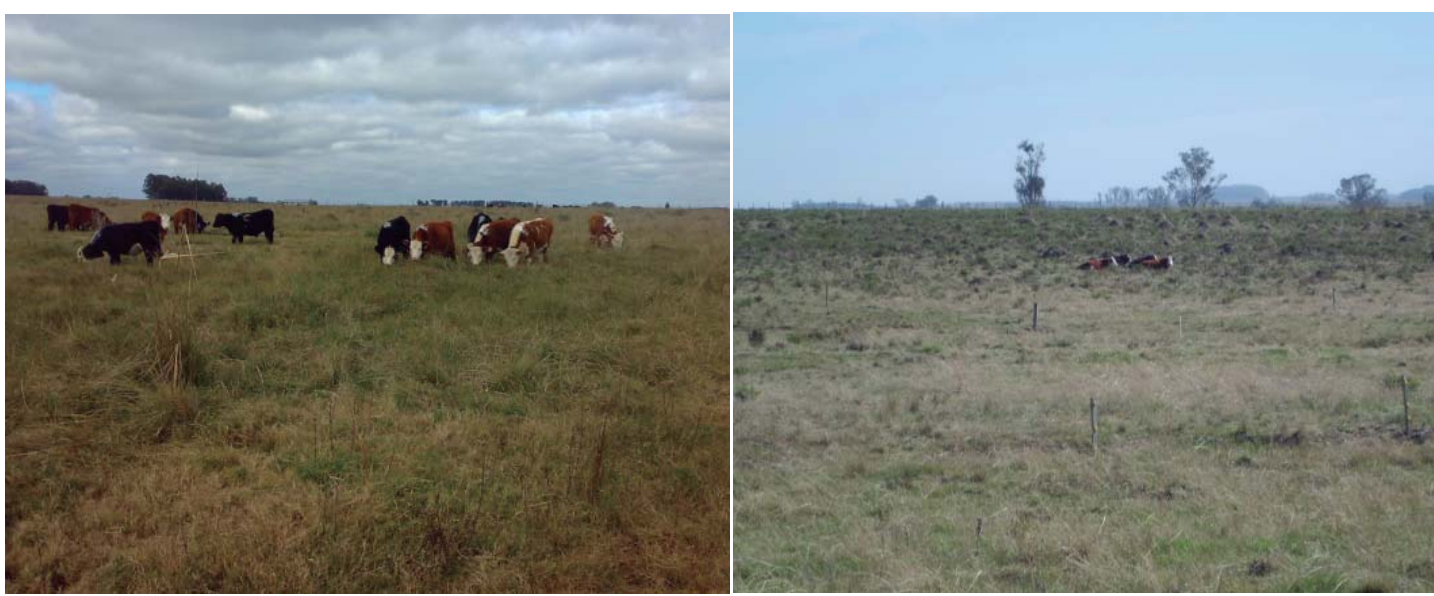

El agregado de urea al grano húmedo de sorgo mejoró el crecimiento y eficiencia de conversión de novillos cuando la proporción de restos secos del campo natural superó el 50\% del forraje disponible total. 
males suplementados registraron un desempeño productivo significativamente mejor que aquellos sin suplementación (394 y -148 g/ $\mathrm{a} / \mathrm{d}$, respectivamente). Como consecuencia, en dicho periodo la eficiencia de conversión del suplemento se encontró en el rango 5,8$8,2 \mathrm{~kg}$ de suplemento por $\mathrm{kg}$ peso vivo adicionado acorde a lo esperado para la categoría de novillos, lo que contrasta con la peor eficiencia de conversión registrada en el periodo 0-58 d coincidente con altas ganancias de peso en todos los tratamientos $(P>0,05)$, incluyendo el grupo testigo sin suplementación.

El área de ojo de bife y espesor de grasa inicial fueron $44,0 \pm 3,6 \mathrm{~cm}^{2}$ y $2,64 \pm 0,47 \mathrm{~mm}$, respectivamente $(P>0,05)$. Para ambas variables no se registraron diferencias significativas entre tratamientos al final del periodo experimental, correspondiendo valores de $50,0 \pm 3,4 \mathrm{~cm}^{2}$ y $3,02 \pm 0,42 \mathrm{~mm}$, respectivamente.

\section{DISCUSIÓN}

Si bien existieron diferencias significativas en la disponibilidad de pasturas al inicio del experimento; la tendencia de evolución del forraje total y la asignación de forraje verde por animal $(6,3 \mathrm{~kg} \mathrm{MS} / 100 \mathrm{~kg}$ peso vivo/ día) fueron similares entre tratamientos. $\mathrm{La}$ baja altura del tapiz $(<6 \mathrm{~cm})$ determinó limitantes de accesibilidad del forraje disponible comprometiendo el desempeño productivo (Prigge y col., 1997; Spörndly y col., 2000). Adicionalmente, durante la segunda mitad del periodo experimental se registró un predominio de restos secos aportando más del $50 \%$ del forraje ofrecido lo que repercutió en la calidad de la pastura (65\% FDN). Limitaciones impuestas por la digestibilidad del forraje y la capacidad ruminal pueden afectar negativamente el consumo voluntario en pastoreo (Forbes, 1988; Hodgson, 1990; Jacobo y col., 2011). Mertens (1987) propuso que el consumo diario de FDN representa aproximadamente $1,2 \%$ del peso vivo, relación utilizada como predicción del potencial de consumo de forraje (Coleman, 2005). En el presente experimento el consumo estimado de forraje de los animales sin suplementación fue 5,7 kg MS/a/día (1,84\% del peso vivo) representando un aporte diario de $560 \mathrm{~g}$ de proteína cruda por animal. Dicho nivel de proteína sería suficiente para garantizar una ganancia de peso en el rango de 200 a 400 g/a/día (NRC, 1984), coincidente con el valor real registrado en el experimento (238 g/a/día).

En las condiciones pastoriles mencionadas existió una respuesta significativa a la suplementación que permitió mejorar el desempeño productivo de los animales comparado con aquellos sin acceso a suplementación (554 y 238 g/a/d, respectivamente). El efecto positivo de la suplementación no sólo debe ser analizado en términos de ganancia de peso sino también en un contexto global de utilización de los recursos alimenticios. Una alta dotación durante el periodo otoño-invernal, cuando disminuye la cantidad y calidad de forraje, permite incrementar la utilización del forraje durante la primavera siguiente, estación de máximo crecimiento de las pasturas (Rearte y Pieroni, 2001; Rovira, 2012a). La mejora en la ganancia de peso de los animales suplementados se debió a un incremento en el consumo de energía digestible en el total de la dieta, a pesar de que el consumo de forraje puede disminuir cuando se utilizan granos energéticos como principal fuente de suplementación (Lamb y Eadie, 1979; Chase y Hibberd, 1987; Sanson y col., 1990; Moore y col., 1999). Cuando el nivel diario de consumo de forraje está por encima de 1,75\% del peso vivo, la suplementación tiende a disminuir la ingesta de forraje (Moore y col 1999). De acuerdo a las estimaciones previamente realizadas el consumo de forraje del grupo de animales sin suplementación habría estado levemente por encima de dicho valor, por lo que la suplementación energética pudo haber disminuido levemente la tasa de consumo de forraje.

No se encontró una respuesta significativa en el desempeño productivo de los animales a la adición de urea al GHS si bien numéricamente los animales suplementados con urea registraron una ganancia de peso $18 \%$ superior que aquellos animales suplementados únicamente con GHS (584 y $493 \mathrm{~g} / \mathrm{a} / \mathrm{d}$, respectivamente). La suplementación proteica es necesaria para optimizar la producción en rumiantes con- 
sumiendo forrajes de baja calidad (Bohnert y col., 2002; Moss y col., 2003). La mejora en el desempeño productivo se debe a un incremento de la concentración de amonio en el rumen resultando en un ambiente ruminal más favorable para el crecimiento de los microorganismos y en una mayor utilización del forraje ofrecido (DelCurto y col., 1990; Ludden y col., 1995, Koster y col., 1996). Holderbaum y col. (1991) evaluaron un suplemento basado en maíz y urea en la ganancia de peso de novillos (340 kg) sobre una pastura con bajo contenido de proteína cruda (6,9\% PC). En dicha experiencia, novillos suplementados con maíz más dos niveles de urea (27 y $116 \mathrm{~g} / \mathrm{a} / \mathrm{d}$ ) registraron una ganancia de peso promedio de 558 g/a/día, sin diferencias significativas entre tratamientos pero significativamente superior a la ganancia registrada por novillos sin acceso a suplementación $(289 \mathrm{~g} / \mathrm{a} / \mathrm{d})$. En el presente experimento no hubo diferencias significativas en el desempeño productivo de los animales entre los distintos niveles de urea adicionados al grano húmedo de sorgo. Considerando el nivel de proteína de la pastura y el grano de sorgo $(9,9$ y $11,1 \%$, respectivamente), y la proporción de cada alimento en la dieta total (2/3 y $2 / 3$, respectivamente), el contenido promedio de proteína cruda ofrecido fue $10,3 \%$, cercano al $11 \%$ estimado como óptimo para el crecimiento microbiano en el rumen (Pathak, 2008). Por tal motivo la respuesta animal a la adición de urea fue marginal comparado con el suministro único de grano de sorgo.

Moore y col. $(1995,1999)$ sintetizaron la información de un gran número de publicaciones científicas referidas a la suplementación proteica de bovinos sobre pasturas templadas y tropicales, y encontraron que los forrajes con una relación NDT:PC $\geq 7,0$ son los que contienen un nivel de proteína marginal relativo a la energía por lo que es de esperar una respuesta positiva a la suplementación proteica. En el presente experimento, la relación NDT:PC fue $5,6(55,1: 9,9)$ lo que explica la ausencia significativa de respuesta a la suplementación proteica. Resultados similares obtuvieron Brown y Adjei (2001) quiénes no registraron efecto de la suplementación con urea en novillos pasto- reando una pastura con una relación digestibilidad de la materia orgánica (DMO):PC entre 6,5 y 8,1 . Según Pitts y col (1992) cuando el forraje contiene al menos 7\% PC no habría una respuesta consistente a la suplementación proteica al no mejorar significativamente el consumo y digestión del forraje.

Una eficiencia de conversión (EC) del suplemento superior a 8:1, como la registrada en promedio durante los 114 días del experimento en los tres tratamientos con suplementación (11:1), es indicador de sustitución de forraje por suplemento y/o de utilización ineficiente de los nutrientes suministrados (Bodine y Purvis, 2003). Cuando se agregó urea al GHS se registró una mejora en la EC del suplemento pasando de 13,3:1 (GHS) a 9,1:1 (GHS+U2) debido al aporte de nitrógeno rápidamente disponible en el rumen incrementando la síntesis de proteína microbiana. La EC fue variable a lo largo del periodo experimental. Los novillos convirtieron el suplemento en ganancia de peso mejor en el periodo 58-114 d (6,8:1) comparado con el periodo 0-58 d (70,6:1), indicando una deficiencia de energía y nitrógeno puntual durante la segunda mitad del experimento cuando las características de la base forrajera fueron más limitantes. Si bien el nivel de proteína en la dieta puede afectar la deposición de grasa subcutánea y el desarrollo de masa muscular (área de ojo de bife) (Dartt y col., 1978; Perry y col., 1983), en el presente experimento no se registró un efecto significativo. Resultados similares fueron obtenidos por Rovira (2012b) en donde la ausencia de respuesta fue atribuida al corto periodo de suplementación y a la baja la proporción del suplemento en la dieta total.

\section{CONCLUSIONES}

La suplementación con grano húmedo de sorgo mejoró el desempeño productivo de novillos pastoreando campo natural en el otoñoinvierno. La adición de urea al grano de sorgo tuvo un impacto significativo en la respuesta animal cuando la calidad de forraje fue más limitante (más seco y con baja concentración de proteína), mejorando en esa situación la 
ganancia de peso de los animales y la eficiencia de conversión del suplemento.

\section{BIBLIOGRAFÍA}

BODINE, T.N.; PURVIS II, H.T.; ACKERMAN, C.J.; GOAD, C.L. 2000. Effects of supplementing prairie haywith corn and soybean meal on intake, digestion, and ruminal measurements by beef steers. J Anim Sci 78:3144-3154.

BODINE, T.N.; PURVIS II, H.T.; LALMAN. D.L. 2001. Effects of supplement type on animal performance, forage intake, digestion, and ruminal measurements of growing beef cattle. J Anim Sci 79:1041-1051.

BODINE, T.N.; PURVIS II, H.T. 2003. Effects of supplemental energy and/or degradable intake protein on performance, grazing behavior, intake, digestibility, and fecal and blood indices by beef steers grazed on dormant native tallgrass prairie. J Anim Sci 81, 304-317.

BOHNERT, D.W.; SCHAUER, C.S.; DELCURTO, T. 2002. Influence of rumen protein degradability and supplementation frequency on performance and nitrogen use in ruminants consuming low quality forage: Cow performance and efficiency of nitrogen use in wethers. J Anim Sci 80:1629-1637.

BOWMAN, J.G.P.; SANSON, D.W. 1996. Starchor fiber-based energy supplements for grazing ruminants. In: Proceedings Grazing Livestock Nutrition Conference. Rapid City, South Dakota. pp. 118-135.

BROWN, W.F.; ADJEI, M.B. 2001. Urea and (or) feather meal supplementation for yearling steers grazing limpograss (Hemarthria altissima var. 'Floralta') pasture. J Anim Sci 79, 310-3176.

CATON, J.S.; DHUYVETTER, D.V.. 1997. Influence of energy supplementation on grazing ruminants: Requirements and responses. J Anim Sci 75:533-542.

CHASE, C.C.; HIBBERD, C.A. 1987. Utilization of low-quality native grass hay by beef cows fed increasing quantities of corn grain. $J$ Anim Sci 65: 557-566.

COLEMAN, S.W. 2005. Predicting forage intake by grazing ruminants. In: Proceedings of
2005 Florida Ruminant Nutrition Symposium, United States Department of Agriculture, pp. 72-90.

DARTT, R.M.; BOLING, J.A.; BRADLEY, N.W. 1978. Supplemental protein withdrawal and monensin in corn silage diets of finishing steers. J Anim Sci 46: 345.

DEL CURTO, T.; COCHRAN, R.C.; CORAH, L.R.; BEHARKA, A.A.; VANZART, E.S.; JOHNSON, D.E. 1990. Supplementation of dormant tallgrass-prairie forage. II. Performance and forage utilization characteristics in grazing beef cattle receiving supplements of different protein concentrations. J Anim Sci 68:532-542.

FASSIO, A., FERNÁNDEZ, E.G.; RESTAINO, E.A.; LA MANNA, A.; COZZOLINO, D. 2009. Predicting the nutritive value of high moisture grain corn by near infrared reflectance spectroscopy. Comput Electron Agr 67, 59-63.

FORBES, T.D.A. 1988. Researching the plant animal interface: the investigation of ingestive behaviour in grazing animals. J Anim Sci 66, 2369.

HODGSON, J. 1990. Grazing Management. Science into Practice. Longman Scientific and Technical, Harlow, UK.

HOLDERBAUM, J.F.; SOLLENBERGER, L.E.; MOORE, J.E.; KUNKLE, W.E.; BATES, D.B.; HAMMOND, A.C. 1991. Protein supplementation of steers grazing limpograss pasture. J Prod Agric 4:437-441.

HORN, G.W.; MCCOLLUM III, F.T. 1987. Energy supplementation of grazing ruminants. In: Proceeding Grazing Livestock Nutrition Conference. Jackson, Wyoming. pp 125-136

JACOBO, E.J.; RODRIGUEZ, A.; PACIN, F. 2011. Factores relacionados con el consumo animal en un sistema pastoril de engorde vacuno en el sudoeste de la provincia de Buenos Aires, Argentina. Arch Latinoam Prod Anim 18, 69-79.

KOSTER, H.H.; COCHRAN, R.C.; TITGEMEYER, E.C.; VANZANT, E.S.; ABDELGADIR, I.; STJEAN, G. 1996. Effect of increasing degradable intake protein on intake an digestion of low-quality, tallgrassprairie forage by beef cows. J Anim Sci 74:2473-2481.

LAMB, D.S.; EADIE, J. 1979. The effect of barley supplements on the voluntary intake and 
digestion of low-quality roughages by sheep. J Agric Sci 92: 235-241.

LUDDEN, P.A.; JONES, J.M.; CECAVA, M.J.; HENDRIX, K.S. 1995. Supplemental protein sources for steers fed cornbased diets: II. Growth and estimated metabolizable amino acid supply. J Anim Sci 73: 1476-1486.

MERTENS, D.R. 1987. Predicting intake and digestibility using mathematical models of ruminal function. $J$ Anim Sci 64:1548-1558.

MOORE, J.E.; KUNKLE, W.E.; BROWN, W.F. 1995. Improving forage supplementation programs for beef cattle. In: Proceeding 6th Annual Florida Ruminant Nutrition Symposium. Univ. of Florida, Gainesville. pp 65-74.

MOORE, J.E.; BRANT, M.H.; KUNKLE, W.E.; HOPKINS, D.I. 1999. Effects of supplementation on voluntary forage intake, diet digestibility, and animal performance. J Anim Sci 77 (Suppl. 2), 122-135.

MOSS, R.J,; CHOPPING, G.D.; THURBON, P.N. 1983. Supplementation of dairy weaners grazing tropical pastures. S African J Anim Sci 13: 6-7.

NRC (NATIONAL RESEARCH COUNCIL). 1984. Nutrient Requirements of Domestic Animals: Beef Cattle. National Academy Press, Washington, D.C.

OLSON, K.C.; COCHRAN, R.C.; JONES, T.J.; VANZANT, E.S.; TITGEMEYER, E.C.; JOHNSON, D.E. 1999. Effects of ruminal administration of supplemental degradable intake protein and starch on utilization of lowquality warm-season grass hay by beef steers. J Anim Sci 77:1016-1025.
PATHAK, A.K. 2008. Various factors affecting microbial protein synthesis in the rumen. Vet World 1, 186-189.

PERRY, T.W.; SHIELDS, D.R.; DUNN, W.J.; OHLER, M.T.1983. Protein levels and monensin for growing and finishing steers. J Anim Sci, 57: 1067-1076.

PITTS, J.; MCCOLLUM, F.T.; BRITTON, C.M. 1992. Protein supplementation of steers grazing tobosagrass in spring and summer. J Range Manage 45, 226-231.

PRIGGE, E.C.; BRYAN, W.B.; NESTOR, E.L. 1997. Sward height on performance of cow-calf units and yearling steers grazing cool season pasture. In: Proceedings 18th International Grassland Congress. Winnipeg/ Saskatoon, Canada. 29:97-98.

REARTE, D.H.; PIERONI, G.A. 2001. Supplementation of temperate pastures. In: Proceedings 19th International Grassland Congress. San Paulo, Brazil. pp. 679-689.

ROVIRA, P. 2012a. Desempeño productivo de novillos sobre pasturas templadas con suplementación energética en autoconsumo. Rev Vet 23, 3-7.

ROVIRA, P. 2012b. Addition of protein sources for calves supplemented with high moisture sorghum grain silage grazing low-quality pastures. Online J Anim Feed Res 2, 283-287.

SANSON, D.W.; CLANTON, D.C. 1989. Intake and digestibility of low-quality meadow hay by cattle receiving various levels of whole shelled corn. J Anim Sci 67: 2854-2862.

SPÖRNDL, Y.E.; OLSSON, I.; BURSTEDT, E.2000.Grazing by steers at different sward surface heights on extensive pastures: a Study of weight gain and fat deposition. Acta Agr Scand A-An 50, 184-192. 


\section{EFECTO DEL NIVEL DE SUPLEMENTACIÓN DE UNA MEZCLA DE}

GRANO HÚMEDO DE SORGO Y NÚCLEO PROTEICO EN EL DESEMPEÑO PRODUCTIVO DE TERNEROS SOBRE CAMPO NATURAL

\section{P. Rovira ${ }^{1}$ \\ J. Echeverría ${ }^{2}$}

\section{RESUMEN}

El objetivo del trabajo fue evaluar el efecto del nivel de suplementación de una mezcla de grano húmedo de sorgo (GHS) y un núcleo proteico (NP, 60,9\% proteína) en el desempeño productivo de terneros sobre campo natural. Los tratamientos fueron: T1) Testigo, T2) suplementación al $1 \%$ del peso vivo (PV) con GHS, T3) suplementación al $1 \%$ del PV con GHS + NP, T4) suplementación al 1,5\% del PV con GHS + NP. La mezcla GHS + NP fue $86,5 \%$ y $13,5 \%$, respectivamente, correspondiendo a una concentración de proteína de $15 \%$ en la mezcla ofrecida diariamente. La disponibilidad de forraje (media \pm d.e.) fue $1735 \pm 184 \mathrm{~kg} \mathrm{MS} / \mathrm{ha}$ ( $58 \%$ restos secos) con una altura del tapiz de $5,3 \pm 0,7 \mathrm{~cm}$ y una concentración de proteína de $9 \%$. Los animales suplementados con GHS+NP al 1,5\% del peso vivo (T4) registraron un peso vivo final (241 kg) significativamente mayor $(P<0,05)$ que aquellos animales en los grupos testigo y sólo sorgo $(179 \mathrm{~kg})$. Los animales del tratamiento T3 presentaron un peso vivo final intermedio $(220 \mathrm{~kg})$. La misma tendencia se registró en la ganancia media de peso durante los 84 días del experimento, correspondiendo valores de -0,093 (T1); 0,066 (T2); 0,354 (T3) y 0,632 (T4) kg/a/día. La adición del núcleo proteico mejoró la eficiencia de conversión del suplemento ( $\mathrm{kg}$ de suplemento necesarios para ganar $1 \mathrm{~kg}$ de peso vivo adicional con respecto al grupo testigo, expresado en base seca), la cual pasó de 10,7:1 kg (T2) a 4,3:1 kg (T3) y 4,1:1 kg (T4). El incremento del nivel de suplementación no afectó la salud de los animales (ej. acidosis) medido a través de la consistencia de la bosta. La suplementación al 1,5\% del peso vivo de una mezcla de sorgo grano húmedo y núcleo proteico suministrado una vez al día mejoró significativamente el desempeño productivo de terneros sobre campo natural comparado con un nivel de suplementación al $1 \%$ del peso vivo.

Palabras claves: terneros, suplementación, sorgo, proteína, campo natural

\section{ABSTRACT}

The objective of the study was to evaluate the effect of the level of supplementation of a mixture composed by high moisture sorghum grain (HMSG) and a protein supplement (PS, 60.9\% protein) on performance of weaning calves grazing low-quality native pastures during winter. There was one control group of animals without supplement (T1) and then 3 groups of animals daily supplemented with either 100\% HMSG at a level of $1.0 \%$ of the body weight (BW) (T2); $86.5 \%$ HMSG $+13.5 \%$ PS at $1 \%$ of BW (T3); or $86.5 \%$ HMSG $+13.5 \%$ PS at $1.5 \%$ of BW (T4). Sward height and average pasture allowance was $5.3 \pm 0.7 \mathrm{~cm}$ and $1735 \pm 184 \mathrm{~kg} \mathrm{DM} / \mathrm{ha}$, respectively, being $58 \%$ of that value supplied by dead and dry forage. Average crude protein (CP) of forage was $9.0 \%$ while the different combinations of supplements had a CP concentration of \% 7.7 (T2); 14.6\% (T3); 15.1\% (T4). At the end of the $84 \mathrm{~d}$ of the experiment calves supplemented at the higher level of supplementation with the mixture HMSG + PS $(\mathrm{T} 4)$ had a greater $(\mathrm{P}<0.05)$ body weight $(241 \mathrm{~kg})$ than animals in T1 and T2 $(179 \mathrm{~kg})$. Animals in T3 showed an intermediate final BW $(220 \mathrm{~kg})$. The same tendency was registered for average daily gain corresponding values of -0.093 (T1); 0.066 (T2); 0.354 (T3) and 0.632 (T4) kg/a/day. Feed efficiency, expressed as the $\mathrm{kg}$ of supplement required to gain $1 \mathrm{~kg}$ additional compared with the 
performance of the control group (T1), improved in animals supplemented with higher levels of protein (4.3 and 4.1 for T3 and T4, respectively) compared with animals in T2 $(10.7: 1)$. The increase in the level of daily supplementation did not affect animal health (i.e. acidosis) measured by the type and consistency of feces. Daily supplementation with a mixture of HMSG and PS at $1.5 \%$ of body weight improved performance and feed efficiency of calves grazing low quality pastures compared with lower levels of supplementation (1\% BW).

Key words: steers, supplementation, sorghum, urea

\section{INTRODUCCIÓN}

La cantidad y calidad del forraje de campo natural durante el invierno determina que las categorías de recría vacuna pierdan peso en dicha estación del año. Trabajos en esta misma publicación demuestran que el agregado de fuentes proteicas al grano húmedo de sorgo a un nivel de suplementación de $1 \%$ del peso vivo permite evitar la pérdida de peso vivo y lograr ganancias de peso moderadas $(0,300-0,400 \mathrm{~kg} / \mathrm{a} / \mathrm{d})$. Para lograr tasas de crecimiento superiores una alternativa es incrementar el nivel de suplementación. Sin embargo, niveles de suplementación con granos energéticos superior al $1 \%$ del peso vivo (en un único suministro diario) pueden afectar la respuesta a la suplementación debido a un descenso del consumo y digestibilidad del forraje (Horn y McCollum, 1987; Pordomingo et al., 1991; Lomas et al., 2009), además de incrementar el riesgo de acidosis ruminal. Por tal motivo, el objetivo del presente trabajo fue evaluar la respuesta productiva de terneros al agregado de una fuente de proteína al grano húmedo de sorgo a distintos niveles de suplementación (1 vs $1,5 \% \mathrm{PV}$ ) en un único suministro diario sobre campo natural.

\section{MATERIALES Y MÉTODOS}

El experimento se llevó a cabo sobre 20 ha de campo natural de la Unidad Alférez pertenecientes al Módulo de Invernada de Bovinos para Carne en la «Unidad Experimental Palo a Pique» (UEPP) de INIA Treinta y Tres. La etapa de aplicación de los tratamientos de suplementación se extendió del 10 de julio al 2 de octubre de 2013 (84 días). Luego, entre octubre y diciembre de 2013 los animales se manejaron en forma conjunta en pastoreo para evaluar efectos residuales de los tratamientos.

Se utilizaron 40 terneros de 9 meses de edad cruza Hereford $x$ Aberdeen Angus provenientes del Módulo de Cría de la UEPP distribuidos al azar en 4 tratamientos (10 terneros/tratamiento) en un diseño completamente al azar con 2 repeticiones (5 terneros/repetición). Cada grupo de animales dispuso de acceso ad-libitum a bebederos para consumo de agua. Los tratamientos se observan en el Cuadro 1.

La suplementación se realizó de lunes a sábado a primera hora de la mañana. Se utilizó sorgo grano húmedo (34\% humedad) cosechado y embolsado en condiciones de anaerobiosis hasta el inicio de la suplementación. Al inicio del experimento los anima-

Cuadro 1. Tratamientos experimentales

\begin{tabular}{lcc}
\hline \multicolumn{1}{c}{ Suplemento } & Abreviación & $\begin{array}{c}\text { Nivel de suplementación } \\
\text { (\% PV, base seca) }\end{array}$ \\
\hline Ninguno (Testigo) & $\mathrm{T}$ & - \\
Sorgo & $\mathrm{S} 1 \%$ & 1,0 \\
85\% sorgo + 15\% núcleo proteico & $\mathrm{SN} 1 \%$ & 1,0 \\
85\% sorgo + 15\% núcleo proteico & $\mathrm{SN} 1,5 \%$ & 1,5 \\
\hline
\end{tabular}


Cuadro 2. Análisis (media \pm desvío estándar) de los suplementos (Laboratorio Nutrición Animal - INIA La Estanzuela)

\begin{tabular}{llllllc}
\hline & \multicolumn{6}{c}{ Parámetro } \\
\cline { 2 - 7 } & MS (\%) & PC (\%) & FDA (\%) & FDN (\%) & C (\%) & EM (Mcal/kg) \\
\hline Sorgo & $65,7 \pm 0,3$ & $7,7 \pm 0,2$ & $8,1 \pm 0,2$ & $10,4 \pm 0,3$ & $2,2 \pm 0,1$ & $2,81 \pm 0,00$ \\
Núcleo proteico & $83,8 \pm 0,1$ & $60,9 \pm 0,3$ & $18,5 \pm 1,2$ & $27,2 \pm 0,8$ & $25,4 \pm 0,1$ & $2,61 \pm 0,02$ \\
\hline
\end{tabular}

MS: Matera Seca; PC: Proteína Cruda; FDA: Fibra Detergente Ácido; FDN: Fibra Detergente Neutro; C: Cenizas; EM: Energía Metabolizable.

les ya sabían comer sorgo (periodo de acostumbramiento no incluido en el periodo experimental). Al inicio del experimento se realizó un periodo de 14 días de acostumbramiento al núcleo proteico el cual contenía $10 \%$ de urea en su composición. El agregado del núcleo se realizaba el día del suministro a los animales en el comedero. La composición nutricional de los suplementos se observa en el Cuadro 2.

Los animales se dosificaron (Ricoverm) previo al comienzo del periodo experimental en función de análisis coprológico. A la mitad del periodo experimental se muestreó el $50 \%$ de los animales en cada tratamiento y se determinó redosificar según resultado de análisis coprológico.

Se registró la disponibilidad, altura y relación verde/seco del campo natural al inicio, mitad y fin del experimento $(0,42$ y 84 días). El valor nutritivo del forraje se determinó al inicio y fin del experimento incluyendo los parámetros proteína cruda (PC), fibra detergente ácido (FDA) y fibra detergente neutra (FDN). El peso vivo lleno de los animales se registró cada 21 días $(0,21,42,63$ y 84 días) estimando la ganancia de peso diaria en el periodo a través de la ecuación de regresión de peso vivo en el tiempo.

Para evaluar la posible manifestación de acidosis o disturbios ruminales en tres momentos durante el desarrollo de trabajo se observó la frecuencia del tipo y consistencia de la bosta fresca seleccionando 10 deyecciones por tratamiento en cada fecha (Cuadro 3). Adicionalmente, se cuantificó la presencia de grano en la bosta de forma subjetiva en las categorías «nada», «poco» $\mathrm{y}$ «mucho».

Las variables de pasturas y producción animal fueron sometidas a análisis de varianza considerando el efecto principal del tratamiento utilizando el comando PROC GLM del paquete estadístico SAS versión 9.12 (SAS Institute, Cary, NC, USA). La unidad experimental fue el grupo de cinco animales en cada repetición. Las medias de los tratamientos fueron comparadas mediante el test de Tukey cuando el valor de $F$ fue significativo $(P<0,05)$. La frecuencia del tipo de bosta se analizó mediante la técnica de Chicuadrado.

Cuadro 3. Clasificación visual de las bostas según forma y consistencia

\begin{tabular}{ll}
\multicolumn{1}{c}{ Consistencia } & \multicolumn{1}{c}{ Descripción } \\
\hline Dura & $\begin{array}{l}\text { Se deponen en forma piramidal, muy secas, sin olor intenso, se obser- } \\
\text { van partículas de fibra gruesa. } \\
\text { Firme }\end{array}$ \\
Deposiciones redondeadas en sus bordes, con una leve depresión en \\
el centro. \\
Blanda & $\begin{array}{l}\text { Acuosas y de olor intenso. Forma aplanada y expandida en una uni- } \\
\text { dad, al deponerse «salpica» bastante. }\end{array}$ \\
Líquida & $\begin{array}{l}\text { Totalmente planas y acuosas, diarreicas («chorros»), se visualiza } \\
\text { entrecortada en el suelo en secciones muy extendidas. }\end{array}$ \\
Líquida - Acidosis & $\begin{array}{l}\text { Similar a la anterior pero de color más claro y brillante, grisácea, con } \\
\text { presencia de burbujas (gases) y/o rastros de sangre o mucus intesti- } \\
\text { nal. }\end{array}$ \\
\hline
\end{tabular}




\section{RESULTADOS Y DISCUSIÓN}

\section{Pasturas}

Debido a que no existieron diferencias significativas $(P>0,05)$ en las características de la base forrajera (disponibilidad de forraje total, disponibilidad de forraje verde y altura del tapiz) la información se presenta promediada sobre los tratamientos. La disponibilidad de forraje total promedio ( \pm desvío estándar) a lo largo del periodo experimental fue $1735 \pm 184 \mathrm{~kg}$ MS/ha correspondiendo un $42 \%$ a forraje verde y el restante $58 \%$ a restos secos. La altura promedio del tapiz fue $5,3 \pm 0,7 \mathrm{~cm}$, la cual tendió a disminuir de 5,9 cm (inicio) a 4,8 cm (final) (Figura 1). En el mismo periodo la disponibilidad de forraje total se mantuvo en el rango de 1500 a $1900 \mathrm{~kg} \mathrm{MS} / \mathrm{ha}$ siendo la proporción de forraje verde 50,30 y $48 \%$, al inicio, mitad y fin del experimento, respectivamente. Esto indica que la mayor disponibilidad de forraje que se observó en la mitad del experimento (Figura 1) fue debido a un incremento de la proporción de restos secos con un mayor porcentaje de materia seca comparado con la fracción verde.

La información de la calidad del forraje se presenta promediada sobre tratamientos ya que no hubo diferencias significativas
$(P>0,05)$ (Figura 2). El parámetro que más varió del inicio al fin del experimento fue la proteína cruda que se incrementó un $28 \%$ en términos relativos (de 7,9\% a 10,1\%). Si bien la proporción de forraje verde al inicio y fin del experimento fue prácticamente la misma (50 y $48 \%$, respectivamente), la concentración de proteína en el forraje verde varió de $9,8 \%$ (inicio) a $13,4 \%$ (final) lo que explicó el incremento de proteína en el forraje hacia el fin del periodo experimental. Dicha variación probablemente estuvo explicada por una mayor proporción de forraje más tierno hacia fines de setiembre, asociado al rebrote primaveral del campo, con mayores niveles de proteína comparado con el forraje verde al inicio del trabajo, que básicamente estaba compuesto por especies que se mantenían verdes pero en estado avanzado de madurez (Figura 3).

\section{Suplementación y respuesta animal}

El aporte del núcleo proteico en la mezcla con el grano de sorgo fue entre 13 y $14 \%$ expresado en base seca (Cuadro 4). En función de dicha proporción, y de acuerdo al valor nutritivo de los suplementos observado en el Cuadro 1, el nivel de proteína en el suplemento entregado diariamente fue $7,7 \%(\mathrm{~S})$;

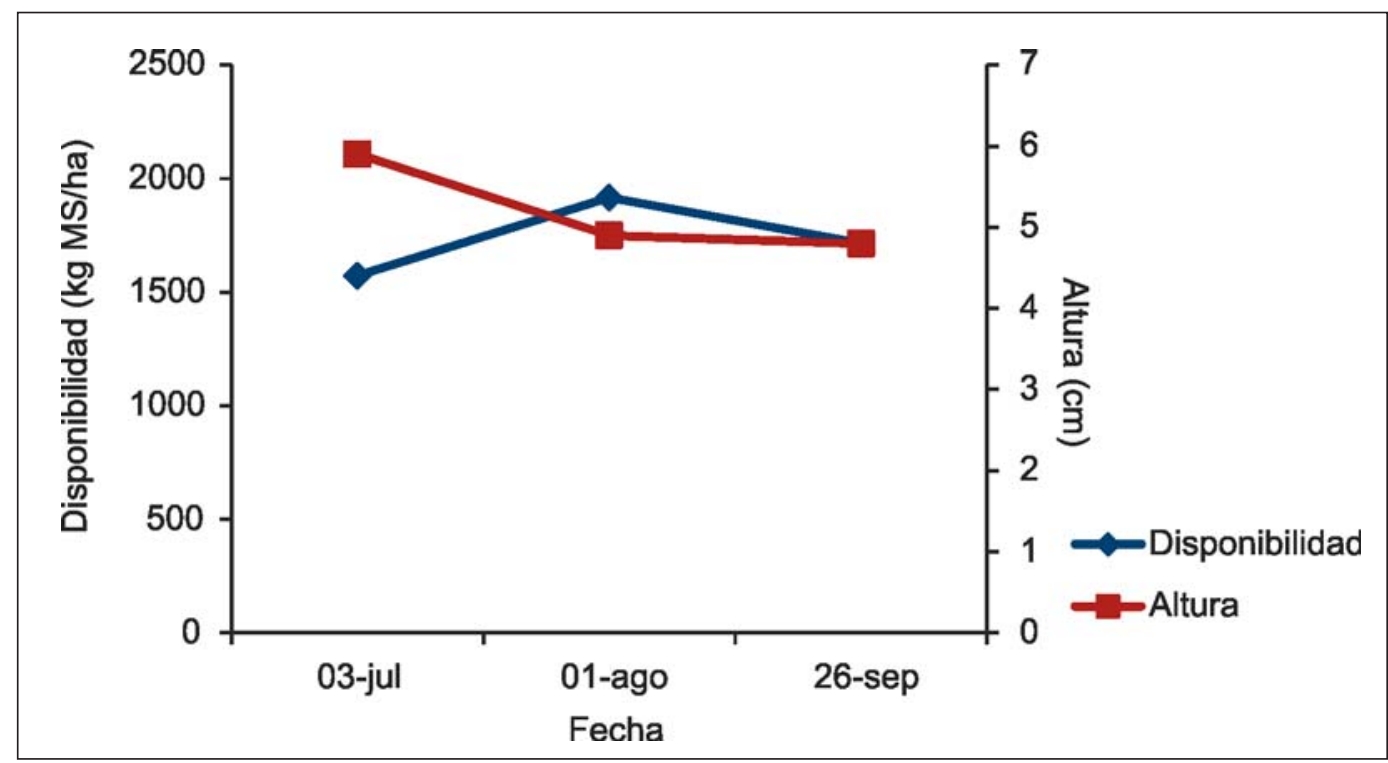

Figura 1. Evolución del forraje disponible y la altura del tapiz. 


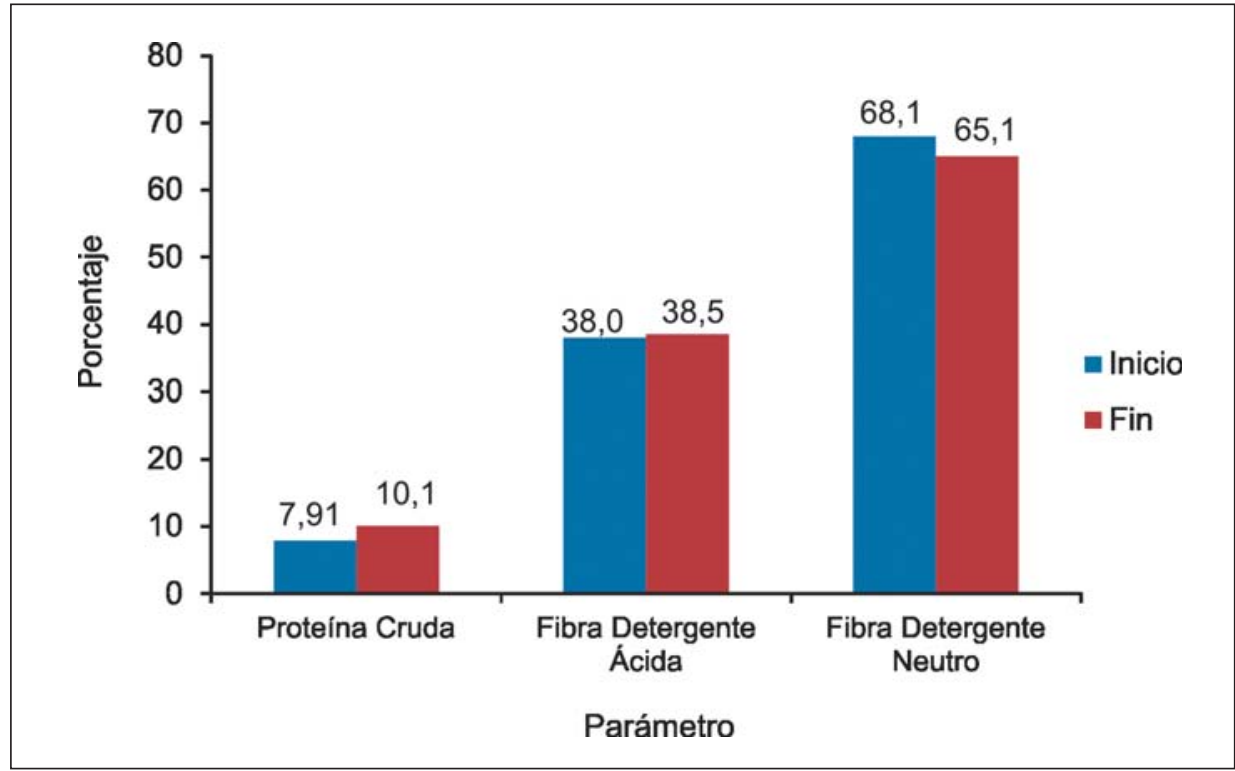

Figura 2. Evolución de la calidad del forraje del campo natural.

Figura 3. Observación del rebrote del campo natural (verde) hacia finales del mes de agosto.

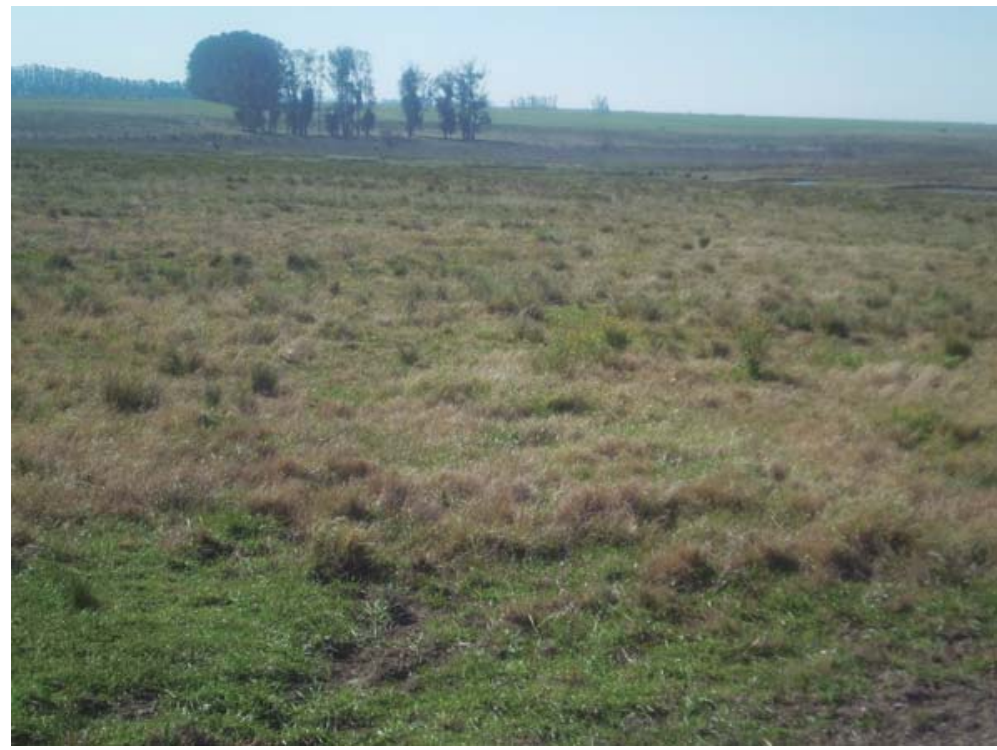

Cuadro 4. Composición (kg MS/a/día) del suplemento ofrecido a los animales (entre paréntesis aporte porcentual de cada suplemento)

\begin{tabular}{lllll}
\hline & \multicolumn{4}{c}{ Tratamiento } \\
\cline { 2 - 5 } Suplemento & $\mathbf{T}$ & \multicolumn{1}{c}{ S1\% } & SN1\% & SN1,5\% \\
\hline Sorgo & - & $1,70(100)$ & $1,95(87)$ & $2,97(86)$ \\
Núcleo proteico & - & - & $0,29(13)$ & $0,49(14)$ \\
Total & - & $1,70(100)$ & $2,24(100)$ & $3,46(100)$ \\
\hline
\end{tabular}

T: Testigo; S1\%: Sorgo; SN1\%: Sorgo + Núcleo proteico al 1\% del peso vivo; SN1,5\%: Sorgo + Núcleo proteico al $1,5 \%$ del peso vivo. 
$14,6 \%$ (SN1\%) y 15,1\% (SN1,5\%). La inclusión del núcleo proteico prácticamente duplicó la concentración de proteína original en el grano húmedo de sorgo mejorando no sólo la oferta total de proteína del suplemento sino también la relación energía-proteína.

Los animales suplementados con grano húmedo de sorgo + núcleo proteico al 1,5\% del peso vivo registraron un peso vivo final
$(241 \mathrm{~kg})$ significativamente mayor $(\mathrm{P}<0,05)$ que aquellos animales en los grupos testigo y sólo sorgo (178,8 kg) (Figura 4). Los animales del tratamiento SN1\% presentaron un peso vivo final intermedio $(220 \mathrm{~kg})$. La misma tendencia se registró en la ganancia media de peso durante los 84 días del experimento, correspondiendo valores de -0,093 (T); 0,066 (S); 0,354 (SN1\%) y 0,632 (SN1,5\%) kg/a/día (Figura 5). Existieron dos

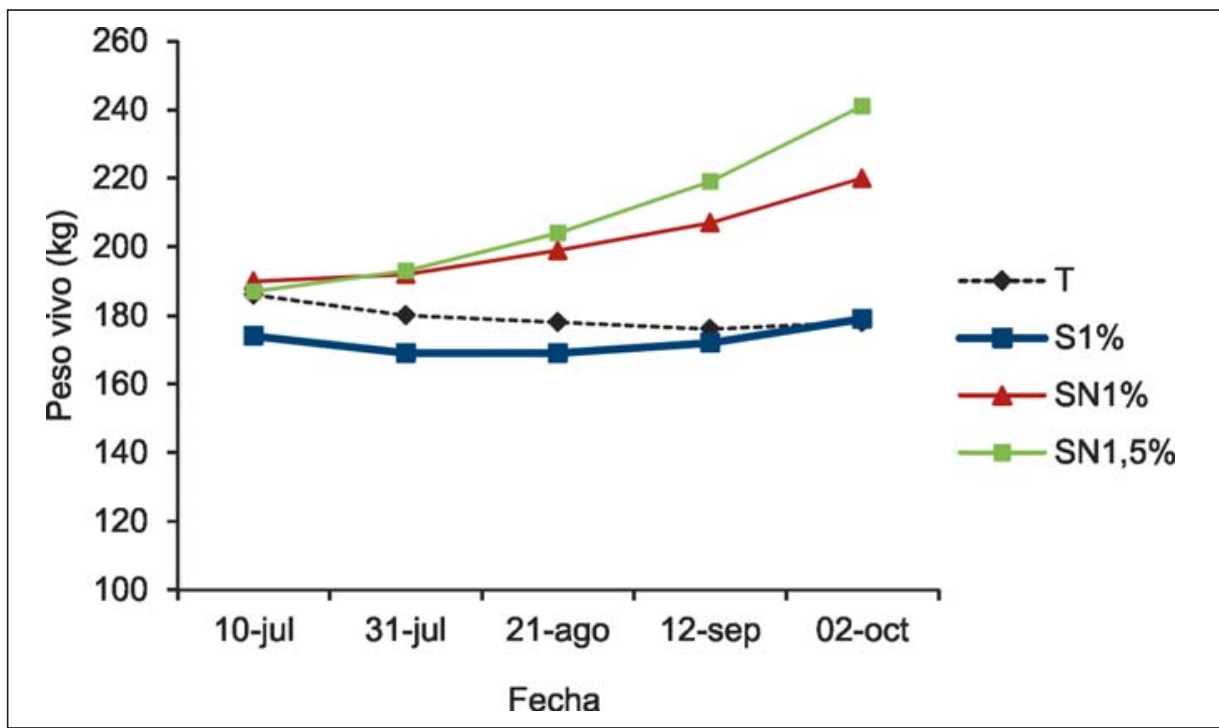

Figura 4. Evolución de peso vivo de los animales. T: Testigo; S1\%: Sorgo; SN1\%: Sorgo + Núcleo proteico al 1\% del peso vivo; SN1,5\%: Sorgo + Núcleo proteico al $1,5 \%$ del peso vivo.

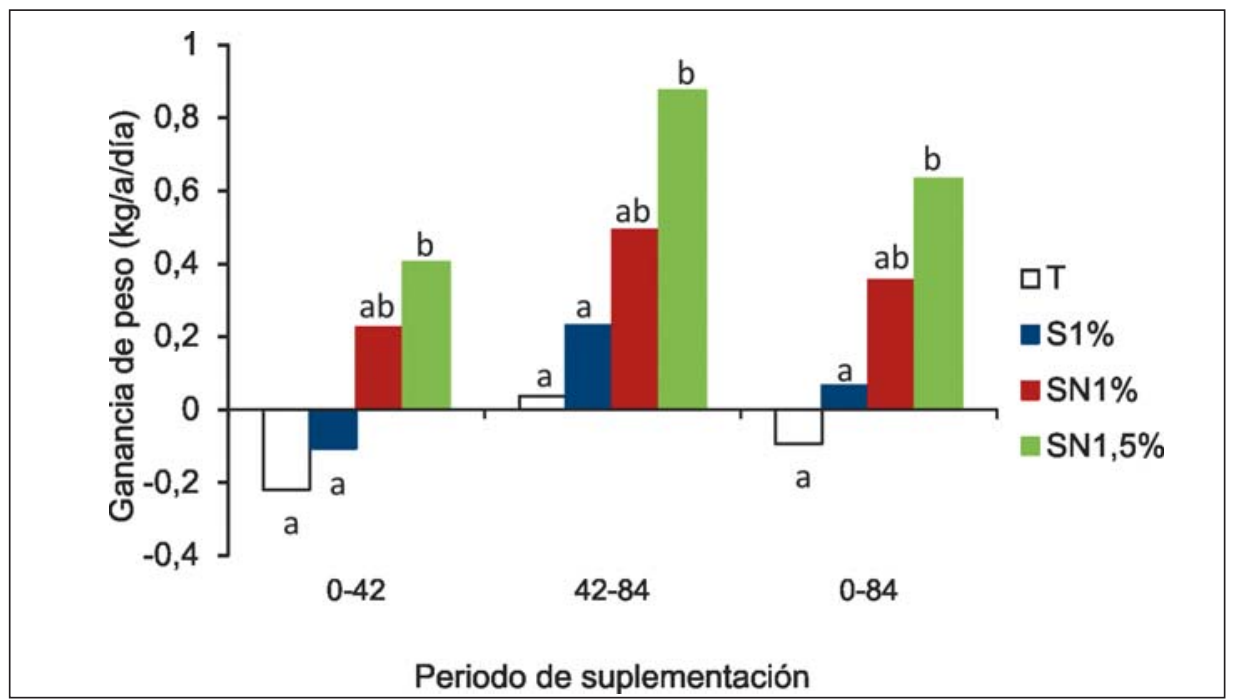

Figura 5. Ganancia de peso según periodo de suplementación: 10 de julio - 21 de agosto (0-42 d); 21 de agosto - 2 de octubre (42-84 d) y 10 de julio -2 de octubre (0-84 d). T: Testigo; S: Sorgo; SN1\%: Sorgo + Núcleo proteico al 1\% del peso vivo; SN1,5\%: Sorgo + Núcleo proteico al 1,5\% del peso vivo. 
periodos bien diferenciados, en donde en la primera mitad del experimento (0-42 d) los animales en los grupos testigo y suplementados sólo con sorgo perdieron peso.

La baja respuesta a la suplementación únicamente con sorgo coincide con otros trabajos que demuestran que el consumo de forraje y la digestibilidad disminuyen cuando se utiliza un grano con alto contenido de almidón y bajo nivel de proteína (ej. maíz, sorgo) como suplemento a bovinos pastoreando forrajes de mala calidad deficientes en proteína (Horn y McCollum, 1987; Bowman y Sanson, 1996; Caton y Dhuyvetter, 1997). Dicho descenso en el consumo y digestibilidad del forraje trae como consecuencia un consumo de energía por debajo de lo esperado al implementar la suplementación (Chase y Hibberd, 1987). Otra tendencia registrada, y que coincide con otros trabajos en esta misma publicación, es que durante los primeros dos tercios del periodo de suplementación los terneros suplementados con sorgo prácticamente mantienen peso. Recién en el último tercio de la suplementación se registraron leves ganancias de peso.

Cuando se suplementa con granos como el maíz o sorgo, ha sido demostrado que la adición de proteína mejora la utilización de pasturas de baja calidad e incrementa el consumo global de energía de la dieta (Olson et al., 1999; Bodine et al., 2000; 2001). La suplementación proteica no sólo puede mejorar la utilización de nutrientes sino también incrementar el consumo de forraje y la digestibilidad (Caton et al., 1988; DelCurto, 1990; Sanson et al., 1990).

La adición del núcleo proteico mejoró sensiblemente la eficiencia de conversión del sorgo ( $\mathrm{kg}$ de suplemento necesarios para ganar $1 \mathrm{~kg}$ de peso vivo adicional con respecto al grupo testigo, expresado en base seca), la cual pasó de 10,7:1 kg (S) a 4,3:1 $\mathrm{kg}(\mathrm{SN} 1 \%)$ y $4,1: 1 \mathrm{~kg}$ (SN1,5\%). Eficiencias de conversión cercanas a 3:1 generalmente son sintomáticas de deficiencias de nitrógeno (McCollum y Horn, 1990) e indican una respuesta asociativa positiva (energía - proteína). En el otro extremo, eficiencias de conversión superiores a 8:1 son típicas en casos de suplementación energética cuando ocurre sustitución o una utilización ineficiente de los nutrientes del suplemento pudiendo ocurrir una interacción asociativa negativa (Bodine y Purvis, 2003). En el presente experimento, la respuesta en ganancia diaria de peso y eficiencia de conversión son indicativas de una situación de deficien-

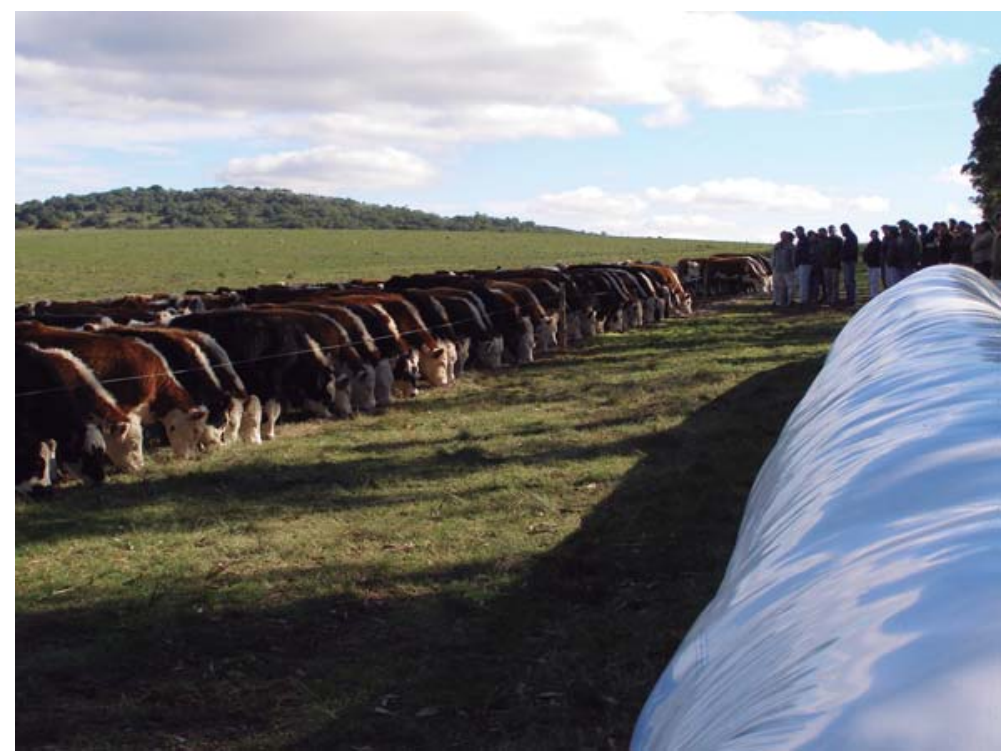

La suplementación al 1,5\% del peso vivo en un único suministro diario de una mezcla grano húmedo de sorgo + núcleo proteico mejoró el desempeño de terneros sobre campo natural sin ocasionar disturbios ruminales. 
cia en los animales tanto en proteína como en energía, ocurriendo la mejor respuesta biológica cuando ambos nutrientes fueron ajustados en el suplemento.

\section{Consistencia de heces}

Existió un efecto significativo $(\mathrm{P}<0,05)$ de los tratamientos en la consistencia y contenido de grano en las bostas (Figura 6). La inclusión del núcleo proteico incrementó la proporción de bostas con consistencia «firme» y también produjo un incremento del nivel de grano observado en la bosta. En ningún caso se observaron bostas con consistencia blanda o líquida que pueden ser un indicador de acidosis o ineficiente utilización de la proteína. El incremento del nivel de suplementación de 1 al 1,5\% del peso vivo no produjo cambios significativos en la bosta. Consistencias blandas o líquidas pueden ser atribuidas a un consumo excesivo de proteína y/o a altos niveles de proteína degradable en el rumen debido a un incremento del consumo de agua para eliminar el exceso de nitrógeno a través de la orina. Adicionalmente, un incremento de la fermentación de carbohidratos en el tracto gastrointestinal con el consecuente incremento de la producción de ácidos puede causar diarrea en los animales (Mgbeahuruike, 2007).

La ausencia de síntomas clínicos de acidosis a niveles de suplementación de 1,5\% del peso vivo, y la buena respuesta animal y eficiencia de conversión en este tratamiento, permiten concluir que es posible sumi- nistrar dicho nivel de suplemento una sola vez al día (ej. en la mañana) sin comprometer la productividad del animal. Aunque pasa a ser más importante el control de los aspectos prácticos de la suplementación a nivel grupal, como que todos los animales efectivamente coman suplemento y lo hagan al mismo tiempo, evitando casos de dominancia. Las características del almidón del grano de sorgo, de menor velocidad de digestión y con menor degradabilidad a nivel ruminal comparado con otros granos, pueden haber ayudado a que no se manifestaran síntomas clínicos de acidosis.

\section{Resultado económico}

Desde el punto de vista del análisis económico de la suplementación, y tomando como referencia precios reales del ternero y de los suplementos durante la realización del experimento, los tratamientos que incluyeron el núcleo proteico fueron los que obtuvieron márgenes positivos (Cuadro 5). Si bien la adición del núcleo proteico incrementó el costo de la suplementación debido a su elevado precio (650 U\$S/ton), dicho incrementó se compensó con una mejora significativa del desempeño productivo de los terneros y por lo tanto de una mayor valorización de los $\mathrm{kg}$ producidos. El nivel de suplementación 1,5\% del peso vivo fue el tratamiento de mejor margen bruto, incluso si se asumiera un precio del $\mathrm{kg}$ de ternero sensiblemente inferior comparado con el tratamiento de 1\% (debido a una desvalorización del kg de ternero al incrementar el peso vivo).
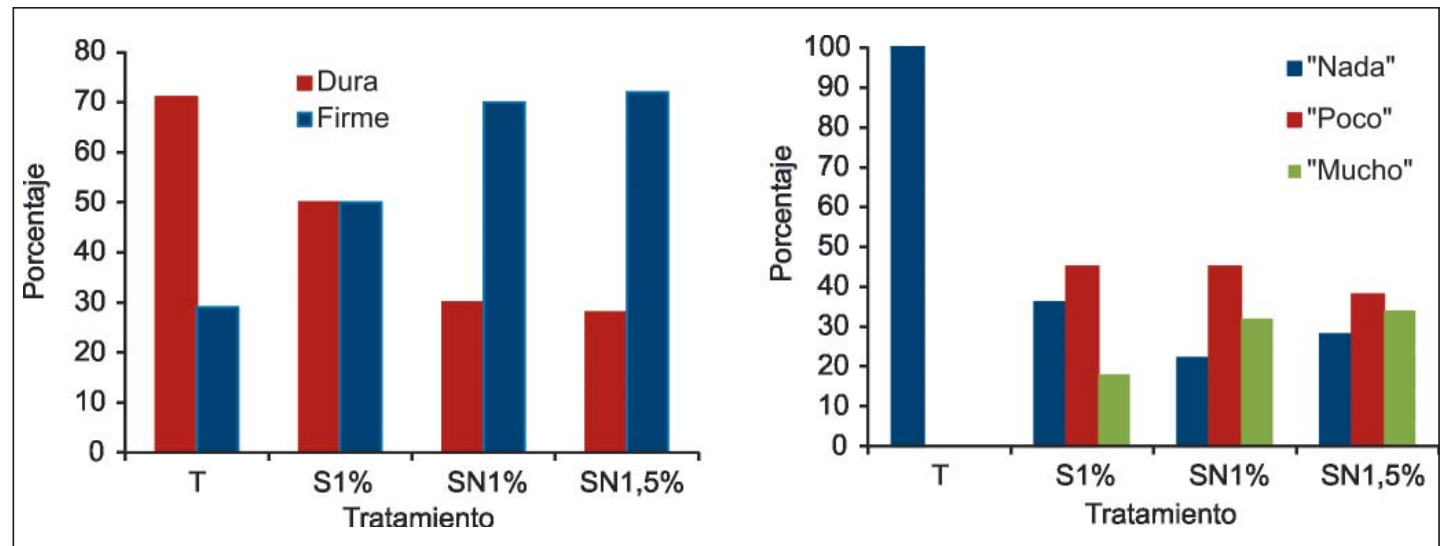

Figura 6. Clasificación del tipo de bosta según consistencia y contenido visual de grano. 
Cuadro 5. Análisis económico de la suplementación (Precios de referencia setiembre 2013)

\begin{tabular}{|c|c|c|c|c|}
\hline & \multicolumn{4}{|c|}{ Tratamiento $^{1}$} \\
\hline & $\mathbf{T}$ & S1\% & SN1\% & SN1,5\% \\
\hline Precio del suplemento ${ }^{2}$ (U\$S/ton) & - & 180 & 246 & 246 \\
\hline Costo diario suplementación ${ }^{3}$ (U\$S/a) & - & 0,31 & 0,55 & 0,85 \\
\hline Costo suplementación en 84 días (U\$S/a) & - & 26 & 46 & 71 \\
\hline Peso vivo agregado en 84 días $^{4}(\mathrm{~kg} / \mathrm{a})$ & -8 & 13 & 38 & 62 \\
\hline Valorización kg producidos (U\$S/a $)^{5}$ & -18 & 30 & 87 & 142 \\
\hline Margen Bruto $(\mathrm{U} \$ \mathrm{~S} / \mathrm{a})^{6}$ & -18 & 4 & 41 & 71 \\
\hline
\end{tabular}

${ }^{1}$ T: Testigo; S1\%: Sorgo; SN1\%: Sorgo + Núcleo proteico al 1\% del peso vivo; SN1,5\%: Sorgo + Núcleo proteico al $1,5 \%$ del peso vivo.

${ }^{2}$ Sorgo: 180 U\$S/ton; Núcleo proteico 650 U\$S/ton. Mezcla 86\% sorgo + 14\% núcleo proteico.

${ }^{3}$ Según cantidades realmente suministradas (Cuadro 4).

${ }^{4}$ Según desempeño productivo real (Figuras 4).

${ }^{5}$ Valor de referencia Asociación Consignatarios de Ganado (22/09/2013): 2,29 U\$S/kg.

${ }^{6}$ Valorización kg producidos-costo de la suplementación en 84 días.

La baja respuesta productiva a la suplementación únicamente con grano húmedo de sorgo determinó un resultado económico apenas positivo de la suplementación en dicho tratamiento, aunque fue suficiente para evitar la pérdida económica comparado con la situación de no suplementar (tratamiento Testigo).

\section{Etapa post-suplementación}

Desde el fin del periodo de suplementación ( 2 de octubre) hasta el 18 de diciembre de 2013 (78 días) todos los animales se manejaron en forma conjunta sobre pasturas mejoradas y campo natural. El objetivo fue evaluar si la estrategia de suplementación invernal tenía o no efecto en el desempeño productivo de los animales durante la primavera siguiente (efecto residual del tratamiento invernal).

De acuerdo a la información generada, aquellos animales más pesados a la salida del invierno (tratamientos con inclusión de núcleo proteico) continuaron siendo más pesados a la salida de la primavera ya que no se registraron diferencias significativas en la ganancia de peso entre octubre y diciembre de 2013, cuando todos los animales se manejaron en forma conjunta (Cuadro 6).

La ausencia de crecimiento compensatorio pudo deberse a que el periodo de evaluación no fue lo suficientemente prolongado, y/o a que la oferta de forraje no fue lo suficientemente abundante para permitir expresar mayores ganancias de peso durante la primavera. La severa restricción proteica de los animales testigo sin suplementación durante el invierno también puede haber explicado la ausencia de crecimiento compensatorio en dicho grupo de animales (Drouillard et al., 1991). Una restricción proteica puede causar la utilización de reservas de proteína en el cuerpo del animal tal cual fue evidenciado por Fatter et al. (1984) y Hovell et al. (1987) lo que puede incremen-

Cuadro 6. Desempeño productivo de los terneros durante la primavera

\begin{tabular}{lllll}
\hline & \multicolumn{3}{c}{ Tratamiento } \\
\cline { 2 - 5 } Suplemento & $\mathbf{T}$ & S1\% & SN1\% & SN1,5\% \\
\hline Peso al final de suplementación $(\mathrm{kg})$ & 179 & 179 & 219 & 241 \\
Peso al final de la primavera $(\mathrm{kg})$ & $226 \mathrm{a}$ & $235 \mathrm{a}$ & $272 \mathrm{~b}$ & $290 \mathrm{~b}$ \\
Ganancia de peso primaveral $(\mathrm{kg} / \mathrm{a} / \mathrm{d})$ & $0,615 \mathrm{a}$ & $0,728 \mathrm{a}$ & $0,682 \mathrm{a}$ & $0,643 \mathrm{a}$ \\
\hline
\end{tabular}

T: Testigo; S1\%: Sorgo; SN1\%: Sorgo + Núcleo proteico al 1\% del peso vivo; SN1,5\%: Sorgo + Núcleo proteico al $1,5 \%$ del peso vivo. 
tar las necesidades de proteína durante la etapa de re-alimentación o recuperación primaveral.

\section{CONCLUSIONES}

La suplementación al 1,5\% del peso vivo de una mezcla de sorgo grano húmedo y núcleo proteico suministrado una vez al día mejoró significativamente el desempeño productivo de terneros sobre campo natural y el resultado económico comparado con un nivel de suplementación al $1 \%$ del peso vivo sin comprometer la salud de los animales.

\section{BIBLIOGRAFÍA}

BODINE, T.N.; PURVIS II, H.T.; ACKERMAN, C.J.; GOAD, C.L. 2000. Effects of supplementing prairie hay with corn and soybean meal on intake, digestion, and ruminal measurements by beef steers. Journal of Animal Science 78:3144-3154.

BODINE, T.N.; PURVIS II, H.T.; LALMAN, D.L. 2001. Effects of supplement type on animal performance, forage intake, digestion, and ruminal measurements of growing beef cattle. Journal of Animal Science 79:1041-1051.

BODINE, T.N.; PURVIS II, H.T. 2003. Effects of supplemental energy and/or degradable intake protein on performance, grazing behavior, intake, digestibility, and fecal and blood indices by beef steers grazed on dormant native tallgrass prairie. Journal of Animal Science 81: 304-317.

BOWMAN, J.G.P.; SANSON, D.W. 1996. Starchor-fiber-based energy supplements for grazing ruminants. In: Proc. Grazing Livest. Nutr. Conf. Rapid City. SD. pp. 118-135.

CATON, J.S.; DHYVETTER, D.V. 1997. Influence of energy supplementation on grazing ruminants: Requirements and responses. Journal of Animal Science 75:533-542.

CATON, J.S.; FREEMAN, A.S.; GALYEAN, M.L. 1988. Influence of protein supplementation on forage intake, in situ forage disappearance, ruminal fermentation and digesta passage rates in steers grazing dormant blue grama rangeland. Journal of Animal Science 66: 2262-2271.
CHASE, C.C. Jr.; HIBBERD, C.A. 1987. Utilization of low-quality native grass hay by beef cows fed increasing quantities of corn grain. Journal of Animal Science 65:557-566.

DELCURTO, T.; COCHRAN, R.C.; CORAH, L.R.; BEHARKA, A.A.; VANZANT, E.S.; JOHNSON, D.E. 1999. Supplementation of dormant tallgrass-prairie forage: II. Performance and forage utilization characteristics in grazing beef cattle receiving supplements of different protein concentrations. Journal of Animal Science 68:532-542.

DROUILLARD, J.S.; FERRELL, C.L.; KLOPFENSTEIN, T.J.; BRITTON, R.A. 1991. Compensatory growth following metabolizable protein or energy restrictions in beef. Journal of Animal Science 69: 811-818.

FATTET, I.; HOVELL, F.D.DeB; ORSKOV, E.R.; KYLE, D.J.; PENNIE, K.; SMART, R.I. 1984. Undernutrition in sheep: the effect of supplementation with protein accretion. British Journal of Nutrition 52:561.

HORN, G.W.; McCOLLUM III, F.T. 1987. Energy supplementation of grazing ruminants. In: Proc. Grazing Livest. Nutr. Conf., Jackson, WY. pp. 125-136.

HOVELL, F.D.DeB.; ORSKOV, E.R.; KYLE, D.J.; MacM. 1987. Undernutrition in sheep: Nitrogen repletion by $\mathrm{N}$-depleted sheep. British Journal of Nutrition 57:77.

LOMAS, L.W.; MOYER, J.L.; MILLIKEN, G.A. 2009. Effect of energy supplementation of stocker cattle grazing smooth bromegrass pastures on grazing and subsequent finishing performance and carcass traits. The Professional Animal Scientist 25, 65-73.

McCOLLUM III, F.T.; HORN, G.W. 1990. Protein supplementation of grazing livestock: A review. Professional Animal Scientist 6:1-16.

MGBEAHURUIKE, A.C. 2007. Faecal characteristics and production of dairy cows in early lactation. Thesis MSc. Faculty of Veterinary Medicine and Animal ScienceSwedish University of Agricultural Sciences. 87p.

OLSON, K.C.; COCHRAN, R.C.; JONES, T.J.; VANZANT, E.S.; TITGEMEYER, E.C.; JOHNSON, D.E. 1999. Effects of ruminal 
administration of supplemental degradable intake protein and starch on utilization of low-quality warm-season grass hay by beef steers. Journal ofAnimal Science 77:1016-1025.

PORDIMINGO, A.J.; WALLACE, J.D.; FREEMAN, A.S.; GALYEAD, M.L. 1991. Supplemental corn grain for steers grazing native rangeland during summer. Journal of Animal Science 69: 1678-1687.
SANSON, D.W.; CIANTON, D.C.; RUSH, I.G. 1990. Intake and digestion of low-quality meadow hay by steers and performance of cows on native range when fed protein supplements containing various levels of corn. Journal of Animal Science 68:595-603. 


\section{ANÁLISIS INTEGRADO DE LOS TRABAJOS EXPERIMENTALES}

\section{CARACTERÍSTICAS DEL CAMPO NATURAL}

El campo natural durante el invierno (mayo a setiembre) registró en promedio $8,2 \%$ de proteína cruda (Figura 1). Dicho valor generalmente es considerado como umbral por debajo del cual existe respuesta a la suplementación proteica por una limitante de disponibilidad de nitrógeno en el rumen de los animales. Si bien se puede considerar que lo que efectivamente consume el animal presenta una mayor concentración proteica por la selectividad del pastoreo, también es cierto que el contenido de proteína del campo natural en pleno invierno, cuando el aporte de restos secos del forraje es máximo, fue menor que el promedio, correspondiendo a valores en el rango de 5,7 a 7,9\%.

El alto contenido de Fibra Detergente Neutro (FDN) (Figura 1) determinó que exis- tiera una limitante física en el consumo de forraje debido a la lenta tasa de digestión y llenado ruminal. De acuerdo al valor promedio obtenido $(68,2 \%)$ y a la ecuación comúnmente utilizada para estimar el consumo diario de forraje (120/FDN), la ingestión de materia seca proveniente del campo natural fue cercana al $2 \%$ del peso vivo de los animales. Esto sucedió siempre y cuando la altura del tapiz no hubiera sido limitante para acceder al forraje. El promedio de altura del tapiz del campo natural en los experimentos fue de $8,2 \mathrm{~cm}$, aunque se registraron valores por debajo de $5 \mathrm{~cm}$ los cuales son restrictivos para que el animal pueda acceder al estrato inferior del tapiz.

El alto contenido de fibra detergente ácido (FDA) está negativamente correlacionado con la energía y digestibilidad del forraje, ya que la fracción FDA incluye aquellos componentes altamente indigestibles de la planta (ej.: lignina). La baja variabilidad de los

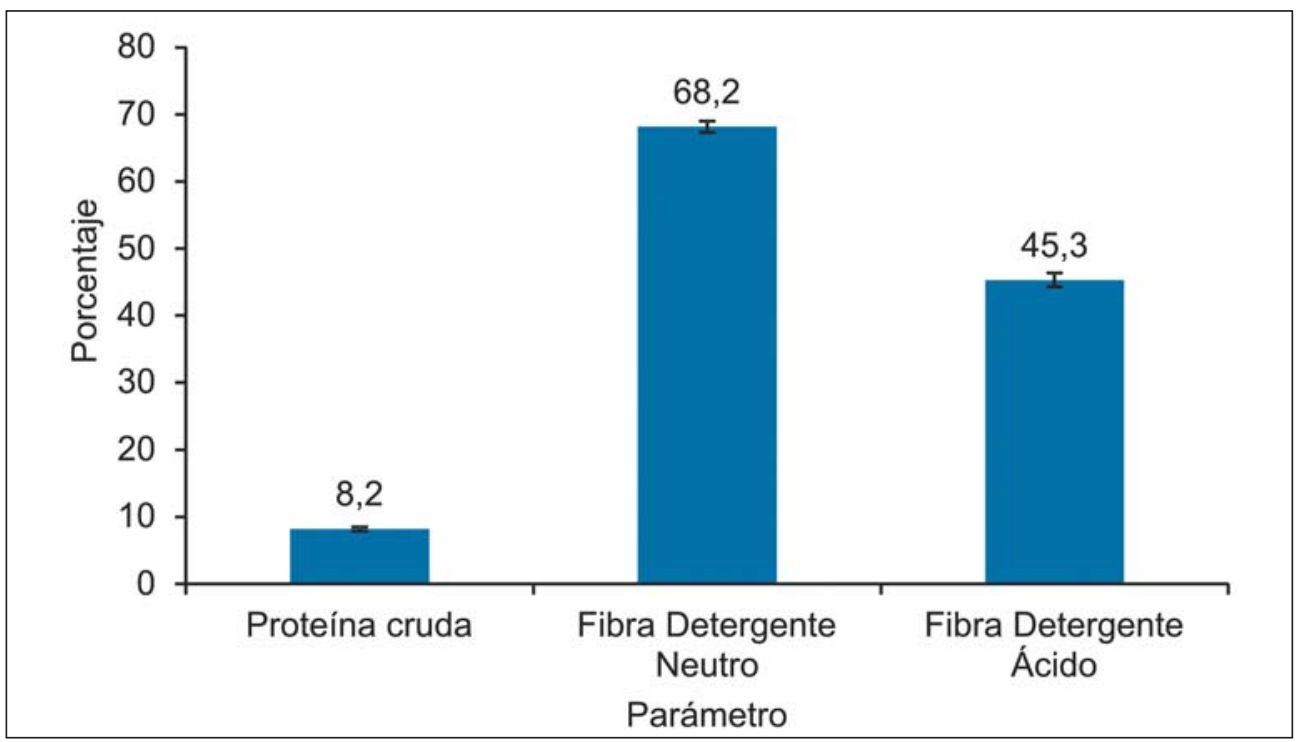

Figura 1. Valor nutritivo del campo natural durante el invierno (promedio de 5 años). Barras verticales en cada columna indican error estándar de la media. 
parámetros evaluados, expresada a través de las barras verticales en cada columna de la Figura 1, implica que la situación de bajo aporte proteico y energético del campo natural con un alto nivel de fibra es algo dable de esperar todos los años más allá de la manifestación de inviernos más o menos benignos.

\section{DESEMPEÑO PRODUCTIVO DE TERNEROS DURANTE LA SUPLEMENTACIÓN}

Analizando en forma conjunta los 3 años en los que se trabajó con terneros sobre campo natural en invierno, aquellos animales que no fueron suplementados perdieron peso (-0,043 kg/a/d) (Figura 2). La suplementación con grano húmedo de sorgo permitió leves ganancias de peso $(0,212 \mathrm{~kg} / \mathrm{a} / \mathrm{d})$, mientras que la inclusión de una fuente proteica para subir la proteína del sorgo a 15-16\% incrementó significativamente la ganancia de peso a 0,415 kg/a/d. La adición de una fuente de proteína no sólo mejoró la ganancia diaria promedio en los 90-100 días de suplementación, sino que también evitó la pérdida de peso vivo durante la etapa más crítica del invierno. Animales suplementados únicamente con grano húmedo de sorgo perdieron peso en el periodo comprendido entre fines de junio y principios de agosto en los 3 años evaluados. El evitar la pérdida de peso vivo, aunque sea por periodos cortos, es muy importante para no comprometer el desarrollo y crecimiento futuro del ternero. Incluso niveles de ganancia de peso de $0,200 \mathrm{~kg} / \mathrm{a} / \mathrm{d}$ como los registrados con la suplementación con grano húmedo de sorgo son limitantes para una categoría en pleno crecimiento como el ternero. La lógica de producción implica que luego el crecimiento compensatorio en la primavera $(>0,800 \mathrm{~kg} / \mathrm{a} / \mathrm{d})$ permite que el ternero llegue al año de edad con un crecimiento y desarrollo acorde. Sin embargo, cada vez son más comunes eventos climáticos adversos en la primavera (ej. sequías) que comprometen la producción de forraje y el desempeño de los animales. Por tal motivo, elevar la ganancia de peso ( $>0,400 \mathrm{~kg} / \mathrm{a} / \mathrm{d})$ de los terneros en invierno, sobre campo natural, mediante la adición de una fuente de proteína al grano húmedo de sorgo permite no sólo un mayor peso vivo del ternero a la salida del invierno sino también tener la seguridad que su crecimiento y desarrollo futuro no está en riesgo.

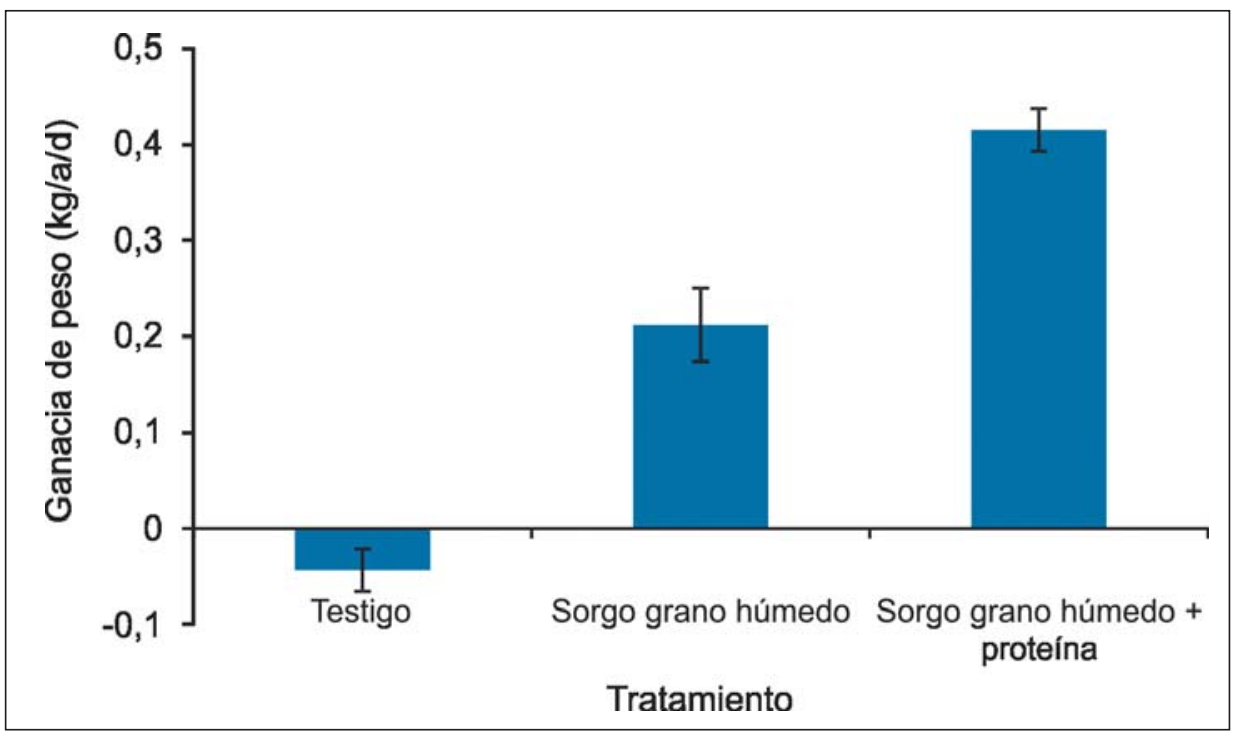

Figura 2. Análisis integrado de la ganancia de peso de los terneros en 3 años $(2009,2011,2013)$ en donde el nivel de proteína del sorgo se elevó a 15$16 \%$ con distintas fuentes proteicas. Líneas verticales en cada columna indican error estándar de la media como indicador de la variación. 


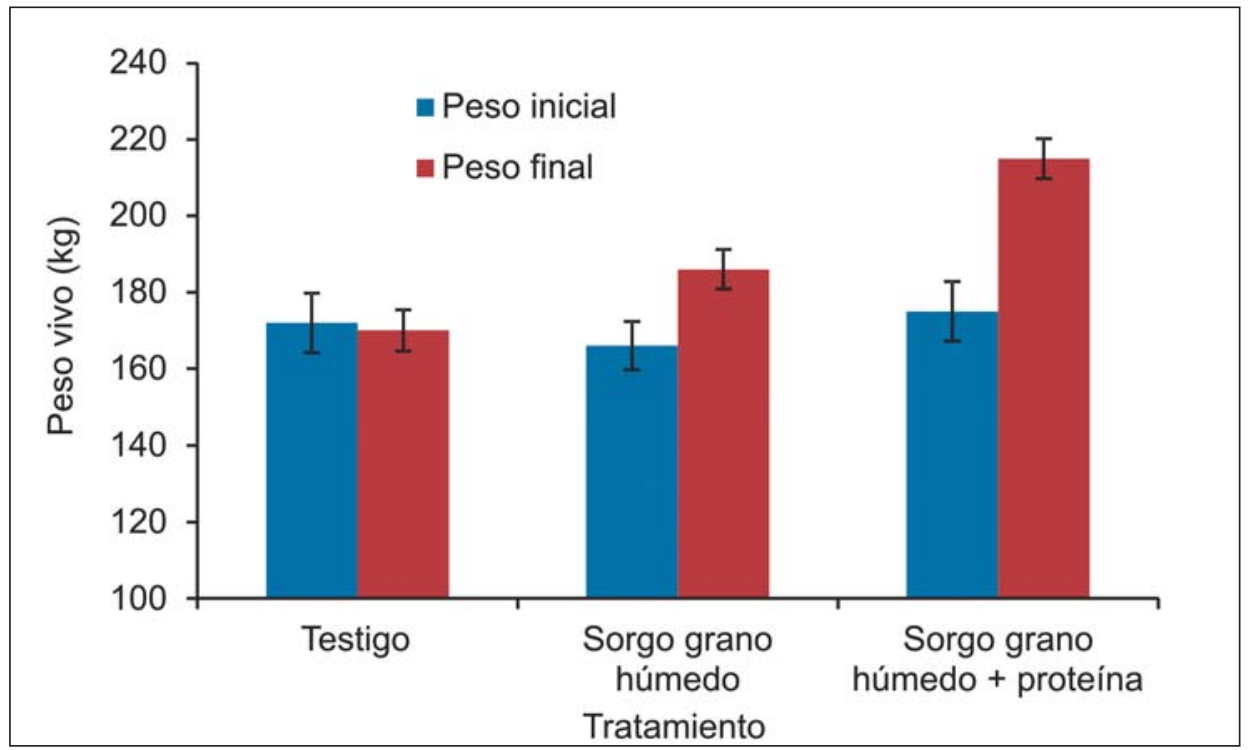

Figura 3. Análisis integrado del peso vivo inicial y final de los terneros en 3 años (2009, 2011, 2013) luego de 90-100 días de suplementación en donde el nivel de proteína del sorgo se elevó a $15-16 \%$ con distintas fuentes proteicas. Líneas verticales en cada columna indican error estándar de la media como indicador de la variación.

Promediando sobre los 3 años evaluados, el incremento de peso vivo en terneros luego de 90-100 días de suplementación fue de 22 kg (sólo sorgo) y 42 kg (sorgo + proteína), comparado con el grupo testigo que perdió peso durante el invierno (Figura 3). En el caso de los terneros suplementados únicamente con sorgo, hubo un año (2013) en dónde el incremento de peso vivo fue de apenas $12 \mathrm{~kg}$ comparado con $37 \mathrm{~kg}$ de incremento cuando se agregó la fuente de proteína. La respuesta animal a la suplementación únicamente con sorgo es variable, ya que depende más del aporte de proteína del campo natural (asociado a la evolución de la relación verde/seco del forraje) y a las características intrínsecas del grano de sorgo utilizado. Con respecto a esto último hay al menos 3 factores relacionados: i) contenido de proteína del sorgo, puede variar de 7 a $10 \%$ aproximadamente; ii) nivel de procesamiento del grano, cuanto más grano entero haya menor va a ser el aprovechamiento de la proteína del sorgo; y iii) presencia de taninos en el grano, cuanto mayor sea el nivel menor será el aprovechamiento de la proteína en el rumen del animal.
El hecho de salir del invierno con un ternero de $170 \mathrm{~kg}$ (testigo), $190 \mathrm{~kg}$ (sorgo) o $215 \mathrm{~kg}$ (sorgo + proteína) no es lo mismo desde el punto de vista del impacto en el sistema de producción. Si es un esquema de engorde, mayor peso vivo al final del invierno permite mejorar la recría y acortar el largo del proceso de invernada, así como acceder a determinados nichos de producción que requieren sistemas más intensivos de crianza (ej.: corrales de engorde para la cuota 481 de carne de calidad para la Unión Europea). En caso de ser un sistema criador, la mejora de la tasa de ganancia de peso de la ternera durante el primer invierno está asociada a una reducción en la edad a la pubertad, con mayor probabilidad de quedar preñada en el primer servicio como vaquillona.

\section{EFICIENCIA DE CONVERSIÓN}

En todos los años, el nivel de suministro diario de los suplementos fue $1 \%$ del peso vivo. La eficiencia de conversión de terneros (kg de suplemento para ganar $1 \mathrm{~kg}$ de peso vivo adicional comparado con el grupo testi- 
go) mejoró de 7,3:1 (sólo sorgo, mín. 5,6:1; máx. 10,7:1) a 4,3:1 (sorgo + proteína, mín. 3,6:1; máx. 5,0:1), en todos los casos expresado en base seca. La mejora de la eficiencia de conversión se produjo por una relación energía/proteína más acorde en el suplemento ofrecido, mejorando fundamentalmente la disponibilidad de proteína (y por lo tanto nitrógeno) en el rumen de los animales.

En el año en el que se utilizaron novillos sobreaño, la eficiencia de conversión también mejoró al incluir proteína (urea) en el sorgo ofrecido a los animales (13,3:1 y 9,1:1 sin y con urea, respectivamente). Los valores numéricos de eficiencia de conversión fueron mayores en novillos que en terneros, debido a que el novillo es una categoría que ya comenzó a depositar grasa, tejido que requiere más energía para su deposición que el músculo (principal tejido de deposición en terneros). La diferencia en engrasamiento se vio reflejada en la medición del espesor de grasa subcutánea a través de ultrasonido en los animales al finalizar los trabajos experimentales, valores que promediaron 2,2 $\mathrm{mm}$ (2011) y 3,0 mm (2012) en terneros y novillos, respectivamente.

\section{FUENTES DE PROTEÍNA}

En la medida que se suministra sólo sorgo sobre campo natural a terneros, la disponibilidad de nitrógeno (expresado en forma de amonio) en el rumen no es suficiente para mantener un crecimiento activo de la masa microbiana, afectando negativamente el nivel de proteína microbiana que pasa luego a ser digerida en el tracto digestivo posterior del animal. Por tal motivo, debido a que la Cuadro 1. Ejemplos de mezclas de grano húmedo de sorgo + fuentes de proteína para lograr una mezcla con una concentración de $16 \%$ de proteína cruda

\begin{tabular}{lccc}
\hline & \multicolumn{3}{c}{ Nivel de cada suplemento en la mezcla (\%) } \\
\cline { 2 - 5 } & $\begin{array}{c}\text { Proteína cruda (\%) } \\
\text { de la fuente proteica }\end{array}$ & Sorgo grano húmedo & Fuente proteica \\
\hline Expeller de girasol & 32 & 67 & 33 \\
Expeller de soja & 44 & 78 & 22 \\
Urea agrícola & 287 & 97 & 3 \\
Núcleo proteico & 50 & 81 & 19 \\
\hline
\end{tabular}

principal limitante es el amonio a nivel ruminal, no existieron diferencias significativas en la eficiencia de conversión entre las distintas fuentes de proteína utilizadas (vegetal, sintética y/o mezcla de ambas). Lo importante es que dicha proteína, cualquiera sea su origen, se desglose en el rumen en amonio y otras formas nitrogenadas, y que pueda ser aprovechada por las bacterias para la síntesis de proteína microbiana, siempre y cuando el aporte de energía sea el adecuado (ej.: sorgo). Esta conclusión es válida para terneros de más de $150 \mathrm{~kg}$ y 6 meses de edad, como los utilizados en los trabajos experimentales. En animales más livianos, y sobre todo en terneros de destete precoz, la utilización de fuentes de proteína vegetal de alta calidad (ej. harina de soja) con proteína que escapa a la degradación ruminal debe ser priorizada sobre fuentes sintéticas (ej.: urea) debido a que la capacidad y/o funcionamiento del rumen de estos animales aún es limitada, y un exceso de amonio en el rumen puede causar síntomas de intoxicación.

El Cuadro 1 brinda ejemplos de distintas combinaciones de grano húmedo de sorgo + fuentes de proteína para lograr una mezcla con una concentración de $16 \%$ de proteína cruda. Suministrada la mezcla al $1 \%$ del peso vivo no existirían diferencias significativas en la respuesta animal debiendo considerar la disponibilidad, costo y riesgo asociado (intoxicación por urea) de la fuente de proteína. Suponiendo que la mezcla suministrada es $1 / 3$ de la dieta (los restantes $2 / 3$ sería campo natural con $8 \%$ de proteína cruda), la fuente de proteína utilizada aportaría alrededor de un 30\% de la proteína total (el resto proviene del sorgo y de la pastura).

Nivel de cada suplemento en la mezcla (\%)

\section{Sorgo grano húmedo Fuente proteica}

${ }^{1}$ En base seca, sorgo grano húmedo con 8\% de proteína cruda. 


\section{NIVEL DE SUPLEMENTACIÓN PROTEICA}

El nivel diario de suplementación proteica, expresado como el porcentaje del peso vivo (kg de proteína aportado por el suplemento/ $100 \mathrm{~kg}$ de peso vivo), fue de $0,08 \%$ (sorgo) y $0,14 \%$ (sorgo + proteína). Por cada 100 kg de peso, se suministraron entre $0,080 \mathrm{y}$ $0,140 \mathrm{~kg}$ de proteína a través del suplemento (en adición a lo que suministró la pastura). Para lograr un nivel de ganancia de peso de $0,400 \mathrm{~kg} / \mathrm{a} / \mathrm{d}$ en terneros en el rango de $140-180 \mathrm{~kg}$ fue necesario suministrar en el suplemento diario alrededor de $0,300 \mathrm{~kg}$ de proteína por animal (Figura 4) con una concentración de energía metabolizable promedio de 2,82 Mcal/kg MS en el suplemento mezcla (sorgo + fuente de proteína).

\section{RELACIÓN ENERGÍA - PROTEÍNA DEL SUPLEMENTO}

Los trabajos analizados hasta el momento fueron todos con un nivel de proteína en la mezcla sorgo + fuente proteica de 15-16\% y con un suministro diario de $1 \%$ del peso vivo. Adicionalmente, en el año 2011 existió un grupo de animales al cual se le ofreció una mezcla con $21 \%$ de proteína, y en el año 2013 existió un tratamiento con un nivel de proteína de $15 \%$ en la mezcla, pero suministrado al 1,5\% del peso vivo. En ambos casos la justificación fue incrementar la oferta de proteína al animal a través de 2 vías diferentes: incrementar la concentración proteica en la mezcla (2011) o incrementar el nivel de suplementación de la mezcla (2013). En ambos años se mantuvo como «testigo» el tratamiento tradicional de suplementación al $1 \%$ del peso vivo con $15-16 \%$ de proteína. El mayor impacto se logró al incrementar el nivel de suplementación al 1,5\% del peso vivo de una mezcla con $15 \%$ de proteína, en donde la ganancia de peso se incrementó significativamente (barras rojas, Figura 5). Sin embargo, no hubo respuesta al subir la concentración de proteína de 16 a 21\% en una mezcla suministrada al $1 \%$ del peso vivo (barras azules, Figura 5) debido a una relación energía/proteína demasiado baja en el suplemento (3,5:1; expresada como el cociente Nutrientes Digestibles Totales/Proteína Cruda, NDT/PC) cuando se subió la concentración de proteína a $21 \%$. Es decir, si bien se levantó la limitante proteica, la energía pasó a ser el nuevo factor limitante.

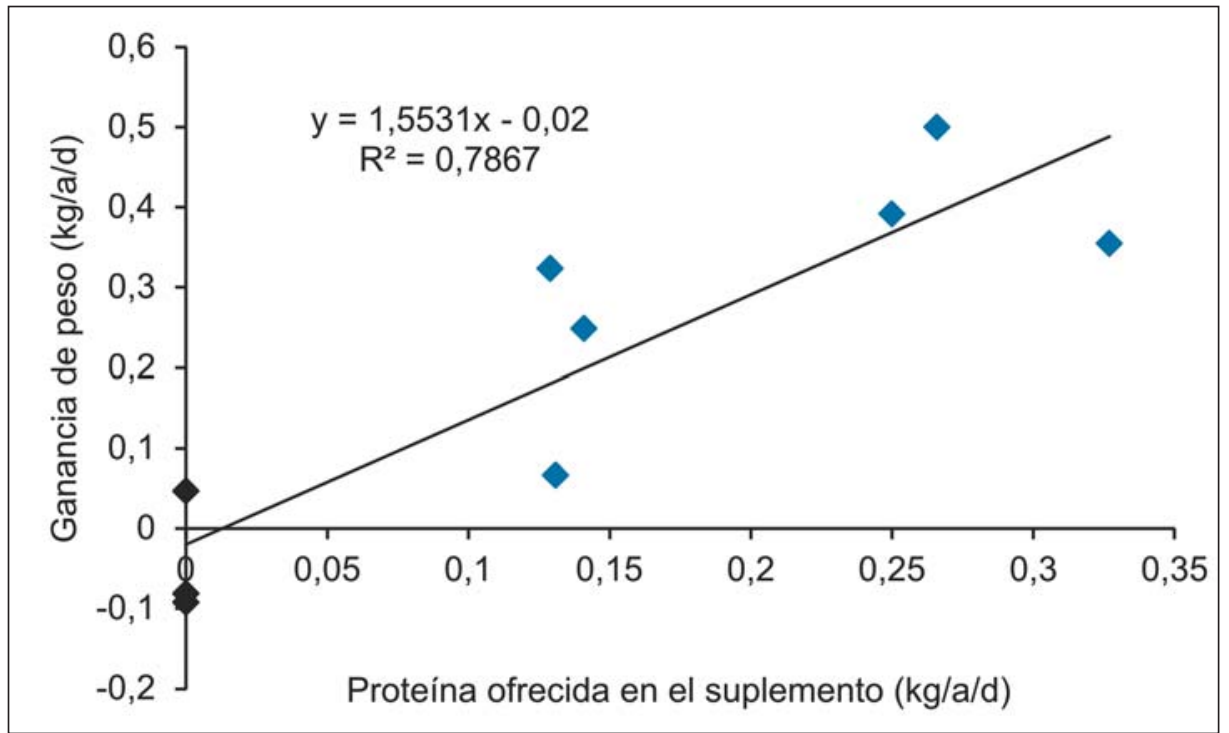

Figura 4. Relación entre la proteína ofrecida en el suplemento y la ganancia de peso de terneros suplementados sobre campo natural. 


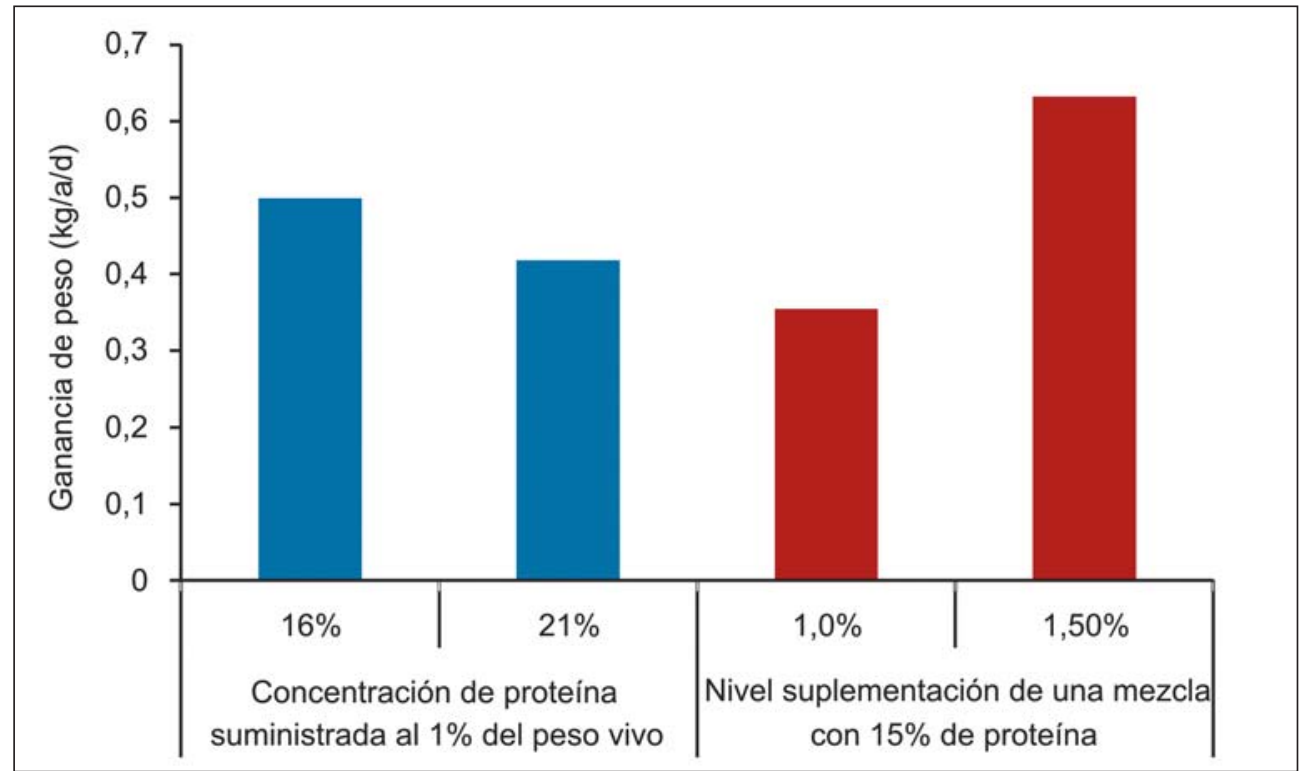

Figura 5. Respuesta animal al incremento de la oferta de proteína a través de un incremento de la concentración proteica en el suplemento (barras azules) o a través de un incremento en el nivel de suplementación (barras rojas).

Lo ideal es que en sistemas pastoriles, y en esta categoría, la relación de NDT/PC en el suplemento suministrado, se mantenga alrededor de 5:1 para optimizar la respuesta biológica. Esto se logra con valores del entorno de $76-78 \%$ de NDT (equivalente a 2,80-
$15-16 \%$ de proteína cruda. Esto se observa más claramente en la Figura 6, en donde a medida que el cociente NDT/PC disminuye de 5:1 a 10:1, la ganancia de peso de los terneros suplementados sobre campo natural desciende de $0,400 \mathrm{~kg} / \mathrm{a} / \mathrm{d}$ a $0,200 \mathrm{~kg} / \mathrm{a} / \mathrm{d}$. Una relación NDT/PC 10:1 equivale a suministrar únicamente

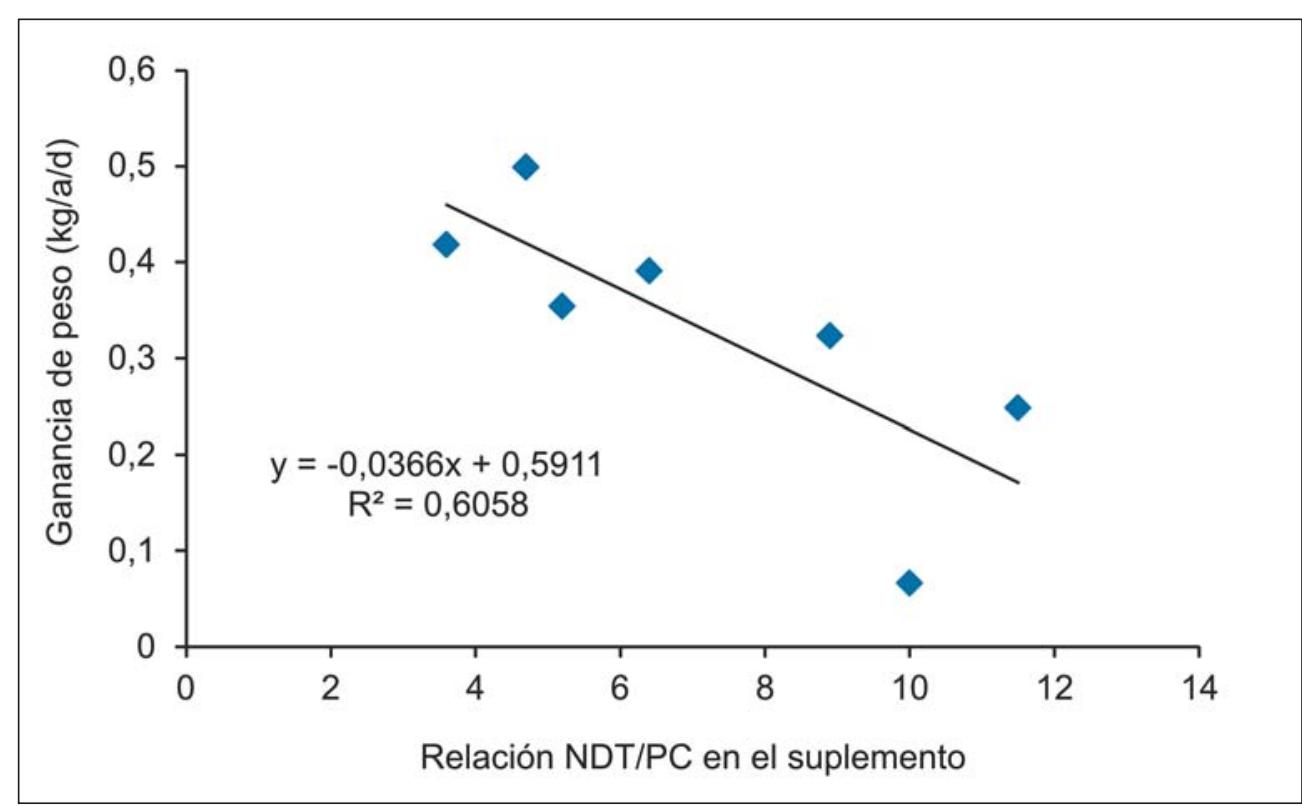

Figura 6. Relación entre el cociente NDT/PC (Nutrientes Digestibles Totales/Proteína Cruda) en el suplemento y ganancia de peso de terneros suplementados al $1 \%$ del peso vivo sobre campo natural. 
sorgo con valores de $82 \%$ de NDT y $8 \%$ de proteína cruda, aproximadamente.

Desde otro punto de vista, el objetivo sería buscar una relación de aproximadamente $50 \mathrm{~g}$ de proteína cruda degradable/Mcal de energía metabolizable a nivel ruminal. Asumiendo una alta degradabilidad (90\%) de la proteína implica que suplementos con una concentración energética de 2,8 Mcal energía metabolizable/kg MS deberían tener una concentración proteica cercana a 16\% PC. De esta manera se estaría optimizando la captura de nitrógeno a nivel ruminal para la síntesis de proteína microbiana que luego será absorbida en el intestino delgado.

\section{REGISTROS DE ULTRASONIDO}

En los años en los que se registró mediante ultrasonografía el área de ojo de bife $\left(\mathrm{AOB}, \mathrm{cm}^{2}\right)$ y el espesor de grasa (EG, $\mathrm{mm}$ ) no se encontró un efecto significativo en ambas variables asociado a la inclusión de proteína al grano húmedo de sorgo. Probablemente el nivel de suplementación de proteína adicional con la fuente proteica no fue lo suficientemente contrastante con el suministro único de sorgo como para detectar diferencias significativas. Hay que considerar que dicha proteína adicional de la fuente proteica se diluye en la dieta total si se asume que dos tercios de la misma continúa siendo a través del aporte del campo natural.

Tanto para terneros como para novillitos sobreaño la suplementación al 1\% del peso vivo con grano húmedo de sorgo (con o sin fuentes de proteína) durante 90-110 días incrementó el área de ojo de bife entre 13 y $16 \%$. Por ejemplo, en el caso de terneros implicó pasar de $24,1 \mathrm{~cm}^{2}$ a $27,9 \mathrm{~cm}^{2}$. Del mismo modo, el periodo de suplementación incrementó numéricamente el espesor de grasa subcutánea de terneros entre un 6 y $7 \%$, pasando en promedio de $2,29 \mathrm{~mm}$ (junio) a 2,44 mm (setiembre). El impacto de la suplementación en términos relativos fue mayor en $A O B$ que en EG por la etapa de crecimiento y desarrollo en que se encuentran los terneros, básicamente depositando tejido muscular.

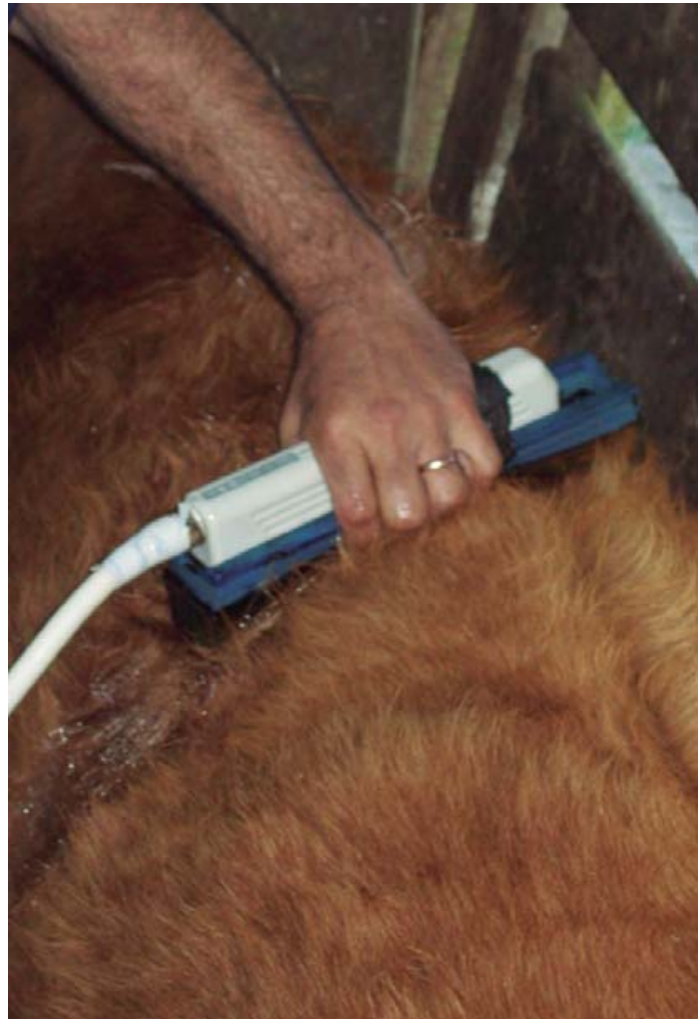

La suplementación de terneros y novillos al $1 \%$ del peso vivo sobre campo natural incrementó numéricamente el área de ojo de bife y espesor de grasa, asegurando un crecimiento y desarrollo acorde en categorías jóvenes.

\section{RESULTADO ECONÓMICO DE LA SUPLEMENTACIÓN}

Promediando sobre los 4 años en donde se realizaron experimentos de suplementación invernal de terneros, la estrategia de no suplementar determinó un margen bruto promedio de -13 U\$S/animal (mín. -36, máx. 12) en un periodo de 90-100 días (Figura 7). Surge de la valorización de los $\mathrm{kg}$ perdidos durante el invierno cuando no se suplementan los terneros. Al incorporar la suplementación con grano húmedo de sorgo sin y con fuentes de proteína el margen bruto se incrementó a 29 (mín. 4, máx. 65) y 55 (mín. 33, máx. 97) U\$S/animal, respectivamente. En ningún año el margen bruto de la suplementación fue negativo. La variabilidad en el margen bruto estuvo asociada fundamentalmente a la respuesta productiva, la cual fue 


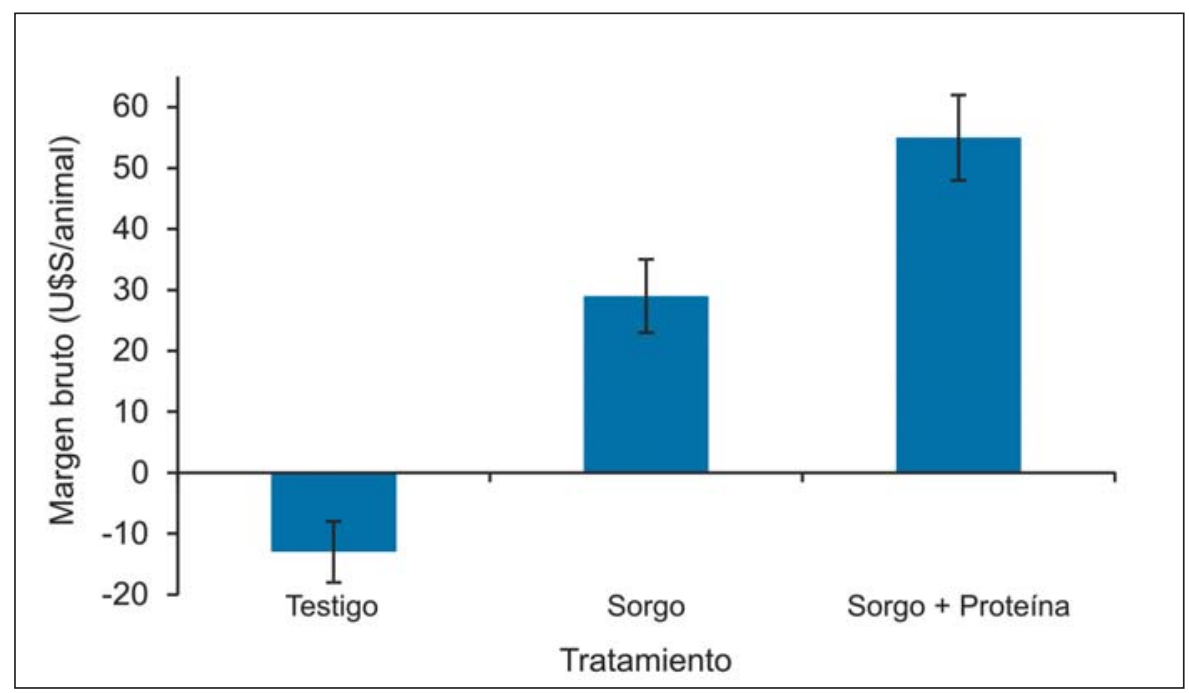

Figura 7. Margen bruto (media \pm error de la media) de la suplementación por ternero (promedio de 4 años).

afectada entre años por el periodo de evaluación y por las características climáticas y forrajeras de cada año en particular.

La respuesta económica positiva y alta a la suplementación se basó en los siguientes puntos:

- El ternero es una categoría altamente eficiente en la conversión de suplemento a peso vivo ( 3,5 a $4,5 \mathrm{~kg}$ de suplemento para ganar $1 \mathrm{~kg}$ de peso vivo adicional).

- El grano húmedo de sorgo es un suplemento de costo relativo bajo, variable según el rendimiento del cultivo al momento de la cosecha y embolsado. En la serie histórica el mismo varió de 92 a 180 U\$S/ tonelada en base seca).

- Si bien la fuente de proteína que se adiciona siempre es más cara que el grano húmedo de sorgo, la misma se incorpora en pequeñas cantidades diluyendo el impacto en el costo total de la mezcla.

- El ternero es una categoría con una alta respuesta a la suplementación proteica por la etapa de crecimiento y desarrollo en la que se encuentra depositando básicamente tejido muscular.

- Entre las categorías vacunas, el ternero es la que presenta mayor valorización. En la serie histórica varió de 1,28 a 2,5 U\$S/kg de peso vivo.

\section{DESEMPEÑO PRODUCTIVO DE TERNEROS DURANTE LA ETAPA POST- SUPLEMENTACIÓN}

En los 3 años en los que se trabajó con terneros sobre campo natural en invierno suplementados al $1 \%$ del peso vivo, todos los animales provenientes de los distintos tratamientos (testigo, sólo sorgo, sorgo + proteína) se manejaron en conjunto y bajo el mismo manejo sanitario y nutricional durante la primavera siguiente (octubre-diciembre). La base forrajera fue campo natural y praderas con una asignación de forraje diario variable entre el 5 y $8 \%$ del peso vivo. El objetivo fue evaluar si el manejo de la suplementación invernal afecta el desempeño futuro de los terneros en el mediano plazo, también denominado como efecto residual del tratamiento. En dicho periodo primaveral la ganancia de peso fue similar para los terneros provenientes de los distintos tratamientos (Figura 8), con un promedio (kg/a/d) de 0,635 (2009); 0,726 (2011) y 0,671 (2013). 


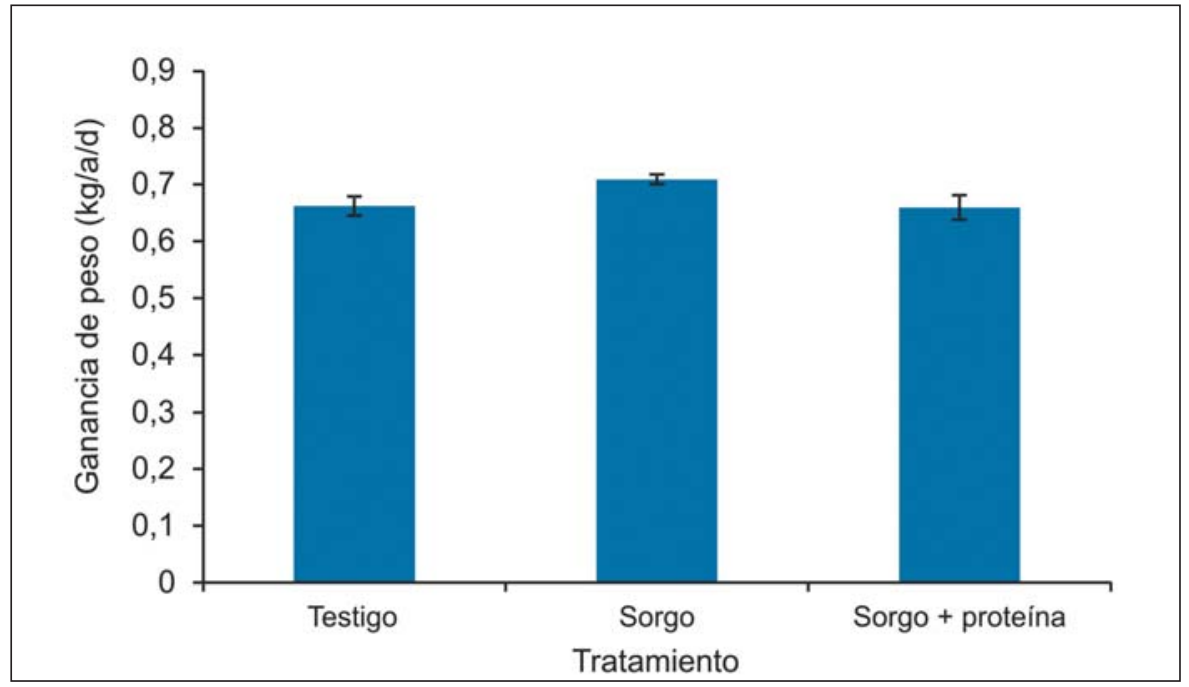

Figura 8. Ganancia de peso de terneros durante la primavera (octubre-diciembre) según manejo de la suplementación invernal. Líneas verticales en cada columna indican error estándar de la media como indicador de la variación.

Aquellos animales más livianos (grupos testigo) a la salida del invierno continuaron siendo más livianos y claramente diferentes en crecimiento y desarrollo a la salida de la primavera comparado con aquellos que habían sido suplementados al $1 \%$ del peso vivo durante el invierno. La misma tendencia se registró al comparar los grupos suplementados con sorgo o sorgo + proteína (estos últi- mos se mantenían más pesados que los primeros en diciembre). No hubo un crecimiento compensatorio significativo en la primavera que «emparejara» los animales provenientes de los distintos manejos en invierno. Probablemente, la tasa de ganancia de peso registrada en la primavera no fue lo suficientemente alta como para permitir la manifestación del crecimiento compensatorio. 
La información presentada demuestra que la adición de fuentes proteicas al grano húmedo de sorgo resulta ser una alternativa viable tanto biológica como económicamente para mejorar el crecimiento de terneros suplementados sobre campo natural en invierno. La actividad operativa no se retrasa por la incorporación de la fuente de proteína, únicamente se recomienda realizar una premezcla con el grano en el caso de utilizar urea. Se destaca la utilidad del uso de la urea como fuente de nitrógeno no proteico para rumiantes, aunque siempre teniendo precauciones en su uso para evitar casos de intoxicación (terneros bien desarrollados, proporción en la mezcla con granos, periodo de acostumbramiento, que todos los animales coman, etc.). Han existido y seguirán existiendo casos de intoxicación y muerte de animales por uso indebido de la urea como fuente proteica en predios comerciales. Lo que demostró la información generada es que haciendo un buen uso de la misma biológicamente no se afecta la respuesta productiva de terneros al sustituir parcialmente fuentes de proteína de origen vegetal por urea. Cada técnico o productor deber sacar sus cuentas y definir el grado de riesgo que está dispuesto a aceptar. En los últimos años han surgido varios productos comerciales de urea de liberación lenta que apuntan a disminuir dicho riesgo en la salud de los animales manteniendo un alto aporte de equivalente proteico.

La adición de fuentes de proteína al grano húmedo de sorgo corrige desbalances nutricionales pero no corrige fallas en la confección y calidad del ensilaje. Por tal motivo, la respuesta positiva de los animales a la fuente proteica en gran medida está determinada por la buena calidad y conservación del grano quebrado y embolsado en ausencia de aire, medido a través de parámetros como la acidez del silo y la presencia de nitrógeno amoniacal. También es importante la humedad con que el grano de sorgo fue embolsado, ya que una humedad acorde a la tecnología del ensilaje (25-35\%) va a favorecer una solubilización más rápida de la urea en caso de que sea utilizada dicha fuente como proteína adicional. Incluso la urea puede ser incorporada al ensilaje durante el proceso de confección del mismo adicionando $2-3 \%$ de urea por tonelada de material cosechado. La urea se hidroliza y solubiliza rápidamente generando un incremento numérico del $\mathrm{pH}$ a valores superiores a 8 lo que permite la conservación del material que incluso no requiere de ser almacenado en ausencia de aire.

Sea cual sea la fuente de proteína y/o el método de incorporación de la misma al grano húmedo de sorgo, el objetivo es permitir no sólo evitar la pérdida de peso vivo de la recría durante el invierno sino lograr tasas de crecimiento no restrictivas en terneros durante el primer invierno $(>0,400 \mathrm{~kg} / \mathrm{a} / \mathrm{d})$. De esta manera no se compromete el desarrollo futuro de ese animal, el sistema se hace menos dependiente del crecimiento compensatorio durante la primavera, y se está en carrera para acceder en un futuro a mercados de mayor valor (ej. como novillito para un corral de engorde en el marco de la cuota 481). Sólo con grano húmedo de sorgo sobre campo natural dicho objetivo se ve comprometido y otras fuentes de suplementación tradicionales en las regiones ganaderas y con una mejor relación energía-proteína (ej. afrechillo de arroz) se vuelven más competitivas comparadas con el grano de sorgo.

Adicionalmente, cuando se compara la utilización de grano húmedo de sorgo + fuentes proteicas con otras alternativas de suplementación hay que considerar que la alternativa del ensilaje de grano húmedo es una tecnología de proceso, que nace con la siembra del cultivo y termina con el suministro del grano a los animales, a diferencia de lo que puede ser la compra de suplementos para uso inmediato (afrechillo de arroz, raciones balanceadas) que se define como una 
tecnología de insumos. Las tecnologías de proceso, y en este caso no es la excepción, requieren de un mayor seguimiento, asesoramiento y continua toma de decisiones para asegurar el éxito de la misma y que efectivamente la adopción de la tecnología genere un incremento adicional de la producción y del retorno económico.

Impreso en Editorial Hemisferio Sur S.R.L. Buenos Aires 335 Montevideo - Uruguay 